\title{
VOCAL COMMUNICATION WITHIN A FOREST
}

\section{BIRD COMMUNITY}

\author{
Joseph Fawzi Azar \\ Submitted to the Victoria University of Wellington \\ in fulfilment of the requirements for the degree of \\ Doctor of Philosophy \\ in Ecology and Biodiversity
}

Victoria University of Wellington

2012 


\begin{abstract}
This thesis takes a community approach to investigate the acoustics of forest birds in Zealandia sanctuary, Wellington. Initially, the annual changes in vocalisation output of 16 study species and their possible effect on bird conspicuousness were described. Environmental factors that may shape these avian vocalisations were addressed though invoking two key hypotheses, the acoustic adaptation hypothesis, and the acoustic niche hypothesis. In addition, the songs of selected species are investigated: the role of song harmonics in the native North Island saddleback, Philesturnus rufusater, and their role in ranging, change in song dialect through time and space in the introduced song thrush, Turdus philomelos, and temporal change in the song of the native grey warbler, Greygone igata.
\end{abstract}

Vocal activity of the study species varied seasonally, affecting their detectability in bird counts. Some species were mostly first heard rather than seen and viceversa. The results lend support to the acoustic niche hypothesis in that vocalisations within the forest bird community appear to have evolved towards divergence, with native species' vocalisations being more dispersed within the community acoustic space than those of the introduced species. However, all species concentrated their energy within relatively narrow frequency bands, supporting the predictions of the acoustic adaptation hypothesis. Adaptation to different transmission properties associated with different singing elevations or physiological parameters such as body weight may have an effect on shaping such bird vocalisations.

Forests provide a complex acoustic space for sound transmission and a "sound window" may not be a constant property of a given forest. The study revealed that a prominent sound window persists in the lower frequency range that is less 
affected by habitat. Some high frequencies may have similar average attenuation values to those of low frequency, however, with greater fluctuation in attenuation. Ground effect is a further factor in determining how well different frequency ranges transmit and birds may use acoustic characteristics of their habitat to enhance their signal.

Harmonics in North Island saddleback chatter song were found to play a potential role in ranging (estimating the distance of signaller), for playback songs with more relative energy within higher harmonics were evidently perceived as coming from a nearby individual.

The repertoire size of the song thrush population studied in Zealandia has apparently evolved to become larger and more varied than the source population of song thrushes in the UK, with more syllables delivered with less repetition than the UK song recordings examined.

Over a period of 7 years, syllables in grey warbler song have shifted to a higher frequency, but there was no difference in the temporal structure of the song. Habitat effect, competition on the acoustic signal from reintroduced birds and ambient noise level are considered as possible casual factors. 


\section{Acknowledgements}

It has been a privilege to spend the last three years in the School of Biological Sciences at Victoria University of Wellington. I am indebted to my supervisor, Associate Professor Ben Bell, whose patience and kindnesses, as well as his academic experience, have been invaluable to me. I am grateful to Dr. Kevin Burns for giving me the opportunity to come to New Zealand and do my PhD at Victoria University. I thank Dr. Dalice Sim for statistical advice.

I would like to thank the Holdsworth Trust and the Centre for Biodiversity \& Restoration Ecology for funding support through a PhD Scholarship and grants-in aid, including an lan Swingland Research Scholarship at Victoria University. I thank the Karori Sanctuary Trust, and the many people who work in Zealandia, especially Matu Booth, Richard Gray and Raewyn Empson who regularly stopped me while doing my field work to inquire about my research. I thank the people who helped me in the field: Edi Putri, Hamish Carson and Muhmmad Manasra. In addition, I thank the several colleagues and friends who assisted me along the way, including Arun Kanakanthara, Ashish Morani, Jeanine Fisher, Muhamad alZeer, Heather Constable and my dearest friend Rasha Haddad.

Finally and most importantly, I would like to thank my family, for their continuous support. 


\section{Table of Contents}

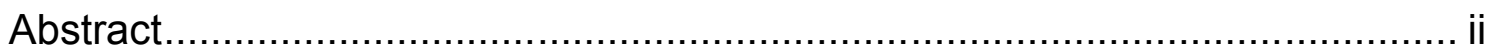

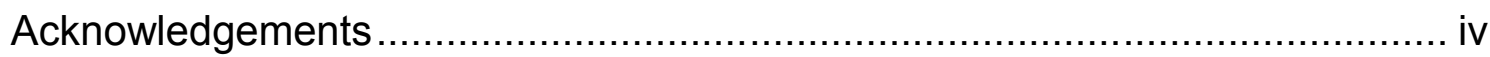

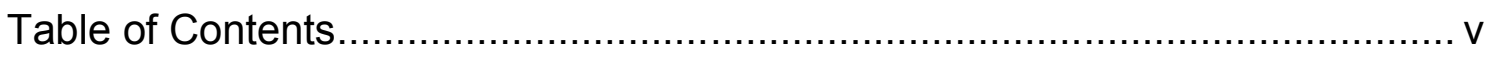

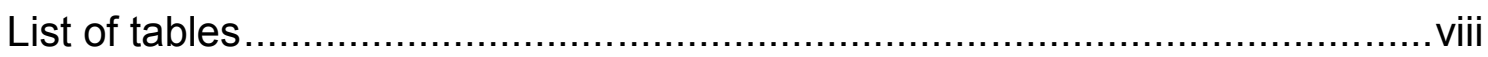

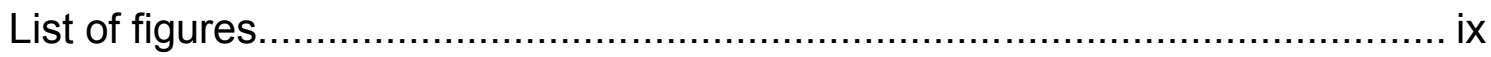

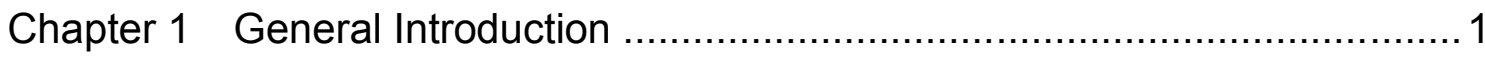

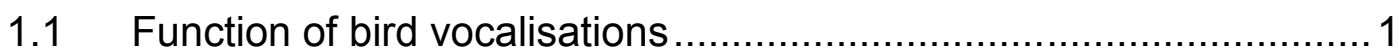

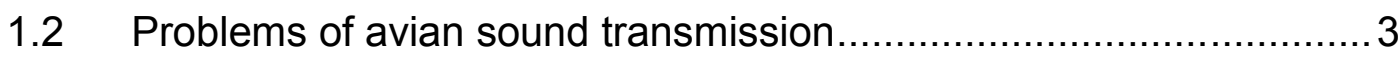

1.3 Effect of the environment on avian vocalisation ........................... 5

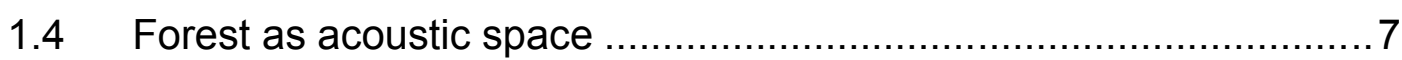

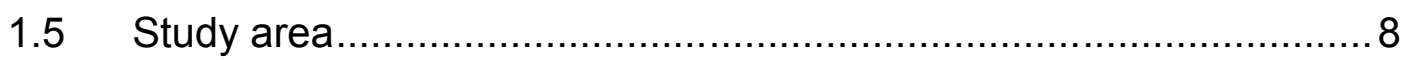

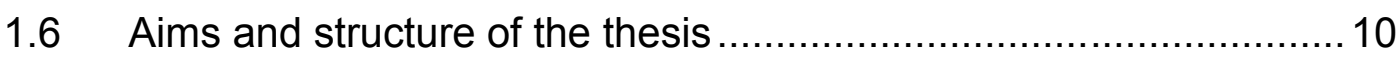

Chapter 2 Seasonal variation in vocalisations: how does vocal output change in the Zealandia forest bird community over the year?

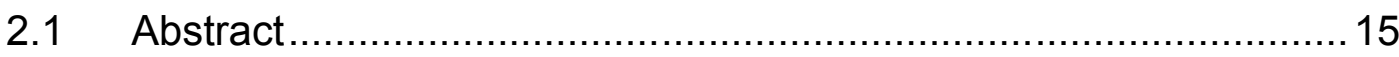

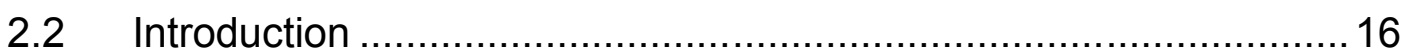

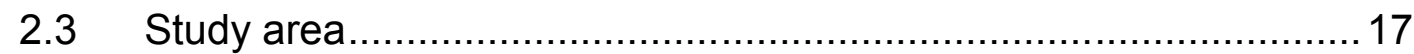

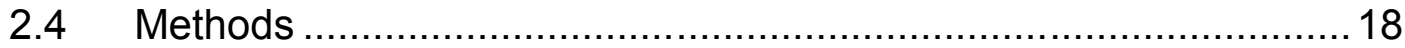

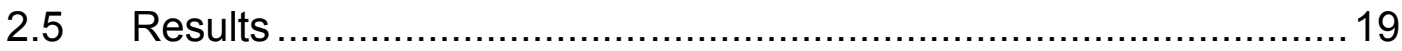

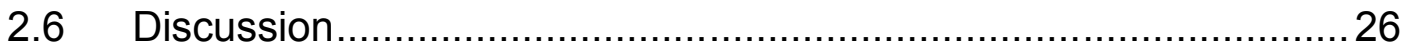

Chapter 3 Do bird vocalisations converge according to the sound transmission properties of their habitat in Zealandia?

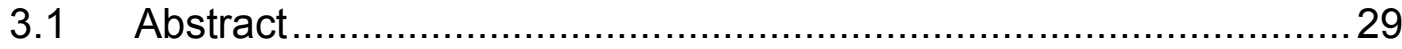

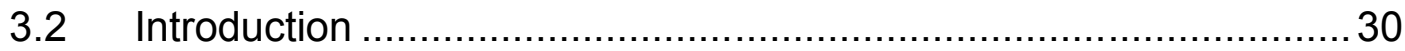

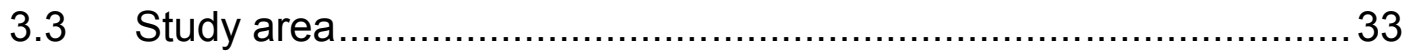

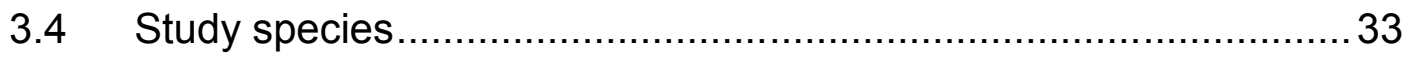

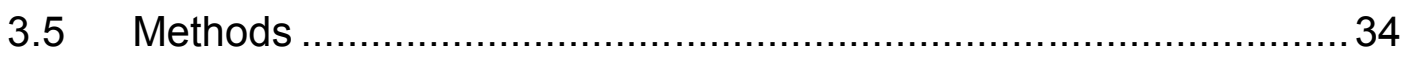


3.6 Results 39

3.7 Discussion

Chapter 4 Is there a "sound window" for avian communication in

Zealandia forest?

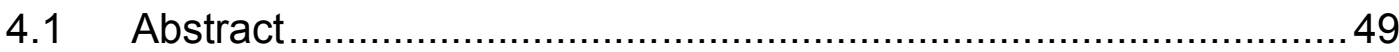

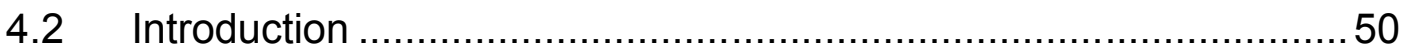

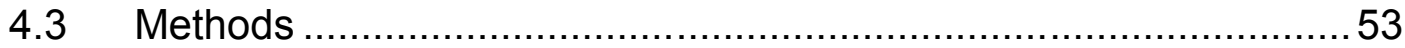

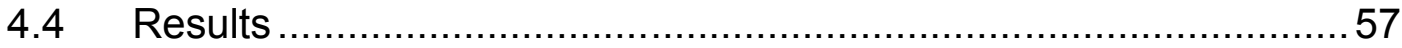

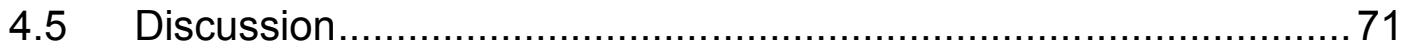

Chapter 5 Chatter song harmonics in the North Island saddleback,

Philesturnus rufusater: do they play a role in ranging?

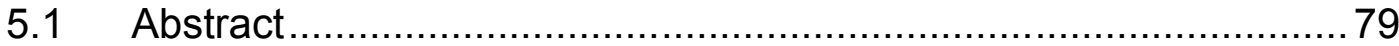

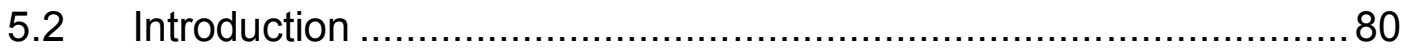

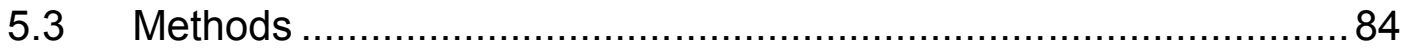

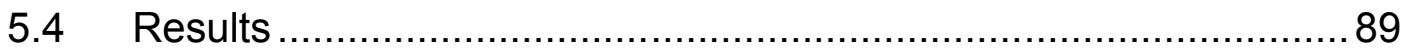

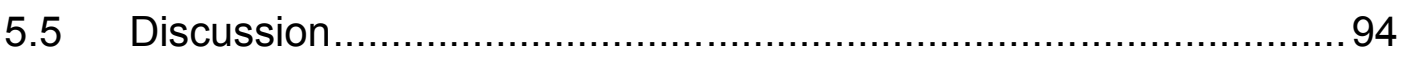

Chapter 6 Song thrush repertoires in Zealandia: have they diverged from their counterparts in Europe?

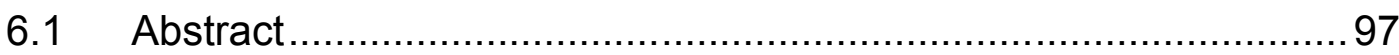

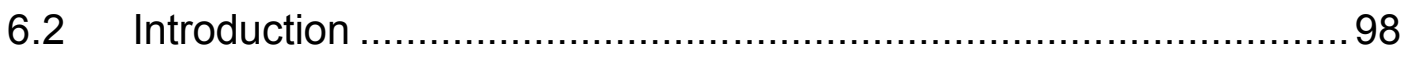

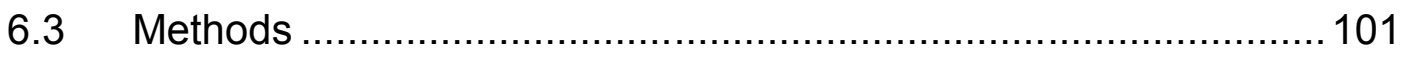

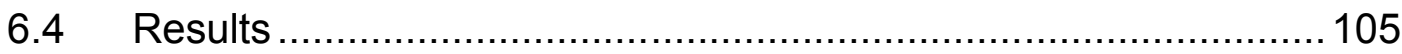

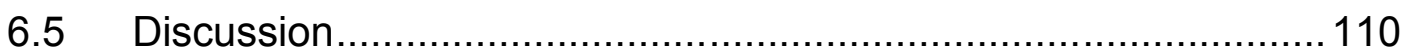

Chapter 7 Temporal variation of the song of the grey warbler, Gerygone igata: has the song changed over time?

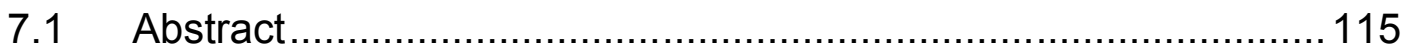

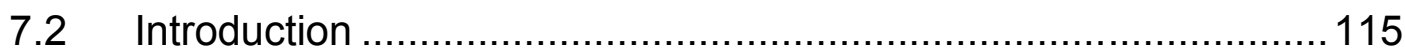

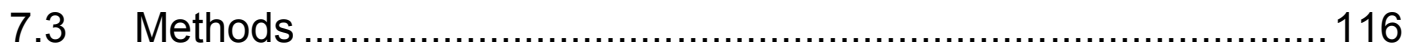




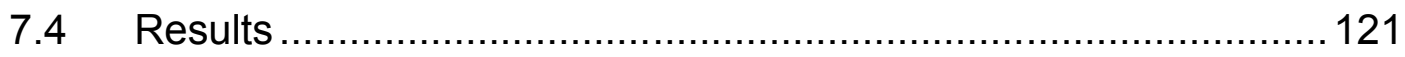

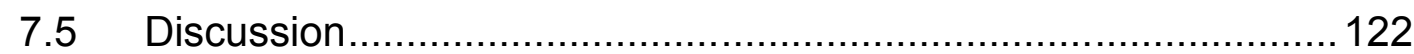

Chapter 8 General discussion and conclusions .................................... 126

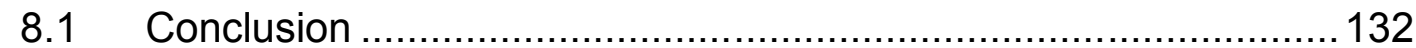

$8.2 \quad$ Further direction .............................................................. 134

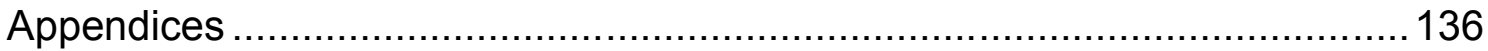

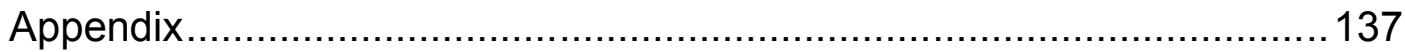

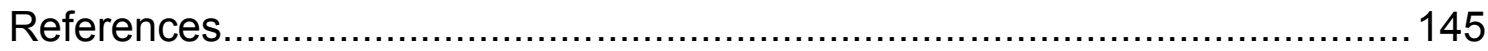




\section{List of tables}

Table 2.1. Bird species recorded during the transect counts in Zealandia: species

selected for bioacoustics study are shown in bold type. 20

Table 3.1. Loadings of vocalisation variables on each of the four principal components $(\mathrm{PC})$ with eigenvalues greater than 1. 40

Table 3.2. Summary of the nearest neighbour distance measurements.

Table 3.3. One-sample Kolmogorov-Smirnov testing for distribution uniformity....42

Table 4.1. Summary of linear regression models of frequency and SD in attenuation at $3 \mathrm{~m}$ speaker height in the broadleaf forest. 61

Table 4.2. Summary of all the linear regression models of frequency attenuation.

The speaker was $3 \mathrm{~m}$ above the ground. 63

Table 4.3. Summary of the linear regression model showing that reverberation in the pine forest was higher in than the broadleaf forest. 66

Table 4.4. Summary of the linear models of attenuation of bird vocalisations for all species studied in the broadleaf forest and pine. 69 Table 6.1. Results of principal components analysis of the physical characteristics of syllables. 108

Table 7.1. Pearson correlations of the average values of measured song variables of 20 grey warbler songs. 120

Table 7.2. Mean values of the measured song variables. The start phrase consisted of four syllables while the repeated phrases consisted of three. 121

Table 7.3. Differences in mean maximum frequency of grey warbler song between 2002 and 2009. 122

Table 7.4. Differences in mean phrase duration in grey warbler song between 2002 and 2009 compared using Mann-Whitney U tests. 122 
Table 8.1. Summary of the main results from each chapter, and their contribution to the acoustic adaptation hypothesis $(A A H)$ and the acoustic niche hypothesis $(\mathrm{ANH})$.

\section{List of figures}

Figure 1.1. Location of Zealandia sanctuary, Wellington, New Zealand. The inset shows the sanctuary with the two lakes (black) and trails within.

Figure 1.2. Summary of the content and themes of the thesis chapters (numbered) and how they relate to key hypotheses.

Figure 2.1 Location of Zealandia sanctuary, Wellington, New Zealand. The inset shows the sanctuary with the two lakes (black) and trails within. The dashed track represents the line transect. 19

Figure 2.2.The overall monthly change in numbers of all birds heard (calling and singing) and seen over the calendar year April 2010 - March 2011.

Figure 2.3. Variation in transect counts of kaka, kingfisher, saddleback, and stitchbird over twelve months in Zealandia in relation to their initial mode of recognition (first seen, first heard singing, first heard calling).

Figure 2.4. Variation in transect counts of grey warbler, bellbird, tui, and whitehead over twelve months in Zealandia in relation to their initial mode of recognition (first seen, first heard singing, first heard calling)

Figure 2.5. Variation in transect counts of fantail, robin, silvereye, and blackbird over twelve months in Zealandia in relation to their initial mode of recognition (first seen, first heard singing, first heard calling) 24

Figure 2.6. Variation in transect counts of song thrush, dunnock, chaffinch and greenfinch over twelve months in Zealandia in relation to their initial mode of recognition (first seen, first heard singing, first heard calling). 
Figure 3.1. Raven window showing the three views used in analysis, using a grey warbler, Gerygone igata, as the example. From the top, the plots are waveform, spectrogram, and power spectrum. Below the graph is the selection table illustrating some of the measurements.

Figure 3.3. Spectrogram of bellbird, Anthornis melanura, song, illustrating some of the variables measured 36

Figure 3.4. Species distribution against PC1 and PC2 axes.

Figure 3.5. The relationship between log song post height $(\mathrm{m})$ and PC1 (linear regression. 43

Figure 3.6. The relationship between log body weight $(\mathrm{g})$ and PC1 (linear regression).

Figure 4.1. Raven window with waveform (upper), and spectrogram (lower) of the 19 generated tones used in the experiment.

Figure 4.2. Spectrogram produced by Raven software showing the reverberated sound (tail) of the generated tones used in the experiment in a recording made in pine forest $40 \mathrm{~m}$ from a speaker at a height of $3 \mathrm{~m}$.

Figure 4.3. Mean frequency response $( \pm S E)$ to propagation in broadleaf forest at 3 different distances, $20 \mathrm{~m}, 40 \mathrm{~m}$, and $80 \mathrm{~m}$, speaker elevation $3 \mathrm{~m}$.

Figure 4.4. Variation in attenuation (SD) in response to frequency change, measured in the broadleaf forest at three different distances, $20 \mathrm{~m}, 40 \mathrm{~m}$, and 80 $\mathrm{m}$, speaker elevation $3 \mathrm{~m}$. The marked frequency ranges show possible sound windows.

Figure 4.5. Attenuation measured at $20 \mathrm{~m}, 40 \mathrm{~m}$, and $80 \mathrm{~m}$ from the speaker, within the broadleaf forest. The speaker was at $3 \mathrm{~m}$ height from ground. 62 Figure 4.6. Attenuation measured at $20 \mathrm{~m}, 40 \mathrm{~m}$, and $80 \mathrm{~m}$ from the speaker, within the pine forest. The speaker was at $3 \mathrm{~m}$ height from ground. 
Figure 4.7. Mean energy $( \pm S E)$ in reverberated sound within the broadleaf forest. Speaker height $3 \mathrm{~m}$

Figure 4.8. Energy in the reverberated sound at different frequencies measured at $3 \mathrm{~m}$ speaker height and $40 \mathrm{~m}$ from the speaker in the pine and broadleaf forests.

Figure 4.9. Attenuation spectra in the dense evergreen broadleaf conifer forest measured at two elevations, close to the ground $(0.5 \mathrm{~m})$ and at $3 \mathrm{~m}$ height across different distances of $20 \mathrm{~m}, 40 \mathrm{~m}$, and $80 \mathrm{~m}$ from the speaker. 68

Figure 4.10. Expected transmission distance of bird vocalisations within the broadleaf forest, with the speaker at $3 \mathrm{~m}$ height.

Figure 4.11. Expected transmission distance of bird vocalisations within the pine forest, with the speaker at $3 \mathrm{~m}$ height.

Figure 4.12. Attenuation, measured at two elevations, close to the ground $(0.5 \mathrm{~m})$ and at $3 \mathrm{~m}$ height across different distances at 20,40, and $80 \mathrm{~m}$ from the speaker. in the broadleaf forest, compared with frequency and the frequencies used by each species within the Zealandia forest. Developed from Fig. 4.9. Species name code as in Fig. 4.10

Figure 5.1 Spectrograms (left) and power spectra (right) of $8 \mathrm{~s}$ saddleback song sample used in playback experiments. (a) control (un-modified song) showing the fundamental frequency (F0) and the harmonics $(\mathrm{H} 1, \mathrm{H} 2, \mathrm{HH}),(\mathrm{b})$ amplified lower harmonics (ALH), (c) amplified higher harmonics $(A H H)$. The darkness of the band represents the relative amplitude.

Figure 5.2. Location of study area and experimental sites at Zealandia sanctuary, Wellington, New Zealand. The inset shows the sanctuary with the two lakes (black) and trails within. 
Figure 5.3. Power spectra of four $5 \mathrm{~s}$ song samples modified for use in experiment 2, showing muted fundamental frequency (F0), muted first harmonic $(\mathrm{H} 1)$, muted second harmonic $(\mathrm{H} 2)$, and muted higher harmonics $(\mathrm{HH})$.

Figure 5.4. The experimental setup and speaker positions used in the forest at Zealandia.

Figure 5.5. Time until the first vocal response, and counter-song duration for all 12 saddlebacks tested in experiment 1. Error bars indicate $95 \%$ standard errors. ....90 Figure 5.6. Mean times to the first flight towards the speaker in response to playback song types in experiment 2 (control and muted F0, H1, H2, HH song). Error bars indicate $95 \%$ standard errors. 92 Figure 5.7. Distance of target saddleback after $30 \mathrm{~s}$ and closest distance to speaker B within 2 min. in relation to different playback song types in experiment 2 (control and muted F0, $\mathrm{H} 1 \mathrm{H} 2 \mathrm{HH}$ song). Error bars indicate 95\% standard errors.

Figure 6.1. World map to illustrate the distances between the locations in the United Kingdom (UK) and New Zealand (NZ). 102

Figure 6.2. Location of eight song thrushes sampled at Zealandia sanctuary, Wellington, New Zealand (left), and the localities of eight song thrush songs sampled in the UK (right). The sample sizes from the UK are shown in parentheses. Not to scale. 103

Figure 6.3. Composite sonograms illustrating a sample (only) of different syllables used by the two song thrush populations, NZ birds (upper) birds and UK birds (lower). 105

Figure 6.4. Box plot showing the variation in number of shared and unique song thrush syllables between NZ and the UK. The two points on the graph represent name of the locality from where bird were sampled. 106 
Figure 6.5. Box plot showing the diversity of song in each population. Diversity was measured by adding the ratios of shared and unique syllables. 107

Figure 6.6. Scatter plot of factor 1 versus factor 2 obtained in the principal component analysis (PCA) for syllable measurements grouped according to individuals. 109

Figure 6.7. Scatterplot of syllable categories plotted against the extracted principle components. Syllables were categorised as shared among to the two populations, or unique to either the NZ or UK population.

Figure 7.1. Spectrogram of grey warbler song showing the start phrase (S) and repeated phrases $(\mathrm{R} 1, \mathrm{R} 2$, and $\mathrm{R} 3)$. All syllables are whistle-like with a relatively narrow frequency bandwidth. The unmarked notes represent those not included in the analysis.

Figure 7.2. Sonogram of grey warbler in 2002 and 2009, and whitehead song introduced to the Zealandia in 2001 and 2002 


\section{Chapter 1}

\section{General Introduction}

\subsection{Function of bird vocalisations}

Acoustic signals play an important role in several aspects of birds' behaviour. Song is thought to serve two main functions, either to attract mates or to defend territories (Catchpole \& Slater 2008). Between males, territorial defence is thought to be the principal function of song (Collins 2004), and this was demonstrated clearly by playback experiments, a technique widely used to test hypotheses on territorial behaviour (Catchpole \& Slater 2008). In a speaker replacement experiment on the great tits, Parus major, Krebs (1977), showed that intruding males were delayed or less frequent on territories defended by song. Comparable studies on other species have since found similar results in, for example redwinged blackbirds, Agelaius phoeniceus (Yasukawa 1981), white-throated sparrows, Zonotrichia albicollis (Falls 1988), and song sparrows, Melospiza melodia (Nowicki et al. 1998). Other playback studies have confirmed that individual song performance can affect male-male territorial interactions (Hultsch \& Todt 1982; Schmidt et al. 2008; De Kort et al. 2009).

The second function of male song is to attract females (Eriksson \& Wallin 1986), and the characteristics of such songs can play a major role in their effectiveness in attracting females. For example, songs with larger repertoires are more attractive to females in the sedge warbler, Acrocephalus schoenobaenus (Catchpole et al. 1984; Buchanan \& Catchpole 1997) and more stimulating to females in the canary, Serinus canaria (Kroodsma 1976). A larger song repertoire, which may include hundreds or even thousands of syllable types, is now widely accepted to have arisen through sexual selection by female choice (MacDougall-Shackleton 1997). 


\section{Chapter 1}

Long and more elaborated songs indicate better male quality (Searcy \& Yasukawa 1996), and affect females' choice by their preference for some phrases over others (Vallet \& Kreutzer 1995; Forstmeier \& Balsby 2002). In addition, other characteristics of the song may convey subtle information about the signalling male, such as the rate of singing, the form of song, and the song duration (Bradbury \& Vehrencamp 1998).

Other functions of acoustic communication involve cooperation rather than conflict, which benefits both receiver and sender. This includes alarm calls, species or kin recognition calls, and parent-offspring communication (Kroodsma \& Miller 1982; Searcy \& Andersson 1986; Catchpole \& Slater 2008). For example, a great tit may give an alarm call to warn its fledglings that a predator is approaching (Catchpole \& Slater 2008). Cooperatively breeding long-tailed tits, Aegithalos caudatus, respond differently to playback of kin and non-kin songs (Hatchwell et al. 2001). Parent-offspring communication is particularly important for birds that nest in large crowded colonies where parents are challenged in finding their own young. For example, king penguins, Aptenodytes patagonicus, use a complex pattern of frequency modulations to form a distinct vocal signature (Jouventin et al. 1999). In some passerine species, parents can recognise begging calls of chicks, e.g. black redstart, Phoenicurus ochruros (Draganoiu et al. 2006) and bank swallows, Riparia riparia (Beecher et al. 1981).

Bird vocalisations are clearly important in bird communication and their composition and structure differs between species according to their specific functions and the intended receiver (Marler 2004b). However, to deliver the information between the sender and the receiver, all the different vocalisations 


\section{Chapter 1}

have to transmit within the habitat and are challenged by sound transmission constraints (Marler 2004b).

\subsection{Problems of avian sound transmission}

Acoustic signals are susceptible to modification by the habitat, posing two fundamental problems for sound transmission between individuals, namely degradation and attenuation (Naguib \& Wiley 2001). Degradation is the sum of structural changes that the signal accumulates at some distance from the source (Morton et al. 1986). Scattering or refraction of sound by vegetation gives rise to degradation by frequency alterations, and timing rearrangements by echoes and reverberations (Bradbury \& Vehrencamp 1998). Habitats with dense foliage impose greater degradation on sound transmission (Blumenrath \& Dabelsteen 2004), which may reduce, or even prevent, the transfer of information between the sender and the receiver (Fotheringham \& Ratcliffe 1995; Fotheringham et al. 1997; Holland \& Rice 1998).

Attenuation is the progressive decrease of signal intensity (energy per unit surface), which takes place as the propagation distance increases (Forrest 1994). Spherical spreading describes the decrease in sound amplitude when it propagates away from a source, and usually it deals with a point source in the middle of an environment that is homogeneous in all directions. Attenuation of bird vocalisations tends to be greater than expected by spherical spreading, due to atmospheric absorption (Bass 1991) and vegetation structure (Taylor 1971; Wiley \& Richards 1978; Martens 1980). Warm, dry air enhances sound transmission (Evans \& Bailey 1956; Harris 1966), while dense foliage increases attenuation (Boncoraglio \& Saino 2007). 


\section{Chapter 1}

Acoustic interference from background noise can also affect sound transmission as it decreases the efficiency of intraspecific communication by decreasing the detectability, the ability to separate a signal from background noise, and the discriminability, the ability to separate similar conspecific signals (Endler 1992). Many examples of communication in noisy environments come from animals communicating in aggregations, such as frog choruses and avian dawn choruses, where it is especially difficult to discriminate conspecific from similar heterospecific signals (Bremond 1978; Wiley 1994; Pfennig 2000; Gerhardt \& Huber 2002; Wollerman \& Wiley 2002; Brumm \& Slabbekoorn 2005). Ambient sounds produced by other bird species and the environment (wind, rain, and insects) can interfere with signal detection and recognition and mask critically important messages.

Vocalisations of other bird species are a common source of background noise (Schwartz \& Wells 1983; Wollerman \& Wiley 2002), and signals with similar features have a greater chance of interfering with each other and creating receiver errors (Wiley 2000). Such errors include response to signals from different species, or lack of responses to appropriate signals, which could result in additional time and risks in finding a mate or confronting a rival (Wiley 1994).

One way to improve communication under noisy conditions is to increase the signal-to-noise ratio, for example king penguins, Aptenodytes patagonicus, produce longer calls with more syllables under windy and noisy conditions (Lengagne et al. 1999), and zebra finches, Taeniopygia guttata, can adjust the amplitude of their song in response to varying noise levels (Cynx et al. 1998). Similar responses are also found in territorial species such as the nightingale, Luscinia megarhynchos (Brumm \& Todt 2002) and the blue-throated hummingbird, 


\section{Chapter 1}

Lampornis clemenciae (Pytte et al. 2003). To avoid the negative effects of acoustic interference, signallers should evolve signals that contrast with the background noise of their environment (Miller 1982; Endler 1992; Wiley 1994; Wiley 2006), and signals that evolved more distinctive features from those of other species should have advantages for conspecific recognition (Falls 1963; Emlen 1972; Nelson \& Marler 1990).

\subsection{Effect of the environment on avian vocalisation}

Environmental selection pressures may shape the physical characteristics of song, such as its spectral and temporal structure (Wiley \& Richards 1982; Endler 1992; Forrest 1994). As noted above the predominant selection pressures that may vary between habitats are sound transmission properties associated with local microclimate and vegetation structure (Wiley \& Richards 1982; Brown \& Handford 2000; Slabbekoorn et al. 2002) and signal interference by local ambient noise patterns (Brenowitz 1982; Ryan \& Brenowitz 1985; Nelson \& Marler 1990). These two phenomena have led to the formulation of two hypotheses on the structure of bird vocalisations within a community.

1- The Acoustic Adaptation Hypothesis (hereafter, AAH) states that animal vocalisations should adapt to sound transmission characteristics of the environment (Ey \& Fischer 2009), and it is supported widely by habitatbased song variation studies (Doutrelant \& Lambrechts 2001; Chilton et al. 2002; Marler \& Slabbekoorn 2004; Koetz et al. 2007; Derryberry 2009). It is based on the fact that different frequencies of sound are absorbed and reflected to a lesser or greater degree by different objects in the habitat, hence, birds should utilise frequencies in their vocalisations that are less affected to modification from habitat, to achieve maximum transmission 


\section{Chapter 1}

distance (Catchpole \& Slater 2008). Marten \& Marler (1977) proposed the presence of a "sound window" within which the frequencies achieve maximum transmission distance. In deciduous or tropical forest, the optimal "sound window" occurs between $1.5 \mathrm{KHz}$ and $2.5 \mathrm{KHz}$ where sounds within these wavelengths are less affected by habitat and travel better than sounds with higher or lower frequencies. In coniferous forest, sounds between $1 \mathrm{KHz}$ and $3 \mathrm{KHz}$ transmit better as they are enhanced by the vegetation (Marten \& Marler 1977). According to the AAH, birds in forest should sing at lower frequencies, and have few rapidly repeated elements since there is greater reverberation and attenuation in forests compared to more open habitat (Rothstein \& Fleischer 1987).

2- The Acoustic Niche Hypothesis (hereafter, ANH) argues that the available frequency range for bird vocalisation is partitioned, and birds call so that overlap between different species in frequency and time is reduced (Krause 1987). Later work on species recognition (Nelson \& Marler 1990; Nelson \& Soha 2004) has stressed the possible negative effect of confusion between similar signals. Interspecific competition for acoustic space should favour birds that adjust their signals to exploit vacant niches in the auditory spectrum to minimise spectral or temporal overlap in interspecific vocalisations (Krause 1993). For example, some species that share the same habitat may adjust their temporal pattern of singing to avoid the overlapping of songs; this is seen in, least flycatchers, Empidonax minimus, which insert their shorter songs between the longer songs of red-eyed vireos, Vireo olivaceus (Ficken et al. 1974).

Species assemblages altered by invasive, or introduced birds might feature a degree of acoustic disturbance, resulting from the alteration of the 


\section{Chapter 1}

previously natural acoustic partitioning (Pijanowski et al. 2011b). This may lead to the prediction that undisturbed habitats with unaltered species assemblages might show higher levels of coordination between inter specific vocalisations than more heavily disturbed habitats (Pijanowski et al. 2011b). In his formulation of the ANH, Krause (1987) pointed out that both the morphological and the behavioural adaptations implied by the $\mathrm{ANH}$ and the $\mathrm{AAH}$ could also be triggered by interspecific interference when bird vocalisations contain similar frequency and timing features. Krause (1987) repeatedly had observed complex arrangements of non-overlapping signals in his recordings of animal vocalisations and natural sounds in an environment with multiple habitat types.

\subsection{Forest as acoustic space}

The "acoustic space" of a given environment is the multi-dimensional space available for sound signals. It is a concept used in analysing the distinctiveness of songs and evaluating the acoustic overlap among bird species in a multivariate way (Marler 2004a). Forests can be very complex auditoria because of the variety of physical processes associated with sound transmission such as attenuation and degradation (Slabbekoorn et al. 2009). Generally, forests have many types of leaf and different twig sizes, variably distributed between sender and receiver, and this will result in an inconsistent effect on sound transmission depending on the density and obstacles in the path of the travelling sound (Martens et al. 1985). For example, there may be a dense shrub layer at one location and more open patches in another, both irregularly interspersed with thick tree trunks, or the ground may be bare or carpeted with vegetation, or flat or hilly. All these factors 


\section{Chapter 1}

contribute to changing patterns of sound absorption and reflection depending on the positions of sender and receiver (Mark 2004).

\subsection{Study area}

This study was based at Zealandia ( $\left.41^{\circ} 18^{\prime} \mathrm{S}, 174^{\circ} 44^{\prime} \mathrm{E}\right)$, a $2.5 \mathrm{~km}^{2}$ valley of secondary forest (Fig. 1.1) located $2 \mathrm{~km}$ west of Wellington city centre. The forest is protected from a suite of mammalian predators introduced to New Zealand, by a $9 \mathrm{~km}$ long $2.2 \mathrm{~m}$ high barrier fence (Campbell \& Atkinson 2002). The forest canopy is predominantly a mixture of evergreen native and exotic tree species, with a welldeveloped native understorey. The forest is inhabited by exotic and native bird species, after a series of successful reintroductions of endemic New Zealand species, such as North Island saddleback, Philesturnus rufusater, in 2002, bellbird, Anthornis melanura, in 2002-2003, North Island robin, Petroica (Miro) longipes, in 2001-2002, whitehead, Mohoua albicilla, in 2001-2002, and North Island kaka, Nestor meridionali septentrionalis, in 2000 (Miskelly et al. 2005; Taylor et al. 2005; Bell 2008). Climate in the area is characterised by mild temperate conditions, with an average daily temperature of $12.8^{\circ} \mathrm{C}$ and annual rainfall of $1,249 \mathrm{~mm}$ (NIWA 2010). Winter is the wettest time of year, while in summer droughts are common (Hurnard 1978). However, compared with many temperate climates, there is relatively little variation between summer and winter temperatures, the mean temperature range between summer and winter being $17.20^{\circ} \mathrm{C}$ to $8.90^{\circ} \mathrm{C}$ (NIWA 2010). The austral summer occurs from December to March, with winter conditions prevailing from June to September. 


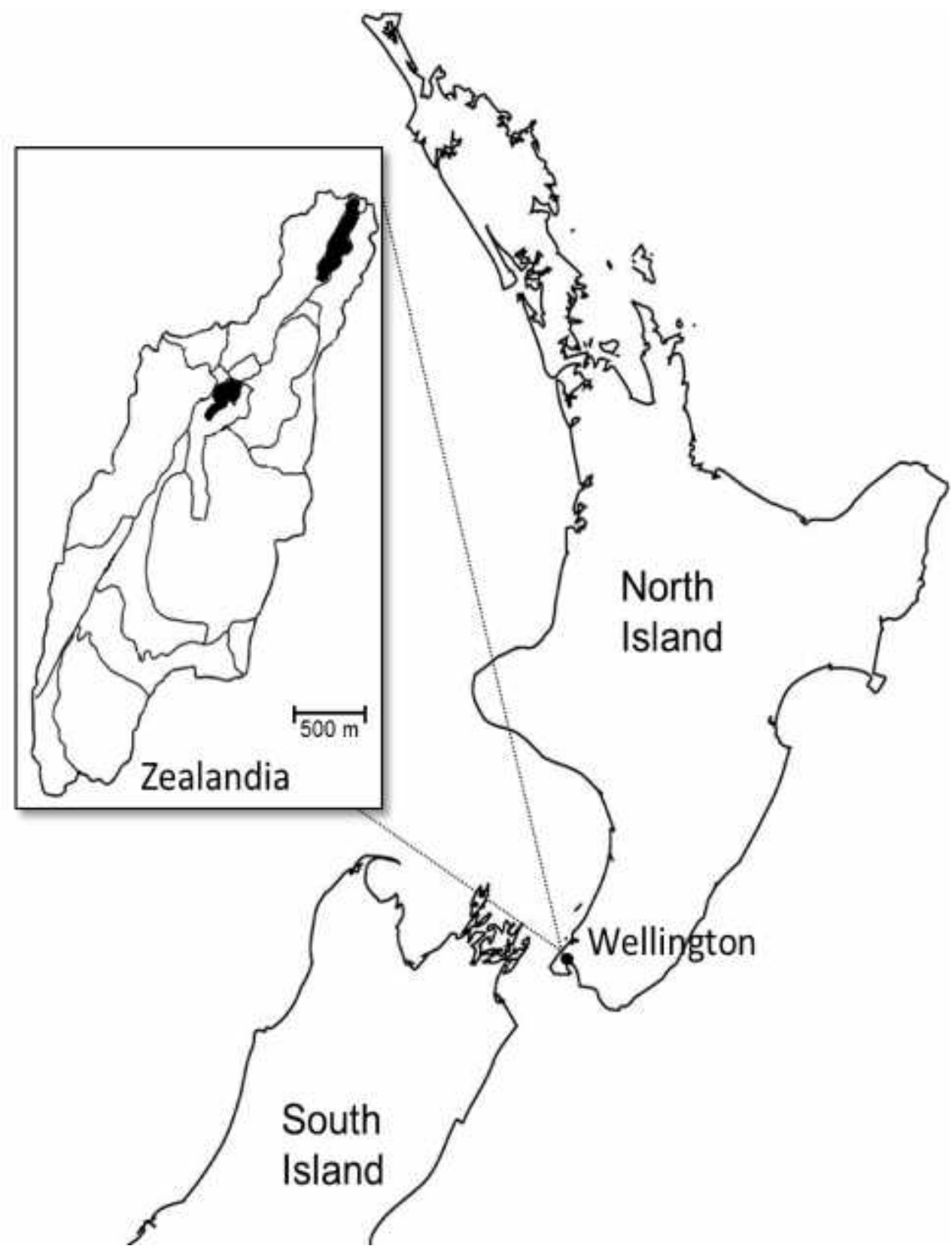

Figure 1.1. Location of Zealandia sanctuary, Wellington, New Zealand. The inset shows the sanctuary with the two lakes (black) and trails within. 


\section{Chapter 1}

\subsection{Aims and structure of the thesis}

Generally, most research on bird vocalisations has focused on Holarctic or Neotropical species, which may ultimately share a common evolutionary history (Blumstein \& Turner 2005). New Zealand offers opportunities for new investigations that examine Southern Hemisphere species that may differ in their patterns of vocal behaviour in a temperate environment. This thesis takes both a community approach and a species approach to bird vocalisations and investigates patterns of songs and calls across spatial and temporal scales. It addresses the $\mathrm{AAH}$ and $\mathrm{ANH}$ hypotheses by examining possible links between the vocal environment and the characteristics of the local avian community that share the same acoustic space in the forest at Zealandia (Fig. 1.2).

While the general aims and hypotheses of this study are listed below, further questions are embedded in each of the subsequent results chapters that are prepared in a format that will facilitate their later publication as research papers.

\section{Chapter 2: Does the seasonal change in the vocal output of bird at Zealandia} affect their conspicuousness?

This chapter serves as an introduction to the avian community studied in subsequent chapters, and describes the seasonal change in the vocal activity of different species. Bird censuses in forests depend largely on hearing rather than on visual detection of birds (Bibby et al. 1992). The reliability of vocal data for measuring population abundance will be highly affected by seasonal changes in singing and calling behaviour (Gibb 1996). Through undertaking a regular linetransect count each month, seasonal changes in vocal output of different species, and the possible effect on their conspicuousness, was investigated. 


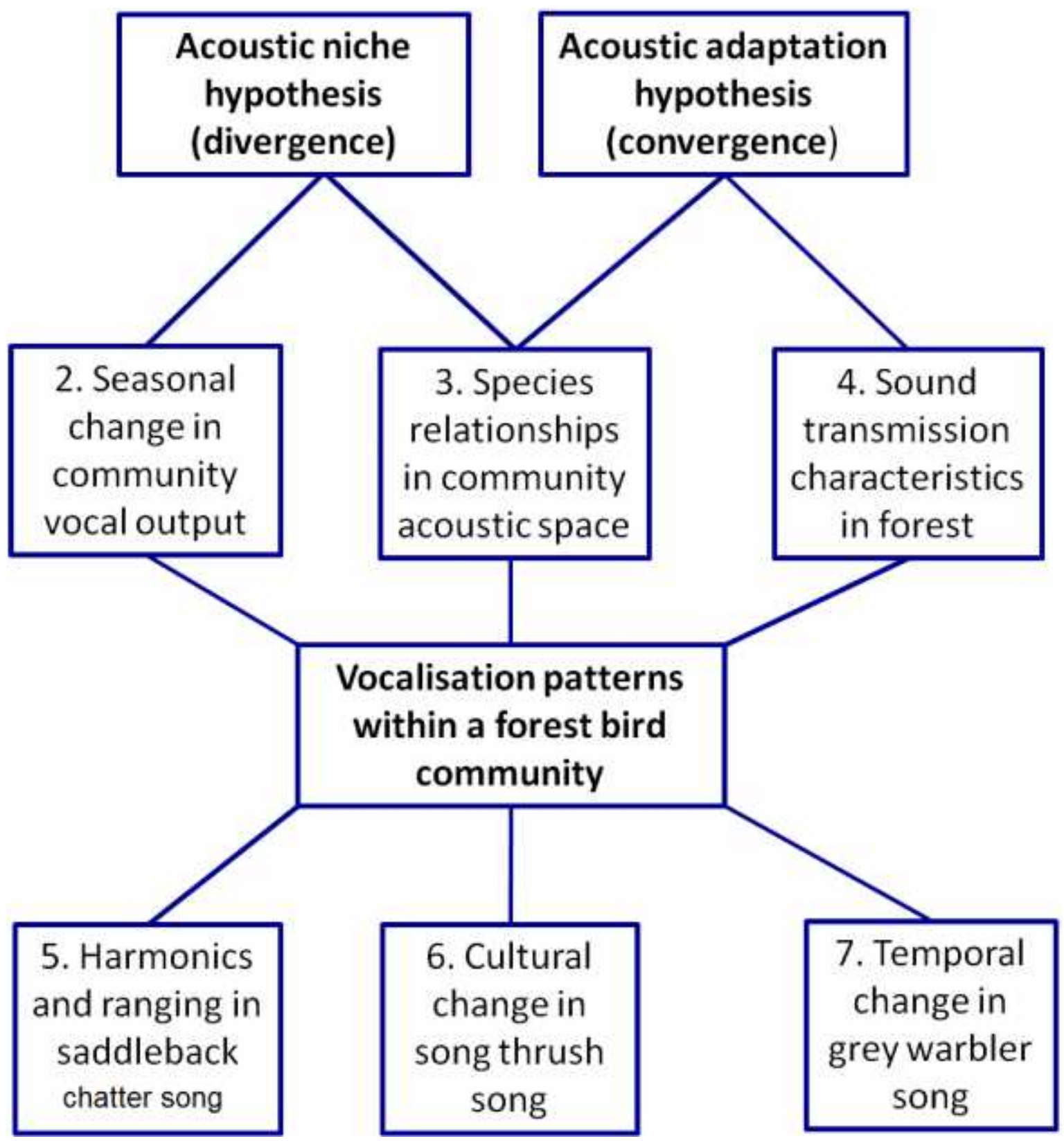

Figure 1.2. Summary of the content and themes of the thesis chapters (numbered) and how they relate to key hypotheses

Chapter 3: Do bird vocalisations of the avian community at Zealandia converge under the sound transmission properties of their habitat? This chapter is an analysis of vocalisation characteristics of the forest bird community at Zealandia, using a multivariate species approach. The primary objective of this chapter was to describe the acoustic community and investigate whether bird vocalisations at Zealandia might have converged in their traits under 


\section{Chapter 1}

the effect of habitat selection pressure for better transmission (Marler \& Slabbekoorn 2004; Ey \& Fischer 2009), or might have diverged to reduce competition among species (Krause 1987; Krause 1993) (Fig.1.2). Bird vocalisations can be affected by their body size, e.g. Brenowitz (1982) and Ryan \& Brenowitz (1985), and by their bill size and shape (Podos 2001; Seddon 2005; Ballentine \& Pfennig 2006), so another aim of this chapter was to assess whether such phenological traits might have an effect on the traits of bird vocalisations.

\section{Chapter 4: Is there a sound window for bird communication at Zealandia forest? What is the expected transmission distance of bird vocalisations within the Zealandia forest?}

This chapter complements the community study (Chapter 2 ) by focusing on the habitat as a source of selection pressures on bird vocalisations and assessing the selection pressure imposed on transmitted sound. Different habitat types have varying effect on the transmitted signal between individuals and a sound window has been described in the low frequency range that is more suitable for sound transmission within forests (Morton 1975; Catchpole \& Slater 2008). This chapter investigated the possible effect of the Zealandia forest on sound transmission by modelling the acoustic environment as it appears during natural signalling and by establishing a reference level of the magnitude of frequency dependent attenuation, degradation, and ground effect, on the acoustic signal. Estimating a signal's actual range and the range of information coded in given bird vocalisations provides a better understanding of how far the intended receiver might be (Brenowitz 1982). A playback method was used to estimate the maximum propagation distances of bird vocalisations. 
Chapter 5: Do chatter song harmonics in North Island saddleback play a role in ranging?

This chapter focused on the perception of sound, namely the role of harmonics in estimating the distance of a signaller. Harmonics have received little attention as distance cues, however chatter song frequency plays a role in estimating the distance of a signaller (i.e., ranging) (Naguib 1995, 1997b). In this chapter, I investigated whether song harmonics in the North Island saddleback play a role in ranging. Playback experiments were used on wild birds to test whether the relative amplitude of harmonics served as a distance cue, and whether a change of harmonic composition of the song had an effect on a territorial bird's response and its likely ability to estimate the distance of the signalling individual.

\section{Chapter 6: Has the song repertoire of the song thrush at Zealandia diverged from the source population in Europe?}

This chapter compares the song repertoire of the song thrush at a macrogeographical level. New dialect patterns emerge in response to habitat selection pressure for optimal transmission through the acoustic environment (Hunter \& Krebs 1979; Handford \& Lougheed 1991; Doutrelant et al. 1999; Slabbekoorn \& Smith 2002b; Patten et al. 2004). This study compares song thrush songs in Zealandia with song samples from its source population in Europe.

\section{Chapter 7: Has the grey warbler song in Zealandia changed over time? This} chapter investigates how songs may change with time by comparing the song of grey warblers between 2002 and 2009, within the same population in Zealandia. Temporal stability of song varies within avian taxa, even within the same 
geographical boundaries, with some dialects persisting unchanged for many generations while others can quickly arise and disappear (Podos \& Warren 2007).

Chapter 8: I finish with a concluding discussion of preceding chapters to provide an overall view of the findings of this thesis, discussing its contributions and its limitations, and suggesting further directions for research. 


\section{Chapter 2}

Seasonal variation in vocalisations: how does vocal output change in the Zealandia forest bird community over the year?

\subsection{Abstract}

The seasonal changes in vocalisation patterns of birds at Zealandia are described based on data collected through line transect counts, carried out over a year within the first week of each month from April 2010 to March 2011. The fixed line transect of $1.5 \mathrm{~km}$ ran through a section of exotic pine and native broadleaf forest to cover a representative range of forest birds. All birds recorded were classified into three categories according to how they were first detected, as either being seen, or heard singing or calling. The predominant mode of detection varied across months and between species. Some species were mostly first heard rather than seen and vice-versa. Singing activity varied seasonally affecting the conspicuousness of different bird species through the year. 


\subsection{Introduction}

To assess the conservation importance of a particular habitat, data on the distribution and the assemblage of bird species is required. Such data are then often used as a measure of the biological importance of a given site (Bibby et al. 1992). Bird census methods in forests typically depend largely on vocal rather than on visual detection of birds (Bibby et al. 1992). In turn, vocal detection data for measuring population abundance will be highly affected by seasonal changes in singing and calling behaviour (Gibb 1996). Most bird species have different patterns of vocalisation throughout the year. For example, many oscine birds do not sing all year round, and the vocalisation pattern can change during the breeding season, including the amount and the structure of vocalisations (Catchpole \& Slater 2008).

Bird counts to estimate abundance rely on the assumption that numbers of individuals detected (e.g. seen, heard) represent a constant proportion of the actual numbers present across space and time (Thompson 2002). The validity of this assumption has been questioned and has been a matter of much debate (Burnham 1981; Buckland et al. 2001; Rosenstock et al. 2002; Thompson 2002). The number of counted birds can be affected by the detectability of different species, among different habitats, and across the time of year (Rosenstock et al. 2002; Thompson 2002). As bird counts in dense forest rely mainly on counting birds heard, seasonal changes in their vocal output influence the overall number of individuals recorded (Bibby et al. 1992).

Variation in species detectability, resulting from conspicuousness and differences in vocal output across months, is a key issue for wildlife surveys and needs to be 
assessed carefully (Sutherland 2006). Indices of bird counts based on the total number of birds heard and seen might not represent the actual species density, especially for birds that have strong seasonal change in the vocalisation output (Haselmayer \& Quinn 2000). In New Zealand, 5-minute point counts are widely used in avian surveys (Dawson \& Bull 1975), however, few studies have evaluated the suitability of this method for particular New Zealand species (Gill 1980; Cassey et al. 2007), or looked at the effect of change of the vocal output on bird counts (e.g. Gibb 1996, Gibb 2000).

The frequency of occurrence of song types or calls is likely to vary seasonally, spatially, and under different social contexts (Brunton \& Li 2006). Different vocalisation types and rates among age classes and sexes are known to have an important effect on species detectability (Wilson \& Bart 1985). Understanding seasonal variation in forest bird counts can be confounded by the effect of detectability of different species, and influenced by changes in song output, calls, or conspicuousness (Simon et al. 2002). Providing a background to sound recording analysis covered later in this thesis, these counts illustrate the seasonality of vocal output for different species in the Zealandia forest bird community.

\subsection{Study area}

This study was conducted at Zealandia, a 250 ha mainland island in New Zealand, protected from invasive mammalian predators by a $9 \mathrm{~km}$ long $2.2 \mathrm{~m}$ high barrier fence (Campbell \& Atkinson 2002). Characterised as a coastal broadleaf-conifer forest (Dawson 1988b; Wardle 2002), the forest is dominated by mähoe, Melicytus ramiflorus, five finger, Pseudopanax arboreus, and pate, Schefflera digitata; tree ferns, Cyathea spp., and Hymenophyllum spp., while shrubs such as hangehange, 


\section{Chapter 2}

Geniostoma rupestre, and kawakawa, Macropiper excelsum, are common in the understorey vegetation. The study site has a mild, temperate climate, with annual rainfall averaging $127 \mathrm{~cm}$, and there is relatively little variation between summer and winter temperatures compared with many temperate climates, the mean temperature range between summer and winter being $17.20^{\circ} \mathrm{C}$ to $8.90^{\circ} \mathrm{C}$ (NIWA 2010).

\subsection{Methods}

A line transect along existing tracks was used in Zealandia to record all birds heard singing, seen or heard calling along a predefined route within the forest. Birds were recorded while walking at a slow constant speed along the route; the route was approx. $1.5 \mathrm{~km}$ long (Fig. 2.1) and took approx. $40 \mathrm{~min}$ to complete. Birds within approx. 20 m either side of the transect were recorded. The study commenced in April 2010 and ended in March 2011, the transect being carried out in the early morning between 7-9 am within the first week of each month. The line transects were done on fine days with calm to moderate wind. Birds were classified into three main categories depending on the way they were first detected: first heard singing, first heard calling, or first seen. Songs were defined as complex vocalisations that appear to occur spontaneously and are often produced in long spells with a characteristic diurnal rhythm(Catchpole \& Slater 2008). Calls were defined as being shorter, simpler and produced in particular contexts which can be related to specific functions such as flight, threat or alarm (Catchpole \& Slater 2008). If a bird was heard first then seen, it was recorded only once according to the first encounter (heard). 


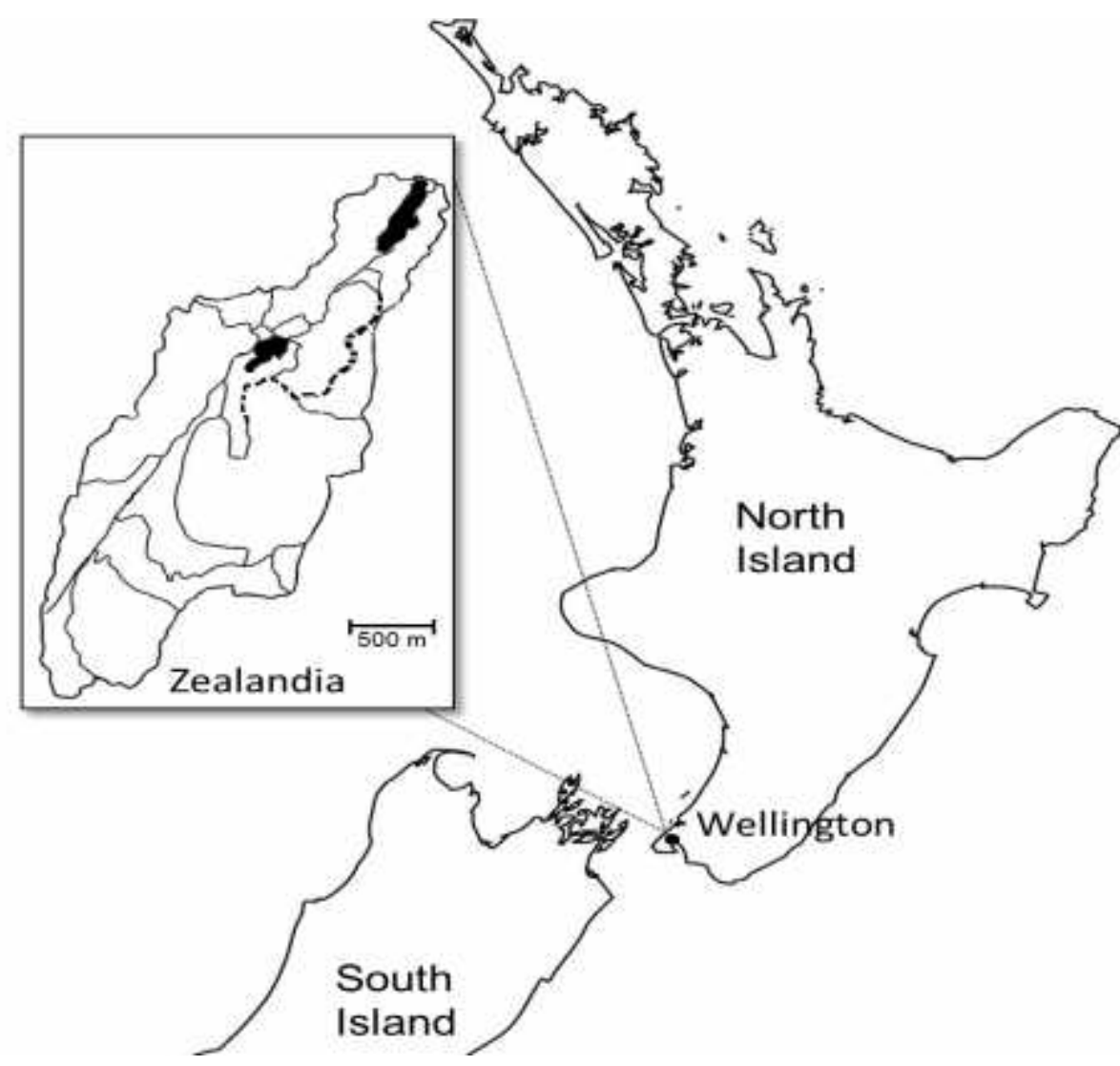

Figure 2.1 Location of Zealandia sanctuary, Wellington, New Zealand. The inset shows the sanctuary with the two lakes (black) and trails within. The dashed track represents the line transect.

The results are represented as stacked bar charts, and Chi-square tests were used to describe the pattern of vocalisation. Graphs and Chi-square tests were done using SPSS 18. When the number of observations was less than five individuals no statistical test was done. The null hypothesis was that species were equally detected seasonally by each of the three counting methods; seen, heard calling, and heard singing.

\subsection{Results}

Over the twelve-month period of counts, a total of 22 species were recorded, including all 16 species whose vocalisations are investigated further in this thesis. These species are listed in Table 2.1. 
Table 2.1. Bird species recorded during the transect counts in Zealandia: species selected for bioacoustics study are shown in bold type.

\begin{tabular}{|c|c|c|c|}
\hline Scientific name & Common name & Status & Hereafter \\
\hline Falco novaeseelandiae & New Zealand falcon & Endemic & Falcon \\
\hline Callipepla californica & California quail & Introduced & Quail \\
\hline Chrysococcyx lucidus & Shining cuckoo & Native & $\begin{array}{l}\text { Shining } \\
\text { cuckoo }\end{array}$ \\
\hline Eudynamys taitensis & Long-tailed cuckoo & Endemic & $\begin{array}{l}\text { Long-tailed } \\
\text { cuckoo }\end{array}$ \\
\hline Platycercus eximius & Eastern rosella & Introduced & Rosella \\
\hline $\begin{array}{l}\text { Nestor meridionalis } \\
\text { septentrionalis }\end{array}$ & North Island Kaka & Endemic & Kaka \\
\hline $\begin{array}{c}\text { Todiramphus sanctus } \\
\text { vaganus }\end{array}$ & $\begin{array}{l}\text { New Zealand } \\
\text { kingfisher }\end{array}$ & Native & Kingfisher \\
\hline Philesturnus rufusater & $\begin{array}{l}\text { North Island } \\
\text { saddleback }\end{array}$ & Endemic & Saddleback \\
\hline Notiomystis cincta & Stitchbird & Endemic & Stitchbird \\
\hline Gerygone igata & Grey warbler & Endemic & Grey warbler \\
\hline Anthornis melanura & Bellbird & Endemic & Bellbird \\
\hline $\begin{array}{l}\text { Prosthemadera } \\
\text { novaeseelandiae }\end{array}$ & Tui & Endemic & Tui \\
\hline Mohoua albicilla & Whitehead & Endemic & Whitehead \\
\hline Rhipidura fuliginosa & North Island fantail & Endemic & Fantail \\
\hline Petroica longipes & North Island robin & Endemic & Robin \\
\hline Sturnus vulgaris & Starling & Introduced & Starling \\
\hline Zosterops lateralis & Silvereye & Native & Silvereye \\
\hline Turdus merula & Eurasian blackbird & Introduced & Blackbird \\
\hline Turdus philomelos & Song thrush & Introduced & Song thrush \\
\hline Prunella modularis & Dunnock & Introduced & Dunnock \\
\hline Fringilla coelebs & Chaffinch & Introduced & Chaffinch \\
\hline Carduelis chloris & Greenfinch & Introduced & Greenfinch \\
\hline
\end{tabular}

Nomenclature follows Gill et al. (2010) 


\section{Chapter 2}

I confine the analysis in this chapter to the commoner 16 species within the forest. The overall trend in numbers of species seen and heard (singing and calling) over the year is shown in Fig 2.2. Overall most birds were counted in spring and early summer (September-December). The number of birds first heard peaked during October, and those first seen in November. When each of these species is examined in turn, different species had different patterns of vocalisation output over the year. The results are presented in bar charts along with a description about the patterns observed for each of the 16 study species.

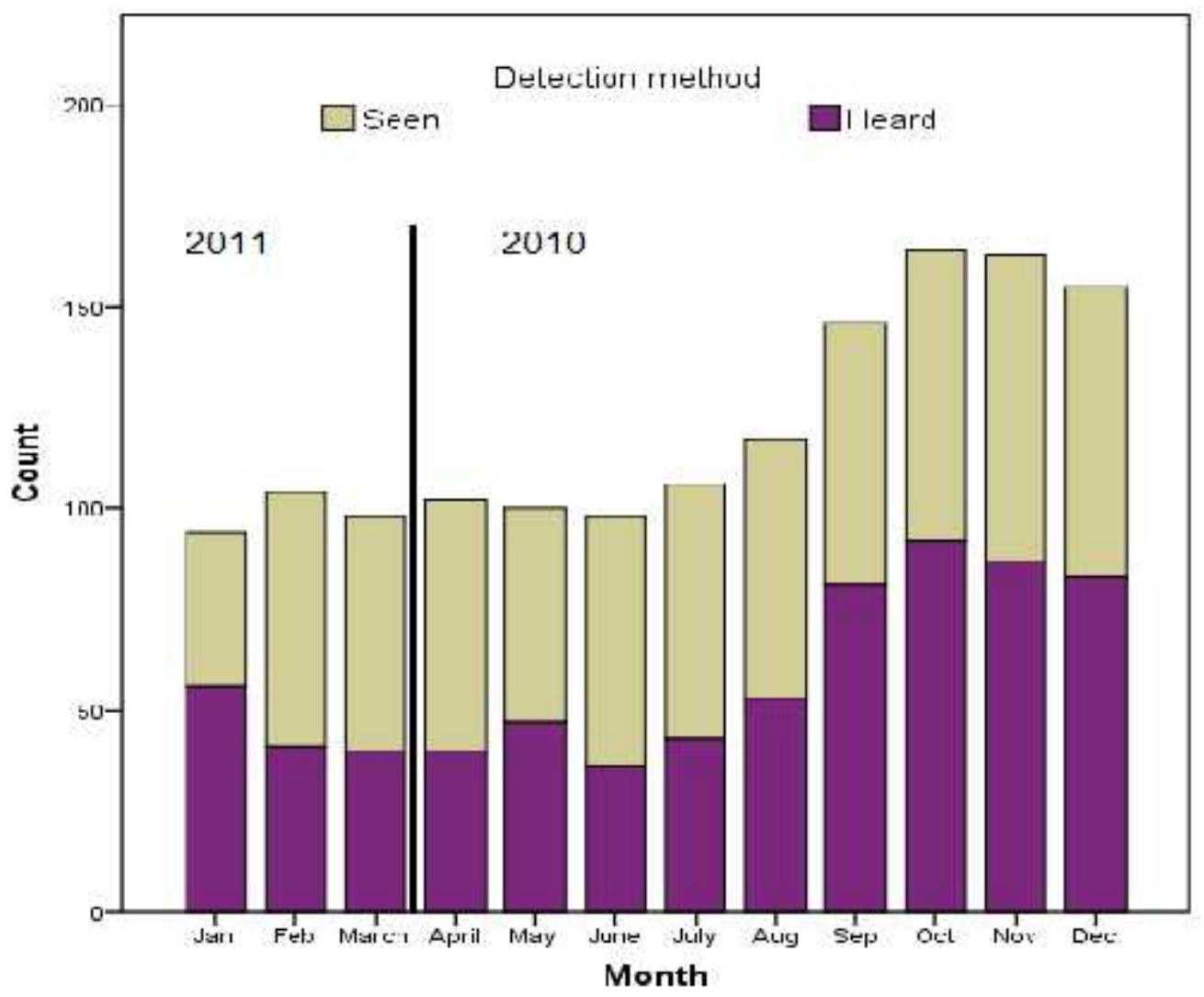

Figure 2.2.The overall monthly change in numbers of all birds heard (calling and singing) and seen over the calendar year April 2010 - March 2011. 


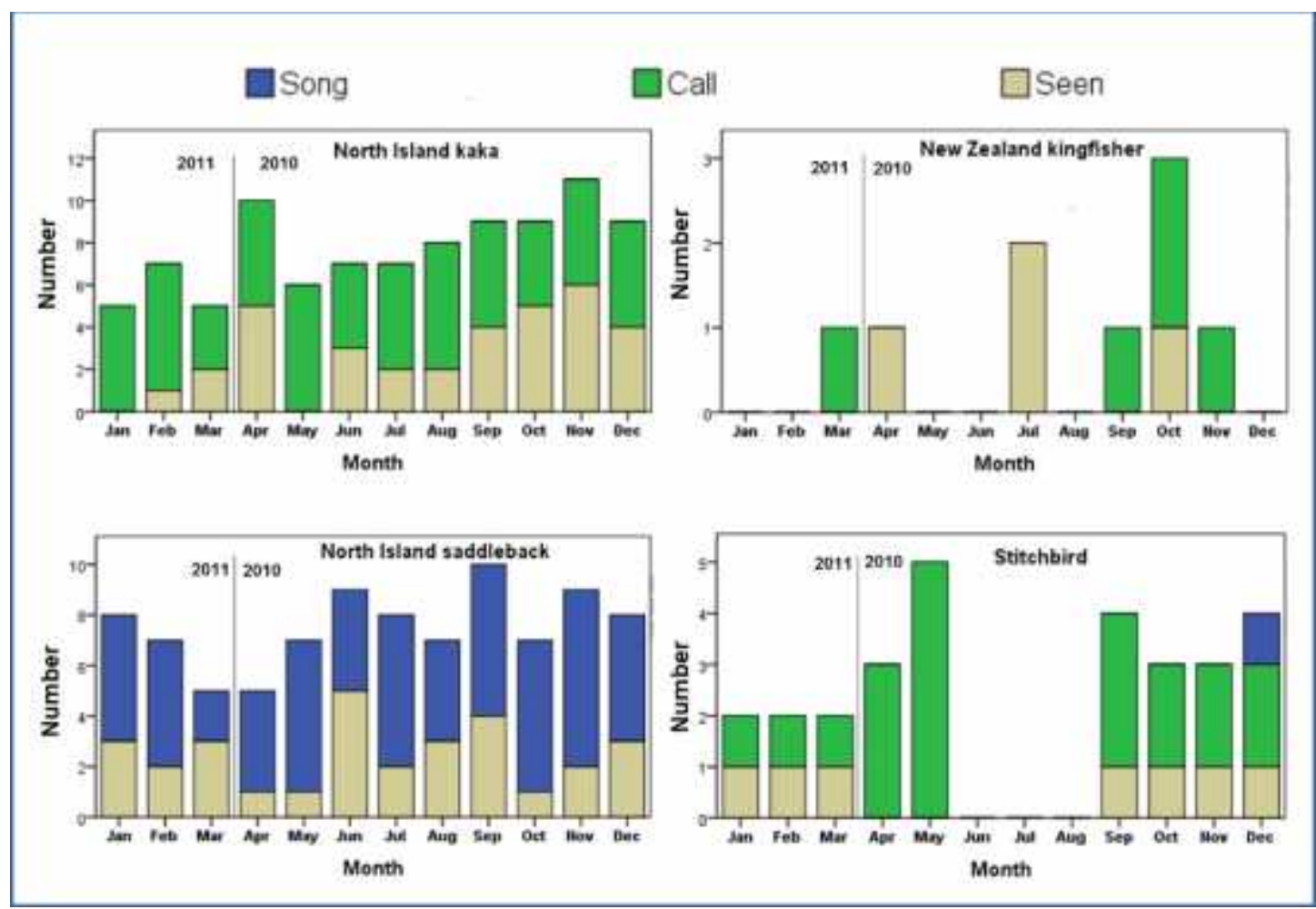

Figure 2.3. Variation in transect counts of kaka, kingfisher, saddleback, and stitchbird over twelve months in Zealandia in relation to their initial mode of recognition (first seen, first heard singing, first heard calling).

Kaka (Fig. 2.3) were vocally active throughout the year, being seen and heard vocalising while flying, often flying in small flocks. Song as such was not recognised in this non-passerine species, but the proportion calling and seen remained statistically similar through most of the year $\left(\chi^{2}=1.8\right.$, d.f $=11, P=0.99$ and $\chi^{2}=11.4$, d.f $=11, P=0.41$ respectively), though in May and January none of the birds were first seen. The kingfisher (Fig. 2.3) was variously first detected by hearing its calls or being seen, but numbers remained relatively low (0-3). It was vocally active mainly from September until November and March, with a peak in October. The saddleback (Fig. 2.3) was heard singing loudly through most of the year and was visually identified year round although the number of birds seen and heard was not different across months $\left(\chi^{2}=8.8,6.1\right.$, d.f $\left.=11, P>0.5\right)$. It was mostly first heard singing $(66.7 \%$ of the total counts) rather than seen (such song 
includes both chatter and male rhythmical songs). The stitchbird (Fig. 2.3) was mainly heard calling rather than singing $\left(\chi^{2}=13.3\right.$, d.f $\left.=1, P>0.5\right)$, its quiet warbling song being heard only once in December. No birds were recorded on the transect in winter $\left(\chi^{2}=44.7, \mathrm{~d} . \mathrm{f}=11, P>0.5\right)$ (June until August).

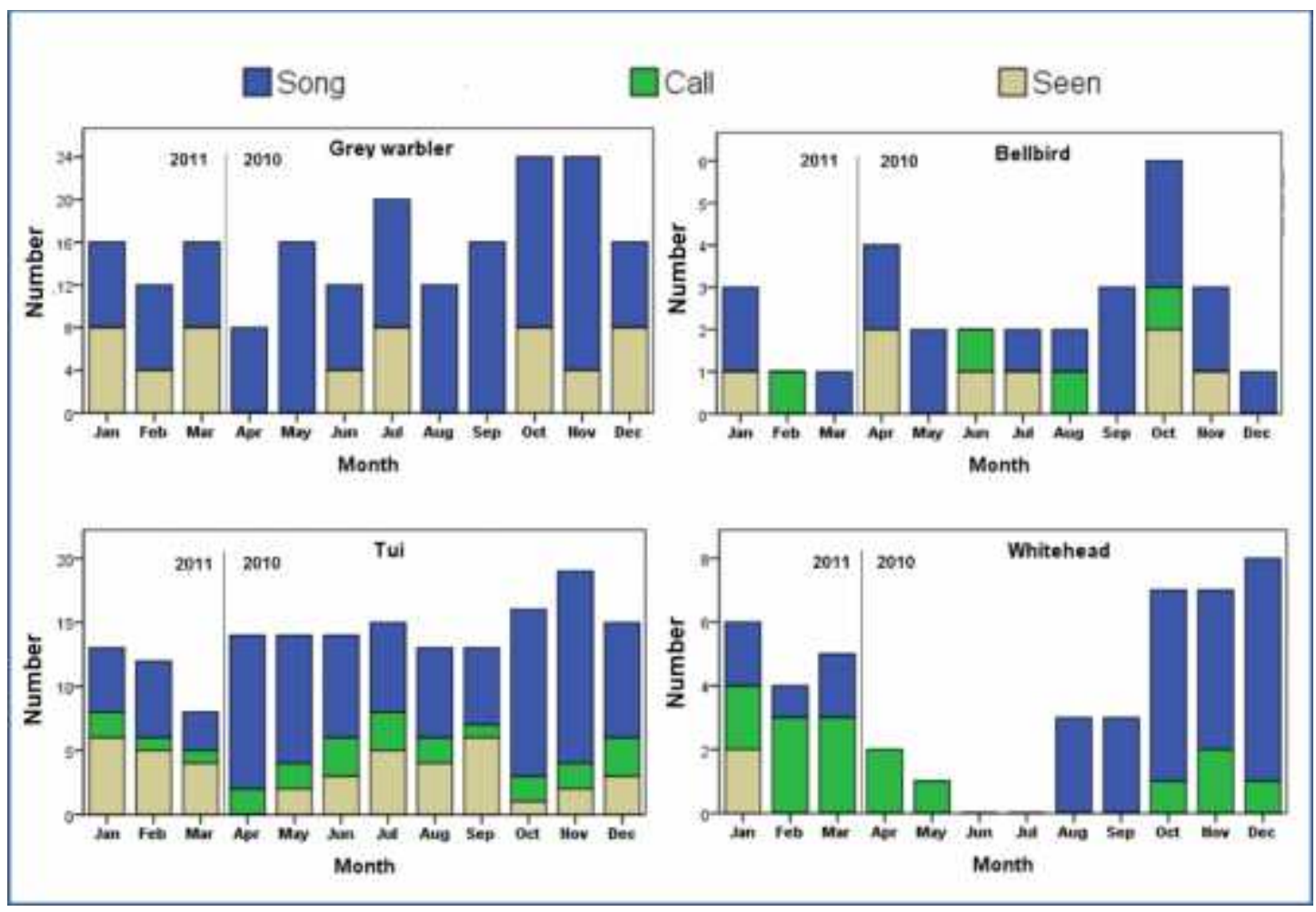

Figure 2.4. Variation in transect counts of grey warbler, bellbird, tui, and whitehead over twelve months in Zealandia in relation to their initial mode of recognition (first seen, first heard singing, first heard calling).

The grey warbler (Fig. 2.4) was more often heard in song than seen $(72.3 \%$ of the total counts). Its song was heard throughout the year, and there was no significant change in the number of singing birds in different months $\left(\chi^{2}=7.6\right.$, d.f $=11, P=$ 0.75); however, the peak singing activity was in August - November. The bellbird's (Fig 2.4) presence was detected mainly by vocalisation $(60.0 \%$ of the total counts). The number of birds singing varied with month $\left(\chi^{2}=22\right.$, d.f $\left.=11, P=0.02\right)$, however it was heard singing most of the year, with the peak singing activity in 


\section{Chapter 2}

September-November (spring). The tui (Fig. 2.4) was vocally active throughout the year $\left(\chi^{2}=7.7, \mathrm{~d} . f=11, P=0.74\right)$, with peak singing activity in April-May and October - December. It is a conspicuous species and its presence was often detected visually ( $24 \%$ of total counts) as well as vocally ( $76 \%$ of total counts). The whitehead (Fig 2.4) was heard vocalising much more than seen (95\% of total counts), and there was a significant difference in numbers of birds singing across months $\left(\chi^{2}=50.1\right.$, d.f $\left.=11, P<0.01\right)$, with peak singing activity from October to December. Its calls were most prominent from February to May.

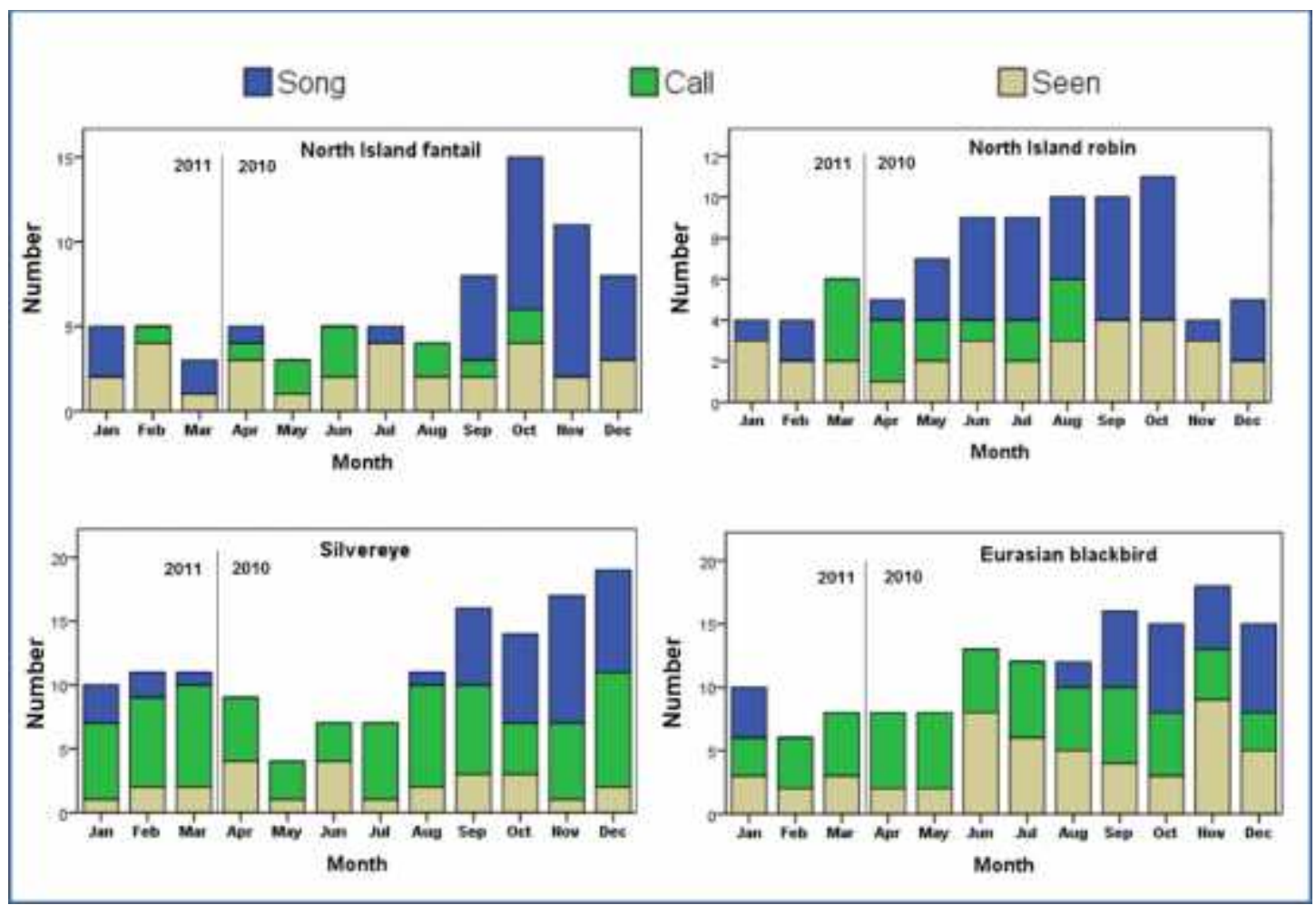

Figure 2.5. Variation in transect counts of fantail, robin, silvereye, and blackbird over twelve months in Zealandia in relation to their initial mode of recognition (first seen, first heard singing, first heard calling).

The fantail (Fig. 2.5) was heard singing on $45.5 \%$ of the total counts, almost as often as being seen (39\% of total count). Its singing activity varied across months $\left(\chi^{2}=54.9\right.$, d.f $\left.=11, P<0.01\right)$, and extended from September to January, peaking 
in October. The robin's song was heard throughout the year (Fig. 2.5), however in March it was seen almost as much as being heard calling, the number of birds seen differing through the year $\left(\chi^{2}=45.9\right.$, d.f $\left.=11, P<0.01\right)$. The silvereye (Fig. 2.5) called throughout the year and was mainly detected by call ( $53 \%$ of the total counts), and its singing output peaked from September to January $\left(\chi^{2}=22.2\right.$, d.f $=$ $11, P=0.02)$. It was visually detected throughout the year. The blackbird (Fig. 2.5) had a strong seasonal singing pattern $\left(\chi^{2}=18.2\right.$, d. $\left.f=11, P=0.01\right)$, with song starting in August and ceasing in January. It was seen on $36.9 \%$ of the counts and heard calling on $41.2 \%$ of them. Birds were encountered throughout the year, but the number calling did not vary across months $\left(\chi^{2}=1.6, d . f=11, P=1.0\right)$.

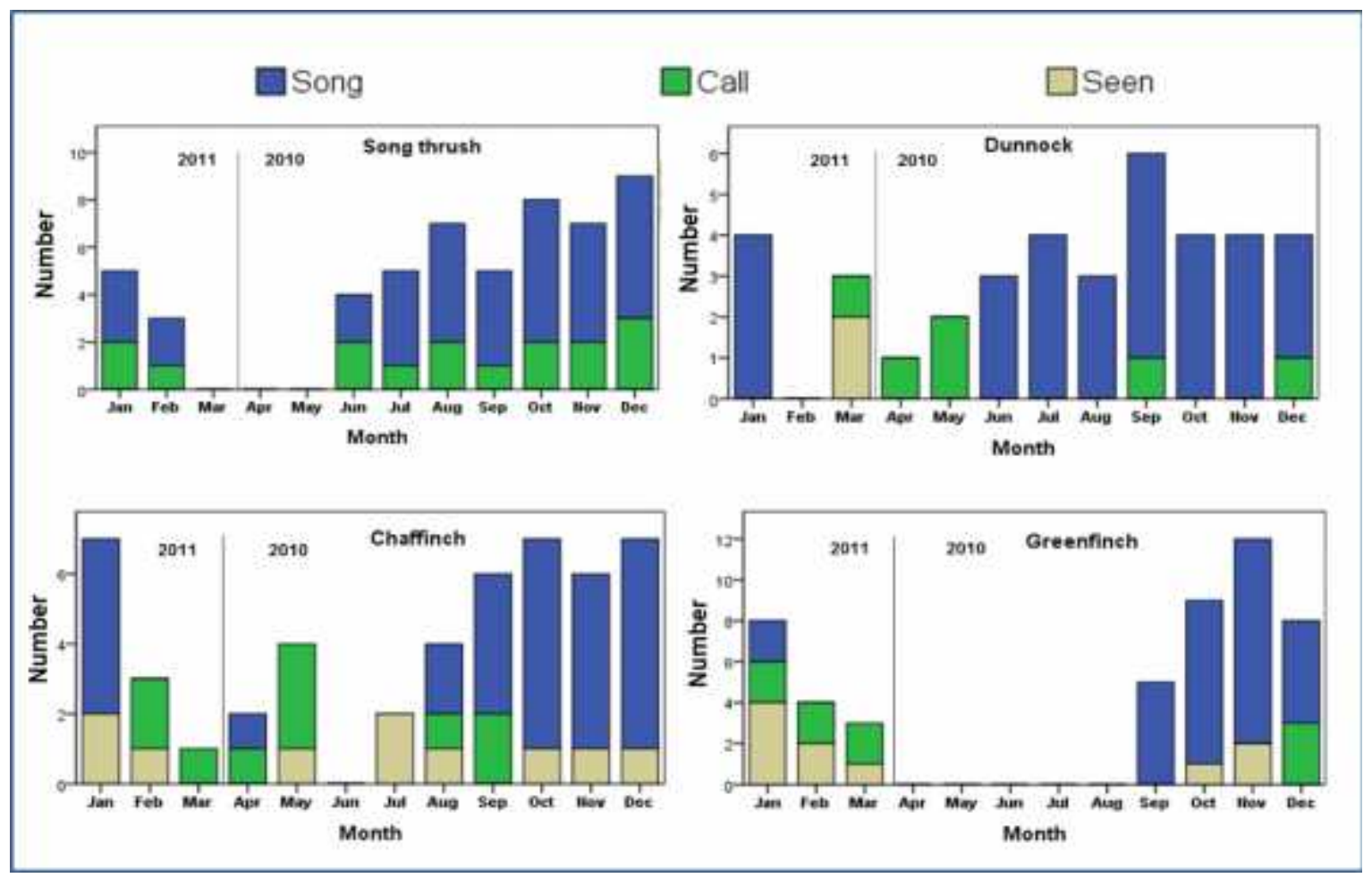

Figure 2.6. Variation in transect counts of song thrush, dunnock, chaffinch and greenfinch over twelve months in Zealandia in relation to their initial mode of recognition (first seen, first heard singing, first heard calling).

The song thrush (Fig. 2.6) was often heard but not seen $\left(\chi^{2}=28.0\right.$, d.f $=11, P<$ $0.05)$, its presence being usually detected by hearing its call $(30.2 \%$ of the total 
counts) or its song (69.8\% of the total counts). It was inconspicuous from March until May. The dunnock (Fig. 2.6) was often heard (94.7\% of the total counts) but not often seen (5.3\% of the total counts) and its song was the most reported vocalisation. Its call was a good indicator of its presence when not singing from March until May $\left(\chi^{2}=15.3\right.$, d.f $\left.=11, P=0.01\right)$. Chaffinches (Fig. 2.6) had a strong seasonal singing pattern $\left(\chi^{2}=50\right.$, d.f $\left.=11, P<0.05\right)$, starting to sing in August and continuing until January, peaking in September and December, but ceasing by February. The greenfinch (Fig. 2.6) also had a strong seasonal pattern $\left(\chi^{2}=95.3\right.$, d.f $=11, P<0.01$ ), its singing starting in September and peaking in November, then dropping gradually until it ceased in February. Greenfinches were inconspicuous from April to August.

\subsection{Discussion}

The total number of bird counted varied seasonally and between species. Some species (e.g. tui, grey warbler, kaka and saddleback) had a relatively constant vocalisation output seasonally. Other species (e.g. blackbird, song thrush, chaffinch, greenfinch, and whitehead) had different vocal and song periods. Song thrush, dunnock, whitehead, greenfinch, silvereye, and chaffinch often sing in spring. The call of kaka, tui, silvereye, and blackbird, were heard across the seasons. Fantail, silvereye, blackbird, were seen at all seasons. In general, each species had its own pattern of vocal output across the seasons; these changes can have a direct effect on the total number of bird counts. Hence comparing the abundance of species between different seasons alone may be misleading.

As the primary goal of bird counts is to obtain a population estimate of the birds present at a given location at a particular time (Bibby et al. 2000), the lack of appropriate adjustment to common methods of surveying birds may be biased 
towards more conspicuous species or vocally active ones (Nichols et al. 2000; Bart \& Earnst 2002; Rosenstock et al. 2002). Comparison of unadjusted counts will be valid only if the numbers represent a constant proportion of the actual population present across space and time (Sutherland 2006). The solution is to adjust counts to account for the detectability of different species (Thompson 2002).

The total number of birds first seen was less variable across months than the number of birds heard (Fig. 2.2). However, these numbers might be biased toward less conspicuous species and larger species that can be seen more easily than smaller species. Counts of the birds heard and seen might also be biased towards more vocally active birds and towards seasonal variability in their vocal output, as singing activity in birds is highly correlated with breeding season (Catchpole \& Slater 2008). Seasonal changes in singing and calling activity probably account for much of the variation in conspicuousness (Gibb 2000) and the increase in the detected birds might be explained by an increase in detectability of vocalising birds (Simon et al. 2002).

Counts carried out in certain months within the year might miss some species that have strong seasonal vocalisation patterns. For example, the kingfisher, stitchbird, whitehead, song thrush, and greenfinch were detected only in some seasons. Another way in which bird presence be may be biased is that some species may be attracted to the human observer, for example the robin. Another source of detection might be wing sounds e.g. bellbird, and tui (Craig 1984). For some species, there was less seasonal variation in conspicuousness, especially for those birds that had less distinguishable songs and calls, for example the tui and bellbird. Furthermore, local movements and the availability of food sources will 
have accounted for some of the variability in the observed bird numbers between seasons.

The counts were carried out over one year from April 2010 to March 2011, but the pattern might vary with years, depending on the environmental conditions which might affect the immediate weather condition or timing of the breeding seasons, hence the vocal output (Catchpole \& Slater 2008). In conclusion, seasonal changes in vocal output were found to have affected bird conspicuousness and the number of birds counted. Standardisation of counting protocols often is suggested to overcome bias in counts (Bibby et al. 1992), so standardisation of the count timing may improve precision when comparing results across years. It cannot remove biases resulting from species conspicuousness, however, accounting for inconspicuous species might be improved by using indices that can account for changes in the numbers of birds counted across the year (Sutherland 2006). These bird count data also confirmed that the sound recordings of targeted species were carried out at the time of year of most vocal output. These sound recordings form the basis of analyses in subsequent chapters and facilitated selection of study species in chapter 2 . In addition, the counts were informative on the distribution of different species within Zealandia. 


\section{Chapter 3}

\section{Do bird vocalisations converge according to the sound}

transmission properties of their habitat in Zealandia?

\subsection{Abstract}

Environmental selection pressures may shape the physical characteristics of bird vocalisations. Habitat-dependent selection pressures may result in convergence of vocalisation characteristics of species living in the same habitat, favouring optimal song transmission features in that habitat. In contrast, competitive interactions for acoustic space between different species may lead to divergence of acoustic signals mediated by character displacement, as many species within the same habitat have to use the available acoustic space. Here, the pattern of bird vocalisations was examined within the forest bird community, to see whether it has converged due selection pressure on sound transmission through the habitat. The vocalisations of 16 bird species were analysed by comparing 13 features from each vocalisation sample. The acoustic space each species occupied was quantified using principle component analysis. The results show that the distribution pattern of the 16 vocalisations was over-dispersed within the acoustic space. Vocalisations of introduced birds were distributed closer to the centre of the acoustic space, while vocalisations of native birds were distributed towards the outer edge. Vocalisation frequency was negatively correlated with perch height and body weight. The results support the acoustic niche hypothesis in that vocalisations within community of native birds appear to have diverged. The results also support the acoustic adaptation hypothesis because the birds concentrated their energy within a narrow frequency band, which may be an adaptation to better transmission in the forest. 


\subsection{Introduction}

Species living in the same habitat experience similar environmental selection pressures, which may in turn drive certain traits to converge into those most advantageous in that habitat (Keddy 1992; Weiher \& Keddy 1995; Weiher et al. 1998). Trait convergence is widespread within species occupying the same niche (Harmon et al. 2005; Langerhans et al. 2006), and among sympatric species adapted to similar environments (Losos 1992; Losos et al. 1998; Rosenblum 2006; Fleischer et al. 2008). Alternatively, trait differentiation through divergent selection can also be favoured across different species within communities when competition over resources is high (Turelli et al. 2001; Doebeli \& Dieckmann 2003).

Acoustic signals in birds have functions, including in long-range communication in species or kin recognition, mate attraction and territorial defence (Kroodsma \& Miller 1982; Searcy \& Andersson 1986; Catchpole \& Slater 2008). Acoustic signals are under selection pressure from vegetation structure (Barker 2008), as transmitted sound between individuals is susceptible to modification by habitat. This poses fundamental problems for sound transmission through degradation and attenuation (Naguib \& Wiley 2001).

Different habitats and vegetation structures have varied sound transmission properties (Wiley \& Richards 1982; Brown \& Handford 2000; Slabbekoorn \& Smith 2002b). Ambient noise may also interfere in the transmission of signals (Brenowitz 1982; Ryan \& Brenowitz 1985; Nelson \& Marler 1990). Song divergence among populations of the same species living in different geographical areas (i.e. song dialects) has been related to the acoustic characteristics of the habitat (Mundinger 1982; Kroodsma 2004). Another example involves the adaptation of species in 
urban areas to background noise, where the temporal and spectral characteristic of their songs are modified, resulting in the utterance of higher frequencies, (e.g. great tit, Parus major (Slabbekoorn \& den Boer-Visser 2006) and blackbird, Turdus merula (Nemeth \& Brumm 2009)). Morton (1975) studied the structure of signals in relation to habitat, and found that forest birds use lower frequency modulated notes than birds living in more open habitat. This was supported by subsequent studies that compared the song of birds living in open and closed habitats (Badyaev \& Leaf 1997; Bertelli \& Tubaro 2002; Tubaro \& Lijtmaer 2006).

Vocalisations of birds may also be affected by their community structure. Some songbirds enrich their song repertoires by adding elements from neighbouring conspecifics or other species, as well as non-avian sounds. This may be based on what is heard best under local acoustic conditions through mechanisms of vocal copying within their acoustic environment (Slabbekoorn \& Peet 2003). Avifaunal complexity may also have a consequence on vocalisations within populations (Kroodsma 1985). Acoustic competition and species densities within the same community may influence vocalisation traits and signal design (Price 2008). For example, an avifaunal community with fewer sympatric passerines may exhibit increased song variability (Kroodsma \& Canady 1985; Naugler \& Ratcliffe 1994). Species singing similar songs may also suffer fitness costs due to ambiguity in species recognition, and this may cause some species to avoid singing when other species using the same frequency range are singing also (Planqué \& Slabbekoorn 2008).

Most bioacoustic studies have focused on individual species, or groups of similar species, and only two other reports have focused on the wider avian community in a given location (but see Luther (2009) and Cardoso and Price (2010)). To my 


\section{Chapter 3}

knowledge, no studies have investigated the vocalisations of a bird community in the temperate broad-leaved rainforests of the southern hemisphere, such as in New Zealand (Ovington \& Pryor 1983). New Zealand's distinctive bird community (King et al. 2009a) allows the study of acoustic adaptation amongst both native and exotic bird species. The primary aim of this chapter is to describe the acoustic characteristics of one such avian community at Zealandia (mainland island), and see whether species vocalisation have converged under the effect of habitat selection pressure for better transmission (Marler \& Slabbekoorn 2004; Ey \& Fischer 2009), or have diverged to reduce competition among species (Krause 1987; Krause 1993).

This chapter addresses the following questions:

1. Does the distribution of bird vocalisations cluster in acoustic space? A clustered distribution indicates convergence of vocalisation characteristics under the influence of habitat selection pressure.

2. Do introduced and native species have similar distribution patterns within acoustic space?

3. Do phenological traits (body size and bill length) influence vocalisation characteristics?

4. Do bird vocalisations show adaption to a particular elevation within the forest? 


\subsection{Study area}

This study was conducted at Zealandia, a 250 ha mainland island in New Zealand, protected from invasive mammalian predators by a $9 \mathrm{~km}$ long $2.2 \mathrm{~m}$ high barrier fence (Campbell \& Atkinson 2002). Characterised as a coastal broadleaf-conifer forest (Dawson 1988b; Wardle 2002), the forest is dominated by mähoe, Melicytus ramiflorus, five finger, Pseudopanax arboreus, and pate, Schefflera digitata; tree ferns, Cyathea spp., and Hymenophyllum spp., while shrubs such as hangehange, Geniostoma rupestre, and kawakawa, Macropiper excelsum, are common in the understorey vegetation. The study site has a mild, temperate climate, with annual rainfall averaging $127 \mathrm{~cm}$, and there is relatively little variation between summer and winter temperatures compared with many temperate climates, the mean temperature range between summer and winter being $17.20^{\circ} \mathrm{C}$ to $8.90^{\circ} \mathrm{C}$ (NIWA 2010).

\subsection{Study species}

The study embraced 16 species comprising 14 passerines, a native kingfisher, Todiramphus sanctus vaganus, and an endemic parrot, the kaka, Nestor meridionalis septentrionalis (Table 1.2). Nine of the passerine species were endemic, while five were introduced from Europe between 1840-1900 (Wodzicki \& Wright 1984; King et al. 2009b). Some species were excluded from the analysis as they occurred along the forest edge rather than within the forest e.g. starling, Sturnus vulgaris, eastern rosella Platycercus eximius, or were less common e.g. falcon Falco novaeseelandiae, shining cuckoo, Chrysococcyx lucidus, and longtailed cuckoo, Eudynamys taitensis. 


\subsection{Methods}

\subsubsection{Sound recording}

This study used vocalisations of bird species recorded during April-December 2009 in the Zealandia sanctuary. The majority of the recordings were from September and December when most species were actively singing (chapter 2). Vocalisations were recorded at a sampling frequency of $44.1 \mathrm{KHz}$ and 16-bit sample size using a Marantz PMD670 solid-state recorder and a Telinga Pro7 parabola microphone. Songs and calls were differentiated following Catchpole and Slater (2008). For the 14 songbirds studied, song samples were analysed while in the two non-passerines, call samples were used. Ten individuals of each of the 16 study species were sampled. Recording sites were plotted on a map to reduce the chance of recording the same individual twice. In most cases, vocalisations were recorded at a distance of 3-10 $\mathrm{m}$ from the bird, to get good quality recordings.

\subsubsection{Sound analysis}

Sound analysis was undertaken using Raven Pro 1.4 software, allowing graphical display of the power spectra, waveforms, and spectrograms (sonograms) of each species' vocalisations (Fig. 3.1). Spectrograms were generated via a standardised procedure with a Hann-filter and a Fast Fourier Transform (FFT) value of 512 points. Overlap was set to $50 \%$ giving a frequency resolution of $86.1 \mathrm{~Hz}$. 


\section{Chapter 3}

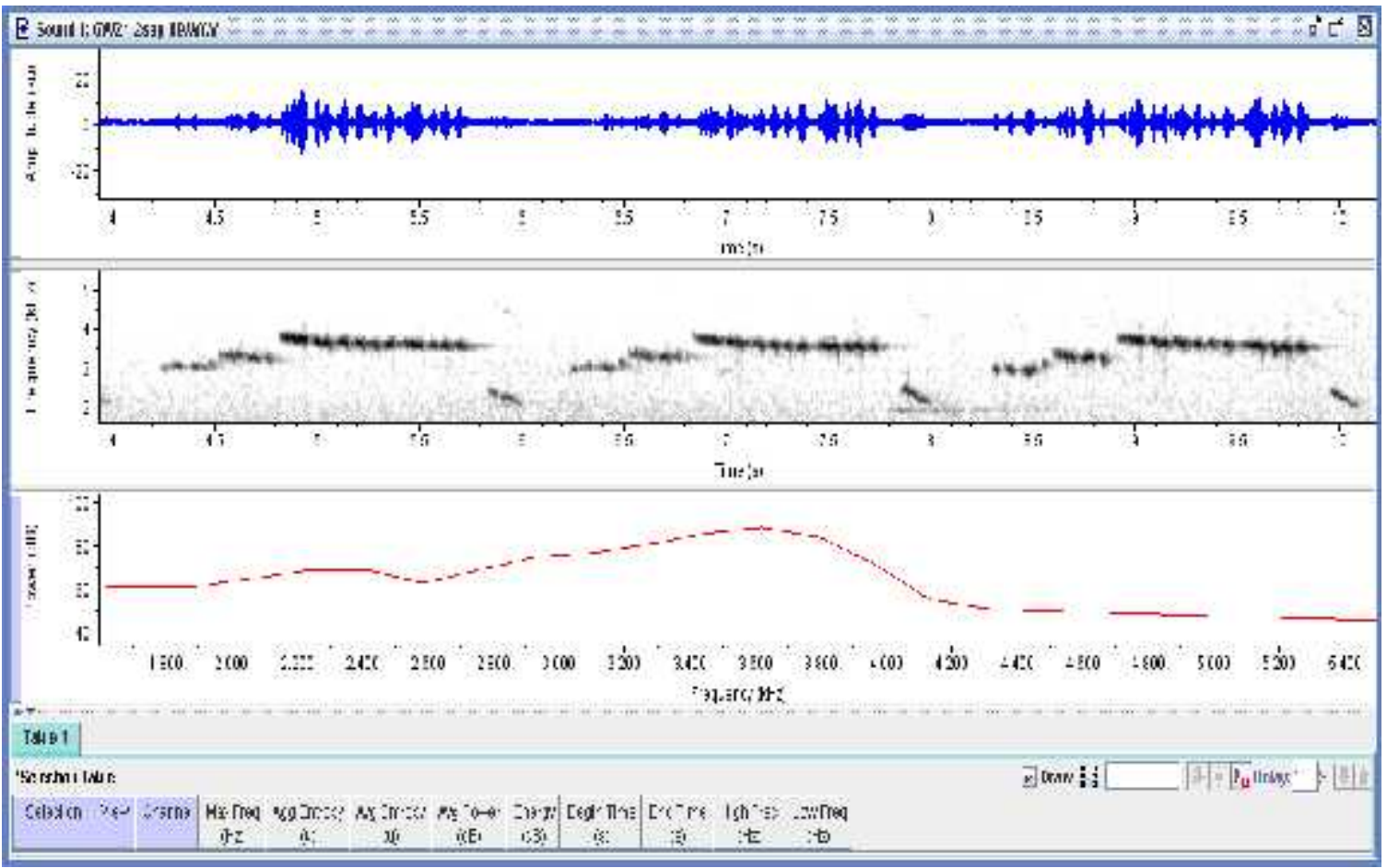

Figure 3.1. Raven window showing the three views used in analysis, using a grey warbler, Gerygone igata, as the example. From the top, the plots are waveform, spectrogram, and power spectrum. Below the graph is the selection table illustrating some of the measurements.

The 13 variables were: (1) Lowest frequency across the song (KHz), (2) Highest frequency across the song $(\mathrm{KHz}),(3)$ Song band-width $(\mathrm{KHz}),(4)$ Mean dominant frequency $(\mathrm{KHz})$ (average of the dominant frequencies in each sample), (5) Centre frequency $(\mathrm{KHz}),(6)$ 1st quartile frequency $(\mathrm{KHz}),(7) 3 \mathrm{rd}$ quartile frequency $(\mathrm{KHz})$, (8) Inter-quartile bandwidth (IQRZ) (KHz), (9) Song duration (s), (10) Number of notes, (11) Inter-note interval (s), (12) Change in song rates between the $1^{\text {st }}$ half and $2^{\text {nd }}$ half of the song, and (13) Change in inter-note interval rates between the $1^{\text {st }}$ half and $2^{\text {nd }}$ half of the song (Fig. 3.2). 


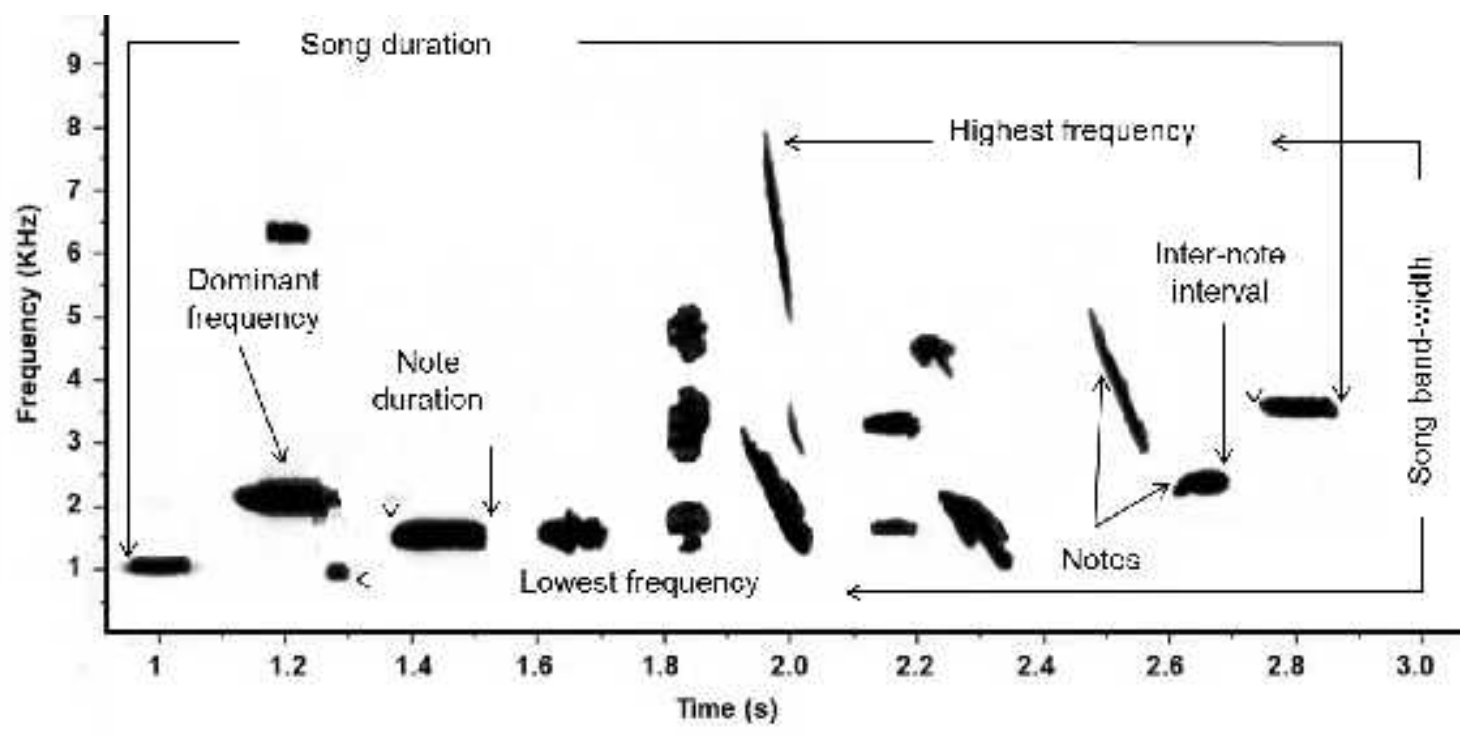

Figure 3.2. Spectrogram of bellbird, Anthornis melanura, song, illustrating some of the variables measured.

For species with more than one song type, the most frequently heard song types were selected for the analysis. In turn, for each recording track, the clearest phrase of the repertoire was selected for analysis. Appendix (1) shows the spectrograms of the vocalisation of the 16 species included in the analysis.

\subsubsection{Quantifying acoustic space}

Principle component analysis (PCA) was used to analyse the vocalisation data. Some of the acoustics features in the vocalisations were inter-correlated, consequently, PCA was used to reduce the dimension of the dataset, while still retaining its spatial characteristics (Peres-Neto et al. 2003). This method is robust against the normality assumption of the data (Locantore et al. 1999), although the temporal variables were normalised by log transformation. Frequency variables of vocalisations were normally distributed. All statistical tests were done in SPSS v 18.0 


\subsubsection{Species distribution in the acoustic space}

Nearest neighbour measurement provided a tool for describing the general spatial distribution of bird vocalisations within the acoustic space defined by the extracted principle components (PC). The Euclidean distances between vocalisations of each species in the defined acoustic space were calculated. Because PCA normalises the resultant principle components, it eliminates differences in scale that result from different units of measurement. The nearest-neighbour distance (NND) for each species is the distance to the closest neighbour in this acoustic space (Peres-Neto et al. 2003).

Spacing patterns were considered at the species level, to determine whether the acoustic community was clustered, random or over-dispersed in the acoustic space following Luther (2009). Using the $R$ score developed by Clark and Evans (1954), the distances between nearest points and the distances that would be expected by chance were compared. An $R$ score approaching zero indicates an extremely clustered distribution, $R=1.0$ indicates a random distribution, while an $R>1.0$ indicates a more widely dispersed pattern than would be expected by chance. $\mathrm{R}$ is the ratio of two statistics, the observed distance from the closest neighbour to each point $\left(r_{a}\right)$, and the distance that would be expected by chance $\left(r_{e}\right)$. In a four dimensions space, the expected NND in a randomly distributed population $\left(r_{e}\right)=0.60813 / \rho^{1 / 4}$ of density $(\rho)$, and the standard error of the mean distance to the nearest neighbour $\left(\sigma\left(r_{e}\right)\right)=0.55326 / \rho^{1 / 4}$. The volume of a 4dimensional hyper-sphere $=\pi^{2} / 2^{*} r^{4}$ defined by the four extracted PC's (see results section) (Clark \& Evans 1979). The radius was the Euclidean distance from the 4dimensional centroid of the acoustic community to the location of the species farthest from the centroid. Outliers were not removed so the hyper-sphere in effect 
incorporated a buffer strip around the occupied volume, as recommended by Donnelly (1978). Table 3.1 summarises the result of NND measurements.

To test how different species may weigh the different variables extracted by the four principle components, the distribution of vocalisation characteristics on the four-principle components extracted was examined. A 1-sample KolmogorovSmirnov test was used to ascertain whether the distribution of bird vocalisations is significantly similar to uniformity. Following Cardoso and Price (2010), the significance at the lower tail ${ }^{1}$ was used to test whether the spacing of vocalisation pattern within the community was more even than random drawing from a uniform distribution (as could be the case if vocalisations have evolved from acoustic competition among sympatric species).

\subsubsection{Relation with body size and bill length}

I obtained body weights and bill lengths of studied birds from Marchant et al. (2006). When both sexes are known to sing, the mean values of males and females were used, while for species in which only the male sang, the measurements for males were used (Appendix 2). The distribution of body mass was slightly right-skewed (Kolmogorov-Smirnov: $Z=1.29, n=16, P=0.073$ ), so was log transformed (after transformation, $Z=0.55, n=16, P=0.93$ ). I tested for a relation between body weight and each of the principal components using General Linear Regressions.

${ }^{1}$ For a lower tail test, the $P$-value is the probability of obtaining a value for the test statistic as small as or smaller than that provided by the sample. 


\subsubsection{Relation with singing post}

Heights of singing posts for all birds were recorded, and the relation between singing post and each of the principal components was examined using linear regression.

\subsection{Results}

\subsubsection{Acoustic space}

Principle component $(\mathrm{PC})$ analysis on the correlation matrix of the 13 variables measured returned four principle components with eigenvalues greater than one, which collectively explained $77 \%$ of the variation in measurements among species. Table 3.3 summarises the PCA result and identifies the aspects of vocalisations explained by each PC (bold font). PC1 explained $29.6 \%$ of the data and it reflected the frequency aspects of the vocalisation, maximum, centre, and the quartile frequencies (Q1 and Q3). PC2 explained $22.6 \%$ of data and quantified the temporal arrangement of the vocalisation, mainly related to longer vocalisations and longer spaces between notes. PC3 related to songs with higher frequency. PC4 explained the IQRZ. These four PCs formed the axes of the acoustic space within which each of the 160 vocalisations produced by the 16 species studied were located. 
Table 3.1. Loadings of vocalisation variables on each of the four principal components (PC) with eigenvalues greater than 1.

\begin{tabular}{llllll}
\hline Trait & PC1 & PC2 & PC3 & PC4 \\
Variance explained & $29.6 \%$ & $22.6 \%$ & $13.6 \%$ & $11.1 \%$ \\
Eigenvalue & 3.8 & 2.9 & 1.7 & 1.4 \\
\hline Lowest frequency & .558 & -.43 & .147 & -.236 \\
Highest frequency & .193 & -.187 & .936 & .034 \\
Delta frequency & .024 & -.036 & .965 & .104 \\
Max. frequency & .892 & .199 & .086 & -.173 \\
Centre frequency & .900 & .204 & .046 & .162 \\
First quartile frequency & .613 & .029 & .093 & -.527 \\
Third quartile frequency & .864 & .197 & .069 & .390 \\
IQRZ & .121 & .171 & .221 & .853 \\
Song duration & .132 & .941 & -.003 & .018 \\
Number of notes & .197 & .929 & -.075 & .051 \\
Interval rate & .024 & .936 & -.054 & -.028 \\
Song rate & -.193 & -.264 & -.003 & -.029 \\
Change in Interval rate & .006 & .151 & .473 & -.495 \\
\hline Trait loadings larger than & 0.5 are in bold & & \\
\hline
\end{tabular}

\subsubsection{Species distribution in the acoustic space (nearest-neighbour distance)}

The distribution of bird vocalisations was over-dispersed indicated by an R score of 1.74 (Table 3.1). To examine the distribution of native and introduced species, the mean nearest - neighbour distance (NND) was calculated for each of the native and introduced species separately. The mean Euclidean distance measured from the centre of the acoustic space for native birds (mean $=1.85, \mathrm{SE}= \pm 0.23, \mathrm{n}$ 
$=10$ ) was significantly higher (one-tailed t test: $t 14=1.88, P=0.04$ ) than for introduced species $($ mean $=1.15, \mathrm{SE}= \pm 0.28, \mathrm{n}=6)$.

Table 3.2. Summary of the nearest neighbour distance measurements.

\begin{tabular}{cccccc}
\hline $\mathbf{r}$ & $\boldsymbol{\rho}$ & $\mathbf{r}_{\mathrm{e}}$ & $\mathbf{r}_{\mathrm{a}}$ & $\mathbf{R}^{*}$ & $\boldsymbol{\sigma}\left(\mathbf{r}_{\mathrm{e}}\right)$ \\
\hline 1.46 & .81 & .59 & 1.03 & 1.74 & .223
\end{tabular}

${ }^{*} R=r_{a} / r_{e}$, where $\left(r_{a}\right)$ is the observed mean nearest-neighbour distance and $\left(r_{e}\right)$ is the expected mean distance if individuals are distributed at random. $r_{e}=0.55 / \rho^{1 / 3}$, $r$ is the radios of observed acoustic space, $\rho$ is the density of the population in number of individuals per unit area $\rho$, and $\sigma(r e)$ is the standard error of the mean distance to the nearest neighbour.

Introduced species were distributed closer to the centre of the acoustic space (Fig. 3.3), indicated by smaller mean NND measured from the centre, while native species were distributed towards the outer edge of the acoustic space.

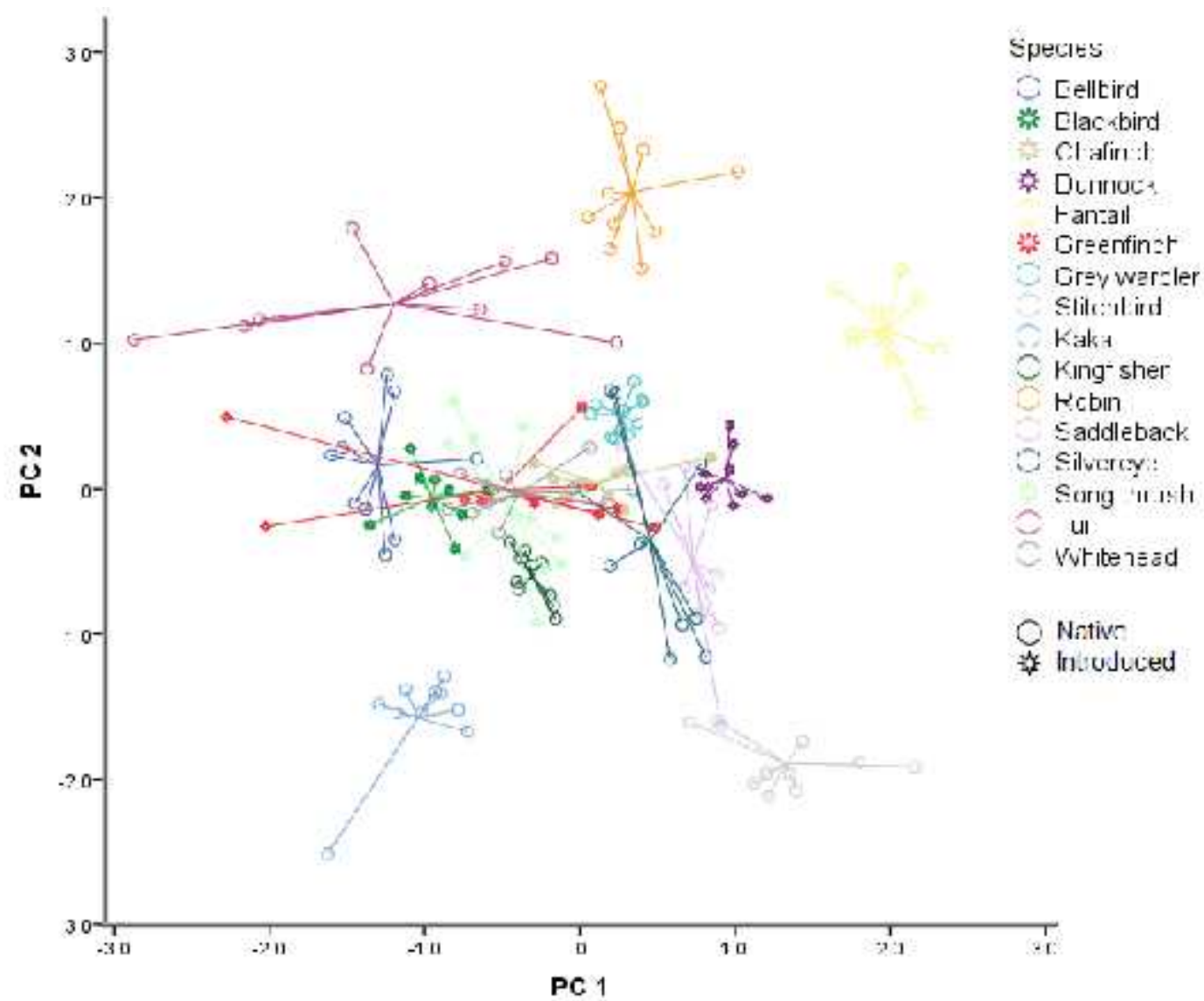

Figure 3.3. Species distribution against PC1 and PC2 axes. 
The distribution of bird vocalisations on PC1, PC2, and PC3 indicated by Kolmogorov-Smirnov tests (Table 3.3), were similar to uniform distribution, while the distribution of bird vocalisations on PC4 was significantly different to a uniform distribution. The distribution of species vocalisation on IQRZ (explained by PC4) was found to be clustered in a narrow frequency distribution (mean $=0.84, \mathrm{SE}=$ $\pm 0.14 \mathrm{KHz}, n=16)$.

Table 3.3. One-sample Kolmogorov-Smirnov testing for distribution uniformity.

\begin{tabular}{lllll}
\hline & PC1 & PC2 & PC3 & PC4 \\
\hline Kolmogorov-Smirnov Z & 0.86 & 0.91 & 0.70 & 1.24 \\
$P$ value & 0.23 & 0.19 & 0.35 & 0.04 \\
\hline
\end{tabular}

The probability of the lower-tailed $Z$ statistic is below 0.05 , meaning that the uniformity distribution is not a good fit model.

\subsubsection{Factors that play a role in vocalisation structure}

\subsubsection{Frequency aspect}

Principle Component 1 (PC1), which explained the frequency characteristics in the song, regressed negatively on body weight ${ }^{2}(\beta=-0.57$, SE $= \pm 0.11), \mathrm{t}_{14}=-2.57, P$ $<0.02)$, and negatively on singing post $(\beta=-0.542$, SE $= \pm 0.65), \mathrm{t}_{14}=-2.41, P<$ 0.03). Larger birds produced lower frequency vocalisations while birds that vocalised closer to the ground used higher frequency vocalisations (Figs. 3.4 \& 3.5).

\footnotetext{
${ }^{2}$ In a simple regression, the standardised regression coefficient $(\beta)$ is the correlation between the predictor and dependent variables, and is thus constrained to be between -1 and +1 .
} 


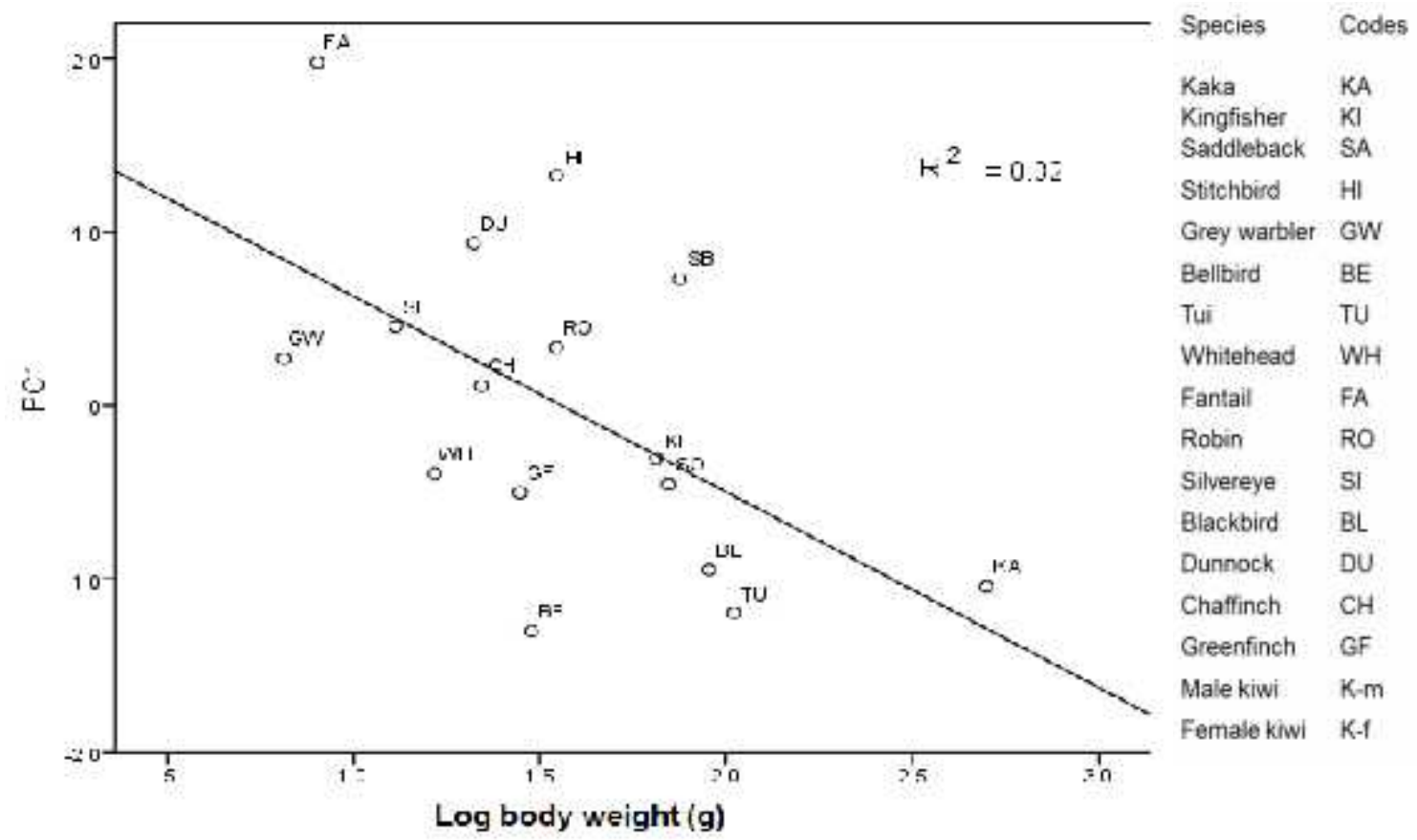

Figure 3.5. The relationship between log body weight (g) and PC1 (linear regression).

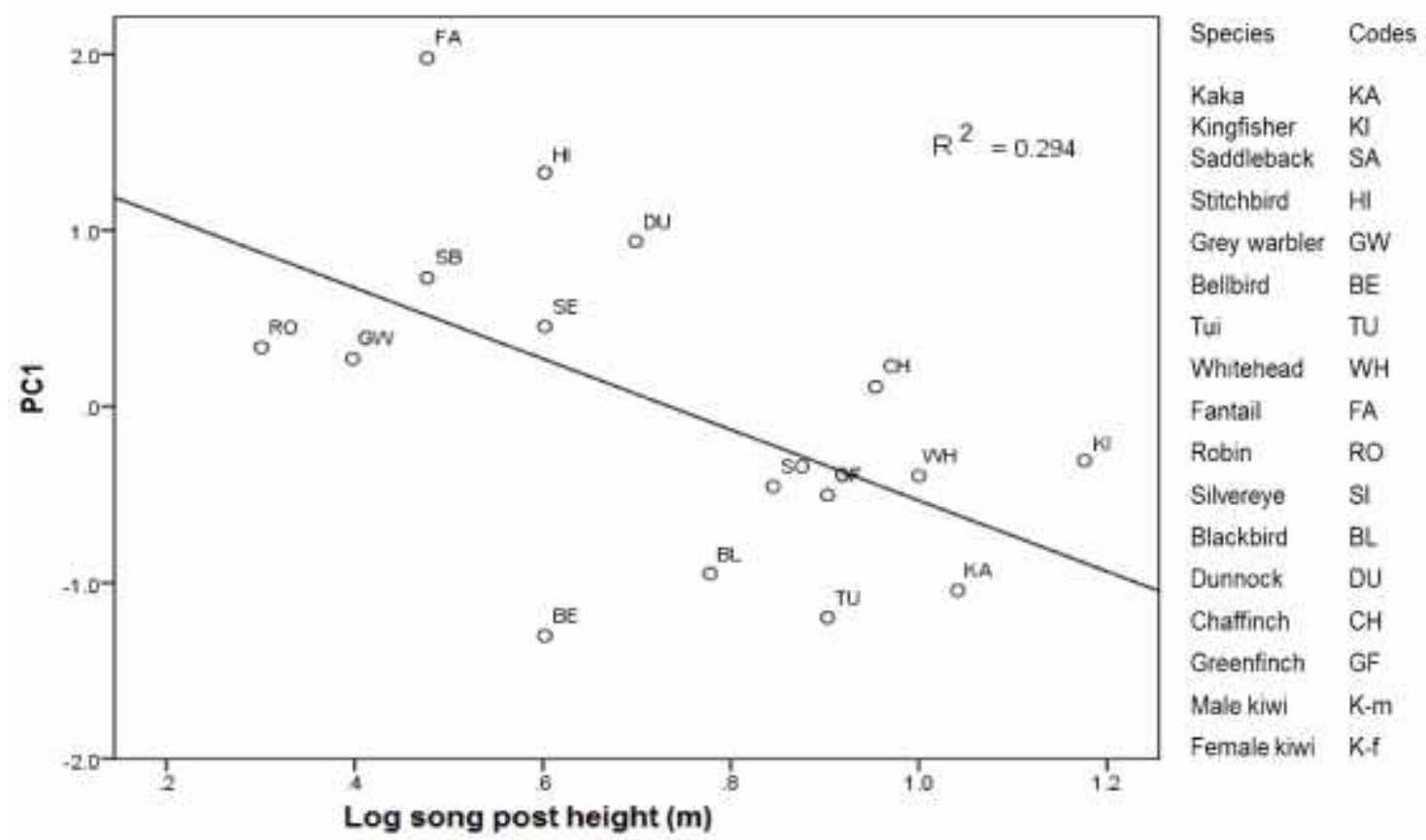

Figure 3.4. The relationship between log song post height $(m)$ and PC1 (linear regression. 
A multiple stepwise regression model between PC1 and predictive variables (body weight, singing post, and bill length) did not increase the fitness of the model (final model: $\beta=-0.57, \mathrm{SE}= \pm 0.44),\left(F_{14,1}=6.6, P<0.02\right)$ and the majority of the variation in the data was explained by the body weight only.

None of the previous predictors had a significant regression on PC2 (the temporal arrangement in the song) at $P=0.05$ levels.

\subsection{Discussion}

This study investigated whether there is evidence that bird vocalisations might be shaped under the effect of habitat selection on sound characteristics (Acoustic Adaptation Hypothesis) (Marler \& Slabbekoorn 2004; Ey \& Fischer 2009), or under the effects of the avifaunal community structure, in a way that reduces vocalisation similarity (Acoustic Niche Hypothesis) (Krause 1987; Nelson \& Marler 1990; Nelson \& Soha 2004). The NND measurements indicated an over-dispersed pattern of bird vocalisations within the acoustic community. The over-dispersed pattern within the acoustic space might indicate that vocalisations have evolved in a way to reduce vocal competition, giving evidence on structuring at the community level, in a way that reduces the overlap of similar sounds. Competition may result in a shift of sound characteristics (Doutrelant \& Lambrechts 2001), for example, Seddon (2005) found that the songs of sympatric pairs of closely related species are more divergent than allopatric pairs. Ambient noise in the habitat can be a powerful selective force, leading to upward shifts of song frequencies among species, or even within populations (Slabbekoorn \& Peet 2003; Brumm \& Slater 2006b). 
The acoustic adaptation hypothesis, reviewed by Barker (2008), predicts that acoustic signals will have lower frequency, simpler structure, and slower pace in densely foliated habitats compared to open habitats. By investigating the spatial distribution of species on the four extracted principle components, the distribution of bird vocalisations was seen to be clustered only on PC4, which explained the inter-quartile energy range. The birds concentrated the amplitude (energy) within their vocalisation in a narrow frequency band, rather than spreading it through a broader range of frequencies. Concentrating in a narrow-frequency band may lead to an increase in transmission distance with minimal degradation (Slabbekoorn et al. 2009), and this feature seems suited to species living in dense forest. However, there was suggestive evidence of uniformly distributed vocalisations on three of the axes (PC1, PC2 and PC3), which characterised the duration, frequency, and number of notes. This may have resulted from acoustic competition between species resulting in regularly spaced phenotypes within the community (Chek et al. 2003). Although there were indications of structuring of vocalisation characteristics on three principle components, Luther (2009) argued that bird vocalisations are complex signals that vary in many dimensions and that there is little importance in structuring vocalisation in bird communities. Newman et al. (2006) found that the pressures on acoustic signals relate to sound transmission, and that sexual selection may be relaxed, as suggested by a reduced response to playback of dark-eyed junco, Junco hyemalis thurberi, songs in an urban population.

The prediction of the AAH is based on the hypothesis that vocalisations should travel the maximum distance with minimal attenuation and degradation. However, signals may be adapted for optimal, rather than maximal distances (Lemon et al. 1981; Nemeth et al. 2006). Maximising the transmission distance might not be necessary or desirable, in cases where the intended receiver is nearby (Kroon \& 


\section{Chapter 3}

Westcott 2006), or when the transmission distance correlates with smaller territory size (Brenowitz 1982), or if degraded signals might serve an intended purpose such as ranging (Naguib \& Wiley 2001).

Native species were distributed towards the outer edge of the acoustic space. The distance between native species indicated by NND was higher than between introduced species. The potential for introduced species to produce sounds that disturb existing endemic acoustic niches is possible (Pijanowski et al. 2011a). Introduced species or non-native vocalising species can mask the vocalisation of native birds. This interaction between native and introduced species is termed biophonic invasion by Pijanowski et al. (2011a).

Species richness may have a strong inverse relationship on song variability within bird communities (Naugler \& Ratcliffe 1994). A similar result was confirmed by Luther (2009) in a study on the acoustic community of birds in a neo-tropical Brazilian rain forest, characterised by a high species diversity, finding that the distribution of bird songs was extremely clustered. Species richness usually decreases with latitude (Gaston 2000), and the low species diversity in my study area (16 species) may have reduced competition on acoustic signals and allowed the birds to more readily explore available signals without strongly competing with other species.

Divergence in bird vocalisations can also be driven by differences in environmental selection pressures, which may even occur within the same habitat when species occupy different forest layers (Kirschel et al. 2009). There was a negative correlation between vocalisation post height and PC1 (maximum frequency measurements). Song post height might influence sound transmission as the vertical structure of the habitat changes due to vegetation stratification (Mathevon 
et al. 2005). Lemon et al. (1981) found that song frequency in 19 species of Parulid warblers is positively correlated with singing height, high-pitched songs being sung at higher song posts where interference by vegetation is expected to be less. Antbirds (Thamnophilidae) in South American neo-tropical rainforests tend to use song posts at different heights, each with different layer-specific transmission and noise characteristics (Nemeth et al. 2001b).

The frequency aspect of bird vocalisations (PC1) was correlated with body size, larger species using lower frequencies. The relationship between body size and frequency has been documented across different bird species, e.g. Brenowitz (1982); Ryan and Brenowitz (1985). Body weight did not correlate with any of the other sound characteristics. Bill length constraints on bird vocalisations are less often examined e.g., Laiolo and Rolando (2003); Seddon (2005), but bill size and shape may influence temporal features of songs (Podos 2001; Seddon 2005; Ballentine \& Pfennig 2006). Bill length did not correlate with the frequency or with the temporal aspects of avian sounds in the Zealandia forest community.

There is little evidence that the avian community affects the evolution of bird vocalisations, especially in closely related species e.g. the Ficedula flycatchers (Gelter 1987). Song evolution through sexual selection is thought to result in species divergence rather than convergence (Irwin 2000). The chance that unrelated species evolve very similar song is therefore likely to be small. However, there is some evidence that similar songs may evolve in different lineages (Price et al. 2007). The acoustic adaptation hypothesis predicts a relationship between signal structure and vegetation density, however vocalisation properties can also evolve as a by-product of habitat-related selection on body size and traits associated with foraging (Barker 2008). Birds may adapt to their acoustical 
environment by evolving different vocalisation types to reduce acoustic interference from other species or they may reduce the overlap with similar signals by choosing different times and places to sing (Luther 2009).

The forest avian community at Zealandia is a mixture of native and non-native species, and the vocalisations of these may have evolved under different habitat selection pressures, imposed by the acoustic properties of the habitat, the avian community and ecological or behavioural factors. Most of the non-native species were introduced to New Zealand in the 1880's (Lever 1987). Whether there are variations in the vocalisations of established introduced species from their original ancestors is not well understood, nor are the changes that might have accumulated in their vocalisations since their introduction (Baker \& Jenkins 1987).

Multispecies study approaches are vulnerable to the influence of confounding variables or to chance, and the signal phenotype might be affected by various forms of character displacement (Seddon 2005). Different species may weigh vocalisation features differently, or may have different mechanisms of sound production (Luther 2009). While it is not possible to be certain about the direct cause of divergence in vocalisation characteristics in the Zealandia bird community, the results are more consistent with the prediction of the ANH. However, the birds focused their vocalisations in a narrow bandwidth presumably needed for better transmission, which is consistent with the AAH. 


\section{Chapter 4}

\section{Is there a "sound window" for avian communication in}

\section{Zealandia forest?}

\subsection{Abstract}

Forests are a complex acoustic space, and as a result the cumulative changes in bird vocalisations with distance are often difficult to predict. Knowing the acoustic properties of the habitat is necessary when examining whether birds adjust the structure of their acoustic signals to reduce the effect of habitat. The physical acoustic characteristics of two types of forest in Zealandia are described, by measuring attenuation, reverberation, and ground effect as a function of sound frequency, distance, and speaker elevation. The maximum transmission range of bird vocalisations of different species w also examined. Generated tones of varying frequency and recorded bird vocalisations were broadcast in both pine and conifer broadleaf forest. The results demonstrate that the exact nature of sound transmission in forests depends on frequency sound, the relative height of the singer above the ground, and the path along which the sound travels. Hence, a "sound window" may not be a constant property of forests, because it can be affected by multiple factors. There was a prominent sound window in the lower frequency range, which was less affected by habitat, although some high frequencies had similar average attenuation values to those of low frequency but with more fluctuation. The ground effect was important in determining how well different frequency ranges transmit. Birds may be able to use the acoustic characteristics of their habitat to enhance their signal transmission. 


\subsection{Introduction}

Natural selection is considered one of the unifying concepts in ecological science that shapes biological traits, hence, quantifying the source of selection in natural populations is critical to understanding the evolution of a particular trait (Loreau 2010). The types of selection that may affect bird vocalisations are varied, and can include, bill morphology (Podos 2001), body size (Ryan \& Brenowitz 1985) and intensity of sexual selection (Vallet \& Kreutzer 1995). The structure of bird vocalisations is shaped by a trade-off between such factors (Derryberry 2009). To serve the main role of communication, however, vocalisations must transmit effectively through the habitat before they can be shaped by other selective pressures (Wiley \& Richards 1982). The selection pressure on bird vocalisations by habitat may have a substantial effect in shaping sound characteristics (Catchpole \& Slater 2008).

Structural changes that accumulate in transmitted sounds with distance are generally the result of attenuation and reverberation imposed by the habitat (Catchpole \& Slater 2008). Attenuation of sound results mainly from three different mechanisms: spherical spreading, atmospheric absorption, and scattering (Naguib \& Wiley 2001). The magnitude of these factors is not constant amongst habitats, resulting in different optimal sound features associated with different habitats (Kroodsma \& Miller 1982). Spherical spreading is the decline in the intensity of sound with the increase of distance it travels, and the basic expectation is that the intensity of sound will decrease by $6 \mathrm{~dB}$ for each doubling of distance (Slabbekoorn et al. 2002). Atmospheric conditions can also affect sound transmission, as attenuation increases with increasing temperature, and is reduced with increasing humidity (Wiley \& Richards 1982). 


\section{Chapter 4}

Obstacles in the forest (foliage, trunks, and branches) scatter the sound away from the path between sender and receiver, which may result in greater attenuation in denser broadleaved forests (Padgham 2004). Frequency ranges are affected differently by scattering, with high frequencies being more prone to scattering than low frequencies. This results in frequency-dependent attenuation (Padgham 2004). Reverberation is another factor that can affect especially sound transmission in forests, for with many sound-reflecting surfaces, this is an increase in the formation of echoes, which appear in sonograms as a smear (tail) following each note (Padgham 2004). Reverberated sound results in irregular patterns of sound 'tail' formation that can overlap with proceeding notes and change the temporal structure of the signal (Wiley \& Richards 1982; Wiley 1991; Naguib 2003). The duration of echoes and their relative amplitude are determined by the interplay between attenuation and accumulation of reverberations (Slabbekoorn 2004b). Reverberated sound may cause a masking effect on closely spaced notes within bird vocalisations but also may be advantageous to the sender and receiver, when the reflected echoes amplify subsequent notes of the same frequency e.g. long whistle notes (Embleton 1996). Birds can also use reverberations as a cue to estimate the distance of the signalling bird (Slabbekoorn et al. 2002).

Vocalisations broadcast at low elevations are affected by interference between sound traveling directly between the sender and receiver, and sound reflected from the ground. This is known as the ground effect (Slabbekoorn et al. 2007). The reflected sound waves may lead to attenuation at some frequencies or amplification at others, depending on the differences in phase (Embleton 1996). Sound waves can either cancel each other causing excess attenuation at certain frequencies, or be additive and amplify the sound at certain frequencies. This will depend on the path of direct and reflected sounds (Embleton 1996). 


\section{Chapter 4}

The exact nature of sound transmission in a particular type of habitat depends mainly on sound frequency, relative heights of the singer and receiver above ground and habitat characteristics (Slabbekoorn et al. 2007). In line with this, Morton (1975) found a sound window at around 1.6-2.5 KHz in woodland. Such a window was not found in more open country. Subsequent studies suggested that such a sound window may occur in a variety of other habitats as well (Catchpole \& Slater 2008). Birds in tropical forests may experience strong selection to produce songs within the window of relatively quiet frequencies $(1-4 \mathrm{KHz})$ to avoid masking from the intense ambient noise created by tropical insects, although this will depend on the particular habitat (Slabbekoorn 2004a). Ellinger and Hodl (2003) found a sound window at $0.5-1.5 \mathrm{kHz}$ on or close to the ground and that attenuation rises smoothly with frequency increase. They also showed a low frequency peak at or below $2.5 \mathrm{~m}$.

This study is complementary to the community study presented in (Chapter 2). It focuses on the habitat as a source of selection pressures on bird vocalisations and endeavours to quantify the selection pressure imposed on the transmitted sound, through broadcasting artificial tones and recording them at different distances within the forest. I model the acoustic environment as it appears during natural signalling by establishing a reference level of frequency-dependent attenuation, degradation, habitat effect, ground effect, and elevation. The study was replicated in two types of forest, indigenous broadleaf conifer coastal forest that dominates Zealandia, and exotic pine forest, Pinus radiata, that also occurs there. Many bird species occupy both types of habitat. Recorded bird vocalisations were used to estimate the maximum propagation of different species.

The following questions were investigated: 
1 Is there a frequency range (sound window) associated with each forest type present in Zealandia that is less affected by attenuation?

2 To what extent do the transmission properties of sound in the broadleaf forest and the pine forest differ?

3 What frequencies are affected more from reflected sound near the ground, and from reverberation?

4 What are the maximum propagation distance of the vocalisations of different bird species?

5 Do bird vocalisations coincide with the sound windows determined for their particular habitat?

\subsection{Methods}

\subsubsection{Study site}

The experiments were conducted in November 2010 to model the acoustic properties in forests within Zealandia, a 250 ha sanctuary surrounded by a mammal-proof fence within the city limits of Wellington, New Zealand $\left(41^{\circ} 17.8^{\prime} \mathrm{S}\right.$, $174^{\circ} 45.3$ 'E). The sound transmission experiments were carried out in two distinctly different forest types, pine forest, and a broad leaf evergreen forest. The pine forest, dominated by Monterey pine, Pinus radiata, was located on the south side of the sanctuary. The trees were approximately 50 to 55 years old, $40 \mathrm{~m}$ tall, and had a mean diameter of $50 \mathrm{~cm}$ at $2 \mathrm{~m}$ height (Karori Wildlife Sanctuary Trust 1997). The understorey was dense at 1-2 $\mathrm{m}$ high and was dominated by regenerating native trees and shrubs. The pine was the only species over $5 \mathrm{~m}$ tall, and it comprised approximately $36 \%$ absolute cover in the overstorey (Moles \& Drake 1999). The second forest type is classified as coastal broadleaf evergreen forest (Dawson 1988a), which is dominated mainly by mahoe, Melicytus 


\section{Chapter 4}

ramiflorus, and fivefinger, Pseudopanax arboreus. There is a dense understory of tree ferns, vines and shrubs, but few canopy emergent trees. The average tree diameter at $2 \mathrm{~m}$ height was $0.18 \mathrm{~m}$ (Karori Wildlife Sanctuary Trust 1997).

\subsubsection{Field techniques}

Generated tones and recordings of bird vocalisations were broadcast from a MIPRO MA-101 portable speaker at two heights, $0.5 \mathrm{~m}$, and $3.0 \mathrm{~m}$ above the ground. These elevations were chosen because an elevation of $3 \mathrm{~m}$ placed the speaker above the surrounding understorey vegetation, and most of the birds usually sing at heights around $3 \mathrm{~m}$ (personal observation). A $0.5 \mathrm{~m}$ elevation was chosen to represent some birds that usually forage and sing close to the ground (e.g. kiwi, robin, and saddleback). The broadcast sound was recorded simultaneously using three sound recording packages (Song Meters SM2) installed at $20 \mathrm{~m}, 40 \mathrm{~m}$ and $80 \mathrm{~m}$ away from the speaker to represent three distance ranges (close, mid and far). The recorders were installed at $2.5 \mathrm{~m}$ above the ground, and their height did not change with change of speaker height. A GPS unit (eTrex 10) was used to measure the distance between the Song Meters from the speaker and a compass was used to ensure all the recorders were facing towards the speaker.

The same experimental design was replicated in the two forests. The experiments were conducted on three successive days with similar weather conditions, fine with few scattered clouds, the temperature being approximately $18^{\circ} \mathrm{C}$, the relative humidity approximately $85 \%$, and the wind was calm, except for occasional mild breezes in the forest. The experiment was replicated five times at each elevation resulting in 10 playbacks within each forest type.

\subsubsection{Playback signal design}




\section{Chapter 4}

Three variables were manipulated in this study: sound frequency, height of the speaker, and habitat. The played-back sound consisted of 19 artificial tones of 0.4 s duration, produced by Adobe Audition 3.0. Each tone had a different frequency but similar amplitude, the lowest frequency being $0.5 \mathrm{KHz}$, with a gradual increase of $0.5 \mathrm{KHz}$ in subsequent notes up to $10 \mathrm{KHz}$. Silence duration of $2 \mathrm{~s}$ duration separated each note (Fig. 4.1). In addition to the generated tones, 18 vocalisations of the 17 study species were included (Appendix 1), namely those 16 species studied in chapter 2 plus a male and female little spotted kiwi, Apteryx owenii (to represent birds that vocalise near the ground). High quality recordings were chosen for the playback, and were played without any modification to their amplitude.
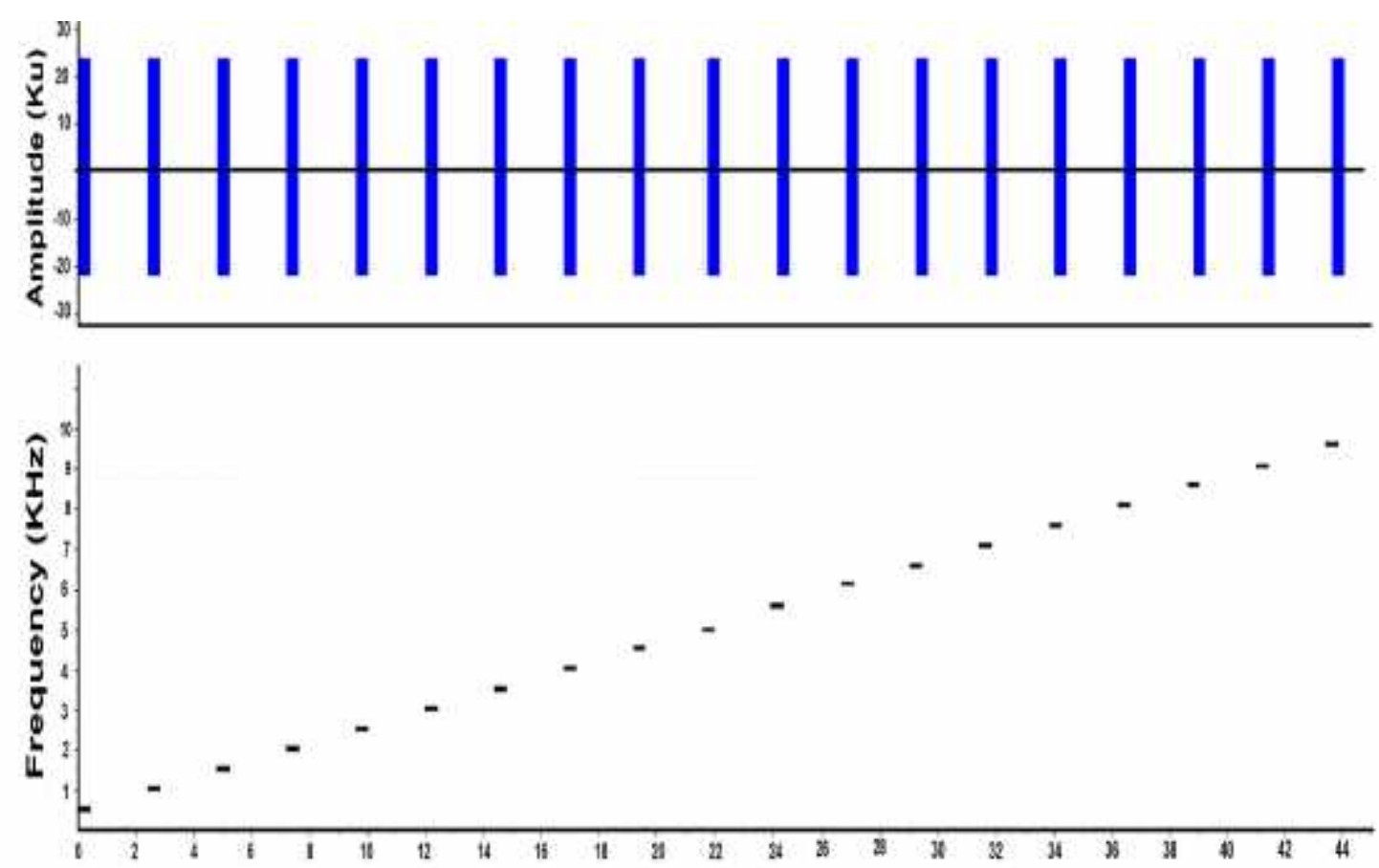

\section{Time (s)}

Figure 4.1. Raven window with waveform (upper), and spectrogram (lower) of the 19 generated tones used in the experiment.

\subsubsection{Sound analysis}




\section{Chapter 4}

To control for the recorder and the speaker effects, the sound was recorded $2 \mathrm{~m}$ away from the speaker and used as a control, to compare the recorded sound within the two habitats and at different elevations and distances. Broadcast sounds were recorded by the Song Meters at $44.10 \mathrm{KHz}$ and 16 -bit sample rate. All sounds were then band pass filtered with a FFT size 1024 Hamming window. Attenuation at each frequency was quantified by measuring the amplitude $(\mathrm{dB})$ of each note using Raven Pro 1.4 software then subtracting that value from the reference amplitude recorded $2 \mathrm{~m}$ away from the speaker. Reverberation was quantified by measuring the amplitude in the echo (shown as a tail in the sonograms) after the end of each note (Fig. 4.2).

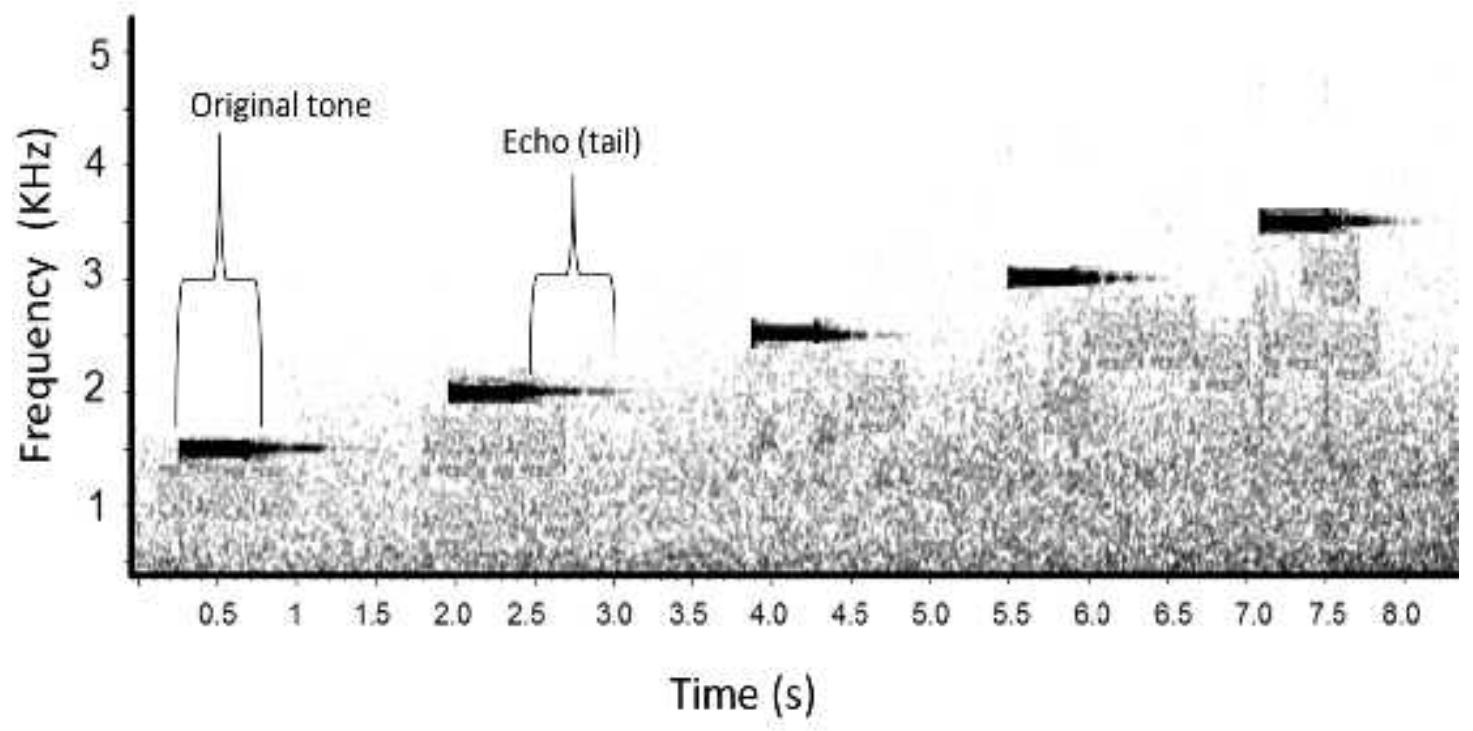

Figure 4.2. Spectrogram produced by Raven software showing the reverberated sound (tail) of the generated tones used in the experiment in a recording made in pine forest $40 \mathrm{~m}$ from a speaker at a height of $3 \mathrm{~m}$.

The attenuation of bird vocalisations was estimated by measuring the amplitude of vocalisation at different distances, the amplitude of a vocalisation being the average amplitude of its syllables. The sound files recorded at $2 \mathrm{~m}$ were used as a 
reference to compare the recordings at each distance. The maximum distance at which the vocalisation could be detected was estimated from the point where the mean amplitude of the syllables equalled the background noise, which was around $60 \mathrm{~dB}$.

\subsubsection{Statistical analysis}

Attenuation graphs were produced by SPSS 18 and smoothed by piecewisepolynomial function (spline). A One-way ANOVA was used followed by a Tukey post hoc test (hereafter 'Tukey') to compare the effect of frequency on attenuation within the same habitat and at different distances. The relative influences of distance, habitat type, and elevation on sound amplitude were quantified using linear regression analysis. The effect of elevation on certain frequencies was compared using an independent sample t-test. Linear regressions were used to model the effect of increased distance on the change of energy in bird vocalisations, and these models were used to estimate the distance each vocalisation could be recorded across the broadleaf forest. SPSS 18 was used for all statistical analysis.

\subsection{Results}

\subsubsection{Attenuation patterns of broadcast sounds in the broad leaved forest (effect of frequency and distance)}

The measured attenuation values of broadcast sounds (Fig 4.1) were normally distributed at 40 and $80 \mathrm{~m}$ away from the speaker (Kolmogorov-Smirnov: $P>$ 0.05 ), but not at $20 \mathrm{~m}$ (Kolmogorov-Smirnov: $P<0.01$ ). There was significant variation in attenuation at $40 \mathrm{~m}$ (Levene's test for homogeneity of variance: $P<$ 0.01 ) but not at $80 \mathrm{~m}$ (Levene's test for homogeneity of variance: $P=0.53$ ). The 
data at $40 \mathrm{~m}$ were not transformed because there was little need to test for the homogeneity of variance ${ }^{1}$.

Attenuation varied as a function of frequency at $40 \mathrm{~m}$ (one-way ANOVA: $F_{19,80}$ =19.6, $P<0.01$ ), $80 \mathrm{~m}$ (one-way ANOVA: $F_{8,36}=4.1, P<0.01$ ) and at $20 \mathrm{~m}$ away from the speaker (no statistical contrast can be drawn but see Fig. 4.3). The plotted sound attenuations in Fig. 4.3 are likely to be the result of spherical spreading and excess attenuation. A general pattern can be perceived on frequency dependent attenuation at different distances from the speaker, with low frequencies around $1 \mathrm{KHz}$ attenuating less than at any other frequency at $20 \mathrm{~m}$ (no statistical contrast can be drawn), $40 \mathrm{~m}$, and $80 \mathrm{~m}$ (Tukey, $P<0.05$ ). At mid distance $(40 \mathrm{~m})$ from the speaker, there was no significant difference in attenuation values of frequencies between $2-4 \mathrm{KHz}$ (Tukey, $P=0.14$ ). Among the high frequency range $(5-10 \mathrm{KHz})$, frequencies of $7.5 \mathrm{KHz}$ had the lowest mean attenuation (mean $=39, \mathrm{SE}= \pm 5.3 \mathrm{~dB}$ ), however this result was not significantly different from the mean attenuation of frequencies $5-6.5 \mathrm{KHz}$ (Tukey: $P>0.05$ ) because of the fluctuation in attenuation represented by the high standard deviation (SD) (Fig. 4.4).

At further distance $(80 \mathrm{~m})$, there was no significant difference in the mean attenuation values of frequencies between $1.5-3 \mathrm{KHz}$ (Tukey: $P>0.05$ ), and frequencies higher than 3.5 showed significant increase in attenuation (Tukey: $P<$ 0.05). Frequencies above $5 \mathrm{KHz}$ were highly affected by attenuation and were not detected (Fig. 4.3).

\footnotetext{
${ }^{1}$ The homogeneity of variances assumption is usually not as crucial as other assumptions for ANOVA, in particular in the case of balanced (equal $n$ ) designs. Levene's test and Brown \& Forsythe's test are not necessarily very robust themselves (Glass \& Hopkins 1996; Hill \& Lewicki 2006).
} 


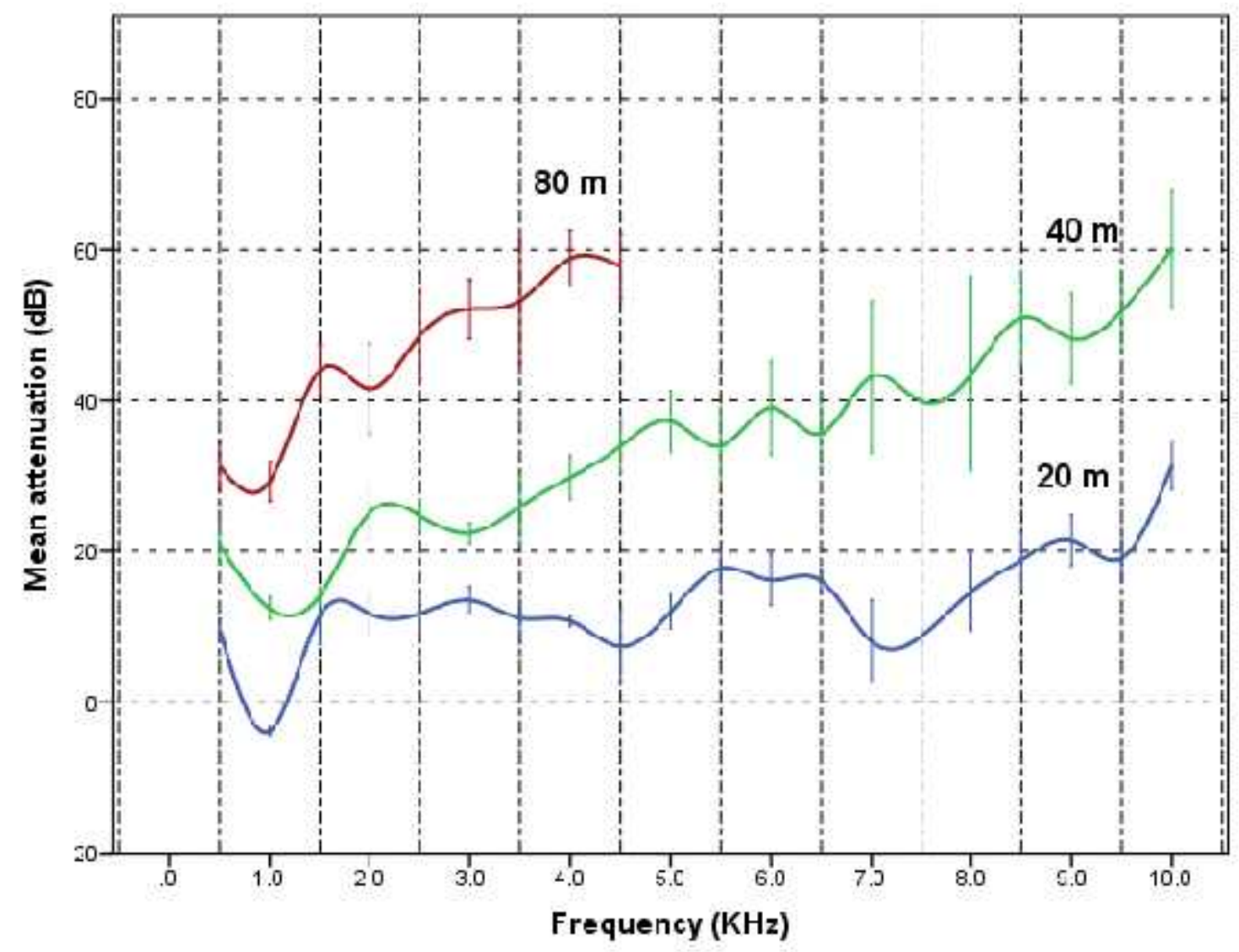

Figure 4.3. Mean frequency response $( \pm S E)$ to propagation in broadleaf forest at 3 different distances, $20 \mathrm{~m}, 40 \mathrm{~m}$, and $80 \mathrm{~m}$, speaker elevation $3 \mathrm{~m}$.

Attenuation fluctuated at different frequencies and at different distances (Figs. 4.3 \& 4.4), although the overall variation observed was greater due to the increase in attenuation with increasing distance. There was a positive correlation between the increase in attenuation and the increase in SD (Fig. 4.4), particularly at $40 \mathrm{~m}$ from the speaker (Table 4.1). At $20 \mathrm{~m}$, much of the variation in attenuation appears to be produced by reflected sound from the ground (ground effect) or from different surfaces in the forest (see sections 4.4.4 \& 4.5.3). 


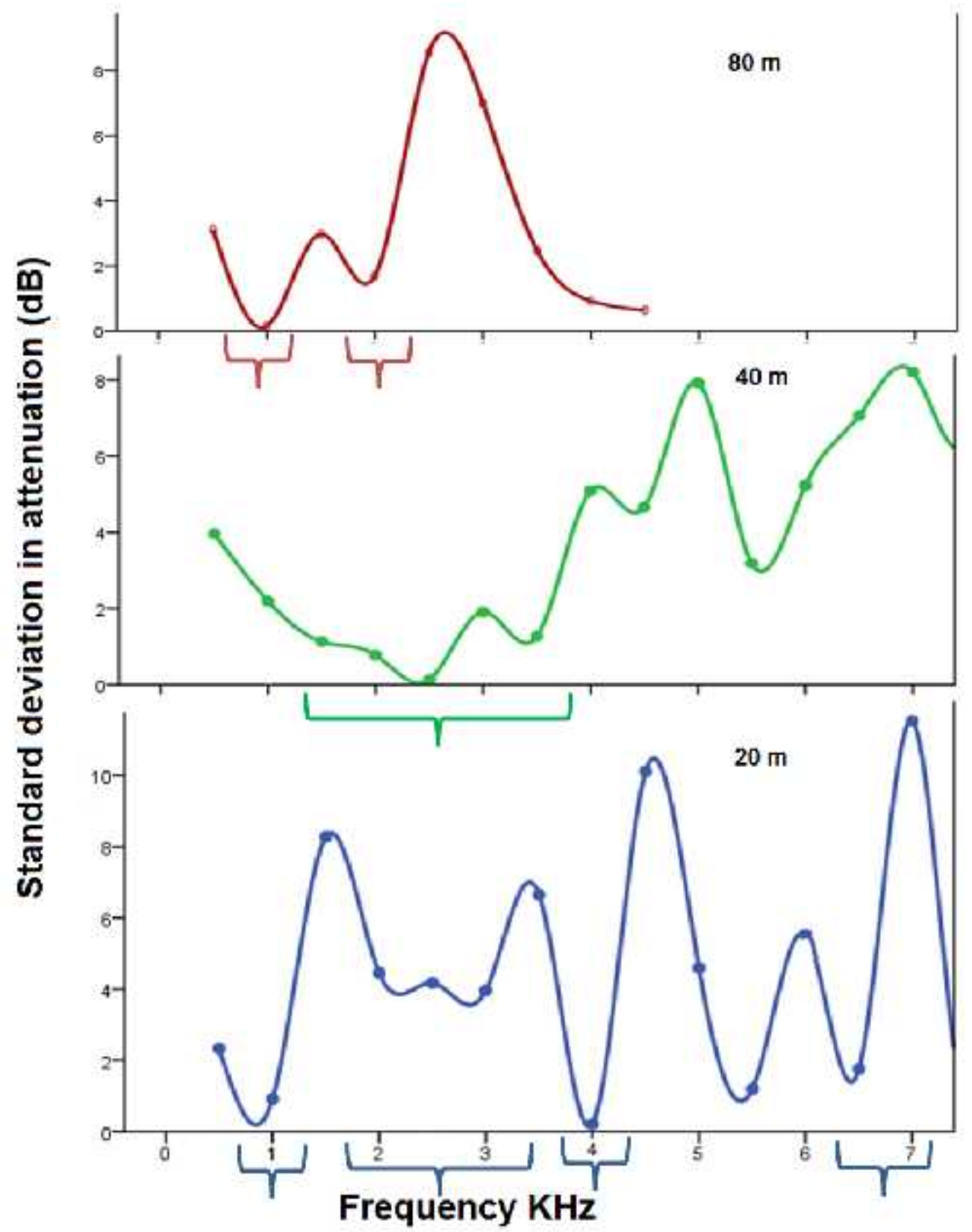

Figure 4.4. Variation in attenuation (SD) in response to frequency change, measured in the broadleaf forest at three different distances, $20 \mathrm{~m}, 40 \mathrm{~m}$, and $80 \mathrm{~m}$, speaker elevation $3 \mathrm{~m}$. The marked frequency ranges show possible sound windows.

A "sound window" can be defined as a frequency or a band of frequencies bounded by a sharp increase in attenuation with a stable pattern of attenuation (low SD) (Douglas et al. 1980). When attempting to determine a sound window from Figs. 4.3 and 4.4, it was found that the $1 \mathrm{KHz}$ frequency attenuated less at all distances from the speaker. At $20 \mathrm{~m}$, a sound window could be defined at 2.5-3.5 


\section{Chapter 4}

$\mathrm{KHz}, 4 \mathrm{KHz}$, and $6.5-7 \mathrm{KHz}$. At each of these frequencies attenuation was less and there was less variation in attenuation. At the mid distance of $40 \mathrm{~m}$, a narrower sound window could be defined between $1.5-3.5 \mathrm{KHz}$ frequency with less attenuation and low SD, while frequencies above $3.5 \mathrm{KHz}$ showed a rapid increase in attenuation (Fig. 4.3). At the further of distance $80 \mathrm{~m}$, a narrower sound window could be defined around $2 \mathrm{KHz}$.

Table 4.1. Summary of linear regression models of frequency and SD in attenuation at $3 \mathrm{~m}$ speaker height in the broadleaf forest.

\begin{tabular}{lllll}
\hline $\begin{array}{l}\text { Distance } \\
(\mathbf{m})\end{array}$ & $\begin{array}{l}\mathbf{R}^{2} \\
\text { value }\end{array}$ & $\begin{array}{l}\text { Spectral } \\
\text { intercept } \\
\text { (dB) }\end{array}$ & Slope & $\begin{array}{l}\text { p value } \\
\text { (ANOVA) }\end{array}$ \\
\hline 20 & 0.08 & 1.2 & 1.2 & 0.23 \\
\hline 0 & 0.53 & 2.9 & 0.73 & 0.00 \\
\hline 80 & 0.15 & 2.1 & 0.4 & 0.29 \\
\hline
\end{tabular}

\subsubsection{Effect of forest type on sound attenuation}

The habitat effect on different frequencies of sound was examined by modelling attenuation in each of the two forest habitats, using linear regression (Figs. $4.5 \&$ 4.6). The slopes of the linear regressions indicate the effect of increased frequency on attenuation. The spectral intercepts of the linear models on the yaxis reflect the minimum attenuation comparable across the two forest types and within the same habitat across different distances (Padgham 2004). Table 4.2 summarises the linear models of frequency attenuation in the two habitats. 


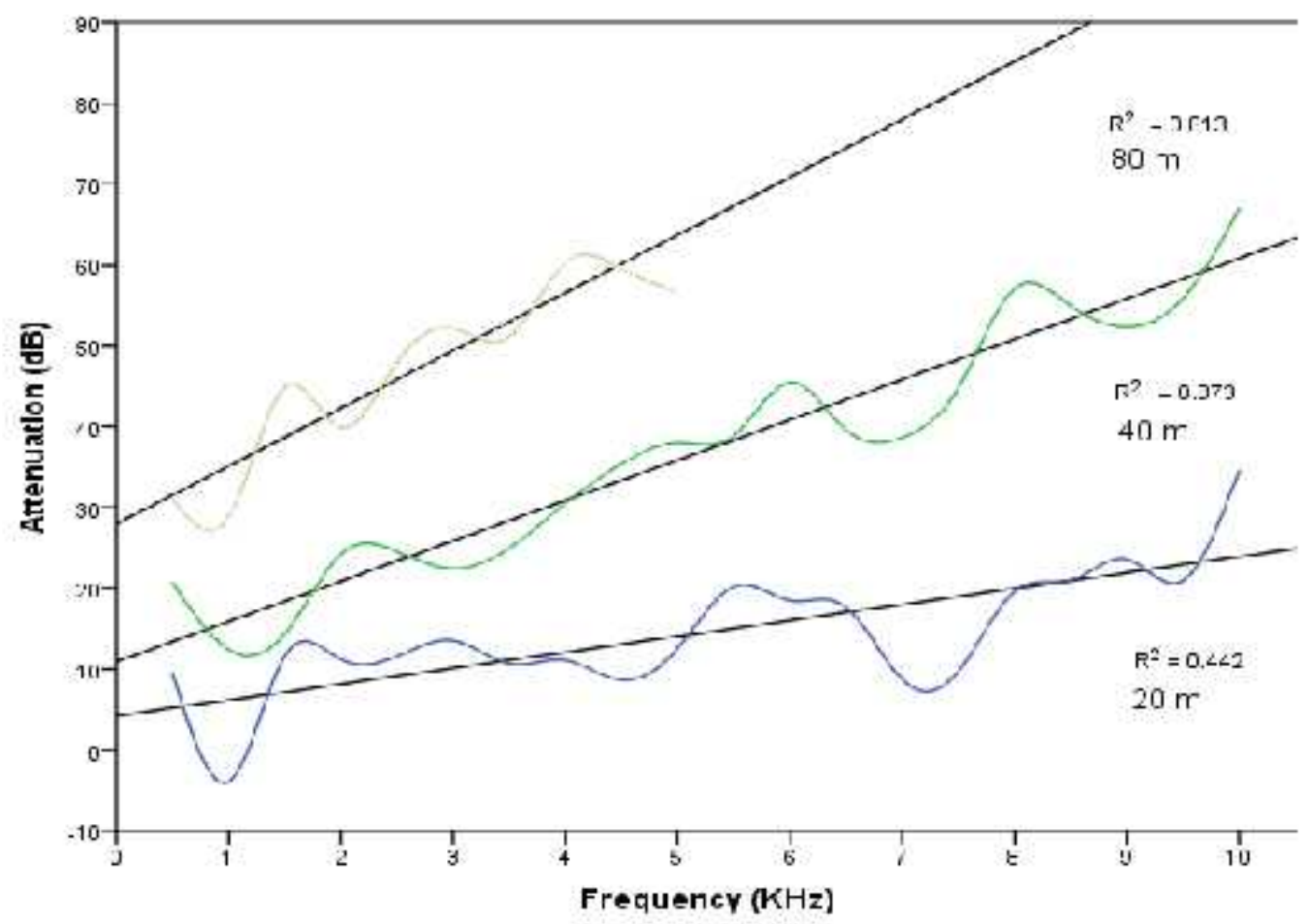

Figure 4.5. Attenuation measured at $20 \mathrm{~m}, 40 \mathrm{~m}$, and $80 \mathrm{~m}$ from the speaker, within the broadleaf forest. The speaker was at $3 \mathrm{~m}$ height from ground.

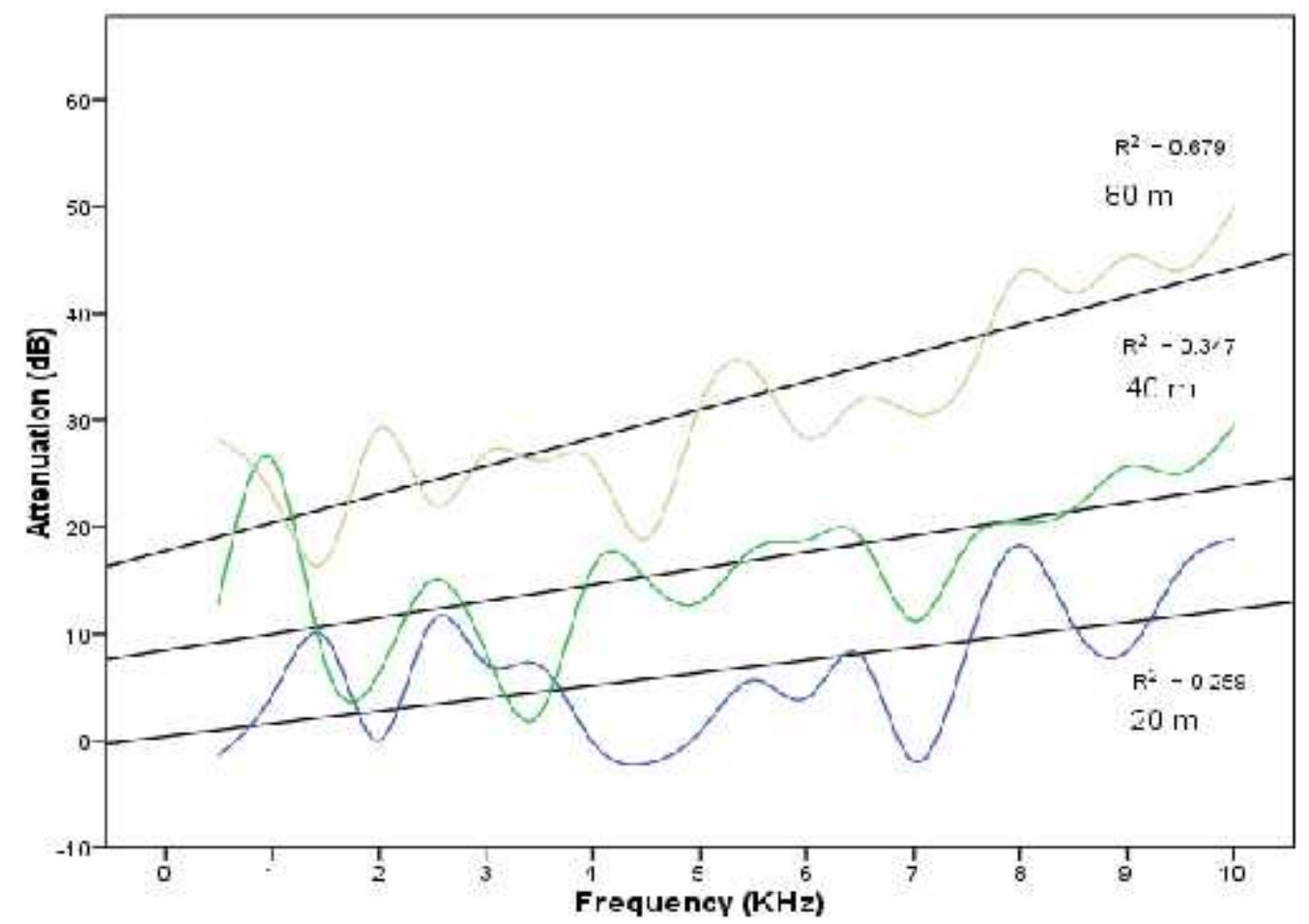

Figure 4.6. Attenuation measured at $20 \mathrm{~m}, 40 \mathrm{~m}$, and $80 \mathrm{~m}$ from the speaker, within the pine forest. The speaker was at $3 \mathrm{~m}$ height from ground. 


\section{Chapter 4}

Estimates of the 'goodness of fit' of the linear regression indicated by $r^{2}$ values, increased with increased distance from the speaker (Table 4.2). Frequency dependant attenuation was obvious in the two habitats, with slopes of the linear regression increasing with distance (Figs. $4.5 \& 4.6$ ). Frequency dependent attenuation was greater in the broadleaf forest than in pine forest, indicated by the higher slope values; they were about three times more in the broadleaf forest, especially at $40 \mathrm{~m}$ and $80 \mathrm{~m}$. The minimum attenuation indicated by linear intercepts with the $\mathrm{Y}$-axis was higher in the broadleaf forest and at all distances. The loss in amplitude was more than $6 \mathrm{~dB}$ with doubling the distance, except between $20 \mathrm{~m}$ and $40 \mathrm{~m}$ within the broadleaf forest, while it was about $15.5 \mathrm{~dB}$ between $80 \mathrm{~m}$ and $40 \mathrm{~m}$ (Table 4.2).

Table 4.2. Summary of all the linear regression models of frequency attenuation. The speaker was $3 \mathrm{~m}$ above the ground.

\begin{tabular}{|c|c|c|c|c|c|}
\hline Forest & Distance & $r^{2}$ value & $\begin{array}{l}\text { Spectral } \\
\text { intercept }\end{array}$ & Slope & $\begin{array}{l}P \text { value } \\
\text { (ANOVA) }\end{array}$ \\
\hline \multirow[t]{3}{*}{ Broadleaf forest } & 20 & 0.39 & 4.9 & 1.6 & $<0.001$ \\
\hline & 40 & 0.77 & 12.7 & 4.1 & $<0.001$ \\
\hline & 80 & 0.74 & 27.7 & 7.5 & $<0.001$ \\
\hline \multirow[t]{3}{*}{ Pine forest } & 20 & 0.24 & 0.82 & 1.0 & $<0.001$ \\
\hline & 40 & 0.25 & 9.3 & 1.2 & $<0.001$ \\
\hline & 80 & 0.47 & 19.3 & 2.1 & $<0.001$ \\
\hline
\end{tabular}




\section{Chapter 4}

In the pine forest, attenuation values were normally distributed at 40 and $80 \mathrm{~m}$ (Kolmogorov-Smirnov: $P>0.05$ ) but not at $20 \mathrm{~m}$ (Kolmogorov-Smirnov: $P=0.04$ ). There was significant variation in variances at 20 and $80 \mathrm{~m}$ (Levene's test for homogeneity of variance: $P<0.01, P<0.01$ respectively). A one-way ANOVA was used followed by a Tukey test to describe the attenuation pattern at $40 \mathrm{~m}$ only, since at $20 \mathrm{~m}$ there was an obvious effect of reverberated sound from the ground in the pine forest (see sections 4.4.4 \& 4.5.4).

At $40 \mathrm{~m}$ in the pine forest, there was no statistical difference between attenuation at $1.5 \mathrm{KHz}, 2 \mathrm{KHz}, 3 \mathrm{KHz}$, and $3.5 \mathrm{KHz}$ (Tukey: $P>0.05$ ), and these had the lowest mean attenuation (Fig. 4.6). The $7 \mathrm{KHz}$ frequency had the second lowest mean attenuation, along with $0.5 \mathrm{KHz}$ (Tukey: $P<0.05$ ). There was no significant difference in the mean attenuation of $2.5 \mathrm{KHz}$ and frequencies between $4-7 \mathrm{KHz}$ (Tukey: $P>0.05)$.

\subsubsection{Reverberation}

The reverberation values in the broadleaf forest were normally distributed at $20 \mathrm{~m}$ (Kolmogorov-Smirnov: $P=0.17)$, and at $40 \mathrm{~m}$ (Kolmogorov-Smirnov: $P>0.05$ ). The amplitude of the reverberated sound varied with frequency change at both 20 m (ANOVA: $\left.F_{19,99}=7.5, P<0.01\right)$ and 40 m (one-way ANOVA: $F_{19,99}=25.0, P<$ 0.01 ), energy in the reverberated sound decreasing with increasing distance from the speaker (Fig. 4.7). At close distance $(20 \mathrm{~m})$ the frequency between 0.5 and 1.5 had the highest mean energy in the reverberated sound (Tukey: $P<0.05$ ), while there was no significant difference between the amplitude of reverberated sound over the $2-5 \mathrm{KHz}$ frequency range. At $40 \mathrm{~m}$ from the speaker, there was no significant difference in the amplitude of the reverberated sound of frequencies 
between 1- $4 \mathrm{KHz}$ (Tukey: $P>0.05)$. At $(80 \mathrm{~m})$ the amplitude in the reverberated sound decreased dramatically with increased frequency (Fig. 4.7).

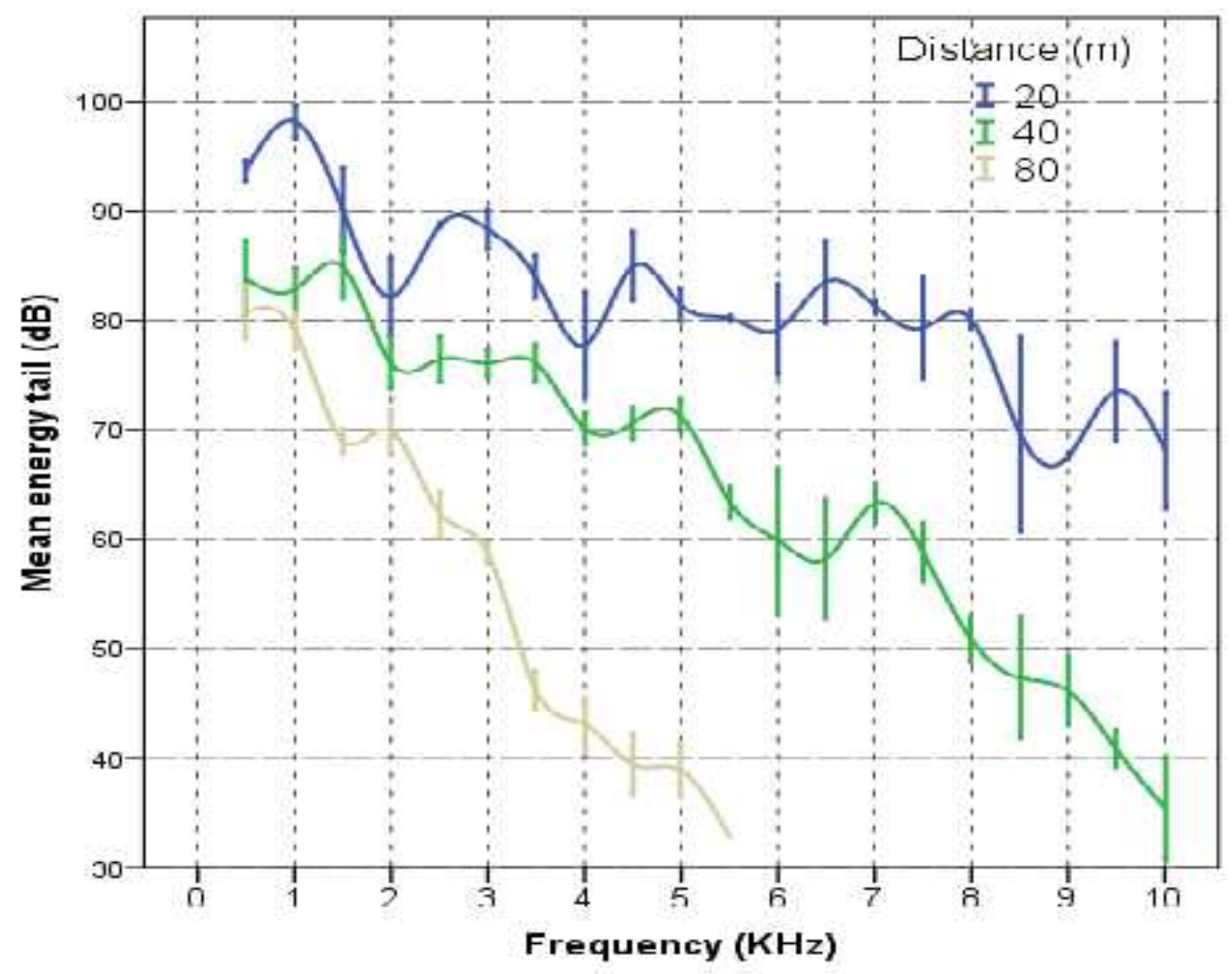

Figure 4.7. Mean energy ( $\pm S E)$ in reverberated sound within the broadleaf forest. Speaker height $3 \mathrm{~m}$.

Linear regression was used to compare the effect of habitat on reverberation at 40 $\mathrm{m}$ at $3 \mathrm{~m}$ speaker height (Table 4.3). Amplitude of the reverberated sound decreased with frequency increase, this pattern being more prominent in the broadleaf forest $\left(R^{2}=0.80\right)$, while in the pine forest there was less variation in the reverberated sounds at lower frequencies $\left(R^{2}=0.46\right)$, especially at the lower frequencies of $1-4 \mathrm{KHz}$ (Fig. 4.8). In the pine forest, frequencies between 1-2 and $3 \mathrm{KHz}$ had high mean reverberation values, while frequencies between 0.5-1.5 $\mathrm{KHz}$ had low amplitude in the reverberated sound (Fig. 4.8); frequencies of 2 and 3.5 $\mathrm{KHz}$ were less affected by reverberation. These same frequencies also were 
less affected from attenuation $80 \mathrm{~m}$ away from the speaker (Fig. 4.6). In the broadleaf forest, the frequency range of $0.5-1.5 \mathrm{KHz}$ resulted in the highest energy $(\mathrm{dB})$ of reverberated sound.

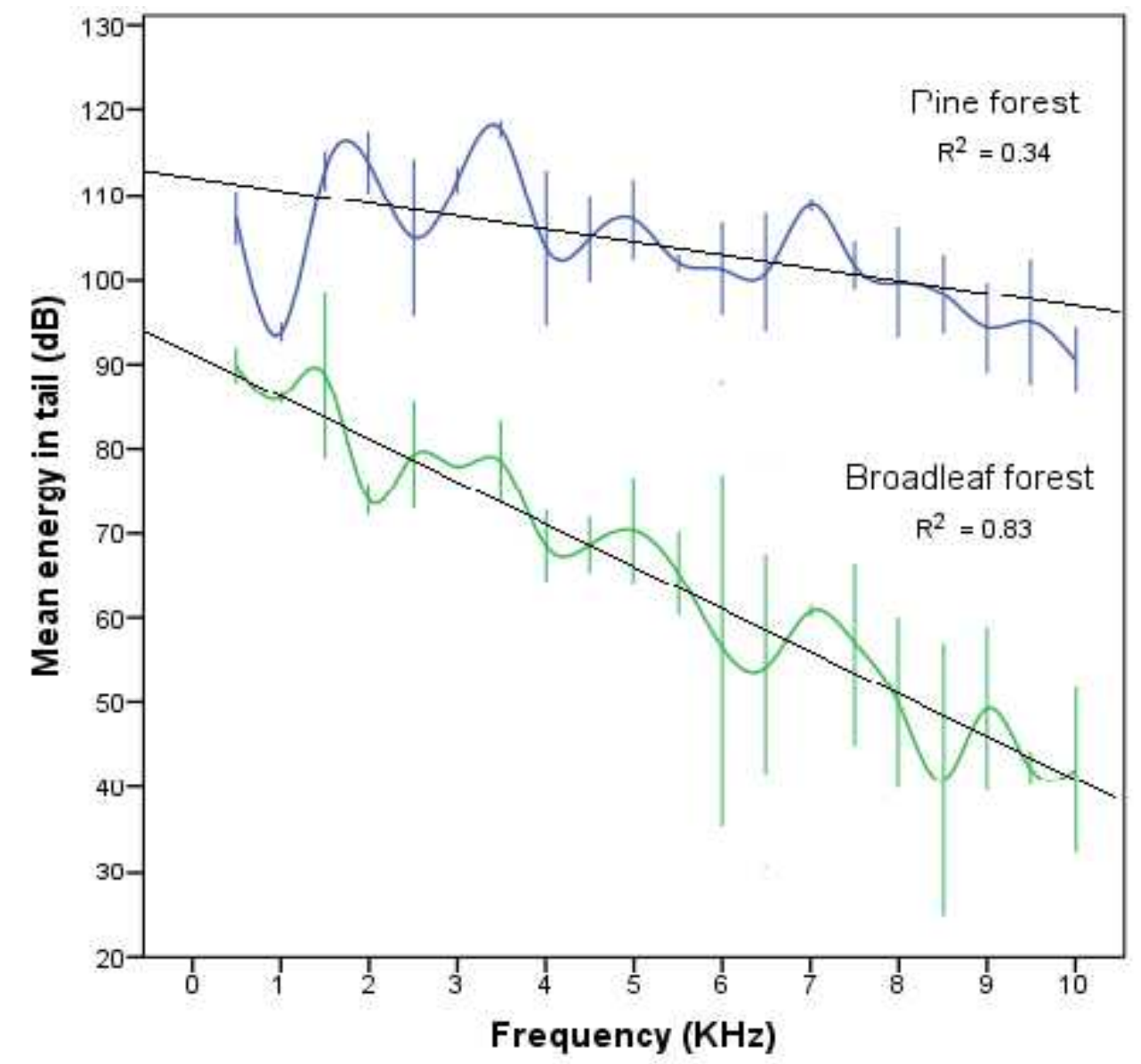

Figure 4.8. Energy in the reverberated sound at different frequencies measured at $3 \mathrm{~m}$ speaker height and $40 \mathrm{~m}$ from the speaker in the pine and broadleaf forests.

Table 4.3. Summary of the linear regression model showing that reverberation in the pine forest was higher in than the broadleaf forest.

\begin{tabular}{llllll}
\hline Forest & $\begin{array}{l}\text { Distance } \\
(\mathbf{m})\end{array}$ & $\begin{array}{l}\mathbf{R}^{2} \\
\text { value }\end{array}$ & $\begin{array}{l}\text { Spectral } \\
\text { intercept }\end{array}$ & Slope & $\begin{array}{l}\boldsymbol{P} \text { value } \\
\text { (ANOVA) }\end{array}$ \\
\hline Broadleaf forest & 40 & 0.83 & 92.2 & -5.5 & $<0.01$ \\
\hline Pine forest & 40 & 0.34 & 112 & -2.6 & $<0.01$
\end{tabular}




\section{Chapter 4}

\subsubsection{Ground effect}

Attenuation was compared at two different elevations in the broadleaf forest and at different distances (Fig. 4.9). At $20 \mathrm{~m}$, low frequencies of 0.5 and $1 \mathrm{KHz}$ attenuated more near the ground (t-test: $\mathrm{t}_{8}=8.4: P<0.05$ and $\mathrm{t}_{8}=25.0: P<0.05$, respectively). Frequencies between $3-4 \mathrm{KHz}$ (t-test: $\left.t_{8}=-3.7,-6.7,-26.6: P<0.05\right)$ and $5-6.5 \mathrm{KHz}$ (t-test: $\left.\mathrm{t}_{8}=-2.9,-3.1,-5.1,-9.1: P<0.05\right)$ attenuated less near the ground $(0.5 \mathrm{~m})$.

At $40 \mathrm{~m}$, the reflected sound from the ground was apparent at frequencies between 4.5 and $5.5 \mathrm{KHz}$, but the $5 \mathrm{KHz}$ frequency attenuated significantly less at $0.5 \mathrm{~m}$ (t-test: $\left.\mathrm{t}_{8}=-3.0: P=0.02\right)$. At $80 \mathrm{~m}$, there were no significant differences between attenuation at the two elevations, the reflected sound of the ground and attenuation having similar patterns at the two elevations (Fig. 4.9). A similar pattern was found in the pine forest; at $40 \mathrm{~m}$, lower frequencies (between 0.5-1.5 $\mathrm{KHz})$ attenuated more near the ground than at $3 \mathrm{~m}\left(\mathrm{t}_{8}=8.5,6.6: P<0.05\right)$.

Frequencies $3 \mathrm{KHz}$ and $5 \mathrm{KHz}$ were attenuated to a lesser extent near the ground (t-test: $\left.\mathrm{t}_{8}=7.0,-3.0: P<0.05\right)$. 


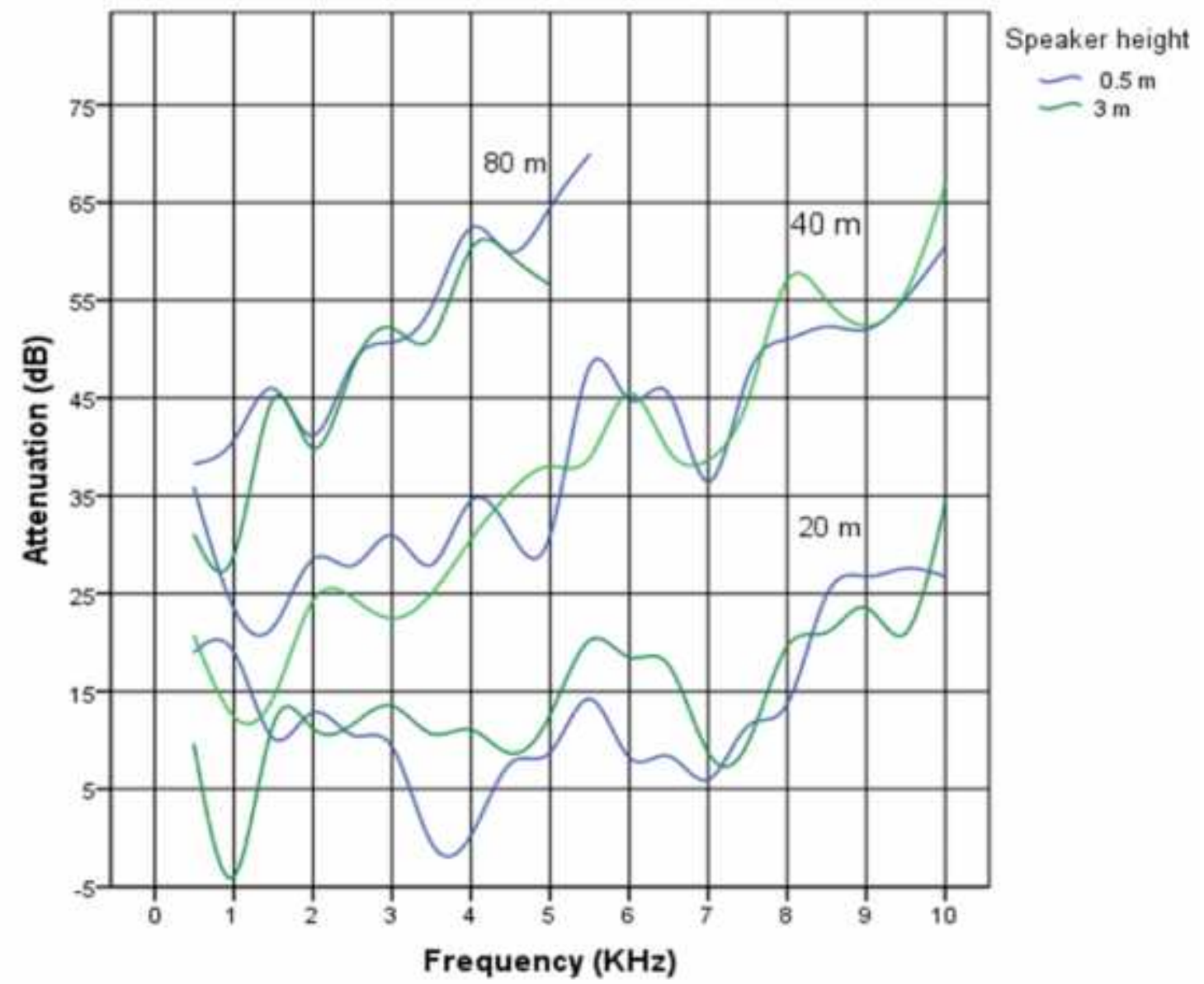

Figure 4.9. Attenuation spectra in the dense evergreen broadleaf conifer forest measured at two elevations, close to the ground $(0.5 \mathrm{~m})$ and at $3 \mathrm{~m}$ height across different distances of $20 \mathrm{~m}, 40 \mathrm{~m}$, and $80 \mathrm{~m}$ from the speaker.

\subsubsection{Attenuation of bird vocalisations}

The mean maximum frequency was less than $2 \mathrm{KHz}$ for two bird species (tui and female kiwi), with most of the broadcast bird vocalisations (11/18) having a mean maximum frequency between $2-4 \mathrm{KHz}$. Four species had a mean maximum frequency over $4 \mathrm{KHz}$, and the fantail had the highest maximum frequency of 7 $\mathrm{KHz}$ (Table 4.4). Linear regressions used to model the effect of increased distance on the change of energy in bird vocalisations in broadleaf forest are summarised in Table 4.4. 


\section{Chapter 4}

Table 4.4. Summary of the linear models of attenuation of bird vocalisations for all species studied in the broadleaf forest and pine.

\begin{tabular}{|c|c|c|c|c|c|c|c|}
\hline & & \multicolumn{3}{|c|}{ Broadleaf forest } & \multicolumn{3}{|c|}{ Pine forest } \\
\hline Species & $\begin{array}{l}\text { maximum } \\
F(\mathrm{KHz})\end{array}$ & Intercept & Slope & $\begin{array}{c}\text { Expected } \\
\text { distance }(\mathrm{m})\end{array}$ & Intercept & Slope & $\begin{array}{l}\text { Expected } \\
\text { distance } \\
\text { (m) }\end{array}$ \\
\hline Little spotted & 1.5 & 115.8 & -0.4 & 138.3 & 114.2 & -0.2 & 298 \\
\hline kiwi (f) & & & & & & & \\
\hline Tui & 1.9 & 127.9 & -0.6 & 119.2 & 125 & -0.4 & 172 \\
\hline Bellbird & 2.3 & 119.4 & -0.5 & 112.1 & 117 & -0.4 & 280 \\
\hline Kaka & 2.3 & 116.3 & -0.6 & 96.1 & 115.6 & -0.3 & 143 \\
\hline Little spotted & 2.7 & 132.5 & -0.8 & 94.1 & 121.2 & -0.3 & 217 \\
\hline kiwi (m) & & & & & & & \\
\hline Saddleback & 4.2 & 125.5 & -0.7 & 89.2 & 122.1 & -0.4 & 178 \\
\hline Song thrush & 3.2 & 125.8 & -0.8 & 82.6 & 121 & -0.4 & 197 \\
\hline Whitehead & 3.1 & 123.3 & -0.8 & 80.0 & 121.2 & -0.3 & 190 \\
\hline Kingfisher & 2.9 & 118.9 & -0.7 & 79.1 & 116 & -0.3 & 176 \\
\hline Chaffinch & 3.8 & 125.6 & -0.8 & 76.9 & 123.4 & -0.4 & 178 \\
\hline Robin & 4.4 & 119.9 & -0.8 & 74.1 & 117.3 & -0.3 & 213 \\
\hline Greenfinch & 3.6 & 117.9 & -0.8 & 71.5 & 116.0 & -0.3 & 183 \\
\hline Fantail & 7.0 & 120.5 & -0.9 & 67.4 & 119.2 & -0.4 & 141 \\
\hline Silvereye & 3.8 & 118.7 & -0.8 & 67.3 & 112.4 & -0.4 & 160 \\
\hline Dunnock & 4.9 & 119.9 & -0.9 & 66.7 & 114.4 & -0.4 & 141 \\
\hline Blackbird & 2.5 & 133.5 & -1.1 & 66.2 & 125.1 & -0.4 & 150 \\
\hline Stitchbird & 5.1 & 106.1 & -0.7 & 65.2 & 104.3 & -0.4 & 108 \\
\hline Grey warbler & 3.3 & 123.1 & -.98 & 68. & 121.1 & -0.3 & 183 \\
\hline
\end{tabular}

Most of the studied bird vocalisations were detectable at less than $100 \mathrm{~m}$ away from the speaker. Kiwi (female), tui, and bellbird were the only species detectable 
at more than 100 from the speaker (Fig. 4.10). The maximum frequency used in bird vocalisations and the predicted distances they travel in the forest were negatively correlated (Fig. 4.10). The vocalisation of female kiwi had the highest transmission distance of $140 \mathrm{~m}$, while stitchbird, dunnock, and blackbird had the lowest transmission distance of about $65 \mathrm{~m}$.

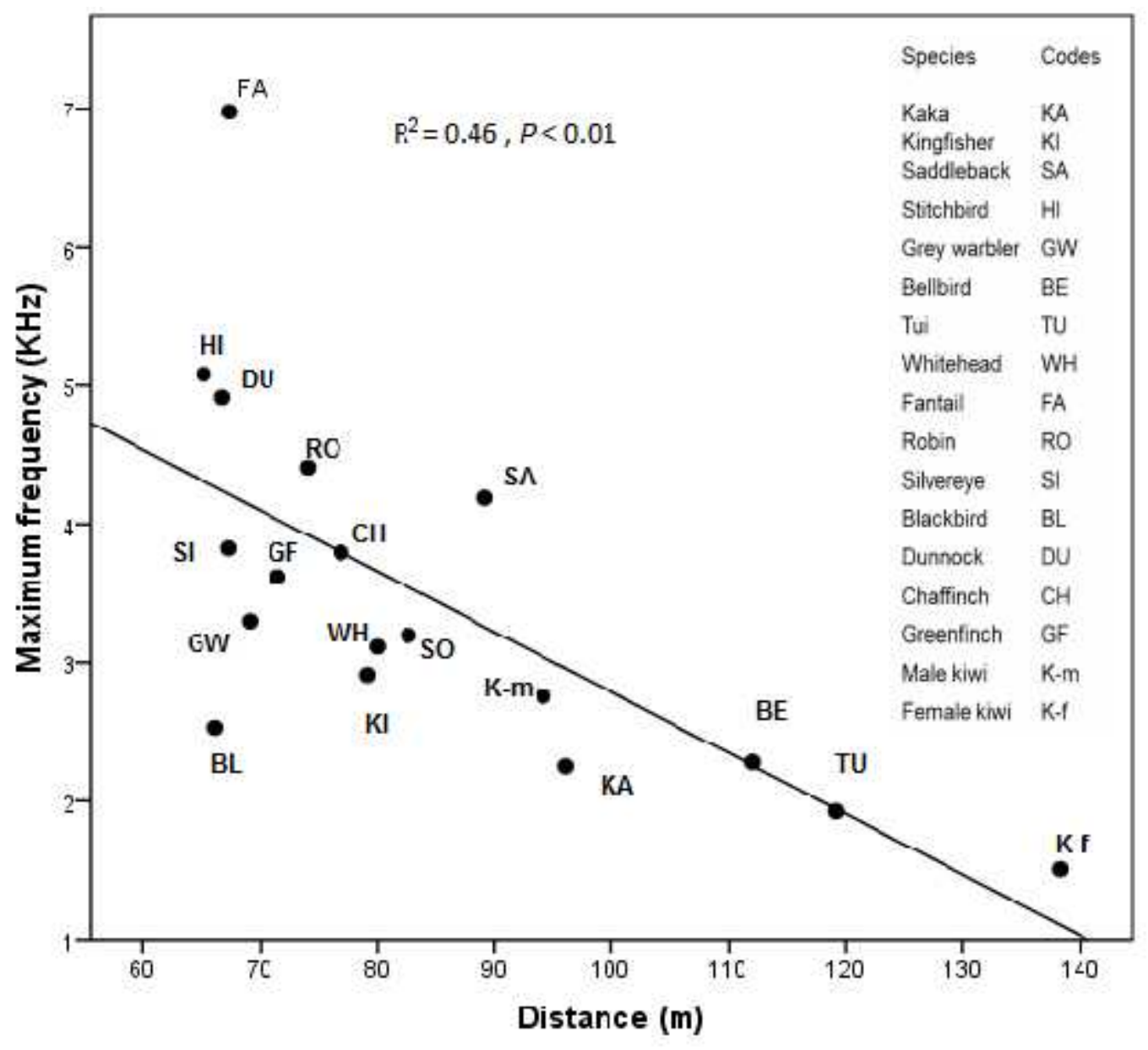

Figure 4.10. Expected transmission distance of bird vocalisations within the broadleaf forest, with the speaker at $3 \mathrm{~m}$ height.

In the pine forest, all vocalisations were detectable at more than $100 \mathrm{~m}$ away from the speaker. Kiwi (female) and bellbird were the only species detectable at more than $250 \mathrm{~m}$ from the speaker (Fig. 4.11). All bird vocalisations were detectable at a greater distance in the pine forest than in the broadleaf forest. The increase in the detectability distance in the pine forest was not consistent across the species 
studied, for example, the detectability distance for robin increased about $170 \mathrm{~m}$ but only 55 m for kaka (Figs. $4.10 \& 4.11$ ).

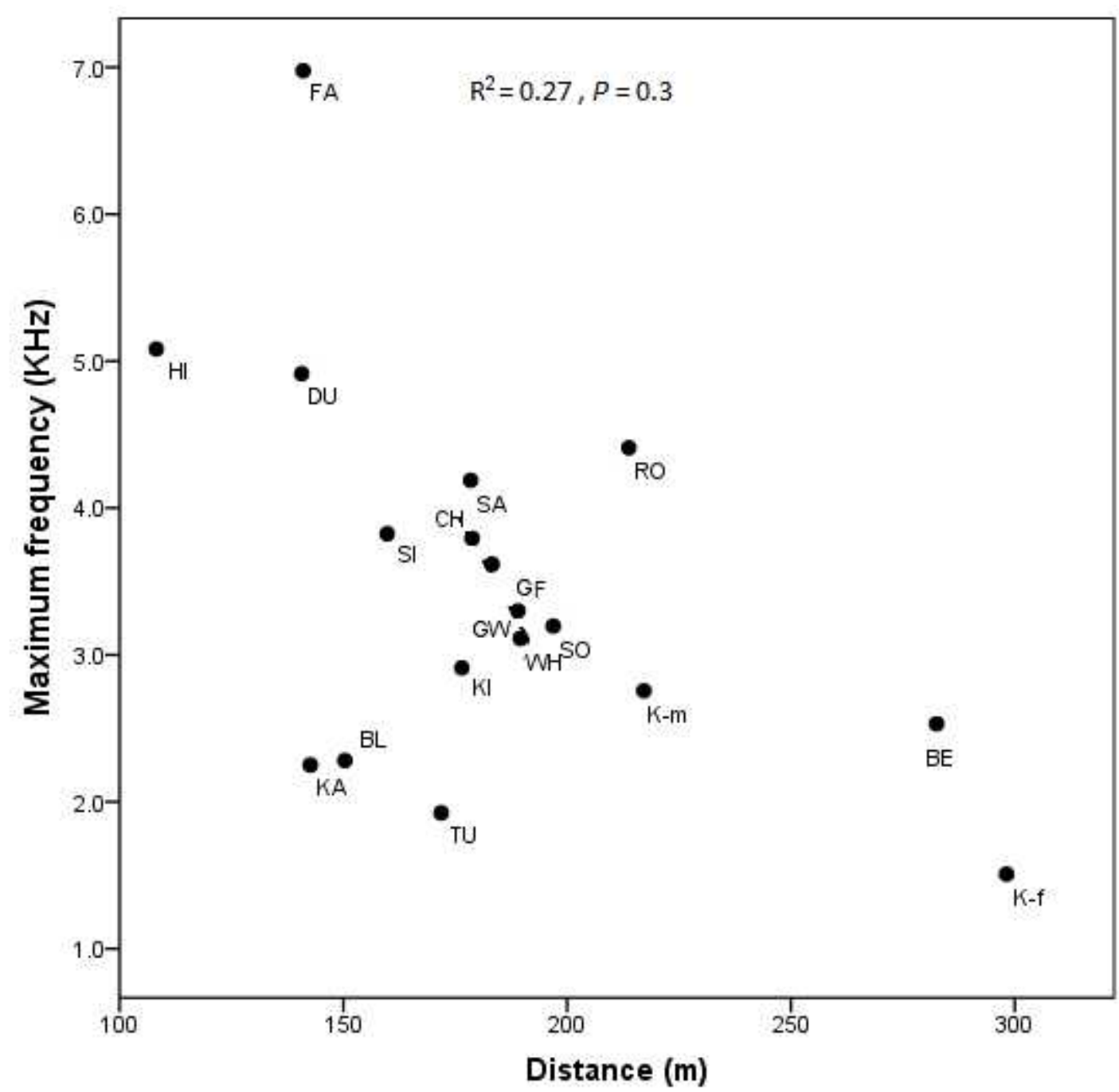

Figure 4.11. Expected transmission distance of bird vocalisations within the pine forest, with the speaker at $3 \mathrm{~m}$ height.

\subsection{Discussion}

This chapter describes experiments that provide a background to the transmission of physical sound in Zealandia in the two predominant forest types there, broadleaf forest and pine forest. The results show that a forest is a complex acoustic space. There was a significant effect on sound transmission of frequency, reverberation, ground effect, forest type, and distance. Other factors can add to the complexity of 


\section{Chapter 4}

the forest acoustics, such as atmospheric absorption and wind that can produce substantial variation over sound frequencies (Larom et al. 1997); the relative elevation of sender and receiver (Nelson 2000); the amplitude of the broadcast signal; and the density of the forest and leaf size (Patricelli \& Blickley 2006). The experiments conducted in Zealandia examined transmitted sound between sender and receiver in a single direct pathway; however, this is not always the case in the natural environment. The properties of the speaker and recorder might have further influenced the observed pattern of sound propagation by being sensitive to particular frequencies. Therefore, the findings of this study need to be examined with these qualifications in mind.

\subsubsection{Frequency dependent attenuation}

The series of experiments in the broadleaf forest emphasise the dependence of sound attenuation on distance and frequency (Padgham 2004). Frequencies less susceptible to attenuation varied with distance, while the sound window available for communication became narrower with increasing transmission distance. For frequencies between $2-5 \mathrm{KHz}$, the attenuation was steadier closer to the speaker, while at mid distance the sound window was limited to frequencies lower than 3.5 $\mathrm{KHz}$, with frequencies below $2.5 \mathrm{KHz}$ being more suitable for long distance communication. Another sound window that might be suitable for mid and short distance communication can be defined around $7 \mathrm{KHz}$. It had a relatively low mean attenuation value and was more susceptible to variation in attenuation. This might have resulted from wind turbulence, however, to which higher frequencies are more susceptible (Larom et al. 1997). Smaller birds challenged by body size constraints may take advantage of this high frequency sound window, e.g. the fantail (Fig. 4.12). 


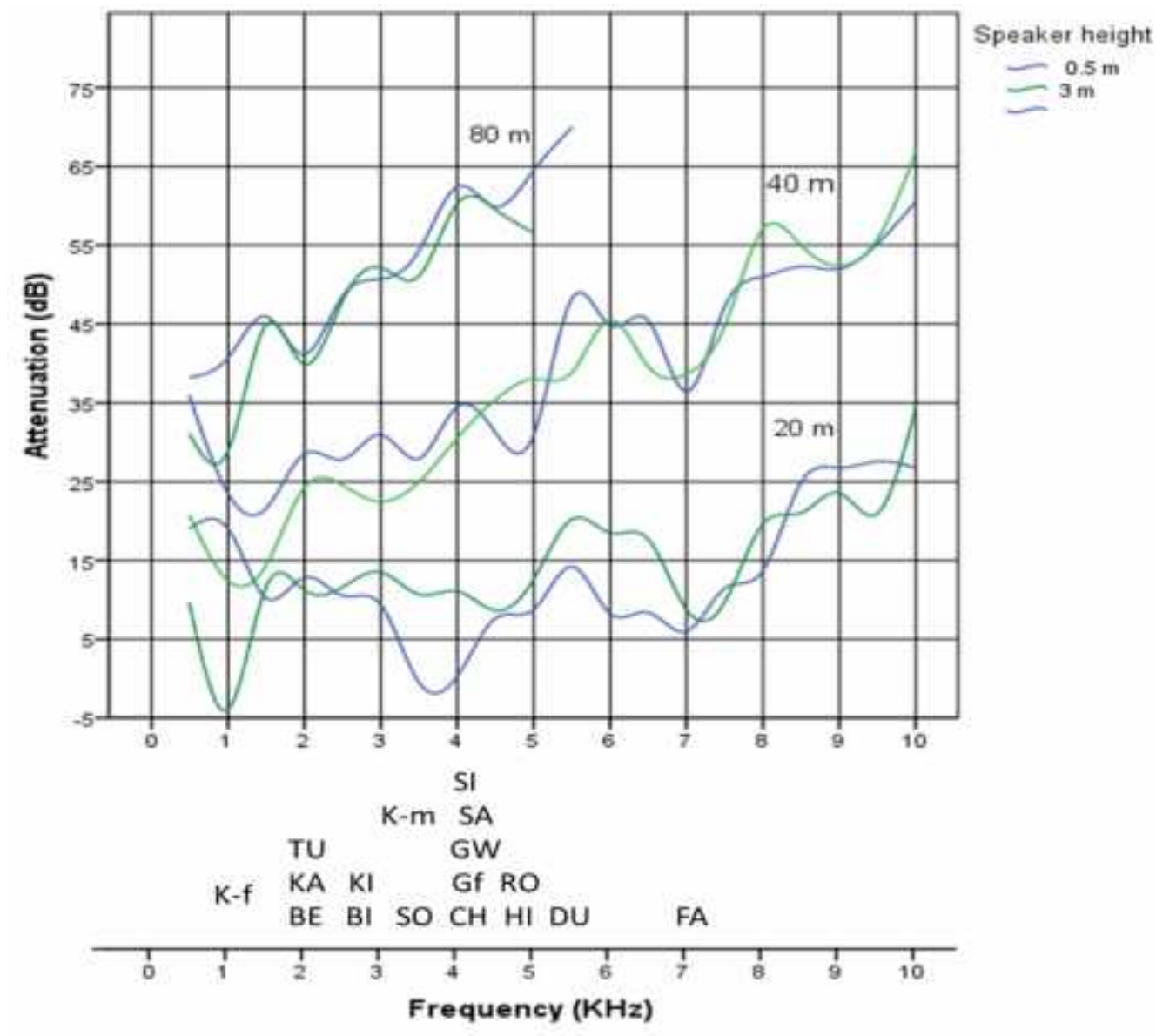

Figure 4.12. Attenuation, measured at two elevations, close to the ground $(0.5 \mathrm{~m})$ and at $3 \mathrm{~m}$ height across different distances at 20,40, and $80 \mathrm{~m}$ from the speaker. in the broadleaf forest, compared with frequency and the frequencies used by each species within the Zealandia forest. Developed from Fig. 4.9. Species name code as in Fig. 4.10.

In terms of mean attenuation values, the results substantiate the presence of a sound window restricted to lower frequency ranges; however, some higher frequencies have mean attenuation values similar to that at lower frequencies. For example, $5 \mathrm{KHz}$ tones did not degrade more, on average, than the $3 \mathrm{KHz}$ signals (at mid distance). However, $5 \mathrm{KHz}$ signals tended to be more variable. Birds may adapt to variability in attenuation rate by having shorter vocalisations and a greater repetition rate (song duration). Previous studies have examined the overall effect of degradation on sound transmission in terms of signal design for long-range 
propagation, e.g. Daniel and Blumstein (1998); Nemeth et al. (2001); Nicholls and Goldizen (2006). Adaptation of a vocalisation to the environment does not necessarily mean a design for maximum transmission. There might be some cost associated with increasing the propagation distance of a vocalisation, such as attracting predators, or stimulating agnostic behaviour from territorial birds (Ward \& Slater 2005). This may lead us to think that birds produce sounds that only transmit for a desired distance that might be beneficial to them. Therefore, from the experimental results, there appears to be an optimal frequency suitable for transmission to particular distance and birds may utilise frequencies in their vocal repertories depending on the distance of the intended receiver.

The frequency dependent sound attenuation results reflect the acoustic features of each habitat type. According to spherical spreading, sound amplitude is expected to be reduced $6 \mathrm{~dB}$ with doubling the distance from a point source in free field conditions (Forrest 1994). However, loss in amplitude with doubling the distance was more than $6 \mathrm{~dB}$ in Zealandia. This may have been due to the variable nature of the forest structure there. In general, the pine forest was less dense than broadleaf forest (visual estimation). The attenuation in the broadleaf forest was distinctly higher than in pine forest confirming that attenuation is greater with increasing vegetation density. This was noted between open habitats and forests (Waser \& Brown 1986), and, within forests, between open and dense forests (Padgham 2004), and in deciduous forest between "before" and "after" foliation (Blumenrath \& Dabelsteen 2004).

\subsubsection{Reverberation}

Reverberation caused irregular patterns of signal tail formation, probably because of the heterogeneous distribution of obstacles in the environment. Variation in the 
exact location of the sender and receiver is likely to contribute to this. Generally, the amplitude of the reverberated sound (tail amplitude) was determined by the amount of attenuation at a particular frequency, lower attenuation rates causing an increase in tail amplitude. In dense forests, narrow frequency band notes may be both extended in length and amplified by reverberation so that the habitat works to their advantage (Slabbekoorn et al. 2002). For example, the $2 \mathrm{KHz}$ frequency signal was less attenuated in the broadleaf forest and produced marked amplitude in the tail that can enhance that frequency. Tui, bellbird, and kaka had a maximum frequency around $2 \mathrm{KHz}$ (Fig. 4.12) and used whistle notes at that particular frequency (Appendix 1) with the notes being more elongated. Robin, silvereye, greenfinch, and dunnock songs contained trill like notes and had a maximum frequency around $4 \mathrm{KHz}$ (Appendix 1), a frequency less affected by reverberation (Fig. 4.8).

The amplitude of the reverberated sound in the pine forest was markedly higher than in the broadleaf forest (Fig. 4.8) and some frequencies had high amplitude in the reverberated sound that was $5-10 \mathrm{~dB}$ less than the original amplitude of the tone (Fig. 4.7). This might have a detrimental effect on some birds that might vocalise in the pine forest, causing masking of subsequent notes. In the pine forest, frequencies between $4-6 \mathrm{KHz}$ had a more stable reverberation pattern, and this might provide a sound window for communication with less reverberation effect, especially as attenuation of frequency is less in the pine forest than in the broadleaf forest. Possible positive effects of reverberations on avian communication in forests have also recently been suggested as distance cues, which may be advantageous to both sender and receiver (Naguib 1996; McGregor et al. 2000). 


\section{Chapter 4}

\subsubsection{Ground effect}

This study shows the importance of the reflected sound from very low sender elevations, as shown in other studies (Morton 1975; Michelsen 1983; Embleton 1996). Ground effect presumably has an important impact on communication of birds foraging on the ground, e.g. North Island robin, saddleback, song thrush, and blackbird, or on flightless birds, e.g. little spotted kiwi. Even though blackbird and song thrush might not sing at low elevation, the location of the receiver might be as important as the location of the sender. The attenuation of sound frequency depended largely on the height of the sound source, and the distance between speaker and recorder (Fig. 4.8). For the given conditions of $0.5 \mathrm{~m}$ speaker height, $2.5 \mathrm{~m}$ recorder height and $20 \mathrm{~m}$ recorder distance, the reflected sound from the ground suppressed the signal at $1 \mathrm{KHz}$, while frequencies between $3-4 \mathrm{KHz}$ and 6 $7 \mathrm{KHz}$ were amplified (Fig. 4.8). Male little spotted kiwi and saddleback seem to employ this ground effect to enhance their vocalisations (Fig. 4.12). Female little spotted kiwi on the contrary used a frequency around $1 \mathrm{KHz}$ that is supressed by the ground effect; presumably female calls have less importance in long range communication such as territorial defence or male contact. At mid distance, most frequencies attenuated more near the ground, probably because of the denser understory cover, however the sound reflected off the ground amplified the $5 \mathrm{KHz}$ frequency (Fig. 4.12). North Island robins seem to utilise this small sound window (Fig. 4.12). Other studies have varying results on the frequency band most affected by sound reflected off the ground. Marten et al. (1977) and Cosens and Falls (1984) found that $1 \mathrm{KHz}$ and $3 \mathrm{KHz}$ bands present a minimal excess attenuation because ground effect is reduced and 1 and $2 \mathrm{KHz}$ are good transmission frequencies. Sakai et al. (2001) found that in a deciduous forest, reflected sound from ground and direct sound meet up at $40 \mathrm{~m}$ from the source. 


\section{Chapter 4}

The different equipment used in my experiments might have caused different results, while the angle of the speaker or recorder might have further affected at the direction the sound will travel.

\subsubsection{Attenuation of bird vocalisation}

Brenowitz (1982) notes that estimating a signal's actual range and the range of information coded in a given set of acoustic signals, gives us a better understanding of the distance of the intended receiver. This invokes the idea of an active space that refers to the area around the sound source over which the signal remains detectable and is recognisable for potential receivers. Avian studies use auditory signals in a range of contexts, e.g. population censuses, or using automated sound recorders with an array of microphones to monitor birds by their distinctive vocalisations. Such detection methodologies could be affected by changes in transmission characteristics of different forest species vocalisations affecting their detection, so this can have important implications when monitoring bird populations (Desante 1986; Haselmayer \& Quinn 2000). Experimental work has potential application to correcting for distance and recognition bias when estimating bird species through point counts or audio techniques.

There was a negative correlation between the maximum frequencies (frequency with highest amplitude) in bird vocalisations and the maximum distance the sound travelled, although the result was obtained from a transmission experiment limited to particular experimental conditions (fixed speaker and receiver heights). Other factors besides attenuation and degradation might also affect the detectability of vocalisations, such as their loudness (amplitude), for example, grey warbler, whitehead, song thrush and kingfisher had a maximum frequency around $3 \mathrm{KHz}$, however the transmission distance of their vocalisations ranged from $65 \mathrm{~m}$ to 85 


\section{Chapter 4}

$\mathrm{m}$. The maximum amplitude of vocalisations can be constrained by body size, and a weak positive correlation between amplitude and body size was documented by Brackenbury (1979) in a comparative survey of 17 songbird species. However, there were inconsistencies with the tiny winter wren, Troglodytes hiemalis, which weighs about $10 \mathrm{~g}$, produced very loud songs averaging $90 \mathrm{~dB}$, whereas the much larger blackbird, Turdus merula, weighing about $96 \mathrm{~g}$ only reached $87 \mathrm{~dB}$ on average (Marler \& Slabbekoorn 2004).

I did not examine the correlation between vocalisation amplitude and body size, because a reliable measurement of sound amplitude requires standardising background noise and the social context of the vocalising bird, and these can be best manipulated under laboratory conditions (Brumm 2009). However, there are multiple selection pressures other than those specifically related to body size that might cause variation in song output level.

High frequency sounds in particular can be beamed in one direction, resulting in a longer transmission distance (Dantzker et al. 1999). For low frequencies, it is more difficult to restrict the beam of radiating sound energy, especially with a small bill (Slabbekoorn 2004b). Acoustic signals can be expected to evolve so that their active space is related to the optimal distance for accomplishing their communicatory function (Lemon et al. 1981). For some signals, this may be 'the further the better', but for others a distance of only one or two territories' may be optimal. 


\section{Chapter 5}

\section{Chatter song harmonics in the North Island saddleback,}

\section{Philesturnus rufusater: do they play a role in ranging?}

\subsection{Abstract}

Birds that counter-sing for communication and territorial maintenance need to localise the source of sound in order to promote an appropriate intra-specific response. Harmonics have received little attention as distance cues. Here, we investigate their role in the chatter song of the North Island Saddleback using playback experiments on wild birds. We test whether the relative amplitude of harmonics serves as a distance cue, and whether a change of harmonic composition of the chatter song has an effect on a territorial bird's response and its likely ability to estimate the distance of the signalling individual. Saddlebacks exhibited stronger responses to playback songs with more relative energy within higher harmonics, suggesting that these are perceived as coming from a nearby individual. Saddlebacks took longer to respond and counter-sang less to chatter songs with more relative energy in lower harmonics, suggesting that they were perceived as coming from a distant bird. We also found that Saddlebacks responded differently to songs from which different harmonic frequencies were removed (muted). Muting the harmonics with the highest amplitude did not affect the birds' ability to locate the speaker. However, birds were unable to locate the speaker accurately when muting other harmonic bands, suggesting their greater importance as distance cues. 


\subsection{Introduction}

Acoustic signals play a significant role in animal behaviour, conveying information about signalling individuals involved in intra-specific interactions, such as repelling rivals in territorial defence or indicating the fitness of singing males to females (Krebs et al. 1978; Catchpole et al. 1984; Buchanan and Catchpole 1997; Slater 2003; Catchpole \& Slater 2008). The distance of a signaller has biological significance, affecting interactions within and between sexes, and hence it should be important to have it encoded in the individual's signal in some way. For bird song, the receiver should be able to use these cues to estimate the distance of the signalling individual, a behaviour known as ranging (McGregor \& Krebs 1984). Correct estimation of distance is important in receiver response for it can lead to avoidance of unnecessary or dangerous interactions or to the better location of mate, or it may promote aggressive responses to defend a territory when a rival is nearby (Richards 1981; McGregor et al. 1983; McGregor \& Krebs 1984; Naguib 1995).

Few studies have focused on the effect of frequency in ranging, though relative intensities of high frequencies have been used to estimate the distance of a signaller, e.g. Carolina Wrens, Thryothorus Iudovicianus (Naguib 1995, 1997b). The combination of frequency-dependent attenuation and reverberation can also give information about the distance of the signaller (Naguib et al. 2000). Again, few studies have focused on the role of harmonics (notes with multi-frequency bands) in ranging (but see e.g. Aubin \& Jouventin (2002)), although other aspects of harmonics function have been investigated. Both Zebra Finches, Taeniopygia guttatal, and Budgerigars, Melopsittacus undulates, were able to detect slight mistuning of one of the harmonics in a simulated female Zebra Finch contact call 


\section{Chapter 5}

(Lohr \& Dooling 1998). In Whooping Cranes, Grus Americana, harmonics provide acoustic cues to individuality and body size (Fitch \& Kelley 2000), and in Redwinged Blackbirds, Agelaius phoeniceus, lower frequency elements of song are essential for species recognition in whereas high frequency elements are not (Brenowitz 1982).

As the sound of a bird's vocalisation travels in the habitat, it is subject to degradation. Changes that accumulate in the songs are the result of reverberation, amplitude fluctuation and frequency-dependent attenuation (Slabbekoorn et al. 2002), with higher frequencies being more susceptible to degradation (Padgham 2004). Playback experiments on birds in natural conditions demonstrate that reverberated songs are judged to be further away than un-degraded songs (Fotheringham et al. 1997). Birds approach closer towards a loudspeaker playing reverberated song or even fly beyond the loudspeaker (Wiley \& Godard 1996). Relative intensities of high frequencies can also be used in bird song ranging (Naguib 1995, 1997a). Combinations of reverberation and frequency-dependent attenuation may therefore serve as distance cues (Naguib 1996). Amplitude varies more with weather than reverberation or frequency-dependent attenuation (Richards 1981), so changes in amplitude may provide a less reliable clue for song ranging. Nevertheless, some species use overall amplitude as a relative cue for ranging conspecific songs (Naguib 1997a; Nelson 2000).

Different syllables in bird songs can have different spectrographic form, whistles being a common type in which the energy is concentrated at a single frequency that may change temporally during utterance. Another type comprises multifrequency bands of harmonics where the energy is distributed into more than one frequency, and where higher frequencies are integer multiples of the fundamental 


\section{Chapter 5}

frequency. The North Island Saddleback, Philesturnus rufusater (hereafter 'Saddleback'), is a member of the endemic New Zealand wattlebird family, the Calleadidae. Saddlebacks stay within their territories and defend them all yearround. Two subdivisions of loud Saddleback song are recognised; male rhythmical songs, used exclusively by site attached pair bonded adult males with each male having one to four patterns (Jenkins 1978), and chatter songs, being more common in a single bird's repertoire, and uttered by both sexies throughout the year (Jenkins 1978, Parker et al. 2010). Chatter songs appear to be important in territorial maintainance (Ludwig \& Jamieson 2007, Jenkins 1978). Quieter songs are used for pair bonding and can only be heard at close distance, avoiding agonistic behaviour between residents that would result from louder long distance signalling (Jenkins 1978). Familiarity with particular male rhythmic song affects Saddleback response in playback experiments (Parker et al. 2010). Hence, this study focussed on the role of harmonics in the common chatter song, which is less likely to vary spatially within the study area and is given by both males and females (Jenkins 1978; Parker et al. 2010; pers. obs.). The chatter song consists of a set of repeated notes varying in number from $3-40$, all of them consisting of sets of harmonics (Fig. 5.1a). The fundamental frequency (F0) is around $1.5 \mathrm{KHz}$, and has the lowest energy compared to other harmonics. The first harmonic $(\mathrm{H} 1)$ is around $3 \mathrm{KHz}$, while the second harmonic $(\mathrm{H} 2)$ is around $4 \mathrm{KHz}$ and is the dominant frequency where most song energy is present. Higher harmonics, over $4.5 \mathrm{KHz}$, have lower energy and are more susceptible to attenuation.

Pitch is the perception of frequency, and in tonal bird song pitch is often a direct function of the fundamental frequency (Lord et al. 2009). It can also be determined by harmonics in the upper frequency range that have greater energy than the fundamental, hence pitch may be relative with respect to F0 (Lord et al. 2009). In 
humans, F0 affects the judgement of both voice quality and recognition (Handel 1995). In other primates, removing the harmonics above the fundamental had a greater effect on the perception of sound than removing the fundamental alone, e.g. Japanese Macaques, Macaca fuscata (May et al. 1989) and Cottontop Tamarins, Saguinus Oedipus (Weiss \& Hauser 2002).
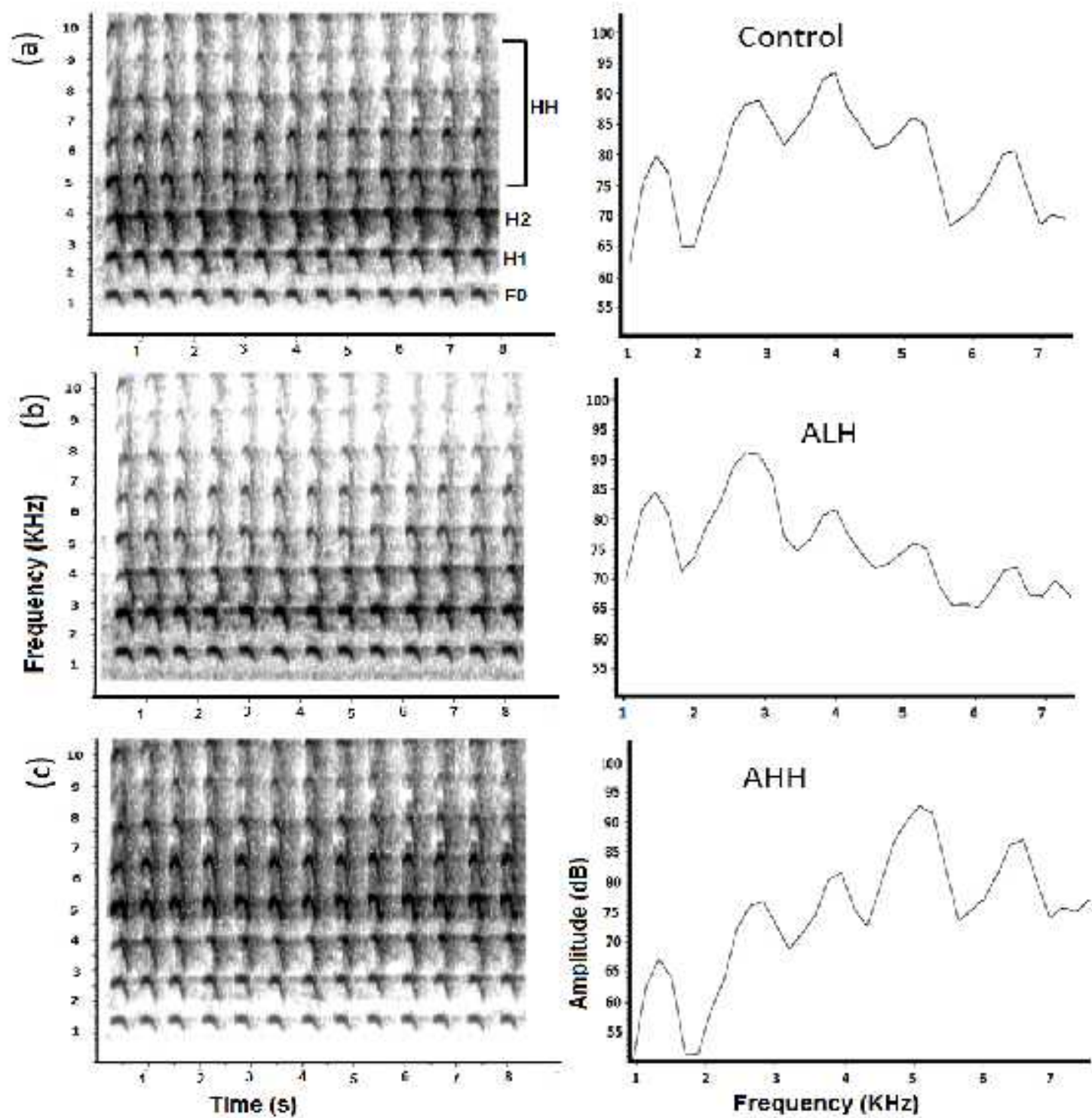

Figure 5.1 Spectrograms (left) and power spectra (right) of $8 \mathrm{~s}$ saddleback song sample used in playback experiments. (a) control (un-modified song) showing the fundamental frequency (F0) and the harmonics $(\mathrm{H} 1, \mathrm{H} 2, \mathrm{HH}),(\mathrm{b})$ amplified lower harmonics (ALH), (c) amplified higher harmonics (AHH). The darkness of the band represents the relative amplitude. 


\section{Chapter 5}

Here I explore whether the Saddleback, uses harmonics as a cue for distance by observing the birds' responses to artificially modified chatter song segments using playback experiments. Given that higher harmonics are more susceptible to attenuation than lower frequency (Mark 2004), songs with relatively more energy in higher harmonics are predicted to produce a greater response than songs with relatively more energy in the lower harmonics, when broadcast with similar amplitude and from the same distance (Brumm \& Slater 2006). Further, I investigate whether the Saddleback is sensitive to changes in the harmonic composition of its chatter song, and how it responds to songs from which some harmonics are removed. Since muting any of the harmonics affects the overall pitch and the energy in the song (Darwin et al. 1994), this results in different transmission properties of the song. I predict that modified songs with muted harmonics will give a false cue of the broadcast location and that this will affect the distance to which the birds approach the speaker. Since the fundamental frequency can be related to body size across different species (Ryan \& Brenowitz 1985; Gil \& Gahr 2002), muting F0 might be less stimulating to a Saddleback looking for the source of the sound, as it might indicate a smaller rival (Ryan \& Brenowitz 1985; Gil \& Gahr 2002). Since harmonics with higher energy transmit further, we predict that muting harmonics with high energy $(\mathrm{H} 1, \mathrm{H} 2)$ will have more effect on song ranging, and that birds will be less able to locate the speaker. Since $\mathrm{HH}$ bands attenuate more when transmitted in the forest, and the Saddlebacks will be accustomed to this, we predict that muting $\mathrm{HH}$ will not affect their ability to locate the speaker.

\subsection{Methods}

\subsubsection{Study site}


The experiments were conducted on the North Island Saddleback over MarchApril 2011 in Zealandia, a 250 ha native forest sanctuary surrounded by a mammal-proof fence within the city limits of Wellington, New Zealand $\left(41^{\circ} 17.8^{\prime}\right.$ S, $174^{\circ} 45.3$ 'E; see Fig. 5.2).

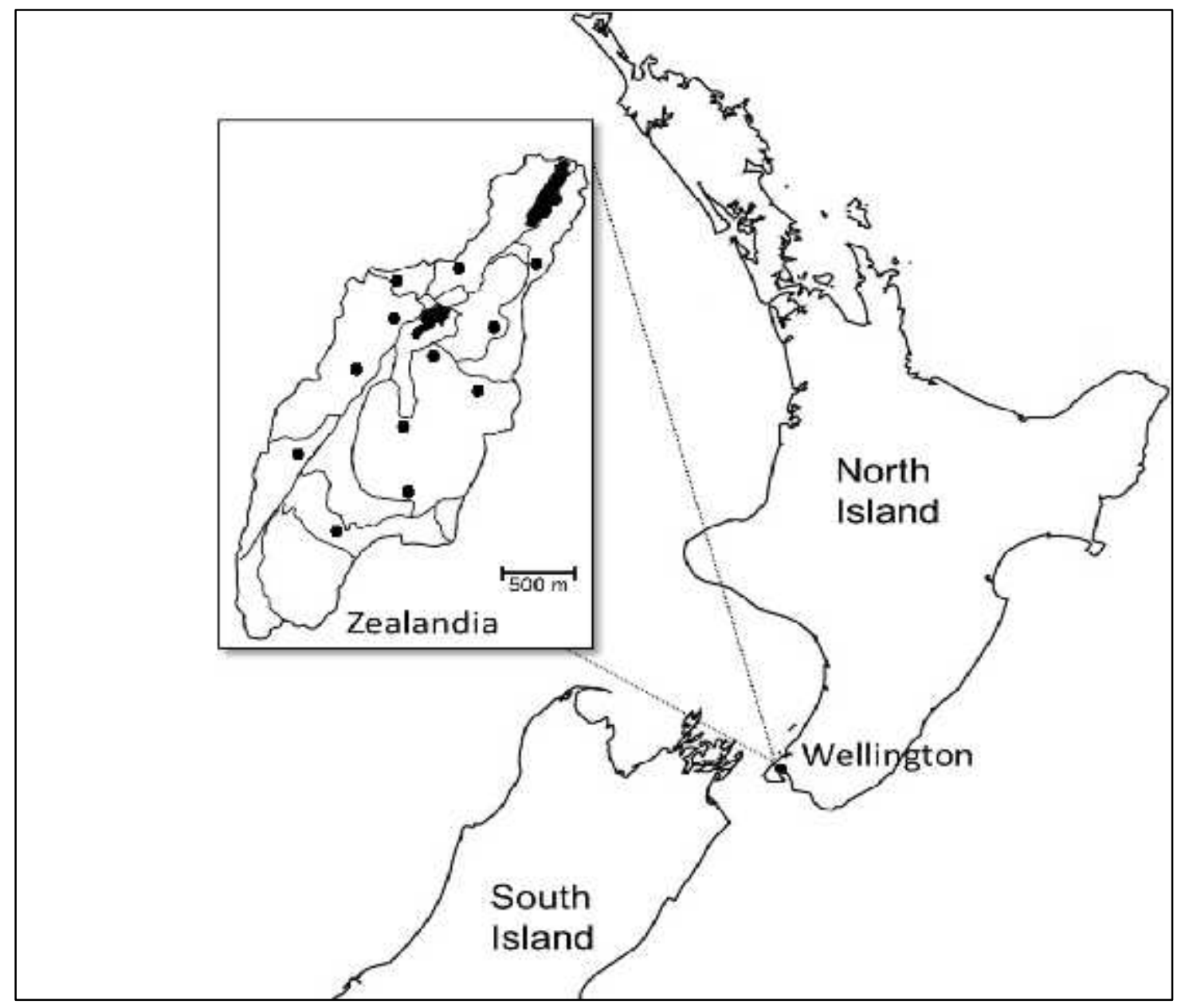

Figure 5.2. Location of study area and experimental sites at Zealandia sanctuary, Wellington, New Zealand. The inset shows the sanctuary with the two lakes (black) and trails within.

\subsubsection{Playback signal design}

The modified natural chatter song extracts used in the playback experiments were recorded in 2009 from the same population using a Marantz model PMD670 portable solid-state recorder with sampling frequency of $44.1 \mathrm{kHz}$ and $16-$ bit sample size. One good quality chatter song recording was selected to produce the 


\section{Chapter 5}

modified songs using Adobe Audition 3 and Raven Pro 1.4 software. We were unable to confirm the sex of birds attracted by the playback sounds, except for those that were colour banded. For experiment 1, to test the response to modifications in harmonics intensity, two types of modification were made (Fig. 5.1): (1) amplification of lower harmonics $(A L H)$ with the attenuation of the higher harmonics, so that the overall energy in the song remained unchanged, and (2) amplification of higher harmonics $(\mathrm{AHH})$ with reduction of the energy in the lower frequency harmonics. We used the unmanipulated song (Fig. 5.1a) as the control. All three-song types had the same amount of energy (125 dB) but with differing amplitude distributions across the frequency spectrum. All songs used in the playback experiments had $5 \mathrm{~s}$ duration. For experiment 2, to test the response to muted harmonics, the song was modified by muting each of the $\mathrm{FO}, \mathrm{H} 1, \mathrm{H} 2$, and $\mathrm{HH}$ harmonic bands (Fig. 5.3). The same unmodified song was used as a control in both 
experiments.

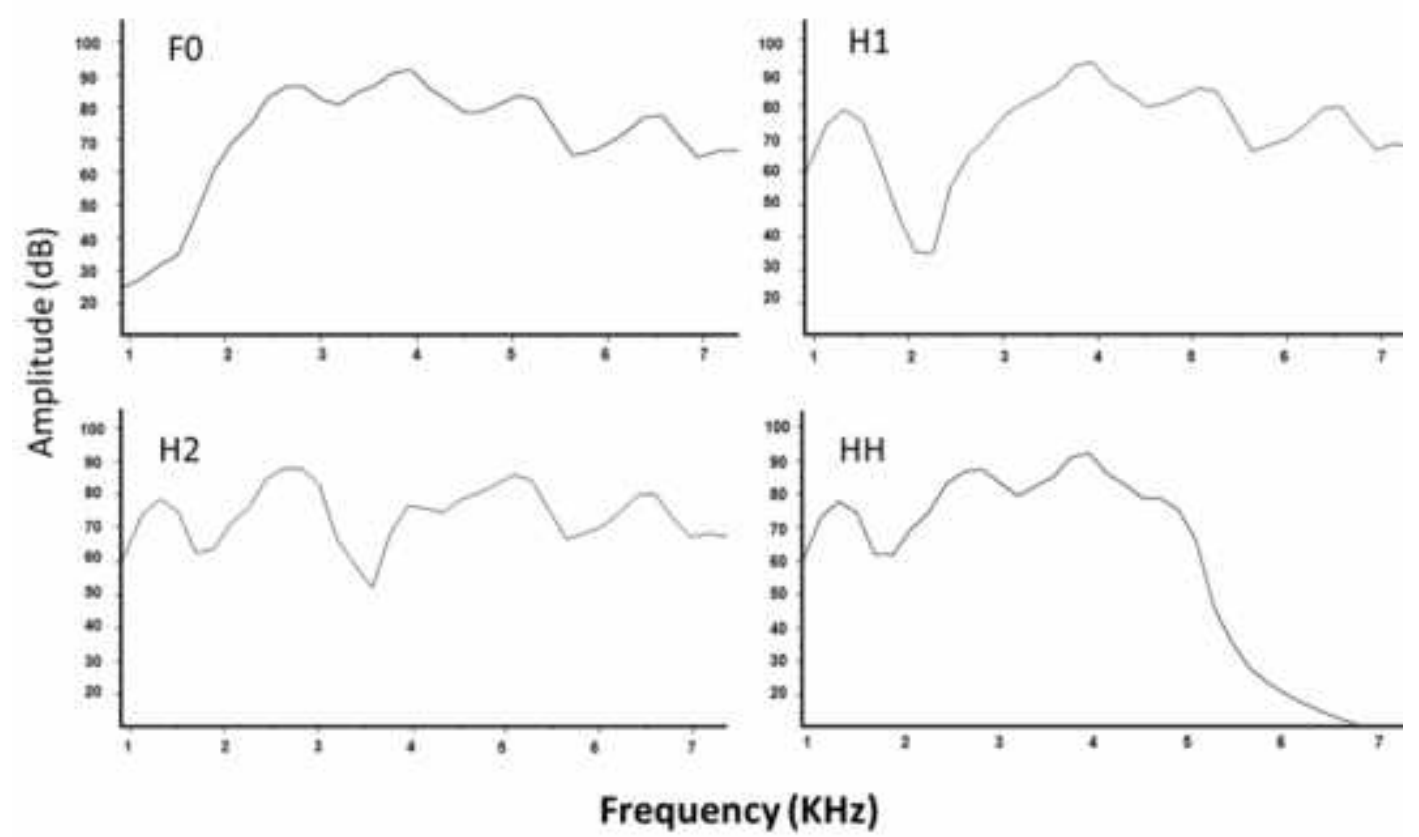

Figure 5.3. Power spectra of four $5 \mathrm{~s}$ song samples modified for use in experiment 2, showing muted fundamental frequency (F0), muted first harmonic $(\mathrm{H} 1)$, muted second harmonic $(\mathrm{H} 2)$, and muted higher harmonics $(\mathrm{HH})$.

\subsubsection{Playback field protocol}

The playback design consisted of two speakers, $20 \mathrm{~m}$ apart from each other (Fig. 5.4). One speaker (A) was a Sony portable RDPM5iP speaker, placed in the forest at $3 \mathrm{~m}$ height, and used to first attract the bird by playing unmodified song, ensuring that it was consistently positioned at a similar distance from the second speaker (B). This second speaker was a Mipro MA-101, placed at $2 \mathrm{~m}$ height, and camouflaged by leaves to prevent the bird from acquiring visual cues of its location. When the bird was within $2 \mathrm{~m}$ from speaker $(\mathrm{A})$, we allowed 2-4 minutes for the bird to settle, and then each stimulus was played once from speaker B. If on any occasion two birds were simultaneously attracted to speaker $(A)$, then the experiment was terminated for that site. 


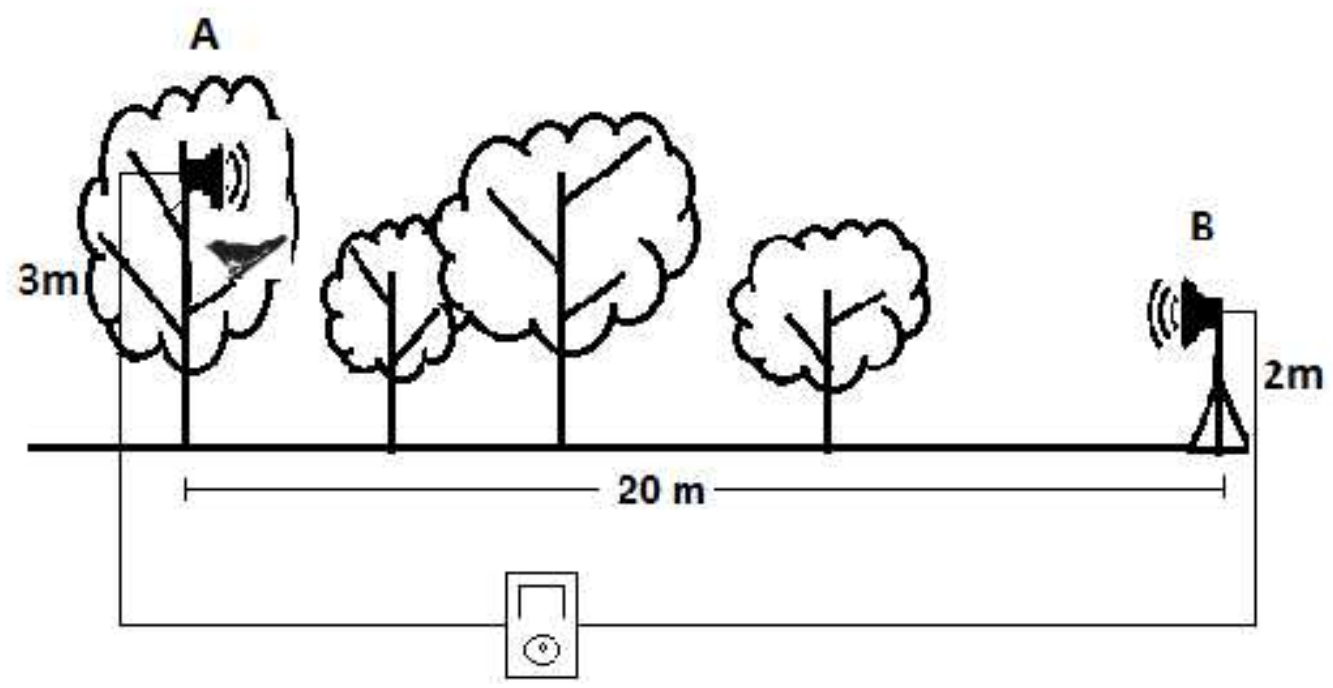

Figure 5.4. The experimental setup and speaker positions used in the forest at Zealandia.

After each stimulus, the unmodified song from speaker A was broadcast to bring the bird to the same starting position. We repeated these procedures until all the modified songs had been played, allowing 10-15 min between playbacks and randomising the order in which each stimulus was played for different birds to eliminate any chance of the targets acquiring more location cues about the source of the sound. Thirteen birds were tested at 13 sites each at least $400 \mathrm{~m}$ apart to provide a substantial degree of vocal isolation between experiments (Fig. 5.2). We tested three birds each day, subjecting them to experiment 1 only, after all birds were tested, we subjected birds to experiment 2, allowing at least four days between the two experiments.

In experiment 1 , each subject received six playbacks of the three chatter song types, (ALH, AHH and control), presented in random order (two replicates). Two responses were measured: (1) time (s) to the first vocal response (counter-singing the stimulus) measured from the moment of the start of the stimulus, and (2) counter-song duration (s) in response to the stimulus. In experiment 2 each 


\section{Chapter 5}

subject $(N=12)$ received five playbacks of songs with muted harmonics (F0, $\mathrm{H} 1$, $\mathrm{H} 2, \mathrm{HH}$ and control) presented in random order. Five responses were measured:

(1) vocal response to the stimulus (yes, no), (2) time of the first vocal response (s),

(3) time until first flight (movement) towards the speaker (s), (4), distance (m) of the bird after $30 \mathrm{~s}$, and (5) the closest distance $(\mathrm{m})$ to speaker B within $2 \mathrm{~min}$, measured from speaker $\mathrm{A}$. A Marked $20 \mathrm{~m}$ rope was used to measure the approach distance of the bird.

The effect of modified song types on the measured bird response was examined using a General Linear Model (GLM) followed by Tukey honestly significant difference (HSD) to identify significant differences between responses to each stimulus. SPSS 18 was used in all statistical tests. In both experiments, the measured responses were the dependent variables, the stimulus and the order they were played were the fixed factors. Bird identity was entered as a random factor to take into account repeated measurements on individuals and intraindividual variance (Little et al. 1991). All values reported in the results are means $\pm S E$.

\subsection{Results}

Experiment 1: the response to modifications in harmonics intensity

Most birds (12/13) responded to the three song types, only one showing no interest in the playback. The response of all 12 birds was swift and aggressive, all counter-singing to the stimulus and then approaching the speaker. The order in which the stimulus was played did not have an effect on the first vocal response ( $F$ $2,11=1.29, P=0.28)$ nor on counter song duration $\left(F_{2,10}=0.83, P=0.44\right)$.

Saddlebacks responded to the (control) playback by counter-singing soon after the 
stimulus had ended (mean $\pm S E, 5.7 \pm 0.3 \mathrm{~s}, N=12$ ), with a counter-song duration (mean $\pm S E, 5.1 \pm 0.3 \mathrm{~s} N=12$ ), about equal to the stimulus duration of $5 \mathrm{~s}$. Birds took longer time to counter-sing the ALH playback (mean \pm SE, $9.0 \pm 1.1 \mathrm{~s}, N=12$ ) and the counter-song duration was shorter (mean $\pm S E, 4.6 \pm 0.2 \mathrm{~s}, N=12$ ) (Fig. $5.5)$.

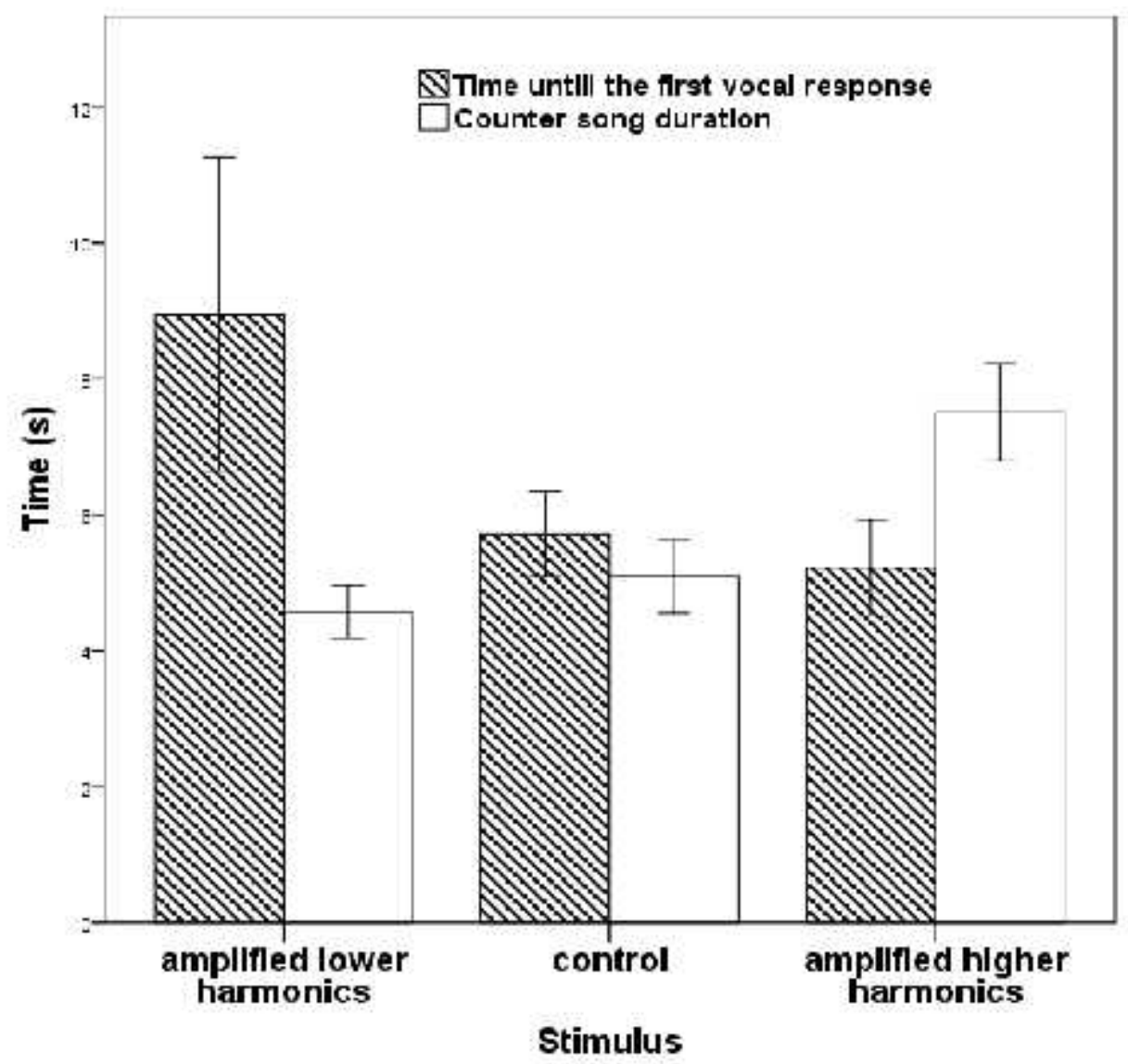

Figure 5.5. Time until the first vocal response, and counter-song duration for all 12 saddlebacks tested in experiment 1. Error bars indicate 95\% standard errors.

There were significant differences in the response time $\left(F_{2,11}=19.9, P=0.03\right)$ and counter song duration $\left(F_{2,10}=32.7, P<0.01\right)$ between stimulus types (Fig. 5.5). Birds responded significantly faster to the $\mathrm{AHH}$ playback compared to the ALH playback (Tukey, $P<0.01$ ), but not to the control (Tukey, $P=0.72$ ). Two birds counter-sang to the ALH playback 17-21 s after the end of the stimulus. 


\section{Chapter 5}

Removing these two extreme responses from the analysis did not affect the significance of the result $\left(F_{2,9}=11.85, P<0.01\right)$ and birds responded faster to $\mathrm{AHH}$ than $\mathrm{ALH}$ (Tukey, $P<0.01)$. Counter-song duration in response to the $\mathrm{AHH}$ playback was significantly longer than to the ALH playback (Tukey, $P<0.01$ ) and to the control playback (Tukey, $P<0.01$ ) (Fig. 5.5).

Experiment 2: the response to muted harmonics

Most birds (12/13) counter-sang to the unmodified control chatter song, while only four, six, one, and three responded to songs with muted $\mathrm{F} 0, \mathrm{H} 1, \mathrm{H} 2$ and $\mathrm{HH}$ playbacks respectively. Change in harmonic composition of the song by muting selected harmonics therefore caused a change in the vocal response of Saddlebacks, with significant differences between song types and whether or not Saddleback would counter sing the stimulus $\left(F_{4,11}=6.4, P<0.01\right)$. All song playback types captured the attention of the targeted birds and stimulated them to approach the speaker. The control stimulated the bird to counter sing after the stimulus ended and then to fly towards speaker B within 5-10 s (Fig. 5.6). The mean time of the first flight differed significantly with changing the stimulus, $\left(F_{4,11}\right.$ $=9.2, P<0.01)$. Multiple comparisons revealed that $\mathrm{F} 0, \mathrm{H} 1$ and $\mathrm{HH}$ playbacks stimulated the bird to search for the source of the sound faster than $\mathrm{H} 2$ and the control playbacks (Tukey, $P<0.05$ ). Nevertheless, there was no significant difference between the response to $\mathrm{F} 0, \mathrm{H} 1$ or $\mathrm{H} 2$ and control playbacks (Tukey, $P$ $>0.05)$. 


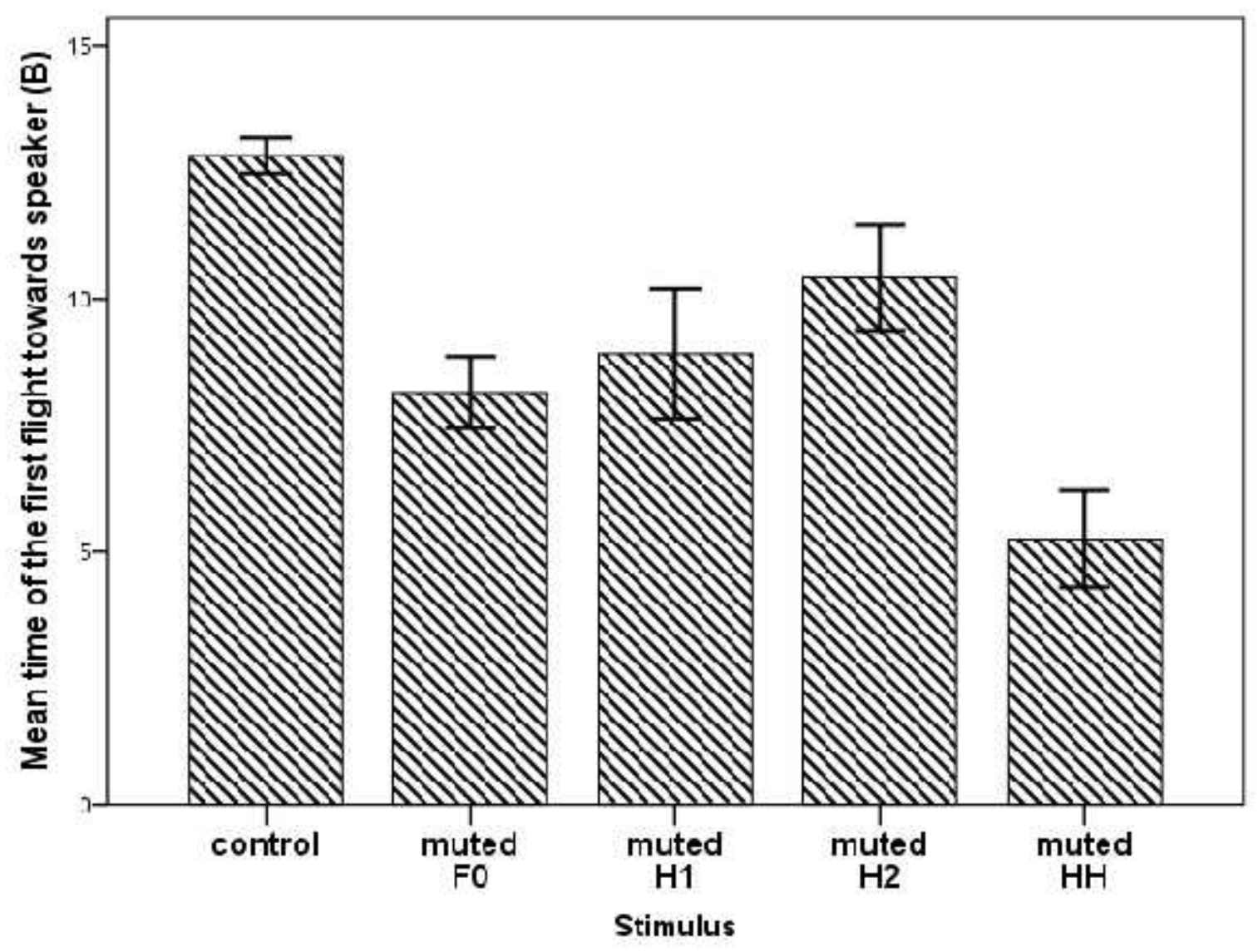

Figure 5.6. Mean times to the first flight towards the speaker in response to playback song types in experiment 2 (control and muted $\mathrm{F} 0, \mathrm{H} 1, \mathrm{H} 2, \mathrm{HH}$ song). Error bars indicate $95 \%$ standard errors.

All the birds moved towards speaker B (Fig. 5.7) after stimuli were played. The mean distances at $30 \mathrm{~s}$ differed with change of stimulus $\left(F_{4,11}=54.8, P<0.01\right)$. Distances after two minutes were also significantly different $\left(F_{4,11}=100.36, P<\right.$ 0.01). Subjects moved significantly faster towards the speaker (expressed by the distance at $30 \mathrm{~s}$ ) when presented with the control and $\mathrm{H} 2$ songs compared with the other playback song types (Tukey, $P<0.05$ ). $\mathrm{H} 1$ and $\mathrm{HH}$ responses were significantly slower than $\mathrm{F} 0, \mathrm{H} 2$, and control playbacks (Tukey, $P<0.05$ ). There was no significant difference between the response to $\mathrm{F} 0$ and $\mathrm{H} 1$ playbacks (Tukey, $P=0.15)$. 


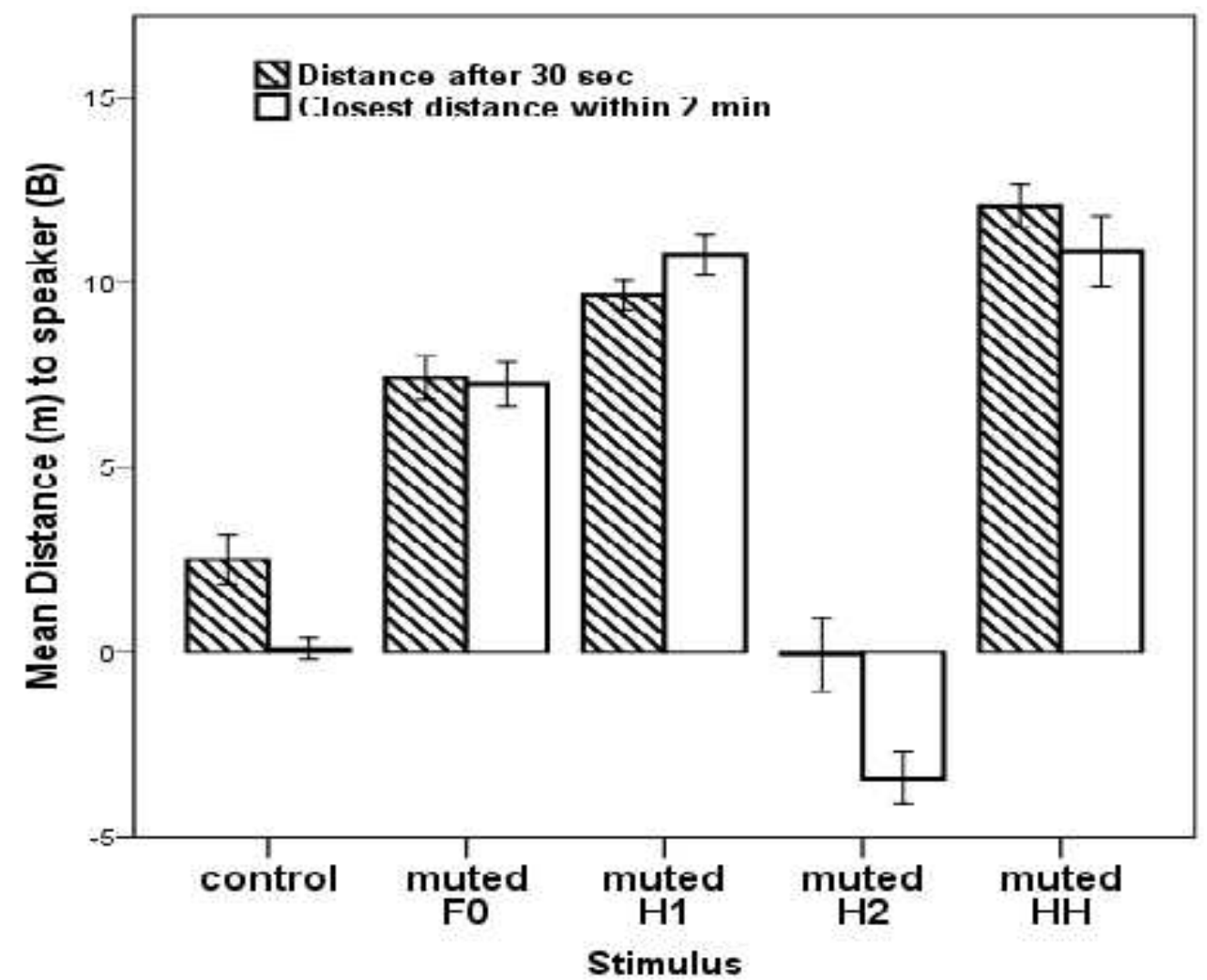

Figure 5.7. Distance of target saddleback after $30 \mathrm{~s}$ and closest distance to speaker B within 2 min. in relation to different playback song types in experiment 2 (control and muted F0, $\mathrm{H} 1 \mathrm{H} 2 \mathrm{HH}$ song). Error bars indicate $95 \%$ standard errors.

The 12 Saddlebacks were able to locate the speaker (indicated by the final distance from the speaker within 2 min) when presented with the control chatter song type, approaching within a mean $( \pm S E)$ of $0.1( \pm 0.3) \mathrm{m}$ of the speaker $\mathrm{B}$. Subjects over flew the speaker when presented with the $\mathrm{H} 2$ song type and were within a mean $( \pm S E)$ of $3.4( \pm 0.7) \mathrm{m}$ from speaker $\mathrm{B}$, significantly different from the control song type (Tukey, $P<0.05$ ). The distance birds approached the speaker in response to the F0 song type (mean \pm SE, $7.3 \pm 0.6 \mathrm{~m}$ ) was significantly less than the control and $\mathrm{H} 2$, but higher than $\mathrm{H} 1$ and $\mathrm{HH}$ (Tukey, $P<0.05$ ). Subjects stayed within similar distance (Tukey, $P=1.00$ ) in response to the $\mathrm{H} 1$ and $\mathrm{HH}$ playbacks 


\section{Chapter 5}

(means $\pm S E=9.3 \pm 0.5 \mathrm{~m}$ and $9.2 \pm 1.0 \mathrm{~m}$ respectively), significantly different from F0, H2 and control playbacks (Tukey, $P<0.05$ ).

\subsection{Discussion}

We found from experiment 1 that Saddlebacks exhibited stronger response towards chatter songs with more relative energy in the higher harmonics than towards chatter songs with more energy in the lower harmonics. The former can be interpreted as coming from a closer mate or rival and thus leading to an increased response, as demonstrated by the shorter time to call back and the longer counter-song duration. The Saddleback presumably modified its response according to its perception of the proximity of the sound source in a cost effective way, by reducing the counter song duration in response to songs that appeared to be further away, or by increasing its response to songs that appeared closer.

Songs used in the playback experiments were broadcast from the same distance and with similar overall amplitude, allowing similar amounts of reverberation and amplitude fluctuation to occur, so it seems less likely that the Saddleback would obtain distance cues from these factors, as found in previous studies showing birds use frequency as a cue for distance (Naguib 1995, 1997a; Naguib \& Wiley 2001). Our results suggest that the Saddleback is less sensitive to a change in relative harmonic amplitudes than to a change in harmonic composition. All individuals responded vocally to signal playback in experiment 1 , but their response varied significantly in response to muting any of the harmonics.

Saddlebacks were able to differentiate clearly between different harmonics in their chatter song. There was variation between vocal responses of individuals, however, although all muted playbacks prompted the bird to look for the speaker. 


\section{Chapter 5}

The Budgerigar and Zebra Finch can both detect mistuned harmonics, and with greater acuity than humans, indicating that harmonics can have an important role in communication, and might potentially encode significant information about the signaller (Lohr \& Dooling 1998). Further, harmonics may be used as vocal signatures for individual discrimination, while they can also reveal such information as caller age (Fitch \& Kelley 2000), sex or reproductive maturity (Marion 1977; Fitch 1999) and size, as proposed by the size exaggeration hypothesis (Fitch 1999).

We have not addressed the specific role of each harmonic in the perception of the song, but have rather focussed on the role of harmonics in ranging. An unexpected result was that chatter songs with muted $\mathrm{H} 2$ (maximum frequency) stimulated Saddlebacks to a faster flight towards the speaker, although the birds failed to vocally respond and were unable to locate the speaker. This suggests that $\mathrm{H} 2$ had little use in ranging, but might contain information about bird identity that stimulated the bird to look for the source of the sound. The birds were unable to locate the speaker with muted $\mathrm{F} 0, \mathrm{H} 1$ and $\mathrm{H} 2$ playbacks. We found no significant difference in the final distance to speaker B across these muted song playbacks, so the complete set of harmonics might be necessary to localise the source of the sound. Considering the high energy in the second harmonic $\left(\mathrm{H}_{2}\right)$ compared with any of the $\mathrm{F} 0, \mathrm{H} 1$ and $\mathrm{HH}$ options, the Saddleback appears to use amplitude as a relative cue of distance, but not as an absolute cue for ranging, since the final distance towards the speaker was significantly lower for $\mathrm{H} 2$ than for any of $\mathrm{FO}, \mathrm{H}$, and $\mathrm{HH}$ song playback types.

Factors that may influence frequency patterns in bird song include bill gape and vocal track filtering. Some birds are able to produce higher frequencies when 


\section{Chapter 5}

increasing the bill gape during song production; this was shown in studies on White-throated Sparrow, Zonotrichia albicollis, Swamp Sparrow, Melospiza georgiana (Westneat et al. 1993), and the Song Sparrow, Melospiza melodia, (Podos et al. 1995). In Zebra Finches, the fundamental and maximum frequencies were highly correlated with bill gape, however this had little effect on harmonic composition (Goller et al. 2004). Tracheal length can also affect song frequency, Fitch (1999) proposing that tracheal elongation lowers the frequencies of harmonics but has little effect on the fundamental frequency. Some passerine species, such as the Trumpet Bird, Phonygammus keraudrenii, exhibit elongated tracheae which are assumed to lower the pitch of the vocalisations (Clench 1978). Modification of harmonic structure might have biological implication, for example adaptation to the changing in transmission properties of the habitat with different season (Naguib 1996), or exaggerating the bird's apparent size (Fitch 1999; Fitch \& Hauser 2003). The effect of bill gape and tracheal elongation on harmonics in Saddleback song are not studied and worth further investigation.

My experiments on the Saddleback support previous studies about the role of relative frequency attenuation in ranging (Naguib 1995), highlighting the importance of harmonics as distance cues in Saddleback chatter song, the birds differentiating between songs with different harmonic composition and responding to them accordingly. More detailed acoustic experiments and analysis, facilitated by developing acoustical software packages, are needed to further explore the role of each harmonic in Saddleback communication, such as their importance as individuality cues, fitness indicators, and in individual location within the territory. Further investigations could also extend to the more complex and varied male rhythmical songs, where distance cues are again likely to be of importance (Jenkins 1978, Parker et al. 2010).. 


\section{Chapter 6}

Song thrush repertoires in Zealandia: have they diverged from their counterparts in Europe?

\subsection{Abstract}

Following the introduction of birds to a novel environment, to what extent their songs have changed? I investigate this question in a New Zealand population of the song thrush, Turdus philomelos, first introduced to the country in 1862 from the United Kingdom (UK). Songs from eight individuals from our study site at the Zealandia sanctuary in Wellington were compared with those from eight individuals in the UK. Syllables within each song sample were visually identified and coded and their physical characteristics measured. Song diversity was measured between the two populations using univariate analysis, while physical measurements of the song syllables were compared using multivariate analysis. The repertoire sizes of the Song Thrushes sampled in NZ were larger and more varied than those recorded in the UK, with more syllables delivered with less repetition. In addition, there were more syllables unique to NZ birds than there were syllables unique to UK birds. Possible reasons for these differences are discussed. 


\subsection{Introduction}

Variations in song and different dialects within a bird species have been described across a range of different geographic scales (Mundinger 1982; Lynch 1996; Slabbekoorn \& Smith 2002a). Micro-geographical variation is related to neighbouring groups of birds which potentially interact with each other, while macro-geographic variations arise in isolated populations or in individual birds that remain within the same area (Leader et al. 2000). Changes in dialects between areas can be sharp, with sudden switches from one song type to another e.g. saddleback (Jenkins 1978) white-crowned sparrow, Zonotrichia leucophrys (Baptista 1975) corn bunting, Emberiza calandra (McGregor 1980), or they may be more gradual, where shared song dialects may occur in the contact zones e.g. orange-tufted sunbird, Nectarinia bouvieri (Leader et al. 2000).

Explanations given to explain song variation are varied, including the suggestion that new dialect patterns emerge in response to habitat selection pressure for optimal transmission through the acoustic environment (Hunter \& Krebs 1979; Handford \& Lougheed 1991; Doutrelant et al. 1999; Slabbekoorn \& Smith 2002b; Patten et al. 2004). Non-adaptive cultural founder effects can result in loss of syllables following colonisation (Baker \& Jenkins 1987; Baker et al. 2006), resulting from the small set of the total pool of song elements carried by the founding individuals to the new population (Baker \& Jenkins 1987; Catchpole \& Slater 2008). Social behaviour and interactions between neighbouring males can prompt new dialect formation (Rothstein \& Fleischer 1987; Payne et al. 1988; Bell et al. 1998), as do changes in the overall intensity of sexual selection, male competition, and female choice (Catchpole 1980; Badyaev et al. 2002). Song dialects can be powerful mechanisms for reproductive isolation and potentially 
lead to speciation due to the importance of songs as mating signals, and to female choice (Grant \& Grant 1997; Slabbekoorn \& Smith 2002a; Podos \& Nowicki 2004). Imitation affects culturally transmitted song traits from one generation to the next (Slater 1986; Lynch 1996; Payne et al. 1998). Errors in copying may account for vocal novelties arising in a population over time, with new songs evolving in subsequent generations because of selection drift for new song syllables (Marler \& Tamura 1964; Lemon 1975; Baptista 1977; Marler \& Peters 1987, 1988; Slater 1989).

New behavioural patterns arise through interaction between innate and learned characteristics (Marler 2004a). Song features can be encoded innately as demonstrated by a study on isolated or deafened song sparrows, Melospiza melodia, which produced songs with sets of complex syntax of several parts, whereas similarly deprived swamp sparrows, Melospiza georgiana, typically produced continuous trills (Marler \& Sherman 1985). Isolated white-crowned sparrows, Zonotrichia leucophrys, reared in captivity without the presence of an adult song model developed atypical song with degraded acoustic structure. When presented with different vocal models, during their sensitive phase of song development, however, they showed precise copying, even when training models had been recorded from non-natal localities (Marler \& Tamura 1964; Baptista 1977; Slater 1989). Such experiments, at least in some species, may explain the origin of new learned vocalisations. Learning to vocalise through imitative vocal learning enables the generation and rapid transmission of novel patterns of vocal structure (Slater 1989; Slabbekoorn \& Smith 2002a).

Song variations among bird species with small repertoire sizes (1-4 song types per male) are well documented (Catchpole \& Slater 2008). However, variation in 
songs with large repertoires are harder to detect, and different song dialects areas can be defined by differences in the structure of complex syllables, for example the white-crowned sparrow, Zonotrichia leucophrys (Mundinger 1982; Nelson 1999), the ortolan bunting, Emberiza hortulana (Osiejuk et al. 2003), and the black-capped chickadee, Poecile atricapillus (Kroodsma 1999). Different dialects of large repertoires might only be detectable when analysis focuses on the distribution of basic units of which songs are composed, such as syllables (Kroodsma \& Pickert 1980).

Birds introduced to novel environments are likely to experience different selection pressures, both physical and/or biotic, compared with their source population, and this may affect the evolution of novel traits (Endler 1992). Changes within species over evolutionary time are difficult to study because of their slow pace, so a comparative approach on how the songs of different species might have diverged from their common ancestor is a more productive (Catchpole \& Slater 2008). Colonisation of birds into new environments provides such an opportunity (Westcott \& Kroon 2002).

This chapter examines songs of the song thrush, first introduced to New Zealand (NZ) in the South Island in 1862 when the Nelson Acclimatisation Society imported and released five birds, with later releases elsewhere that year (24 birds) in different parts of NZ, followed by 30 in the Auckland region in 1868, with a further 95 later that year, then eight in the Wellington region in 1878. By 1930, the song thrush had established itself widely throughout NZ (Lever 1987).

The NZ environment is strikingly different to that of the song thrush's native European breeding range. High average rainfall, yet abundant and intense sunshine typically occur in NZ evergreen forest (Allan 1937). Less exposure to 
extreme weather, particularly cold winters, the abundance of higher quality resources, and some relief from natural predators enhance the niche opportunities for introduced birds in NZ (MacLeod et al. 2009). In the UK the song thrush population has suffered a substantial decline during the last three decades, this leading to it being categorised as a species of high national conservation concern (Robinson et al. 2004). In contrast, the NZ song thrush population appears comparatively stable (Robertson et al. 2007). Given these environmental differences between Europe and NZ, and the different bird communities in the two regions, the repertoires of the song thrush, and indeed of other introduced NZ passerines are worthy of further investigation. This study therefore compares the song of the introduced Song Thrush in Zealandia, NZ, with those of the same species in the UK, providing a measure of the extent of song differentiation that may have occurred between the two populations.

This study compares the song of the introduced song thrush in Zealandia, NZ, with their ancestral stock in the UK to provide a measure of the magnitude of song differentiation between the two populations, following an earlier investigation in Wellington including Zealandia site (Garland et al. 2004).

\subsection{Methods}

\subsubsection{Study population and song recording}

Territorial songs of male NZ song thrushes were recorded within Zealandia, a 250 ha patch of coastal broadleaf-conifer forest surrounded by a mammal-proof fence within the city limits of Wellington (Campbell \& Atkinson 2002) over July September 2009, coinciding with the early stage of egg laying from May February (Heather \& Robertson 2000). The forest vegetation is dominated by mähoe, Melicytus ramiflorus, five finger, Pseudopanax arboreus, tree ferns, 


\section{Chapter 6}

Cyathea spp., and pate, Schefflera digitata (Dawson 1988b; Wardle 2002).

Territorial songs of UK birds were recorded by Ben Bell over 1997 -1998 in June, which is somewhat later in the breeding season there (Mason 1998). Songs were sampled from five locations in England (Fig. 6.1 \& 6.2), in woodland edge or rural hedgerow habitats.

A Marantz PMD670 solid-state recorder was used to record Song Thrush songs in NZ, while in the UK,DAT recordings were made on a Sony TCD-D10 Pro II DAT. All songs were recorded at a frequency of $44.1 \mathrm{KHz}$ and 16 -bit sample size using a Telinga parabolic microphone.

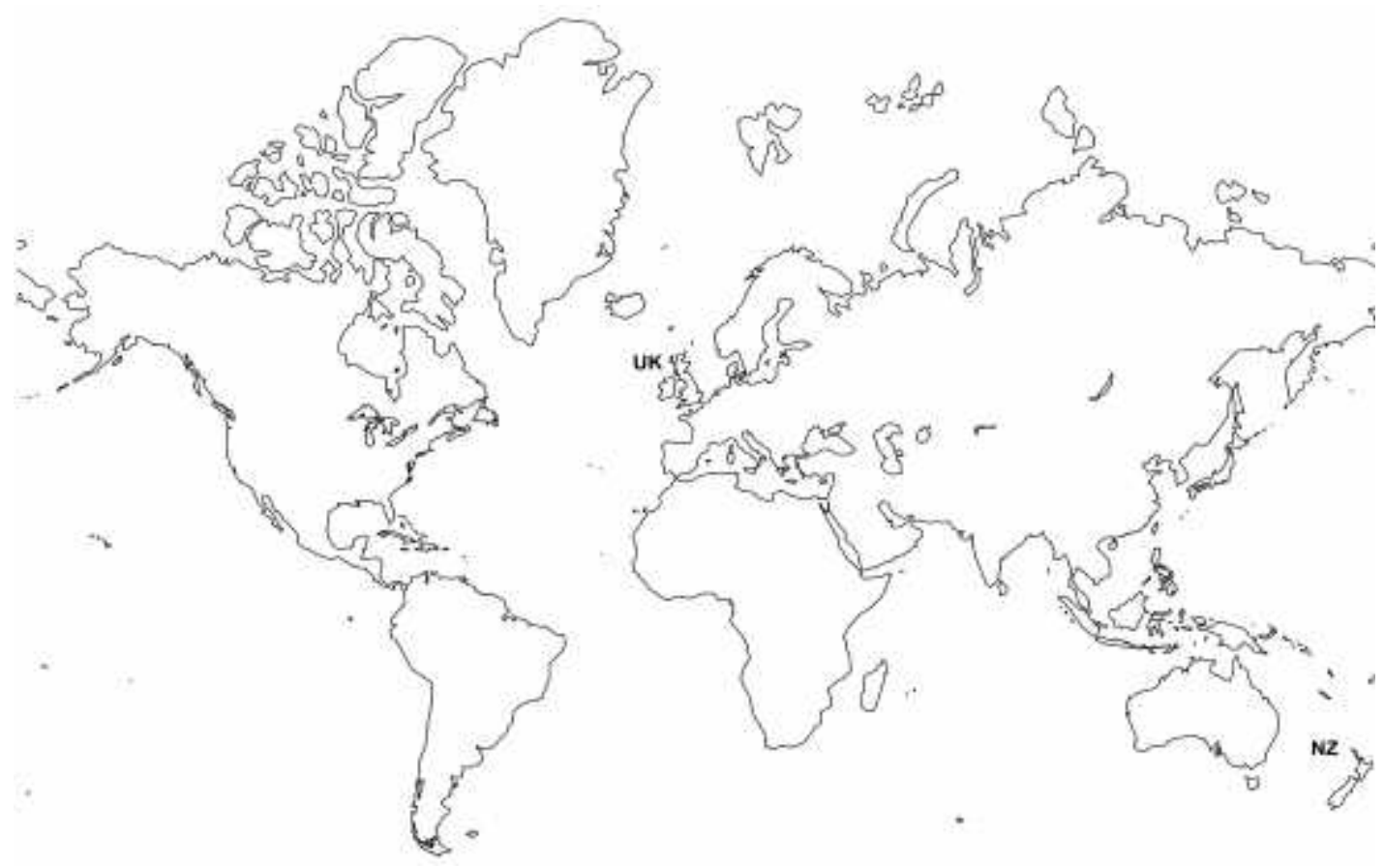

Figure 6.1. World map to illustrate the distances between the locations in the United Kingdom (UK) and New Zealand (NZ). 

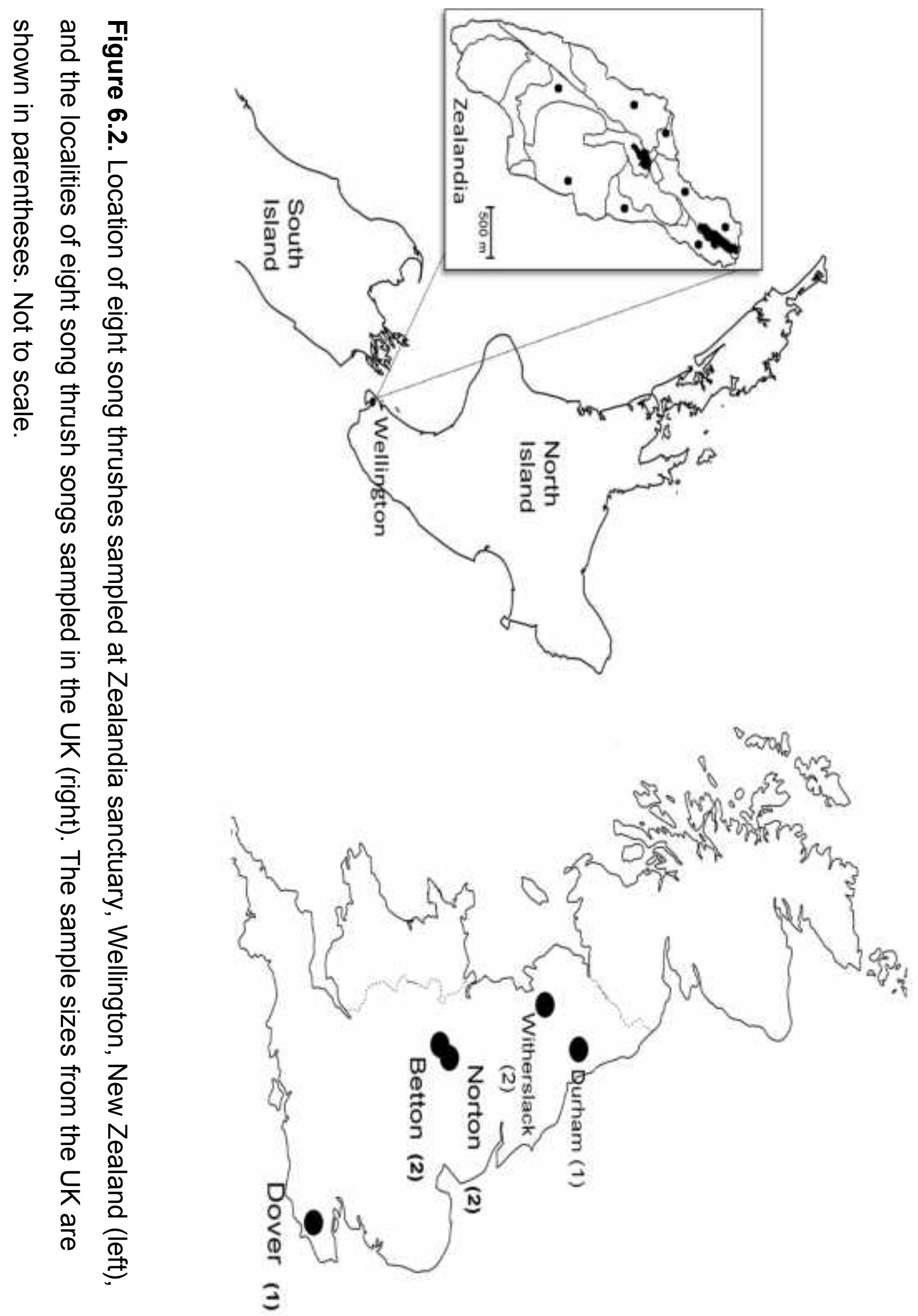


\subsubsection{Sound analysis}

For each individual, spectrograms were generated using Raven Pro 1.4 software, with a Hann-filter and a Fast Fourier Transform (FFT) value of 512 points. Overlap was set to $50 \%$ giving a frequency resolution of $86.1 \mathrm{~Hz}$. Because different individuals had different pause times between syllables, 80 successive syllables were sampled from each individual. Syllables within each song sample were visually identified and coded to produce a pool of observed syllable types (Fig. 6.3). Syllables were further categorised according to whether they occurred in both UK and NZ populations (shared syllables), or if they were specific to either the UK or NZ population (country specific). The diversity of the song was calculated using the following formula: song diversity $=$ (repetition of shared syllables /number of shared syllables) + (repetition of unique syllables/number of unique syllables). The number of shared and unique syllables were normally distributed (KolmogorovSmirnov: $P>0.05, n=8$ ), and variances between groups were not unequal (Levene's Test for Equality of Variances for all three variables: all $P>0.05$ ). Independent sample t-tests were used to compare the results. SPSS 18 was used for statistical analysis.

The physical characteristics of each syllable that were measured were: (1) Minimum frequency $(\mathrm{KHz}),(2)$ Maximum frequency $(\mathrm{KHz})$, frequency with maximum energy, (3) Syllable bandwidth (KHz), and (4) Syllable duration (s). Principal components analysis (PCA) was used to summarise the patterns of correlation among measured song variables. General Linear Model (GLM) followed by Tukey honestly significant difference (HSD) was used to compare the mean factor loading of the three syllable categories (shared syllables, UK specific, or NZ specific) on the extracted principle component (PC). The factor loadings were the dependent variables, syllable categories were the fixed factors. 


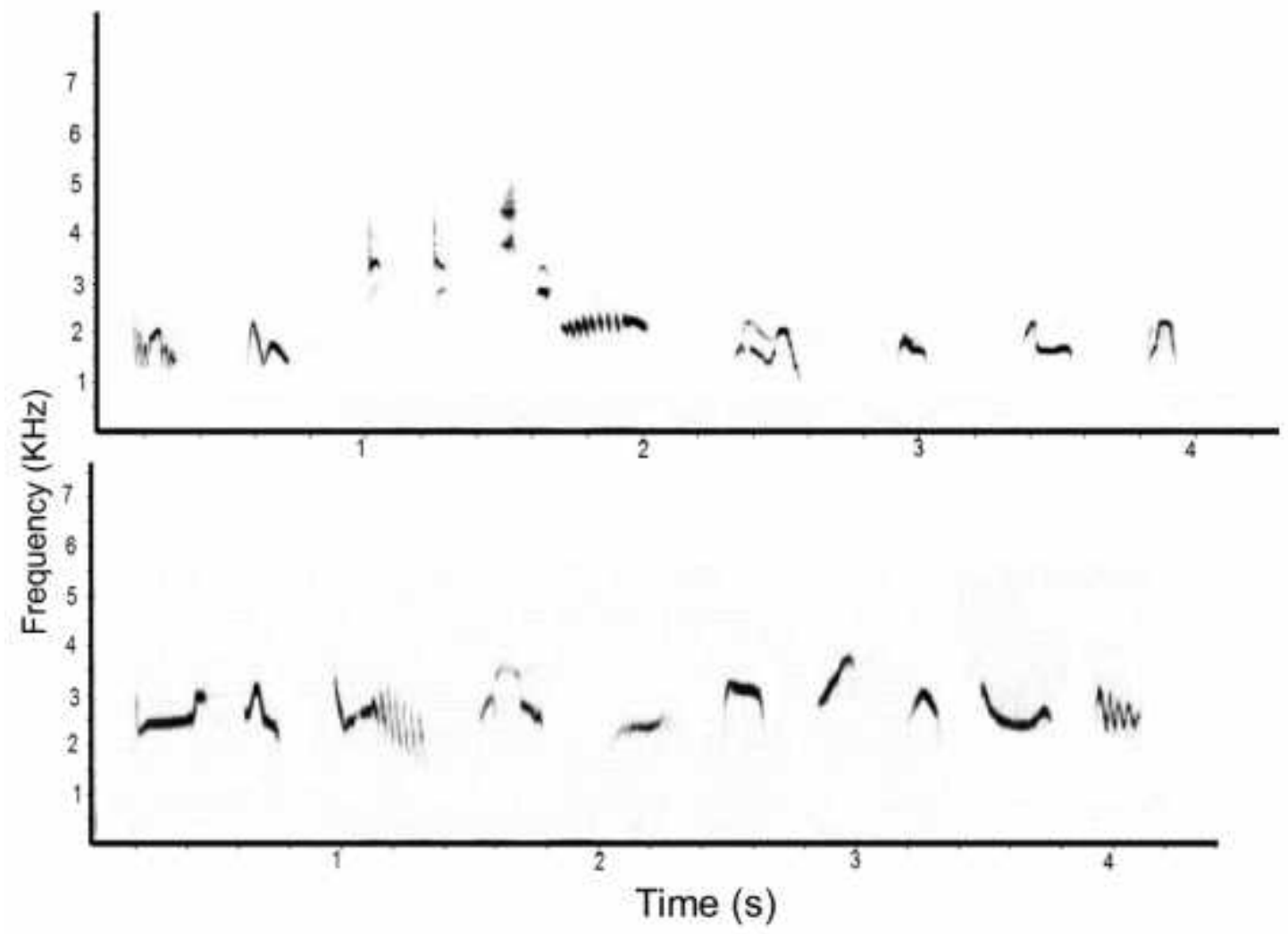

Figure 6.3. Composite sonograms illustrating a sample (only) of different syllables used by the two song thrush populations, NZ birds (upper) birds and UK birds (lower).

Bird identity was entered as a random factor to take into account repeated measurements on individuals and intra-individual variance (Littel et al. 1991). An independent sample t-test was used to compare the factor loading of the two populations on the extracted PC.

\subsection{Results}

The Song thrush tended to repeat the same syllable a few times before switching to another syllable type. The total number of different syllables recorded was 242 , recorded across the 16 individuals, eight from each population. Thirty (12.4\%) syllables were shared between the two populations sampled, but 143 (59.1\%) 
syllables were unique to NZ birds, and 69 (28.5\%) syllables were unique to UK birds. NZ birds included more syllable types in their repertoires than UK birds.

The mean number of "shared syllables" used by individuals of the two populations was not significantly different (t-test: $t_{14}=-0.72, P=0.48$; means $( \pm S E) 6.1( \pm 0.64)$ and $6.7( \pm 0.59)$ for the UK and NZ birds respectively). However, NZ birds had significantly more unique syllables within their population (t-test: $\mathrm{t}_{14}=-3.7, P<$ 0.01; means ( \pm SE) for NZ birds $24( \pm 3.2)$ and for UK $10.5( \pm 1.8)$ ) (Fig. 6.4).

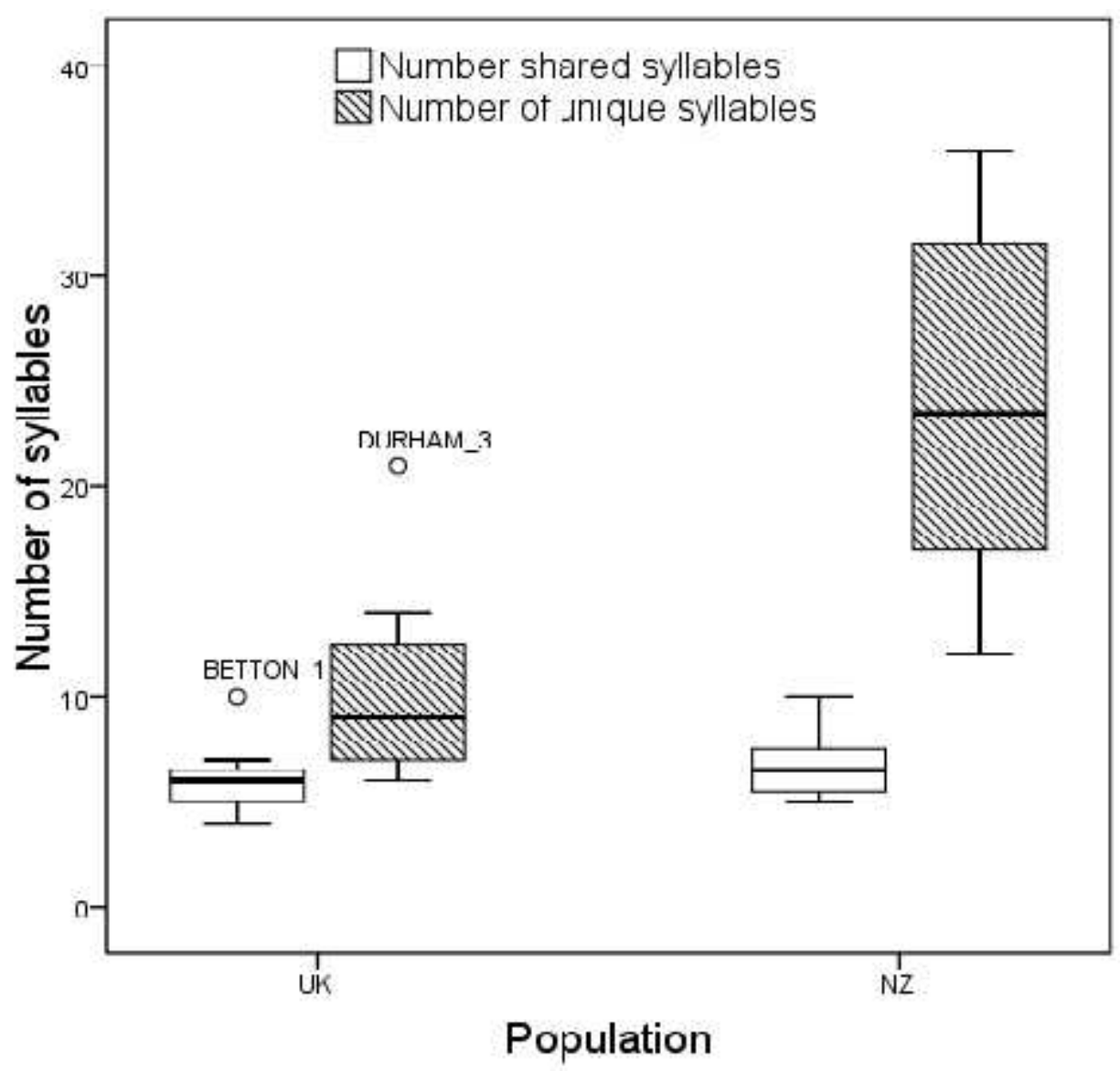

Figure 6.4. Box plot showing the variation in number of shared and unique song thrush syllables between NZ and the UK. The two points on the graph represent name of the locality from where bird were sampled.

\subsubsection{Song comparison}


The NZ song thrushes had a faster mean delivery rate of syllables (mean $=38.3$, $\mathrm{SE}= \pm 4$ syllable/min), than the UK birds (mean $=22.2, \mathrm{SE}= \pm 1.6 \mathrm{syllable} / \mathrm{min}),(\mathrm{t}-$ test: $\left.\mathrm{t}_{14}=-4.05 P<0.01\right)$. The minimum song duration analysed was $1.5 \mathrm{~min}$ for a $\mathrm{NZ}$ bird and the maximum was $4.5 \mathrm{~min}$ for a UK bird. This marked variation in delivery rate was due to larger inter syllable intervals in UK birds. Diversity of song was significantly higher for the NZ song thrush; (t-test: $\mathrm{t}_{14}=-3.5, P<0.01$ ). While the two populations had an equal number of shared syllables, NZ birds had more unique syllables with less repetition (Fig. 6.5).

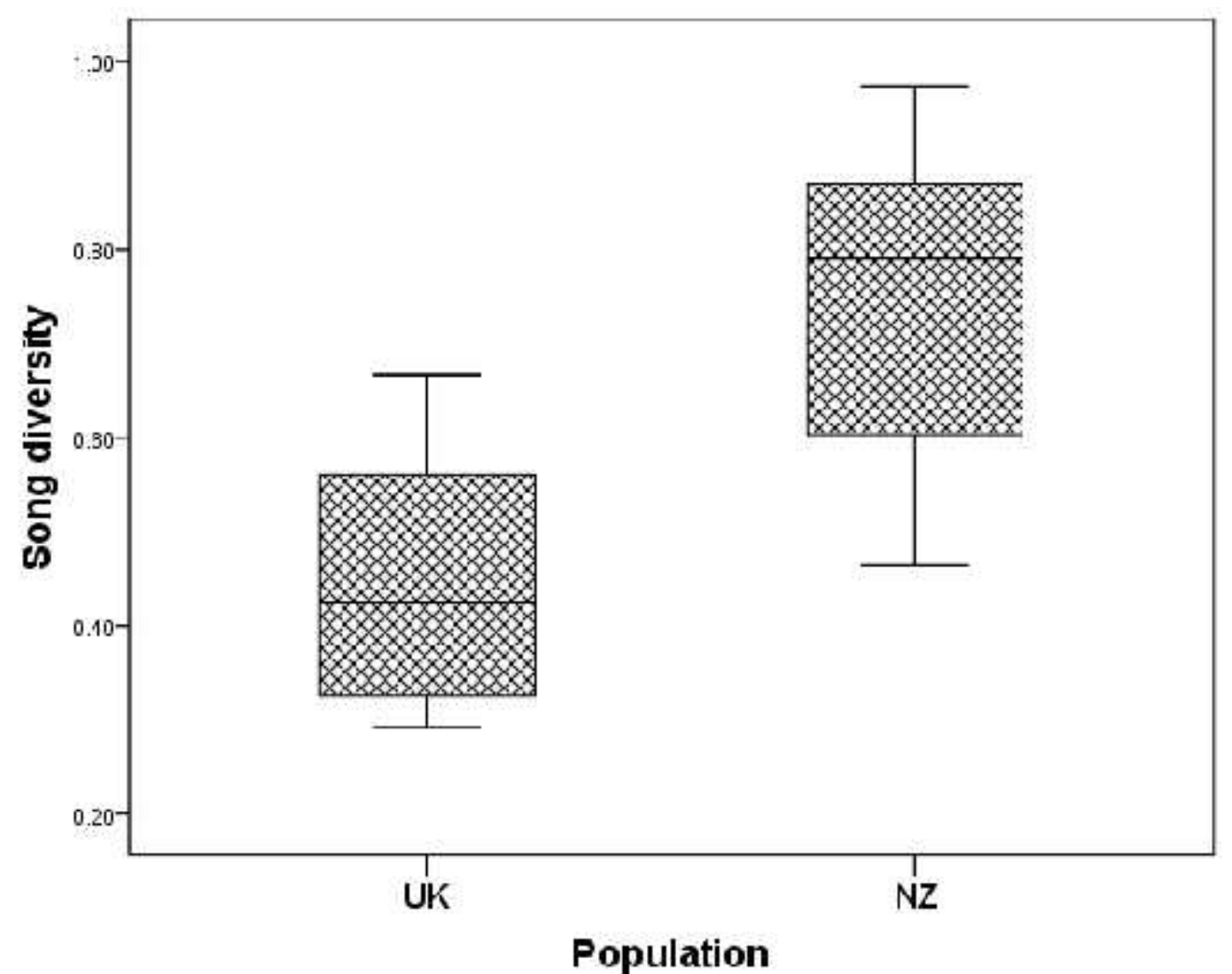

Figure 6.5. Box plot showing the diversity of song in each population. Diversity was measured by adding the ratios of shared and unique syllables.

Principal components analysis (PCA) was used to summarise the patterns of correlation among the four measured song variables, and to produce a reduced number of new variables (factors) that described independent elements of 
variation in the song. This yielded two factors with eigenvalues greater than 1.0, which accounted for $75 \%$ of the total variation within the 1280 syllables measured, comprising 16 different songs (Fig. 6.6). The first principal component (PC 1) represented the major source of variation (48\%) among syllables in this sample, having a high positive correlation with lower frequency and maximum frequency (shown in bold numbers in Table 6.1). Thus, variation in PC 1 was primarily associated with variation in frequency measurements. The second principal component (PC 2) accounted for $28 \%$ of the variance among syllables, and was positively correlated with a higher bandwidth and longer syllables (Table 6.1).

Table 6.1. Results of principal components analysis of the physical characteristics of syllables.

\begin{tabular}{lcc}
\hline Variables & PC 1 & PC 2 \\
\hline Eigenvalue & 1.9 & 1.1 \\
Percent & 48 & 28 \\
Cuml. percent & 48 & 76 \\
\hline Lower frequency & .89 & -.14 \\
Maximum frequency & .93 & .26 \\
Syllable duration & -.16 &. $\mathbf{7 7}$ \\
Band width & .36 &. $\mathbf{7 2}$ \\
\hline
\end{tabular}

To examine variation between the two populations, I grouped the factor loading of syllables in two categories, first based on individuals that produce them, and second on the classification of syllables as being either unique to any of the populations or shared among them (Figs. $6.6 \& 6.7$ ). 


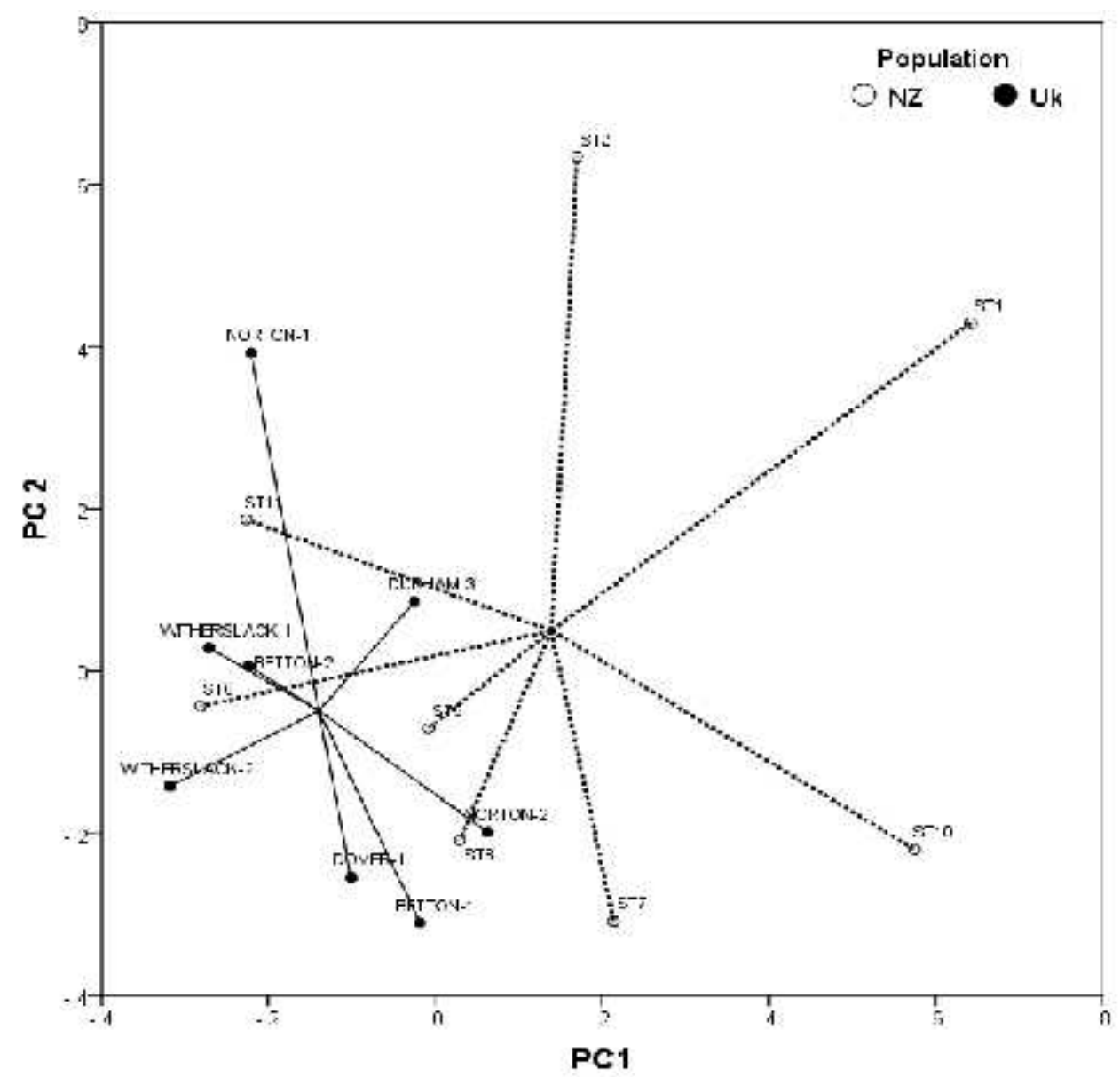

Figure 6.6. Scatter plot of factor 1 versus factor 2 obtained in the principal component analysis (PCA) for syllable measurements grouped according to individuals.

There was a significant difference in the mean score of the two populations on PC 1 , suggesting that the NZ song thrush has a higher value for both the maximum and lower frequencies (t-test: $\mathrm{t}_{14}=2.16, P=0.048$ ). There was no statistical difference in the mean score of the two populations on PC 2 (t-test: $\mathrm{t}_{14}=0.69, P=$ $0.5)$.

GLM was used to test whether there was a significant difference on the loading of the three syllable categories on PC 1 and PC 2. The mean loading factor differed significantly on PC $1\left(F_{2,15}=6.64, P<0.01\right)$. Syllables used by the NZ birds had a higher mean loading on PC 1 than shared and UK syllables (Tukey, $P<0.05$ ). 


\section{Chapter 6}

However, there was no statistical difference between loading of UK and shared syllables on PC 1 (Tukey, $P>0.05$ ). The mean loading on PC 2 also differed significantly within note categories $\left(F_{2,15}=42.54, P<0.01\right)$. NZ syllables had a significantly higher mean loading than UK syllables and shared syllables (Tukey: $P$ $<0.05)$ (Fig. 6.7)

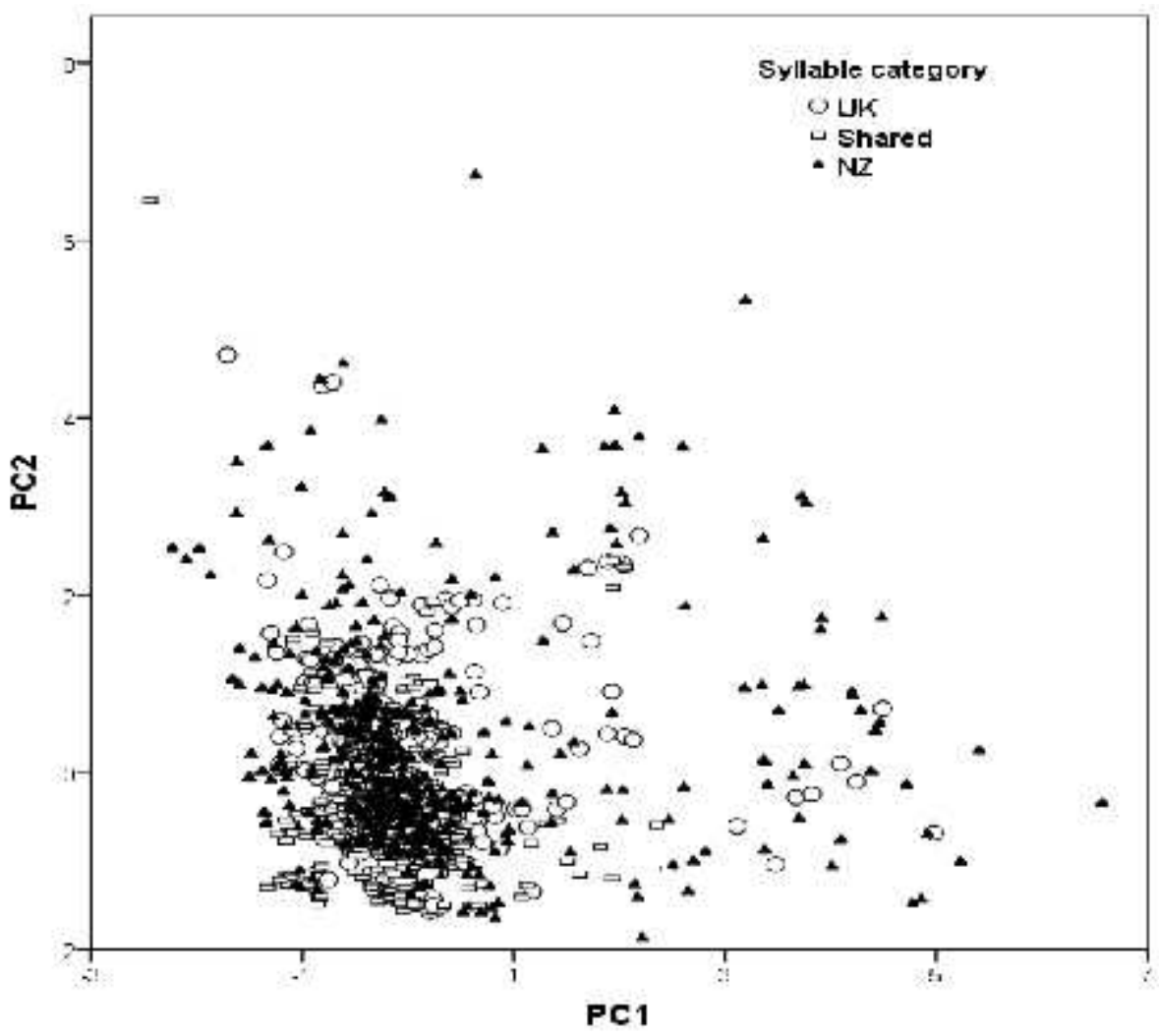

Figure 6.7. Scatterplot of syllable categories plotted against the extracted principle components. Syllables were categorised as shared among to the two populations, or unique to either the NZ or UK population.

\subsection{Discussion}

There was distinct geographical variation between the song samples of song thrushes in NZ and the UK. The NZ repertoires in Zealandia were larger and more varied with more syllables delivered per unit time and less repetition than in the UK populations sampled. This increase in song diversity in NZ is unlikely to be due to 
a founder effect or to selection at the genetic level, for these normally cause songs to become simpler (Baker \& Jenkins 1987). It seems more likely that the song thrush song has evolved through learning, new syllables being learnt from songs or sounds the birds hear in their local NZ environment, which they then incorporate into their repertoires. In Europe, the song thrush is known to mimic songs and calls of a wide variety of passerines and non-passerines, notably waders (Cramp \& Snow 1988).

The evolution of a larger and more diverse song repertoire in the NZ song thrush may have occurred under local ecological and social conditions in which competition for resources is relatively high. A recent study on breeding bird density estimates for birds introduced to NZ showed these to be on average 22 times higher than for the same species in comparable habitats in the UK (MacLeod et al. 2009). The NZ song thrushes sampled here came from the relatively small Zealandia sanctuary, with an avian community boosted by many successful reintroductions of endemic New Zealand species, such as, saddlebacks, bellbirds, robins, whiteheads and kakas (Miskelly et al. 2005; Taylor et al. 2005; Bell 2008), and potentially high bird species diversity and abundance, resulting in high competition between males and frequent interactions with other bird species.

NZ exhibits less extreme seasonality than the UK with a moderate climate and warmer winter. This results in longer avian breeding seasons compared with the UK, however NZ birds lay smaller clutches (Evans et al. 2005). This could imply that NZ song thrushes have to hold their territories for longer periods throughout the breeding season, so a higher level of singing may be required to defend and maintain territoriality during that longer season. In the UK population, the prolonged periods of very cold temperatures during the winter can reduce over- 
winter survival and lower breeding bird population sizes (Baillie 1990). Such extreme events are less intense or frequent in New Zealand, so introduced bird species may have higher over-winter survival, and consequently higher breeding densities than in their native range. Short lifespan, short breeding season, or high predation risks may also affect whether larger repertoires are favoured (Collins 2004)

The selective pressure on the song operates through sexual selection, either through female choice or male-male interaction (Catchpole \& Slater 2008). Studies on great tits and red-winged blackbirds in replacement experiments showed that territories held by males with larger repertoires were less likely to be intruded on by other males (Hunter \& Krebs 1979; Yasukawa 1981). Female choice is regarded as favouring elaborate or complex forms of vocal signals (Catchpole \& McGregor 1985; Searcy \& Yasukawa 1996). Evolution of large song repertoires is also favoured in social circumstances where competition for resources is continually high, as in dense populations (Kroodsma 1999).

Hultsch and Todt (2008) illustrate four steps in the song development of the song thrush in Europe: early plastic songs (week 30); plastic songs (week 37); late plastic song week (43); and crystallised song (week 50). Baptista and Petrinovich (1984) found that species which learn their song at an early stage, might retain the ability to learn new songs later in life. The timing of song acquisition itself may be a consequence of selection on other traits such as dispersal distances or length of breeding season (Nelson 1999). The vocal output of NZ song thrushes was longer, coinciding with their longer breeding season (Fig. 2.5). This might give young birds a longer time exposure to the song and a longer time to develop their song, 
compared with the shorter vocal output during the shorter breeding season in the UK.

The recordings made in NZ were made over July -September, coinciding with an early stage of the breeding season and period of high song output (Fig. 2.5), while in the UK songs were recorded in June coinciding with a later stage in the breeding season. Song thrushes might exhibit temporal change in song characteristics with season. Over the year, the song thrush song can have distinct phases, including an extended one at the end of the breeding season, possibly for repertoire learning by offspring or for territorial marking for subsequent season (Snow \& Perrins 1998). Seasonality in song has been documented in many temperate bird species and it can affect song structure and song type, for example in the white crowned sparrow, Zonotrichia leucophrys (Smith et al. 1995), some migratory European Acrocephalus warblers (Catchpole 1973), the great tit, Parus major (Rost 1990), and in the European robin, Erithacus rubecula (Schwabl \& Kriner 1991). Given the seasonal mismatch between Song Thrush song in NZ (spring) and the UK (summer), interpreting results of this UK - NZ comparison requires caution, although it seems clear that novel phrases occur in the NZ birds, including vocal appropriation of phrases from native species - e.g. North Island Saddleback. Although singing vigorously (B. Bell, press. comm.), it is possible that the UK birds had reduced their song output somewhat, and this may have been a factor in the more limited repertoire recorded for UK birds in this study.

The NZ study site is a predator free sanctuary, surrounded by a mammal proof fence, conferring possible advantages on the Song Thrush population as singing can be a costly activity in terms of the risk of exposure to predators (Catchpole \& Slater 2008). The predatory NZ falcon, Falco novaeseelandiae, and the 
Australasian harrier, Circus approximans, do occur there, however. Another species the chaffinch (Fringilla coelebs) may have changed its singing behaviour there, as a male gave was observed giving song from the ground (Bell 2006). Additional studies of NZ song thrushes outside of the Zealandia sanctuary are needed to further investigate its song variation.

The physical properties of syllables (duration and frequency) were different for the unique syllables used in NZ and UK song thrushes populations. This may be due to different habitat selection pressures for optimum sound transmission. The dense vegetation in NZ forest may have influenced the selection of acoustic signals, with different attenuation and degradation features favouring certain syllables over others. There were also fine differences in song frequency between the two populations; the unique syllables to NZ birds having higher frequencies than syllables unique to UK birds. Cultural selection for optimal sound transmission has also been implicated in the divergence of song among populations of a number of species (Podos \& Nowicki 2004).

In conclusion, this song thrush study provides some possible insight on how improvised song may have evolved. Other studies e.g. on the white-crowned Sparrow, do not address the potential influence of improvisation on geographic song patterns (Kroodsma \& Verner 1978), while local dialects inevitably seem to develop when repertoires exceed five or so song types (Kroodsma 1999). With a relatively large and varied song repertoire, the song thrush is unlikely to retain the same song elements over such geographically separate areas as the UK and NZ, so our identification of differences is to be expected. However, the extent of the differences we measured was marked and paves the way for further study on this and other introduced species. 


\section{Chapter 7}

\section{Temporal variation of the song of the grey warbler, Gerygone}

igata: has the song changed over time?

\subsection{Abstract}

Bird song can vary from place to place and such variation may reflect ecological heterogeneity within the habitat, yet understanding how this process occurs over time within the same population is limited. Here, a vocal change over time in a population of the grey warbler was investigated. Spectral and temporal aspects of the song were compared in the same population at an interval of seven years (2002 and 2009). There was a significant shift in the song syllables to a higher frequency, but no difference in the temporal structure of the song. The frequency difference in song possibly suggests adaptation to increased ambient noise. Alternatively, the change may reflect changes in vegetation and song transmission properties at the study site.

\subsection{Introduction}

Song dialects are a form of vocal variation that is characteristic of birds that learn their songs. Geographical variation and interspecific differences in song structure can be explained by the characteristics of the habitat used by each species (Warren 2002). Further, variation may arise through cultural evolution of song, which can be described as alteration or change in a learned behavioural trait from one generation to the next (Byers et al. 2010). Temporal stability of song varies within taxa, even within the same geographical boundaries, with some dialects persisting unchanged for many generations while others can quickly arise and disappear (Podos \& Warren 2007). For example, the song elements in the 


\section{Chapter 7}

yellowhammer, Emberiza citrinella, are transmitted culturally through a considerable number of generations (Hansen 1999). Other examples of songs that are maintained for decades or longer come from species such as rufous-collared sparrow, Zonotrichia capensis (Handford 1988), chaffinch, Fringilla coelebs (Ince et al. 1980) and wood thrush, Hylocichla mustelina (Whitney 1992). In contrast, some species can modify their songs in a year or less, such as the yellow-rumped cacique, Cacicus cela (Trainer 1989), the indigo bunting Passerina cyanea (Payne et al. 1981) and the lazuli bunting, Passerina amoena (Greene et al. 1997).

Despite numerous observations and studies regarding local song dialects, factors that influence the formation of new dialects or the resistance of change in others are still unknown (Catchpole \& Slater 2008). However, the same factors argued to influence geographical dialect formation could also influence bird song evolution over time (Luther \& Baptista 2010), for example, change in the physical transmission properties of the environment (Slabbekoorn et al. 2009), sexual selection (MacDougall-Shackleton 1997) and song learning (Slabbekoorn \& Smith $2002 b)$.

To investigate the possible cultural evolution of grey warbler songs over time, song samples recorded seven years apart (2002 and 2009) were studied within the same population at Zealandia.

\subsection{Methods}

\subsubsection{Species studied}

The grey warbler, Greygone igata, is an endemic New Zealand passerine in the family Acanthizidae (Heather \& Robertson 2000). Pairs are formed prior to the breeding season and males are territorial, with some territories being maintained 


\section{Chapter 7}

year round. Grey warblers build enclosed, pensile nests at heights of 1-10 m, averaging $3.5 \mathrm{~m}$ (Gill 1982). Songs are given only by males and are important in maintaining territory (Gill et al. 1980). The song is described as a soft, sweet trilling warble, sometimes subdued, regular and cricket-like (Buller 1888). It is a long plaintive, rambling indeterminate trill, of about 8 notes, usually lasting $5 \mathrm{~s}$, but sometimes as long as $12 \mathrm{~s}$. The birds do not weave several themes into one song, but rather appear to have a number of themes, and to sing by repetition (Andersen 1926), at times broken off suddenly when seemingly not complete (Paul \& McKenzie. 1975).

\subsubsection{Song analysis}

In 2002, grey warbler songs were recorded in the Zealandia Sanctuary by M. Borowiec (Wroclaw University, Poland) and B.D.Bell (Victoria University) in October - December. From this sample of recordings, I selected 10 songs recorded at different locations within Zealandia (hereafter referred to as the 2002 songs). To examine changes within the song of this species, I recorded the song of a further 10 birds in 2009 (hereafter referred to as the 2009 songs), between September and October. Songs sampled in 2002 were recorded on a Sony TCDD10 Pro II DAT, equipped with a Telinga parabola microphone; all songs were digitised at a sampling frequency $44.1 \mathrm{KHz}$ and 16-bit sample size. 2009 songs were recorded on a Marantz PMD670 solid-state recorder, equipped with a Telinga Pro 7 parabola microphone also set to a sampling frequency $44.1 \mathrm{KHz}$ and 16-bit sample size.

The main parts of the grey warbler's song were classified into, a start phrase, and then a following phrase repeated once or up to six times (Fig 7.1). I measured the physical characteristics of syllables forming each phrase. There were faint whistle 


\section{Chapter 7}

notes of low frequency between syllables, which were difficult to detect in some recordings, due to the quality of recordings or interference from ambient noise, but these were not included the analysis (Fig 7.1). For each individual song, spectrograms were viewed and measured using Raven Pro 1.4 software, with a Hann-filter and a Fast Fourier Transform (FFT) value of 678 points, overlap being set to $50 \%$ giving a frequency resolution of $86.1 \mathrm{~Hz}$.

The four syllables in the start phrase and three in the repeated phrases were the basic units of analysis. For each phrase, the average value of the following temporal and frequency variables were calculated: (1) lowest frequency $(\mathrm{KHz}),(2)$ maximum frequency (frequency with maximum energy $\mathrm{KHz}$ ), (3) highest frequency $(\mathrm{KHz})$, and (4) syllable duration (s). 


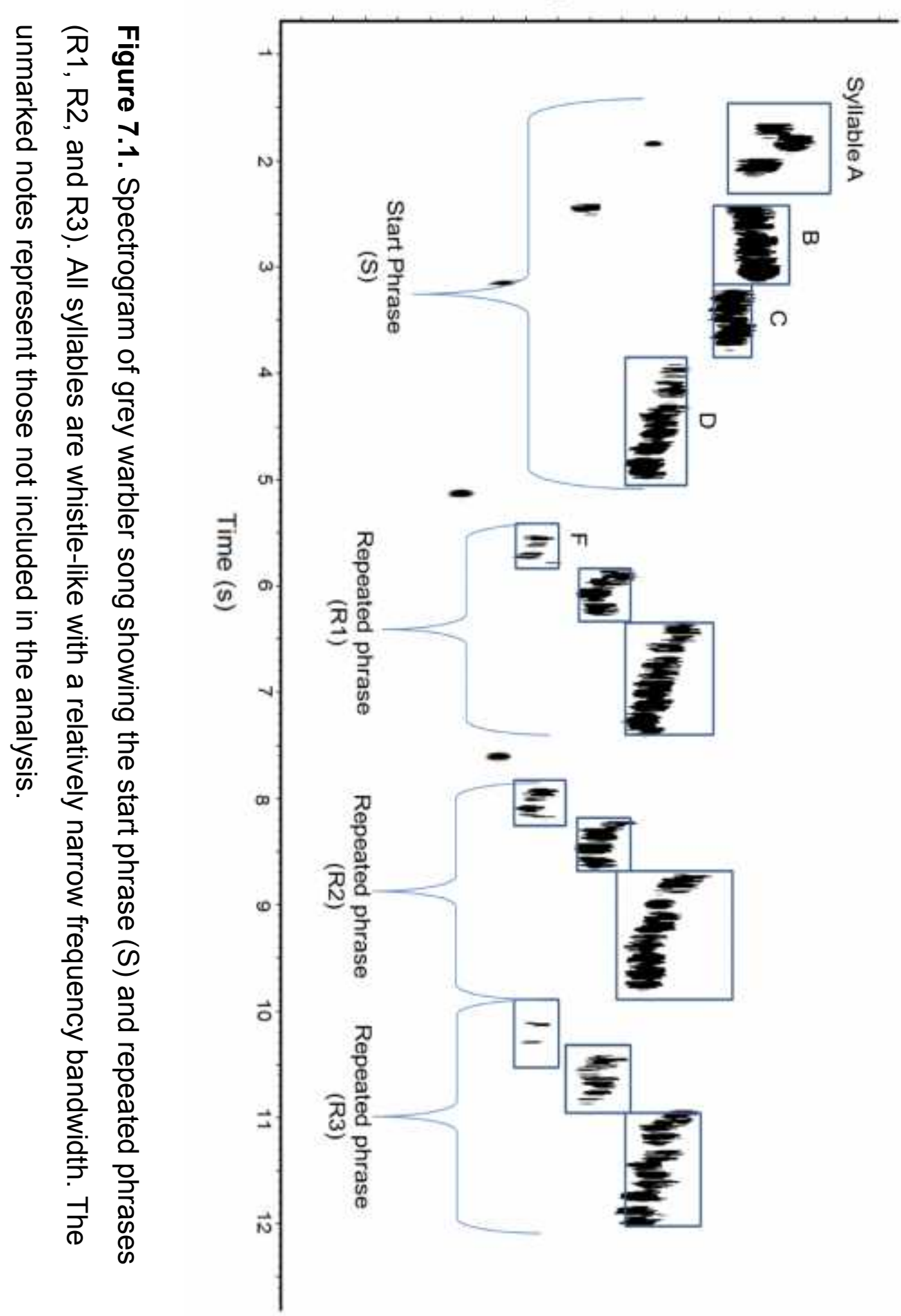




\section{Chapter 7}

\subsubsection{Statistical analysis}

The data set was reduced and the maximum frequency was used as a representative measure for spectral characteristics of song elements, because the phrases in the grey warbler's song had a narrow frequency bandwidth, and the lower and highest frequencies were being highly positively correlated with maximum frequency of both the start phrase and repeated phrases (Table 7.1).

Table 7.1. Pearson correlations of the average values of measured song variables of 20 grey warbler songs.

\begin{tabular}{|c|c|c|c|}
\hline Song part & Variables & $\begin{array}{c}\text { Pearson correlations } \\
(\mathrm{r})\end{array}$ & $P$ value \\
\hline \multirow{2}{*}{ 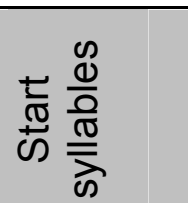 } & maximum frequency, lower frequency & 0.994 & $P<0.01$ \\
\hline & maximum frequency, highest frequency & 0.996 & $P<0.01$ \\
\hline \multirow{2}{*}{ 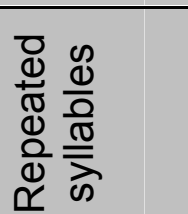 } & maximum frequency, lower frequency & 0.987 & $P<0.01$ \\
\hline & maximum frequency, highest frequency & 0.988 & $P<0.01$ \\
\hline
\end{tabular}

The maximum frequency values were normally distributed (Kolmogorov-Smirnov: $P>0.5)$ and the variances between groups were not unequal (Levene's Test for Equality of Variances for all three variables: all $P>0.05)$, thus the one sample test was appropriate to test group differences. An independent sample t-test was conducted to compare song variables between the two years. Syllable durations were not normally distributed (Kolmogorov-Smirnov: $P<0.05$ ), so the nonparametric Mann-Whitney-U test was used to compare temporal results between the two years. 


\subsection{Results}

The song structure of grey warblers in 2002 and 2009 differed in its spectral characteristics but not in its temporal characteristics (Table 7.2). The sample size for R2 and R3 varied because some songs ended suddenly after the second or third phrase.

Table 7.2. Mean values of the measured song variables. The start phrase consisted of four syllables while the repeated phrases consisted of three.

\begin{tabular}{|c|c|c|c|c|c|c|c|}
\hline \multirow[b]{2}{*}{ Variable } & \multicolumn{3}{|c|}{2002} & \multicolumn{4}{|c|}{2009} \\
\hline & $\begin{array}{l}\text { Song } \\
\text { part }\end{array}$ & Mean & $\mathrm{N}$ & $\overline{S E}$ & Mean & $\mathrm{N}$ & SE \\
\hline \multirow{4}{*}{ 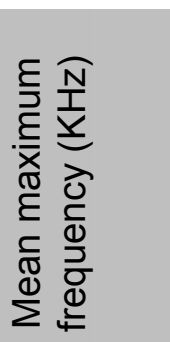 } & $\mathbf{S}$ & 3.6 & 40 & 0.04 & 4.1 & 40 & 0.05 \\
\hline & R1 & 2.7 & 30 & 0.02 & 3.01 & 30 & 0.03 \\
\hline & R2 & 2.9 & 30 & 0.02 & 3.3 & 30 & 0.03 \\
\hline & R3 & 3.2 & 27 & 0.02 & 3.6 & 30 & 0.06 \\
\hline \multirow{4}{*}{ 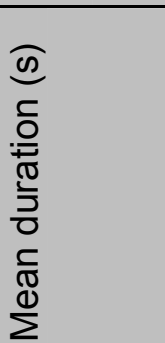 } & $\mathbf{S}$ & 0.5 & 40 & 0.05 & 0.42 & 40 & 0.04 \\
\hline & R1 & 0.22 & 30 & 0.01 & 0.22 & 30 & 0.01 \\
\hline & R2 & 0.38 & 30 & 0.05 & 0.36 & 30 & 0.03 \\
\hline & R3 & 0.85 & 27 & 0.03 & 0.74 & 30 & 0.01 \\
\hline
\end{tabular}

Maximum frequencies in all parts of the song, (S, R1, R2, and R3) were significantly higher in 2009 than in 2002 (Table 7.3). The average increase in the frequency in 2009 songs was between 0.34 and $0.45 \mathrm{KHz}$. 
Table 7.3. Differences in mean maximum frequency of grey warbler song between 2002 and 2009.

\begin{tabular}{lllllll|l|l}
\hline & \multicolumn{3}{l}{ Levene's Test } & \multicolumn{5}{c}{ t-test statistics } \\
\hline $\begin{array}{l}\text { Song } \\
\text { part }\end{array}$ & $F$ & $P$ & $\mathrm{t}$ & $\mathrm{d} . \mathrm{f}$ & $P$ & $\begin{array}{c}\text { Mean } \\
\text { difference }\end{array}$ & $\mathrm{SE}$ \\
\hline $\mathrm{S}$ & 0.12 & 0.9 & -6.5 & 18 & $.001^{*}$ & -0.45 & 0.07 \\
\hline R1 & 0.61 & 0.8 & -10.7 & 18 & $.001^{*}$ & -0.35 & 0.03 \\
\hline R2 & 0.05 & 0.8 & -10.4 & 18 & $.001^{*}$ & -0.4 & 0.04 \\
\hline R3 & 2.8 & 0.11 & -5.8 & 18 & $.001^{*}$ & -0.34 & 0.06 \\
\hline
\end{tabular}

There was no significant change in the mean phrase duration for S, R1 and R2, however R3 was $0.11 \mathrm{~s}$ longer in 2002 (Table 7.4)

Table 7.4. Differences in mean phrase duration in grey warbler song between 2002 and 2009 compared using Mann-Whitney U tests.

\section{Song part Mann-Whitney U $\quad Z \quad P$}

\begin{tabular}{lll|l}
\hline S & 658 & -1.3 & 1.7 \\
\hline R1 & 422 & -0.7 & 0.5 \\
\hline R2 & 404 & -0.8 & 0.42 \\
\hline R3 & 181 & 646 & $>0.01$ \\
\hline
\end{tabular}

\subsection{Discussion}

There was a marked difference in the spectral frequency characteristics of grey warbler songs between 2002 and 2009. The use of higher frequencies in all parts of the song phrases in 2009 suggest a positive shift to a higher song frequency as an adaptation to increased levels of anthropogenic low-frequency noise, as 
suggested for the great tit (Slabbekoorn \& Peet 2003; Slabbekoorn \& den BoerVisser 2006). Similar results have been reported for the European blackbird, Turdus merula (Nemeth \& Brumm 2009), the song sparrow, Melospiza melodia (Wood et al. 2006) and the house finch, Carpodacus mexicanus (FernandezJuricic et al. 2005). In these species, there was a positive correlation between the song frequencies and sound pressure level of ambient noise in their habitat. The ambient noise between the two periods in Zealandia could not be compared, but the result could suggest that the warblers may have compensated for some increase in ambient noise in the area.

The grey warblers did not show a significant change in the duration of their song syllables. Other studies reveal that city birds may have a faster delivery rate of song and a shorter inter-song interval (Slabbekoorn \& den Boer-Visser 2006), possibly as an adaptation to a more open habitat in the city.

An alternative explanation for differences in song frequency relates to signal transmission in the habitat that might possibly be associated with different seasons and weather conditions. Atmospheric conditions can affect sound transmission properties of the habitat, as sound attenuation increases with the increase in temperature, and is reduced with increasing humidity (Wiley \& Richards 1982). As both sets of samples were taken over periods of weeks, however, atmosphere differences between 2002 and 2009 seem unlikely.

Another explanation for differences between years might be related to the possible influence of seasonal change in breeding density on vocal communication. Change in the breeding densities with years, and the re-introduction of new species to Zealandia may have influenced the grey warblers' song in some way through acoustic competition. Intra-specific competition within males and 


\section{Chapter 7}

motivational changes in singing activity can cause a shift in song features

(Goretskaia 2004). Inter-specific interactions may lead to character displacement

of song characteristics of different species, which in turn may be caused by

reintroduced birds appearing or by increase in the relative densities of bird species

that use a similar frequency bandwidth. For example, the mean $( \pm S E)$ maximum

frequency in the reintroduced whitehead was $3.1( \pm 0.2) \mathrm{KHz}(n=22)$ which more

or less equals the mean maximum frequency of $3.0( \pm 0.5) \mathrm{KHz}(n=10)$ for 2002 grey warblers (Fig. 7.2).

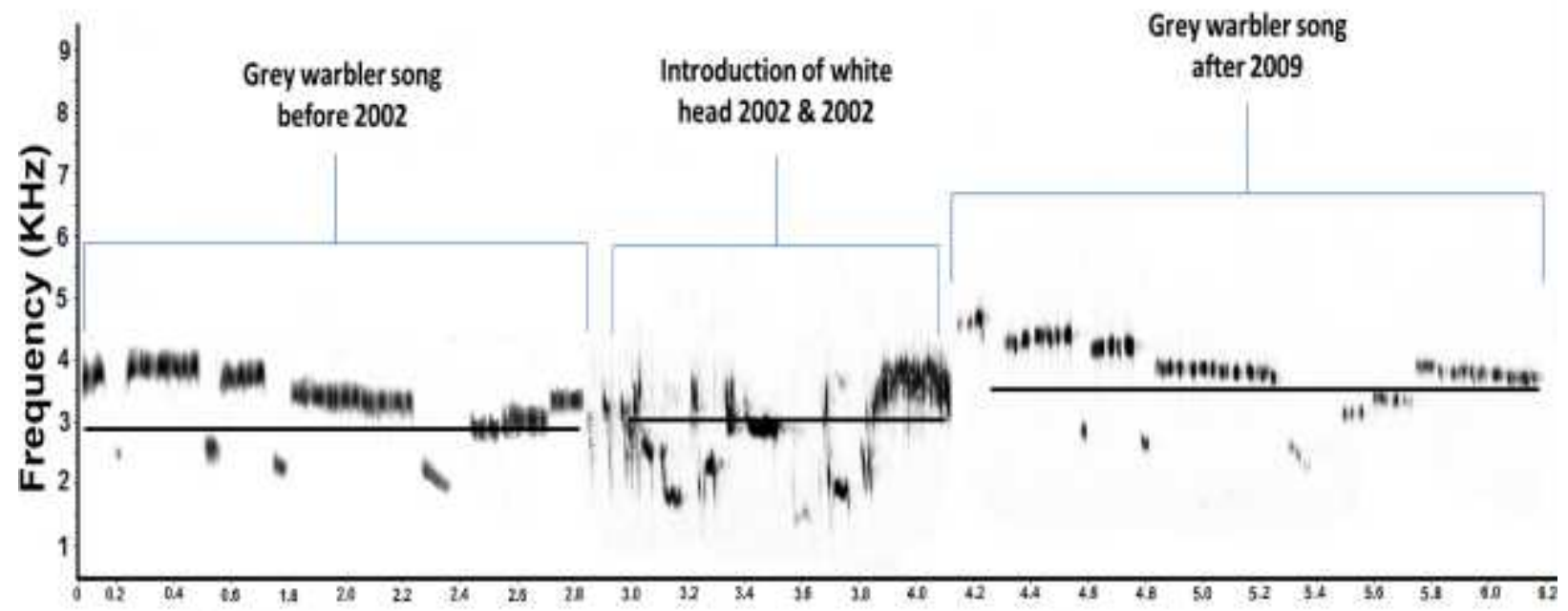

Time (s)

Figure 7.2. Sonogram of grey warbler in 2002 and 2009, and whitehead song introduced to the Zealandia in 2001 and 2002.

The equipment used to record the songs in the two years was different (a DAT recorder in 2002 and a solid-state digital recorder in 2009). The effect of these different recorders used in the study was investigated by using both types of equipment to record a series of generated tones simultaneously. The recorded tones were then analysed using Raven Pro 1.4 software. There was no difference in the frequency or the temporal aspects of the recoded tones, ruling out the 
possibility that different equipment use led to the different mean frequencies (Appendix 3 \& 4).

In conclusion, the Inter-specific competition on acoustic signal between the reintroduced whitehead and grey warbler may have lead to character displacement of song characteristics, causing a shift in the song of grey warbler song to higher frequency. 


\section{Chapter 8}

\section{General discussion and conclusions}

This study represents one of very few comprehensive analyses on the acoustics of an entire forest bird community, and evidently the first in the temperate Australasian region. The study investigated the annual cycle of change in the vocal activity of the study species, and provided some insights into the relationship between the structure of the bird community, the characteristics of local avian vocalisations, and the physical characteristics of the habitat, obtained through analysis of bird vocalisations and sound transmission experiments. The study aimed at relating the characteristics of avian vocalisations in native and introduced species to the sound transmission properties of the habitat. It investigated the perception of sound by the receiver, an important aspect in communication, and focused on song harmonics in saddleback, one of the least studied characteristics of bird song.

Chapter 2 reported on the annual change in the vocal output of forest birds, and showed that some species have stronger seasonal patterns than others. The change in the vocal output was found to affect the detectability of forest species within different seasons. There was a significant change in the vocal output for some of the study species at Zealandia during the year, for example bellbird, whitehead, fantail, robin, blackbird, and chaffinch (Figs. 3.3, 2.4 \& 3.5). However, for other species there was no significant change in the vocal output, for example kaka, saddleback, grey warbler, and tui (Figs. 3.2 \& 3.3). Variation in species detectability resulting from conspicuousness and differences in vocal output across months is a key variable in wildlife surveys and needs to be assessed carefully (Sutherland 2006). Indices of bird counts based on the total number of 
birds heard and seen might not represent the actual species density, especially for birds that have strong seasonal change in their vocal output (Haselmayer \& Quinn 2000). The lack of proper adjustment in the most common methods of surveying birds may mean the results are biased towards more conspicuous species or vocally active ones (Nichols et al. 2000; Bart \& Earnst 2002; Rosenstock et al. 2002). Comparison of unadjusted counts will be valid only if the numbers represent a constant proportion of the actual population present across space and time (Sutherland 2006).

Chapter 3 examined the inter-relationships of vocalisations of the forest bird community at Zealandia and found that vocalisations were over-dispersed in acoustic space. Interestingly, native species were more dispersed and separated than introduced species, which might indicate that native bird vocalisations have evolved to reduce vocal competition, supporting the acoustic niche hypothesis. One possible explanation for the difference between native and introduced species, is that introduced species are more generalist, and can be found in a variety of habitats (open habitats and shrub lands), hence their vocal signals might be under less environmental selection pressure for transmission in the dense forest.

The evidence for habitat-related convergence of avian vocalisations is mixed. The acoustic adaptation hypothesis suggesting that evolution has favoured acoustic signals that match the bird's habitat so that they become less affected by sound degradation and attenuation (Marler \& Slabbekoorn 2004; Ey \& Fischer 2009). In one of few forest-based community studies on avian acoustics, Luther (2008) studied the distribution of bird acoustics of Amazonian birds, including 82 species compromising sub-oscines, oscines, and non-passerines. He found o vocalisations 


\section{Chapter 8}

to be clustered, however at a smaller spatio-temporal scale, birds that vocalise within the same stratum or within the same time of day were over-dispersed within the community. This contradicts the suggestion that vocalisations within the same stratum should converge to adapt to the transmission properties of that stratum (Naguib \& Wiley 2001; Seddon 2005).

A relatively low species diversity in the study area compared with e.g. Brazil (Luther 2009), may have allowed birds to incorporate a wider range of signals within their acoustic space without competing with other species. My results supported the acoustic adaptation hypothesis in only one aspect, namely that birds concentrated the amplitude (energy) within their vocalisations in a narrow band rather than spreading it through a broader range of frequencies, a possible adaptation to increasing the transmission distance with minimal degradation (Barker 2008).

In another community-based study, Cardoso (2009) examined communities of European and North American birds, comparing those within open and closed habitats. He found that bird vocalisations have converged between similar habitats. Interspecific acoustic competition did not have an effect on shaping the acoustic community overall, rather it had localised importance only between closely related species.

While it is not possible to be certain about the direct cause of divergence in vocalisation characteristics in the Zealandia bird community, the results are more consistent with the prediction of the acoustic adaptation hypothesis. As noted by Seddon (2005), and Luther (2009), multispecies approaches are vulnerable to the influence of confounding variables or chance, especially when signal phenotype might be affected by various forms of character displacement because different 


\section{Chapter 8}

species may weigh vocalisation features differently, or have different mechanisms of sound production.

In addition, chapter 3 found that the frequency component of bird vocalisations at Zealandia was negatively correlated with body size, larger species using lower frequencies (Fig. 4.5) and higher song posts (Fig. 4.6). The effect of body size on frequency has been documented for a range of bird species (Brenowitz 1982; Ryan \& Brenowitz 1985; Bell 1994). However, body weight did not affect the temporal aspects of vocalisations at Zealandia. The correlation between song post height and frequency contradicts the finding of Lemon et al. (1981), that song frequency is positively correlated with song height. High-pitched songs are sung at high song posts where interference by vegetation is expected to be relatively low (Ficken et al. 1974; Lemon et al. 1981; Marler \& Slabbekoorn 2004).

The different results may have resulted from different forest types, and differences in the vocalisation heights investigated. Lemon et al. (1981) sampled 19 species of warblers in two Neotropical forests, a coniferous spruce-balsam fir forest of Picea abies and deciduous maple-birch forest of Acer spp. and Betula spp. Different heights in forests have different specific transmission and noise characteristics (Nemeth et al. 2001) and the change in forest density might also vary with different forests, hence the sound transmission properties associated with different forest layers.

Chapter 4 reported on the physical effect of broadleaf forest and pine forest on the transmitted signal. As noted by Brumm and Naguib (2009), understanding how habitat affects transmitted signals, noise interference, and signal perception by the receiver, is crucial for complete understanding of the factors shaping bird vocalisations. This chapter showed that forests provide complex acoustics 
auditoria for avian vocalising. The heterogeneity of the forest vegetation and its density between sender and receiver add complexity to sound transmission. In addition, acoustical properties of forests can vary with elevation, posing different selection pressure on bird vocalisations at different levels within forests (Kirschel et al. 2009). Frequency dependent attenuation, reverberation, ground effects, and forest types are but part of the many factors that can affect transmitted signals (Nemeth et al. 2006).

Reflected sound waves from the ground can affect the transmitted signal as they cause excess attenuation at some frequencies and amplification at others (Embleton 1996) and presumably have an important effect on communication of birds foraging or vocalising on the ground or at low elevation (Fig. 4.9). In Zealandia, these include North Island robin, North Island saddleback, little spotted kiwi, and possibly birds that forage on the ground like blackbird and song thrush, which may be affected since the location of the receiver might be as important as the location of the sender. This chapter also found that bird vocalisations are detectable at different distances in the pine and broadleaf forests (Figs 4.10 \& 4.11). This invokes the idea of an active space over which the signal remains detectable and is recognisable for potential receivers.

Chapter $\mathbf{5}$ studied the receiver part of sound communication and focused on song harmonics in saddleback and their role in ranging. Hearing and perception of sound by the receiver is an important aspect of communication as it adds to our understanding of the forces shaping vocalisation patterns and structures (Catchpole \& Slater 2008). Few studies have investigated the effect of harmonics in ranging, though relative intensities of high frequencies have been used to estimate the distance of a signaller (Naguib 1995, 1997b). Correct estimation of 
the source of vocalisation is important in the receiver response for it can lead to avoidance of unnecessary or dangerous interactions, or may promote aggressive responses to defend a territory when a rival is nearby (Richards 1981; McGregor et al. 1983; McGregor \& Krebs 1984; Naguib 1995).

This chapter found that saddlebacks were potentially able to use harmonics in their song as distance cues and differentiate between songs with different harmonic composition and respond to them accordingly. In addition, this chapter implied that harmonics might have important behavioural aspects, such as in transmitting information about individuality and body size cues.

Chapter 6 compared song thrush song repertoire recordings between NZ and UK populations, and found that NZ song thrush song contained a larger number of syllables delivered with less repetition. In addition, it found that syllables unique to the NZ song thrush had higher mean frequency range. The larger repertoire size for the NZ song thrush contrasts with the founder effect principle, which predicts a loss in song diversity (Jenkins 1978). However, the result suggests that local ecological and social conditions are important in the development of new song repertoires (Seddon 2005), especially with the ability of the song thrush to mimic songs and calls from other species (Cramp 1988). The effect of the bird community on avian communication and the evolution of signals across species in a community are little studied (Marler 2004b).

Chapter 7 compared grey warbler song across time, and documented that their song has shifted to a higher frequency, without any change in the temporal pattern of the song. Arrival of reintroduced native species under Zealandia's restoration programme and/or increase in the relative densities of existing species that use a similar frequency bandwidth to grey warblers, can lead to increased Inter-specific 


\section{Chapter 8}

interactions, which in turn may lead to character displacement of song characteristics of different species. Much of the evidence from relevant studies stresses the effect of habitat on signal transmission and on the evolution of new vocalisation patterns (Wiley \& Richards 1978; Nottebohm et al. 1986; Slabbekoorn 2004b). Social conditions involving intraspecific and interspecific competition for resources might also affect the evolution of new vocalisation patterns (Nelson 1997; Catchpole \& Slater 2008). Ambient noise is a further selective force that can change bird vocalisations, and increased ambient noise levels may cause a shift in bird song to higher or lower frequency (Nemeth \& Brumm 2009).

Geographical or temporal change in bird song can be easy to document through sound analysis software currently available, but to explain new patterns in bird songs can be challenging, involving many potential factors that govern sound production, transmission, and perception (Marler \& Slabbekoorn 2004).

\subsection{Conclusion}

This study was one of a few to characterise the acoustic properties of a forest bird community. Chapter 2, describes the temporal change of vocal output of Zealandia forest birds over a year. Chapter 3 compares avian vocalisation between forest species. Chapter 4 characterises the habitat selection pressures on sound transmission in different forest types. Chapter 5 investigates the role of harmonics in estimating the distance of a signaller in the saddleback. Chapter 6 examines possible geographical change in the song of the introduced song thrush at Zealandia. Chapter 7 reports on a temporal frequency change after seven years in grey warbler song within Zealandia, seeking possible reasons for this. 


\section{Chapter 8}

Overall, the results of this study indicate that patterns of change in vocal output can have important effects on species detectability and need to be accounted for when comparing point counts across different months of the year, or when calculating relative abundance of species. The temporal change in vocal output across different months can explain the (ANH) (Table 8.1).

Table 8.1. Summary of the main results from each chapter, and their contribution to the acoustic adaptation hypothesis $(\mathrm{AAH})$ and the acoustic niche hypothesis $(\mathrm{ANH})$.

\begin{tabular}{|c|c|}
\hline ANH & AAH \\
\hline $\begin{array}{l}\text { Temporal partitioning (change in song } \\
\text { output at different months) }(\mathrm{CH} 2)\end{array}$ & \\
\hline Divergence of bird vocalisation $(\mathrm{CH} 3)$ & $\begin{array}{l}\text { Focus energy in a narrow frequency } \\
\text { band width }(\mathrm{CH} 3)\end{array}$ \\
\hline $\begin{array}{l}\text { Multiple sound windows can be present in } \\
\text { forest }(\mathrm{CH} 4)\end{array}$ & $\begin{array}{l}\text { Prominent sound window at lower } \\
\text { frequencies }(\mathrm{CH} 4)\end{array}$ \\
\hline $\begin{array}{l}\text { Adaptation to optimum transmission } \\
\text { distance rather than maximum }(\mathrm{CH} 4)\end{array}$ & \\
\hline $\begin{array}{l}\text { Shift in song syllables to a higher } \\
\text { frequency (character displacement of } \\
\text { song })(\mathrm{CH} 7)\end{array}$ & \\
\hline
\end{tabular}

The results provided some evidence of the partitioning of acoustic signals between species. Vocalisations within the Zealandia bird community, especially amongst the native species, gave support to the acoustic adaptation hypothesis in that the birds concentrated energy in their vocalisations in a relatively narrow bandwidth 


\section{Chapter 8}

(Table 8.1). The study also found that there was a negative correlation between vocalisation frequency and both body size and song post within the community. The sound transmission experiment demonstrated that forests are complex auditoria and that changes that accumulate in a transmitted sound will differ with sound frequency, forest type, vegetation density, and the relative elevation of signaller and receiver. Species that vocalise near the ground might benefit from sound reflected from the ground, and for different species, there might be multiple "sound windows" that achieve optimum transmission for different vocalisations. However, there was a prominent sound window at the lower frequency range (Table 8.1). The experimental study of chatter song harmonics in the saddleback demonstrated their likely importance as distance cues. The song of the introduced song thrush population at Zealandia has evidently evolved to become larger and more varied than its source population in the UK, with more syllables delivered with less repetition than the UK population, contradicting with what might be expected by the founder effect. Finally, the songs of both the grey warbler and the song thrush appear to have had a significant shift in song syllables to a higher frequency (Table 8.1), although there was no difference in the temporal structure of their songs. Reasons for this were discussed, with increased species density and diversity as a consequence of Zealandia management being a possible factor.

\subsection{Further direction}

Several directions of further study emerge as a result of this preliminary acoustic investigation of the avian community in Zealandia forest:

Some species have developed means of sound communication other than vocal signalling, for example tui, bellbird, and kereru can produce mechanical sounds by 


\section{Chapter 8}

their wings during flight (Heather \& Robertson 2000). What functions do these sounds play in communication?

Song harmonics were found to be important for ranging in saddleback; however, more detailed acoustic experiments and analyses are needed to further explore the role of each harmonic in saddleback communication, e.g. their importance as individuality cues, fitness indicators, and individual location within the territory. The perception of sound by the receiver can give important insights into the information coded in vocalisations. As the transmission distance of different elements in a given vocalisation varies, what information is encoded in the long distance and short distance elements?

Behavioural aspects of sound production (e.g. in tui, bellbird, and saddleback) are of interest such as singing posture or tracheal elongation. Little is known about these aspects in native species and requires further study. A study on tracheal elongation would add to our understanding of the vocal exaggeration hypothesis (Fitch 1999) and give new insights into vocal production mechanisms.

The predator free environment at Zealandia might have had an effect on the evolution of bird song there. What effect does the predator free environment have on the evolution of local song, including the complexity, duration, and singer's position? 
Appendices 
Appendix 1

Spectrograms of the vocalisations of the 16 species included in the analysis
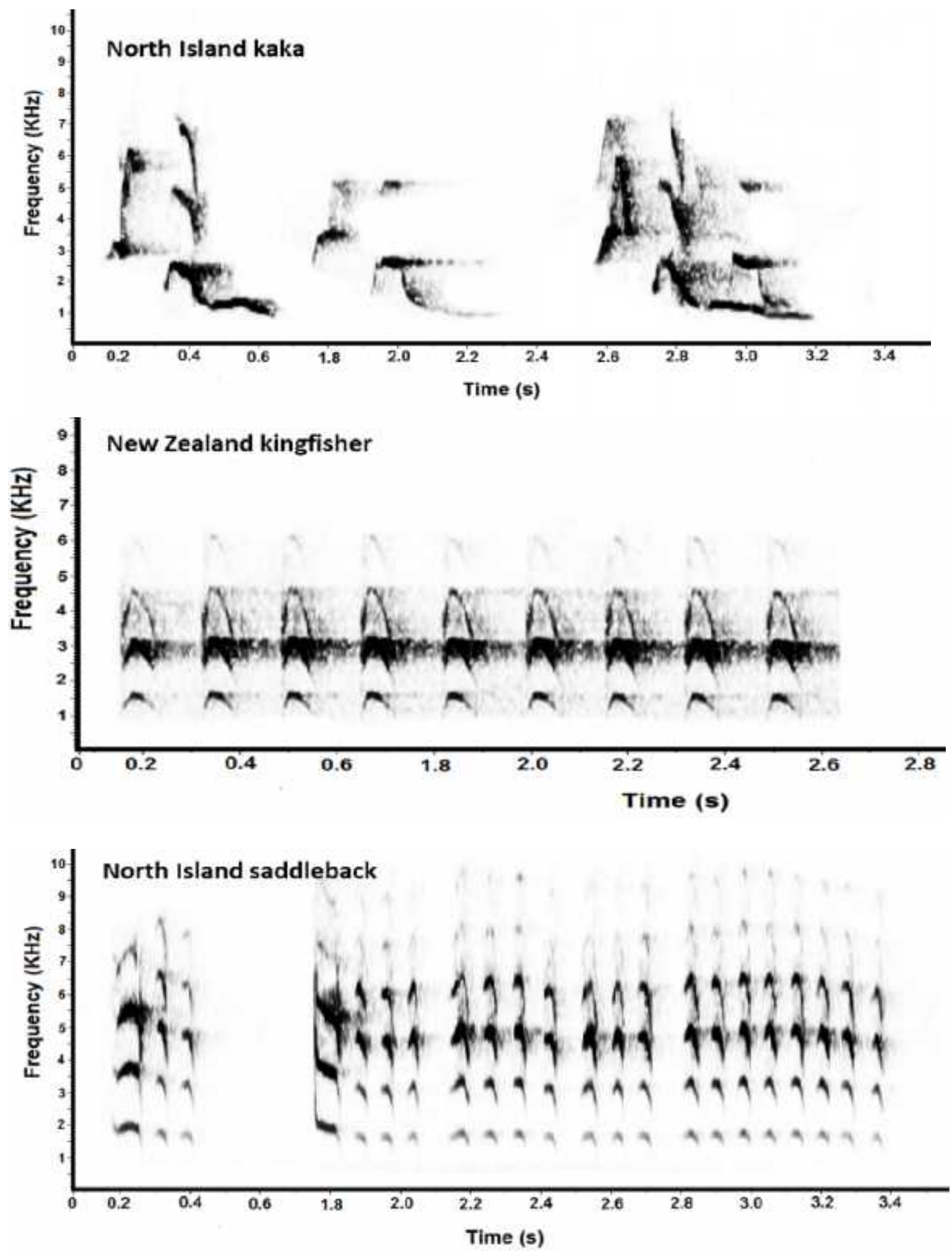

137 

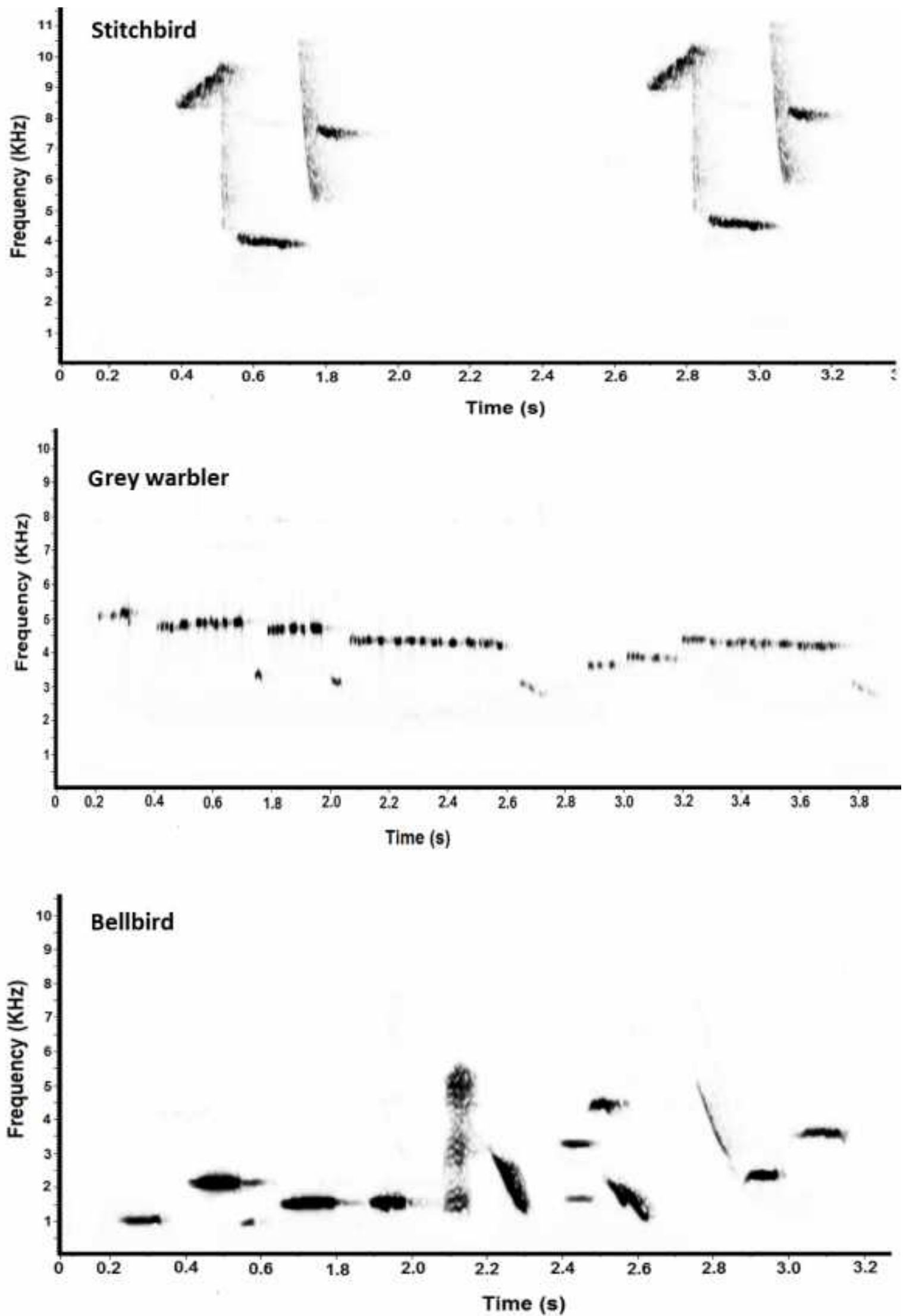

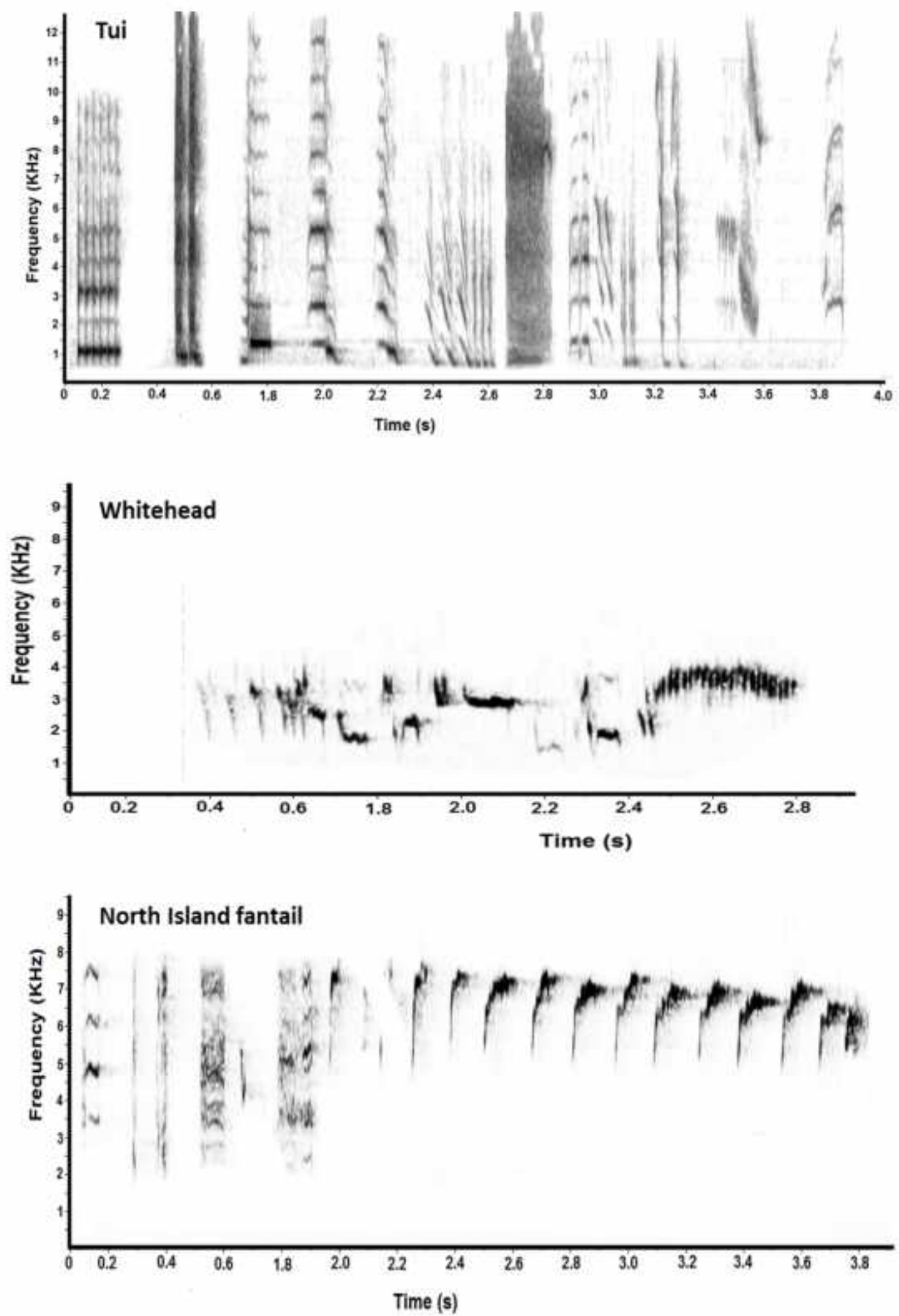

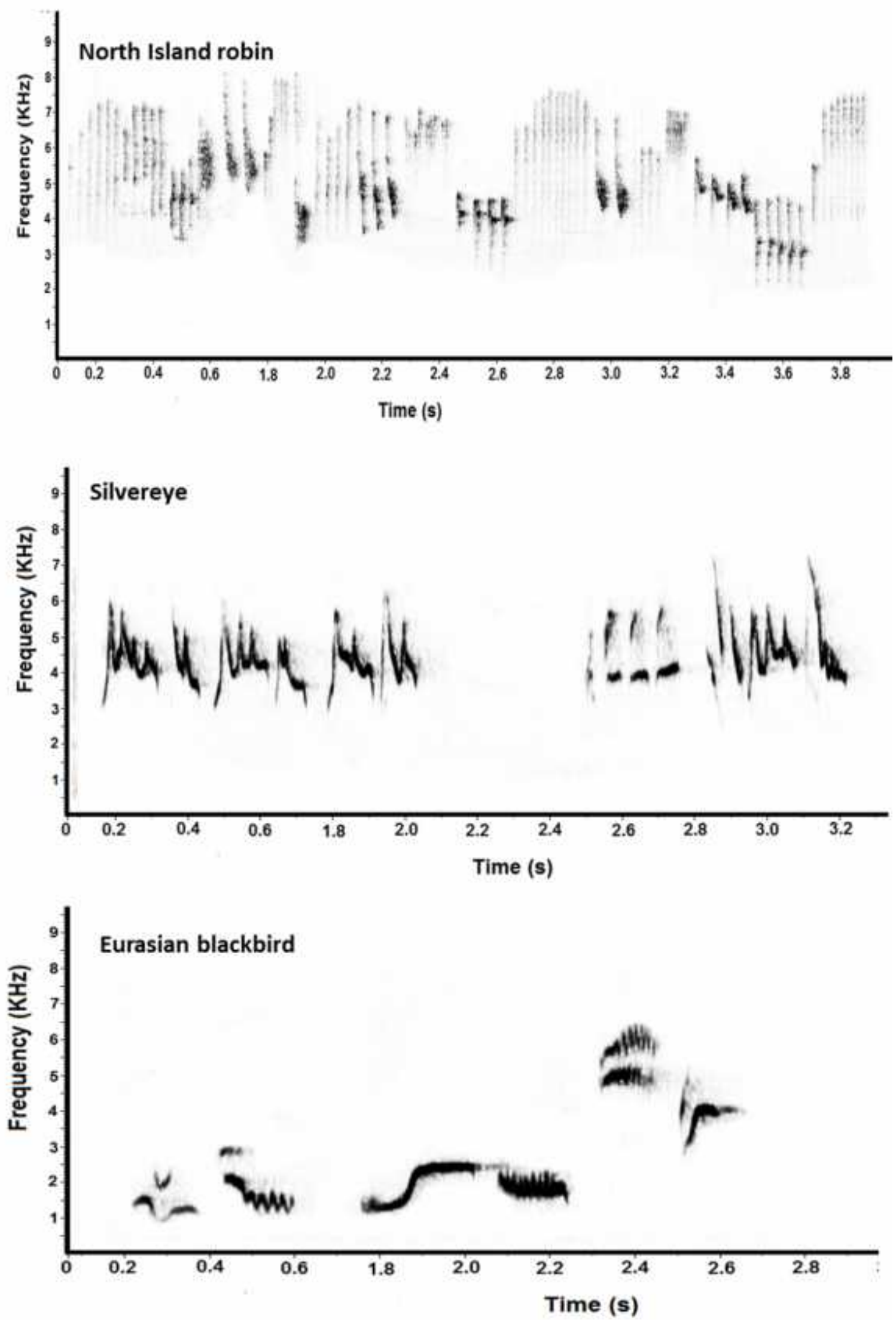

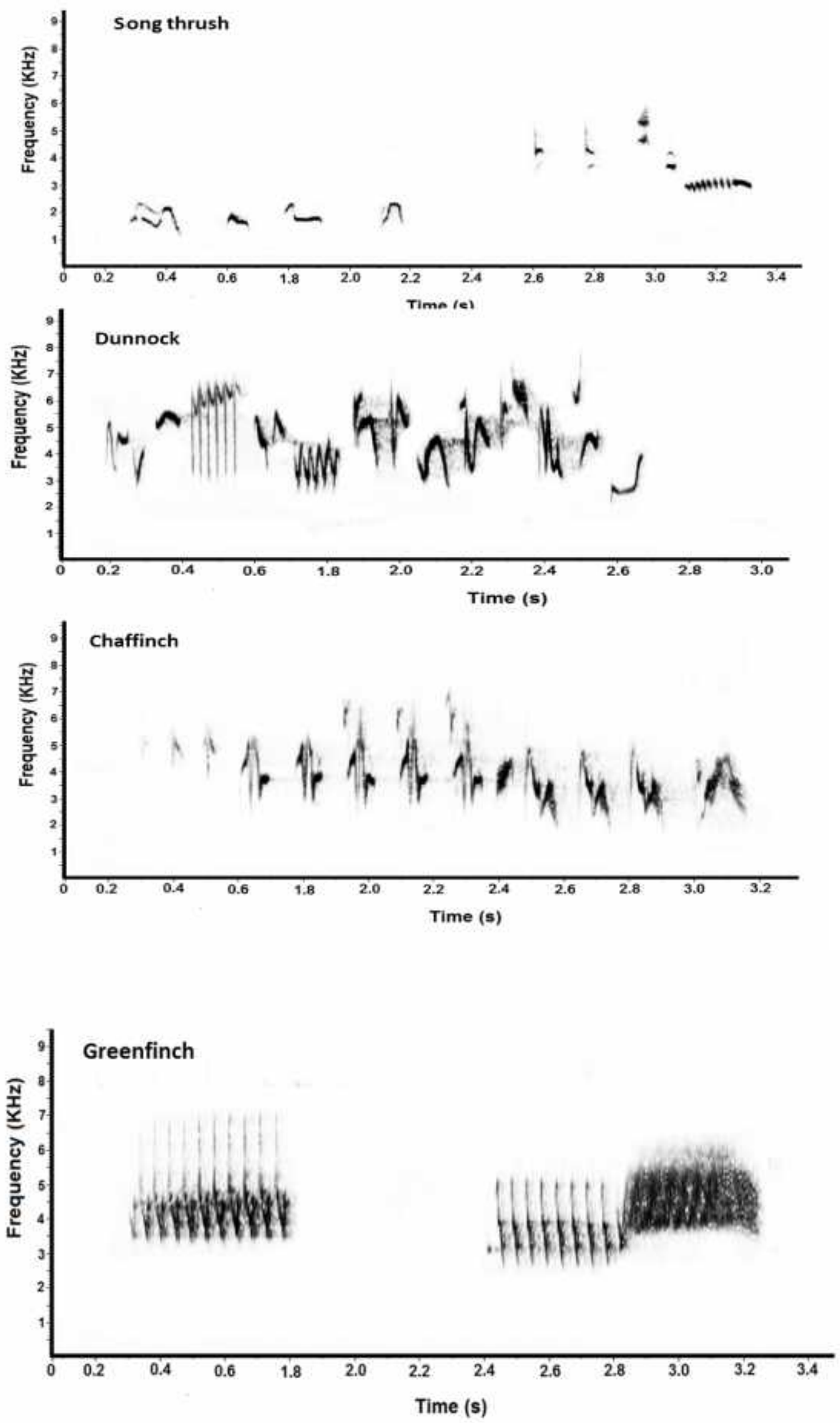


\section{Appendix 2}

When both sexes are known to sing the mean values of males and females were used (indicated as (mf)), while for species in which only males sing, the male measurements were used (indicated as $(m)$ ). IQRZ is the frequency with maximum amplitude.

\begin{tabular}{|c|c|c|c|c|c|c|}
\hline Species & $\begin{array}{l}\text { Lowest } \\
\text { frequency } \\
(\mathrm{KHz})\end{array}$ & $\begin{array}{l}\text { Highest } \\
\text { frequency } \\
(\mathrm{KHz})\end{array}$ & $\begin{array}{l}\text { Delta } \\
\text { frequency } \\
(\mathrm{KHz})\end{array}$ & $\begin{array}{l}\text { Maximum } \\
\text { frequency } \\
(\mathrm{KHz})\end{array}$ & $\begin{array}{l}\text { IQRz } \\
(\mathrm{KHz})\end{array}$ & $\begin{array}{l}\text { Body } \\
\text { mass }(\mathrm{g})\end{array}$ \\
\hline Bellbird (mf) & 0.7 & 5.4 & 5.0 & 2.3 & 0.7 & 30 \\
\hline Blackbird (m) & 1.3 & 5.7 & 4. & 2.6 & 0.5 & 90 \\
\hline Chaffinch (m) & 1.6 & 8.0 & 6.3 & 3.8 & 0.7 & 22 \\
\hline Dunnock (m) & 2.0 & 7.5 & 5.5 & 4.7 & 0.8 & 21 \\
\hline Fantail (mf) & 1.6 & 9.1 & 7.5 & 7.0 & 0.6 & 8 \\
\hline $\begin{array}{l}\text { Greenfinch } \\
(\mathrm{mf})\end{array}$ & 2.0 & 5.4 & 3.1 & 3.9 & 1.5 & 28 \\
\hline $\begin{array}{l}\text { Grey warbler } \\
\text { (mf) }\end{array}$ & 2.0 & 4.6 & 2.6 & 3.9 & 0.5 & 6.5 \\
\hline Stitchbird (mf) & 3.2 & 11.0 & 7.9 & 4.3 & 2.0 & 35 \\
\hline Kaka (mf) & 0.7 & 5.7 & 5.0 & 2.3 & 0.6 & 500 \\
\hline $\begin{array}{l}\text { Kingfisher } \\
\text { (m)r }\end{array}$ & 2.0 & 3.3 & 1.3 & 2.9 & 0.2 & 65 \\
\hline $\begin{array}{l}\text { North Island } \\
\text { robin (mf) }\end{array}$ & 1.7 & 7.9 & 5.8 & 4.5 & 1.1 & 35 \\
\hline $\begin{array}{l}\text { Saddleback } \\
\text { (mf) }\end{array}$ & 2.9 & 5.1 & 2.4 & 4.1 & 0.4 & 75 \\
\hline Silvereye (mf) & 2.4 & 6.2 & 3.8 & 3.8 & 0.7 & 13 \\
\hline $\begin{array}{l}\text { Song thrush } \\
\text { (m) }\end{array}$ & 1.4 & 8.9 & 7.5 & 3.2 & 0.7 & 70 \\
\hline Tui (mf) & 0.4 & 11.1 & 10.7 & 2.0 & 2.1 & 105 \\
\hline $\begin{array}{l}\text { Whitehead } \\
\text { (mf) }\end{array}$ & 1.2 & 5.2 & 4.0 & 3.2 & 0.5 & 16.5 \\
\hline
\end{tabular}




\section{Appendix 3}

Graph illustrating the effect of different recorders used in the study showing no difference in the recorded frequency.

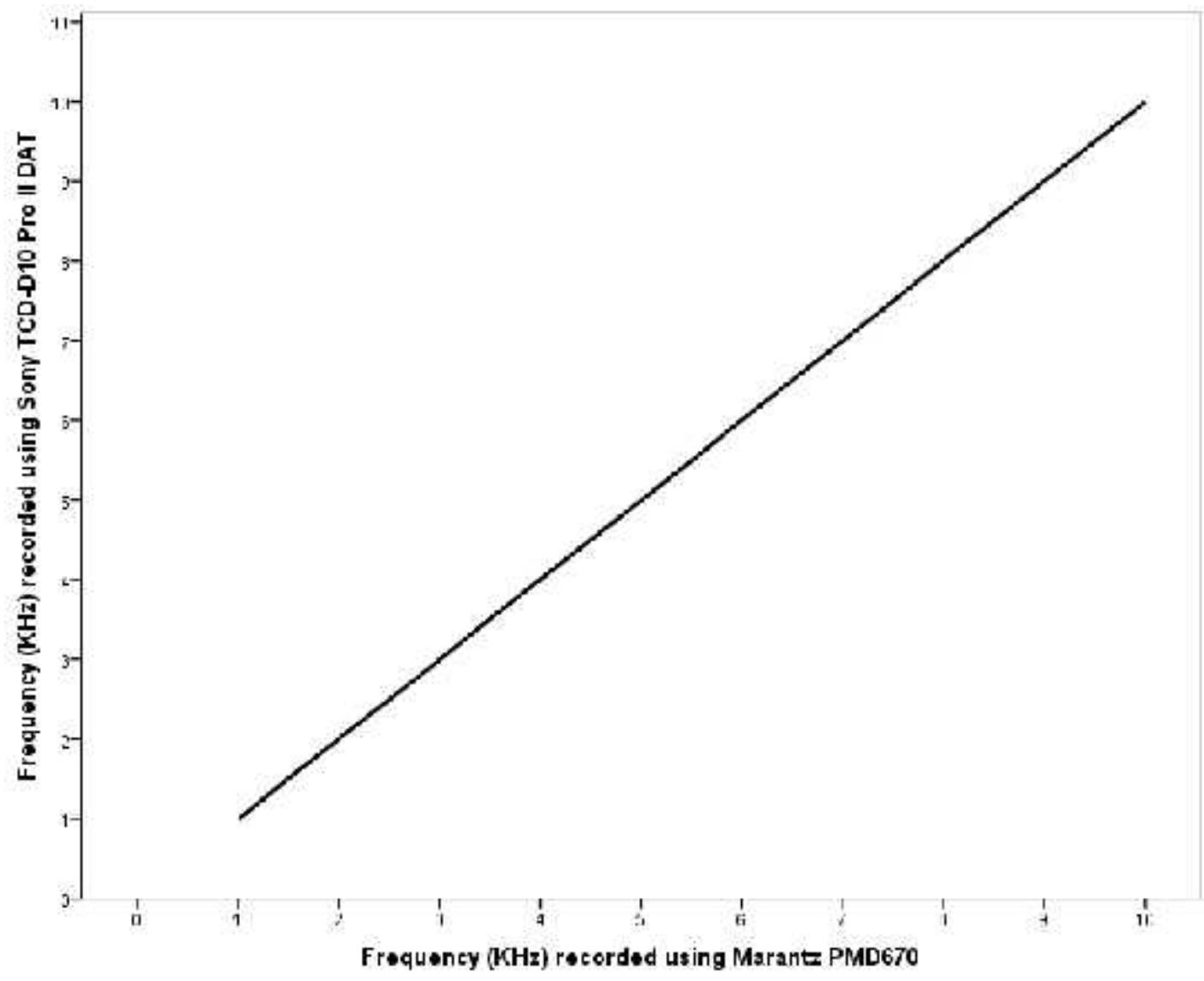




\section{Appendix 4}

Graph illustrating the effect of two different sampling rates for frequency measurements (16-bit and 24-bit).

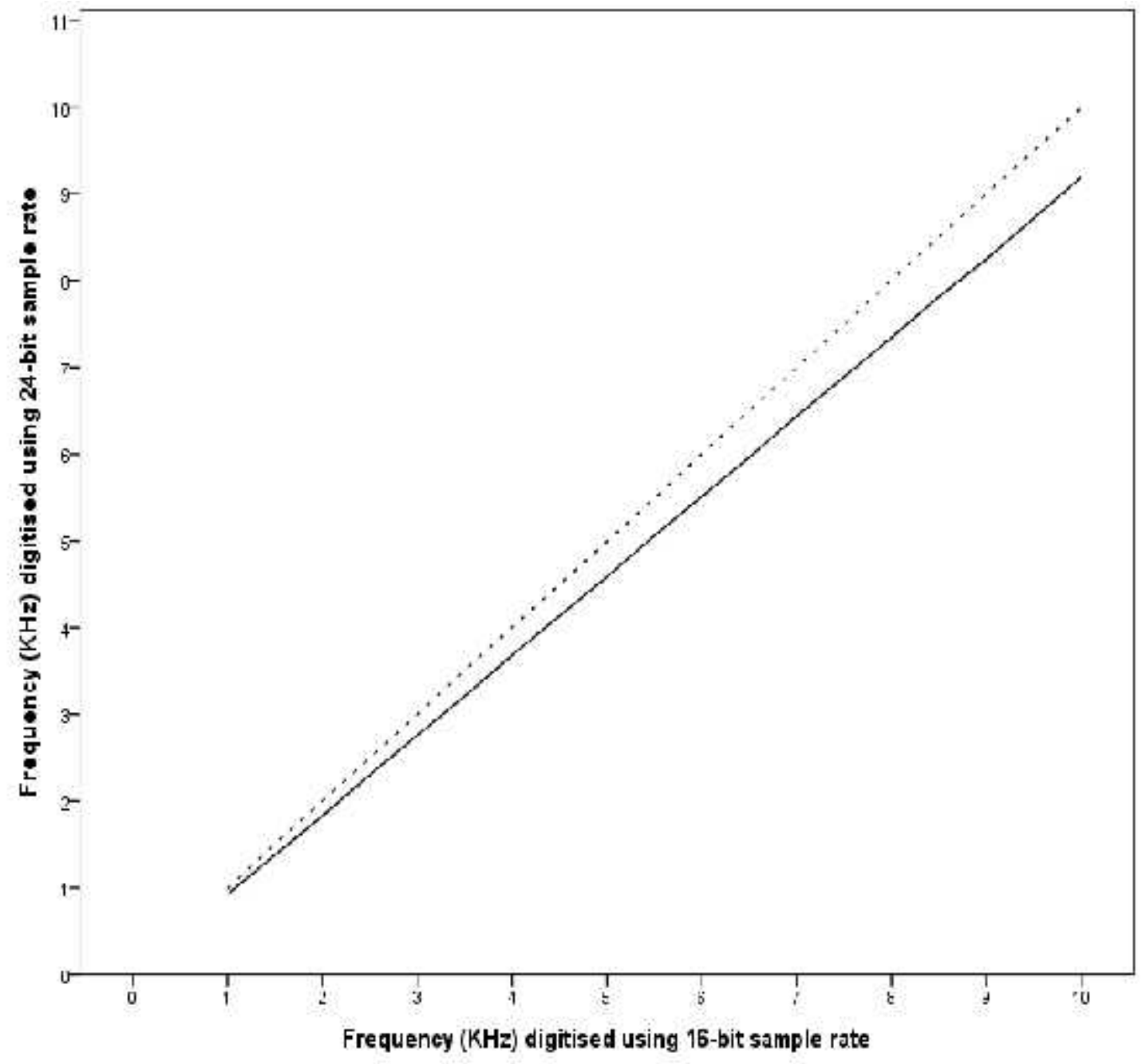




\section{References}

Allan, H. H. 1937. A consideration of the "Biological Spectra" of New Zealand. Journal of Ecology, 25, 116-152.

Andersen, C. 1926. Bird-Song and New Zealand Song Birds. Auckland, New Zealand: Whitcombe and Tombs.

Aubin, T. \& Jouventin, P. 2002. Localisation of an acoustic signal in a noisy environment: the display call of the king penguin Aptenodytes patagonicus. Journal of Experimental Biology, 205, 3793-3798.

Badyaev, A. V., Hill, E. \& Byron, V. W. 2002. Species divergence in sexually selected traits: increase in song elaboration is related to decrease in plumage ornamentation in finches. Evolution, 56, 412-419.

Badyaev, A. V. \& Leaf, E. S. 1997. Habitat associations of song characteristics in Phylloscopus and Hippolais warblers. Auk, 114, 40-46.

Baillie, S. R. 1990. Integrated population monitoring of breeding birds in Britain and Ireland. Ibis, 132, 151-166.

Baker, A. J. \& Jenkins, P. F. 1987. Founder effect and cultural evolution of songs in an isolated population of chaffinch, Fringilla coelebs, in the Chatham Islands. Animal Behaviour, 35, 1793-1803.

Baker, M. C., Baker, M. S. A. \& Tilghman, L. M. 2006. Different effects of isolation on evolution of bird songs: examples from an island-mainland comparison of three species. Biological Journal of the Linnean Society, 89, 331-342.

Baker, M. C. \& Cunningham, M. A. 1985. The biology of bird-song dialects. Behavioral and Brain Sciences, 8, 85-100.

Ball, G. \& Balthazart, D. 2002. Neuroendocrine mechanisms regulating reproductive cycles and reproductive behavior in birds. In: Hormones, Brain and 
Behavior (Ed. by D. Pfaff, A. Arnold, A. Etgen, S. Fahrbach \& R. Rubin), pp. 649798. USA: Elsevier Science.

Ballentine, B. \& Pfennig, D. 2006. Morphological adaptation influences the evolution of a mating signal. Evolution, 60, 1936-1944.

Baptista, L. F. 1975. Song dialects and demes in sedentary populations of the white-crowned sparrow (Zonotrichia leucophrys nuttalli). University of California Publications in Zoology, 105, 1-52.

Baptista, L. F. 1977. Geographic Variation in Song and Dialects of the Puget Sound White-Crowned Sparrow. The Condor, 79, 356-370.

Baptista, L. F. \& Petrinovich, L. 1984. Social interaction, sensitive phases and the song template hypothesis in the white-crowned sparrow. Animal Behaviour, $32,172-181$.

Barker, N. 2008. Bird song structure and transmission in the Neotropics: trends, methods and future directions. Ornitología Neotropical, 19, 175-199.

Bart, J. \& Earnst, S. 2002. Double sampling to estimate density and population trends in birds. Auk, 119, 36-45.

Bass, H. E. 1991. Atmospheric Acoustics. Encyclopedia of Applied Physics, 2, $145-179$.

Beani, L., Panzica, G., Briganti, F., Persichella, P. \& DessiFulgheri, F. 1995. Testosterone-induced changes of call structure, midbrain and syrinx anatomy in partridges. Physiology and Behavior, 58, 1149-1157.

Beecher, M. D., Beecher, I. M. \& Hahn, S. 1981. Parent-offspring recognition in bank swallows (Riparia riparia): Development and acoustic basis. Animal Behaviour, 29, 95-101. 
Bell, B. D. 1994. Vocalisations of Pacific island Acrocephalus warblers. The Ornithological Notebook of the XXI International Ornithological Congress, Vienna: Behaviour, p. 612.

Bell, B. D. 2006. Sustained song from the ground by a male chaffinch (Fringilla coelebs) in the Karori Wildlife Sanctuary, Wellington, New Zealand. Notornis, 53, 258-260.

Bell, B. D. 2008. The birds of the south Wellington region. In: The Taputeranga Marine Reserve (Ed. by J. P. A. Gardner). Wellington, New Zealand: First Edition Publishers.

Bell, D. A., Trail, P. W. \& Baptista, L. F. 1998. Song learning and vocal tradition in Nuttall's white-crowned sparrows. Animal Behaviour, 55, 939-956.

Bertelli, S. \& Tubaro, P. L. 2002. Body mass and habitat correlates of song structure in a primitive group of birds. Biological Journal of the Linnean Society, $77,423-430$.

Bibby, C. J., Burgess, N. D. \& Hill, D. A. 1992. Bird Census Techniques. London: Academic Press.

Bibby, C. J., Burgess, N. D., Hill, D. A. \& Mustoe, S. H. 2000. Bird Census Techniques, 2 edn. London: Acadimic Press.

Blumenrath, S. H. \& Dabelsteen, T. 2004. Degradation of great tit (Parus major) song before and after foliation: implications for vocal communication in a deciduous forest. Behaviour, 141, 935-958.

Blumstein, D.T \& Turner, A.C. 2005. Can the acoustic adaptation hypothesis predict the structure of Australian birdsong? Acta ethologica, 8, 35-44.

Boncoraglio, G. \& Saino, N. 2007. Habitat structure and the evolution of bird song: a meta-analysis of the evidence for the acoustic adaptation hypothesis. Functional Ecology, 21, 134-142. 
Bowman, R.I. 1979. Adaptive morphology of song dialects in Darwin's finches. Journal of Ornithology, 120, 353-389.

Brackenbury, J. H. 1979. Power capabilities of the avian sound-producing system. Journal of Experimental Biology, 78, 163-166.

Bradbury, J. W. \& Vehrencamp, S. L. 1998. Principles of Animal Communication. Sunderland, MA: Sinauer Associates.

Bremond, J. C. 1978. Acoustic competition between the songs of the wren (Troglodytes troglodytes) and the songs of other species. Behaviour, 65, 89-98.

Brenowitz, E. A. 1982. Long-range communication of species identity by song in the red-winged blackbird. Behavioral Ecology and Sociobiology, 10, 29-38.

Brown, T. J. \& Handford, P. 2000. Sound design for vocalizations: quality in the woods, consistency in the fields. Condor, 102, 81-92.

Brumm, H. 2009. Song amplitude and body size in birds. Behavioral Ecology and Sociobiology, 63, 1157-1165.

Brumm, H. \& Naguib, M. 2009. Environmental acoustics and the evolution of bird song. In: Advances in the Study of Behavior (Ed. by N. Marc, Z. Klaus, S. C. Nicola \& M. J. Vincent), pp. 1-33: Academic Press.

Brumm, H. \& Slabbekoorn, H. 2005. Acoustic communication in noise. Advances in the Study of Behavior, 35, 151-209.

Brumm, H. \& Slater, P.J.B. 2006a. Ambient noise, motor fatigue, and serial redundancy in chaffinch song. Behavioral Ecology and Sociobiology, 60, 475-481.

Brumm, H. \& Slater, P. J. B. 2006b. Animals can vary signal amplitude with receiver distance: evidence from zebra finch song. Animal Behaviour, 72, 699-705. Brumm, H. \& Todt, D. 2002. Noise-dependent song amplitude regulation in a territorial songbird. Animal Behaviour, 63, 891-897. 
Brunton, D. H. \& Li, X. 2006. The song structure and seasonal patterns of vocal behavior of male and female bellbirds (Anthornis melanura). Journal of Ethology, $24,17-25$

Buchanan, K. L. \& Catchpole, C. K. 1997. Female choice in the sedge warbler Acrocephalus schoenobaenus multiple cues from song and territory quality. Proceedings of the Royal Society of London, Series B, 264, 521-526.

Buckland, S. T., Anderson, D. R., Burnham, K. P., Laake, J. L. \& Borchers, D. L. 2001. Introduction to Distance Sampling: Estimating Abundance of Biological Populations. Oxford: Oxford University Press.

Buller, W. L. 1888. A History of the Birds New Zealand. 2edn, the author, London, U.K.

Burnham, K. P. 1981. Summarizing remarks: environmental influences. Studies in Avian Biology, 6, 324-325.

Byers, B. E., Belinsky, K. L. \& Bentley, R. A. 2010. Independent cultural evolution of two song traditions in the chestnut sided warbler. American Naturalist, $176,476-489$

Campbell, D. J. \& Atkinson, I. A. E. 2002. Depression of tree recruitment by the Pacific rat (Rattus exulans Peale) on New Zealand's northern offshore islands. Biological Conservation, 107, 19-35.

Cardoso, G. \& Price, T.D. 2010. Community convergence in bird song. Evolutionary Ecology, 24, 447-461.

Cassey, P., Craig, J.L., McArdle, B.H. \& Barraclough, R.K. 2007. Distance sampling techniques compared for a New Zealand endemic passerine (Philesturnus carunculatus rufusater). New Zealand Journal of Ecology, 31, 223231.

Catchpole, C. K. 1973. The functions of advertising song in the sedge warbler and reed warbler. Behaviour, 46, 300-320. 
Catchpole, C. K. 1980. Sexual selection and the evolution of complex songs among European warblers of the genus Acrocephalus. Behaviour, 74, 149-166. Catchpole, C. K., Dittami, J. \& Leisler, B. 1984. Differential responses to male song repertoires in female songbirds implanted with oestradiol. Nature, 312, 563564.

Catchpole, C. K. \& McGregor, P. K. 1985. Sexual selection, song complexity and plumage dimorphism in European buntings of the genus Emberiza. Animal Behaviour, 33, 1378-1380.

Catchpole, C. K. \& Slater, P. J. B. 2008. Bird song: Biological Themes and Variations, 2 edn. Cambridge, UK: Cambridge University Press.

Chek, A.A., Bogart, J.P. \& Lougheed, S.C. 2003. Mating signal partitioning in multi-species assemblages: a null model test using frogs. Ecology Letters, 6, 235247.

Chilton, G., Wiebe, M. O. \& Handford, P. 2002. Large-scale geographic variation in songs of gambel's white-crowned sparrows. Condor, 104, 378-386.

Clark, P.J. \& Evans, F.C. 1979. Generalization of a nearest neighbor measure of dispersion for use in $\mathrm{k}$ dimensions. Ecology, 60, 316-317.

Clark, P. J. \& Evans, F. C. 1954. Distance to nearest neighbor as a measure of spatial relationships in populations. Ecology, 35, 445-453.

Collins, S. 2004. Vocal fighting and flirting: the functions of birdsong. In: Nature's music (Ed. by P. Marler \& H. Slabbekoorn), pp. 39-79. San Diego, CA: Elsevier Academic Press.

Cosens, S. E. \& Falls, J. B. 1984. A comparison of sound propagation and song frequency in temperate marsh and grassland habitats. Behavioral Ecology and Sociobiology, 15, 161-170.

Craig, J. L. 1984. Wing noises, wing slots, and aggression In New Zealand honeyeaters (Aves: Mehphagldae). New Zealand Journal of Zoology, 11, 195-200. 
Cramp, S. \& Snow, D. 1988. Handbook of the Birds of Europe, the Middle East and North Africa. The Birds of the Western Palearctic. Volume 5. Tyrant and Flycatcher to Thrushes. pp.995-996: Oxford University Press.

Cynx, J., Lewis, R., Tavel, B. \& Tse, H. 1998. Amplitude regulation of vocalizations in noise by a songbird, Taeniopygia guttata. Animal Behaviour, 56, 107-113.

Daniel, J. C. \& Blumstein, D. T. 1998. A test of the acoustic adaptation hypothesis in four species of marmots. Animal Behaviour, 56, 1517-1528.

Dantzker, M. S., Deane, G. B. \& Bradbury, J. W. 1999. Directional acoustic radiation in the strut display of male sage grouse Centrocercus urophasianus. Journal of Experimental Biology, 202, 2893-2909.

Darwin, C. J., Ciocca, V. \& Sandell, G. J. 1994. Effects of frequency and amplitude modulation on the pitch of a complex tone with a mistuned harmonic. The Journal of Acoustical Society of America, 95, 2631-2636.

Dawson, D. G. \& Bull, P. C. 1975. Counting birds in New Zealand forests. Notornis, 22, 101-109.

Dawson, J.W. 1988a. Forest Vines to Snow Tussocks: The Story of New Zealand Plants. Wellington N.Z.: Victoria University Press.

De Kort, S. R., Eldermire, E. R. B., Valderrama, S., Botero, C. A. \& Vehrencamp, S. L. 2009. Trill consistency is an age-related assessment signal in banded wrens. Proceedings of the Royal Society of London, Series B, 276, 23152321.

Derryberry, E. P. 2009. Ecology shapes birdsong evolution: variation in morphology and habitat explains variation in white-crowned sparrow song. American Naturalist, 174, 24-33.

Desante, D. F. 1986. A field test of the variable circularplot censusing method in a Sierran (California, USA) subalpine forest habitat. Condor, 88, 129-142. 
DeVoogd, T. J. 1991. Endocrine modulation of the development and adult function of the avian song system. Psychoneuroendocrinology, 16,41-66.

Doebeli, M. \& Dieckmann, U. 2003. Speciation along environmental gradients. Nature, 421, 259-264.

Donnelly, K. 1978. Simulations to determine the variance and edge-effect of total nearest neighbor distance. In: Simulation Methods in Archeology (Ed. by I. Hodder), pp. 91-95. London, England: Cambridge University Press.

Douglas, G. R. \&Wiley R.H. 1980. Reverberation and amplitude fluctuation in the propagation of sound in a forest: implication for animal communication. The American Society of Naturalist. 115, 381-399.

Doutrelant, C. \& Lambrechts, M. 2001. Macrogeographic variation in song-a test of competition and habitat effects in blue tits. Ethology, 107, 533-544.

Doutrelant, C., Leitao, A., Giorgi, M. \& Lambrechts, M. M. 1999. Geographical variation in blue tit song, the result of an adjustment to vegetation type? Behaviour, 136, 481-493.

Draganoiu, T. I., Nagle, L., Musseau, R. \& Kreutzer, M. 2006. In a songbird, the black redstart, parents use acoustic cues to discriminate between their different fledglings. Animal Behaviour, 71, 1039-1046.

Ellinger, N. \& Hodl, W. 2003. Habitat acoustics of a Neotropical lowland rainforest. Bioacoustics, 13, 297-321.

Embleton, T. F. W. 1996. Tutorial on sound propagation outdoors. Acoustical Society of America, 100, 31-48.

Emlen, S. T. 1972. An experimental analysis of the parameters of bird song eliciting species recognition. Behaviour, 41, 130-171.

Endler, J. A. 1992. Signals, signal conditions, and the direction of evolution. American Naturalist, 139, 125-153. 
Eriksson, D. \& Wallin, L. 1986. Male bird song attracts females: a field experiment. Behavioural Ecology and Sociobiology, 19, 297-300.

Evans, E. J. \& Bailey, E. N. 1956. The absorption of sound in air at audio frequencies. Acustica, 6, 238-245.

Evans, K. L., Duncan, R. P., Blackburn, T. M. \& Crick, H. Q. P. 2005. Investigating geographic variation in clutch size using a natural experiment. Functional Ecology, 19, 616-624.

Ey, E. \& Fischer, J. 2009. The 'acoustic adaptation hypothesis': a review of the evidence from birds, anurans and mammals. Bioacoustics, 19, 21-48.

Falls, J. 1963. Properties of bird song eliciting responses from territorial males. Proceedings of the13th International Ornithological Congress, 1, 259-271.

Falls, J. B. 1988. Does song deter territorial intrusion in white-throated sparrows (Zonotrichia albicollis)? Canadian Journal of Zoology, 66, 206-211.

Fernandez-Juricic, E., Poston, K. D., Collibus, R., Morgan, T., Bastain, B., Martin, C., Jones, K. \& Tremininio, R. 2005. Microhabitat selection and singing behavior patterns of male house finches (Carpodacus mexicanus) in urban parks in a heavily urbanized landscape in the western U.S. Urban Habitats, 3, 49-69. Ficken, R. W., Ficken, M. S. \& Hailman, J. P. 1974. Temporal pattern shifts to avoid acoustic interference in singing birds. Science, 183, 762-763.

Fitch, W. T. 1999. Acoustic exaggeration of size in birds via tracheal elongation: comparative and theoretical analyses. Journal of Zoology, 248, 31-48.

Fitch, W. T. \& Kelley, J. P. 2000. Perception of vocal Tract resonances by whooping cranes Grus grus americana. Ethology, 106, 559-574.

Fleischer, R. C., James, H. F. \& Olson, S. L. 2008. Convergent evolution of Hawaiian and Australo-Pacific honeyeaters from distant songbird ancestors. Current Biology, 18, 1927-1931. 
Forrest, T. G. 1994. From sender to receiver: propagation and environmental effects on acoustic signals. American Zoologist, 34, 644-654.

Forstmeier, W. \& Balsby, T. J. S. 2002. Why mated dusky warblers sing so much: territory guarding and male quality announcement. Behaviour, 139, 89-111. Fotheringham, J. \& Ratcliffe, L. 1995. Song degradation and estimation of acoustic distance in black-capped chickadees (Parus atricapillus). Canadian Journal of Zoology, 73, 858-868.

Fotheringham, J. R., Martin, P. R. \& Ratcliffe, L. 1997. Song transmission and auditory perception of distance in wood warblers (Parulinae). Animal Behaviour, $53,1271-1285$.

Garland, E. C., Phillips, S. K. \& Steer, J. E. 2004. Do New Zealand song thrush (Turdus philomelos) sing the songs of their native range? Unpublished postgraduate report, Victoria University of Wellington.

Gaston, K. J. 2000. Global pattern in biodiversity. Nature, 405, 200-222.

Gelter, H. P. 1987. Song differences between the pied flycatcher Ficedula hypoleuca, the collared flycatcher $F$. albicollis, and their hybrids. Ornis Scandinavica, 18, 205-215.

Gerhardt, H. \& Huber, F. 2002. Acoustic Communication in Insects and Anurans. Chicago: University of Chicago Press.

Gibb, J. A. 1996. First seen or first heard? A useful distinction when counting forest birds. Notornis, 43, 7-13.

Gibb, J. A. 2000. Activity of birds in the Western Hutt Hills, New Zealand. Notornis, 47, 13-35.

Gil, D. \& Gahr, M. 2002. The honesty of bird song: multiple constraints for multiple traits. Trends in Ecology and Evolution, 17, 133-141.

Gill, B. J. 1980. Abundance, feeding and morphology of passerine birds at Kowhai Bush, Kaikoura, New Zealand. New Zealand Journal of Zoology, 7, 235-224. 
Gill, B. J. 1982. Breeding of the grey warbler (Gerygone igata) Kaikoura, New Zealandia. Ibis, 124, 123-147.

Gill, B. J., Bell, B. D., Chambers, G. K., Medway, D. G., Palma, R. L., Scofield, R. P., Tennyson, A. J. D. \& Worthy, T. H. 2010. Checklist of the Birds of New Zealand, Norfolk and Macquarie islands, and the Ross Dependency, Antarctica, 4th edn. Wellington, New Zealand: Ornithological Society of New Zealand and Te Papa Press.

Gill, B. J., Powlesland, M. H. \& Powlesland, R. G. 1980. Notes on the brown creeper (Finschia novaeseelandiae). Notornis, 27, 129-132.

Gish, S. \& Morton, E. 1981. Structural adaptations to local habitat acoustics in Carolina wren songs. Zeitschrift für Tierpsychologie, 56, 74-84.

Goretskaia, M. I. 2004. Song structure and singing behaviour of willow warbler (Phylloscopus trochilus acredula) in populations of low and high density. Bioacoustics, 14, 183-195.

Grant, P. R. \& Grant, B. R. 1997. Mating patterns of Darwin's finch hybrids determined by song and morphology. Biological Journal of the Linnean Society, $60,317-343$.

Greene, E., Muehter, V. R. \& Davison, W. 1997. Lazuli Bunting (Passerina amoena). In: The Birds of North America (Ed. by A. Poole \& F. Gill). Washington, DC: Academy of Natural Sciences /American Ornithologists' Union.

Handel, S. 1995. Timbre perception and auditory object identification. In: Hearing, pp. 425-461. San Diego, CA: Academic Press.

Handford, P. 1988. Trill rate dialects in the rufouscollared sparrow (Zonotrichia capensis) in northwestern Argentina. Canadian Journal of Zoology, 66, 2658-2670.

Handford, P. \& Lougheed, S. C. 1991. Variation in duration and frequency characters in the song of the rufous-collared sparrow (Zonotrichia capensis) with respect to habitat, trill dialects and body size. Condor, 93, 644-658. 
Hansen, P. 1999. Long-term stability of song elements in the yellowhammer (Emberiza citrinella). Bioacoustics, 9, 281-295.

Harmon, L. J., Kolbe, J. J., Cheverud, J. M. \& Losos, J. B. 2005. Convergence and the multidimensional niche. Evolution, 59, 409-421.

Harris, C. M. 1966. Absorption of sound in air versus humidity and temperature. Journal of the Acoustical Society of America, 40, 148-159.

Hartley, R. S., Chinn, M. S. \& Ullrich, N. F. E. 1997. Left syringeal dominance in testosterone-treated female canaries. Neurobiology of Learning and Memory, 67, 248-253

Haselmayer, J. \& Quinn, J. S. 2000. A comparison of point counts and sound recording as bird survey methods in Amazonian Southeast Peru. Condor, 102, 887-893

Hatchwell, B. J., Ross, D. J., Fowlie, M. K. \& McGowan, A. 2001. Kin discrimination in cooperatively breeding long-tailed tits. Proceedings of the Royal Society of London, Series B, 268, 885-890.

Heather, B. \& Robertson, H. 2000. The Field Guide to the Birds of New Zealand. Auckland, New Zealand: Viking.

Holland, B. \& Rice, W. R. 1998. Perspective: chase-away sexual selection: antagonistic seduction versus resistance. Evolution, 52, 1-7.

Hultsch, H. \& Todt, D. 1982. Temporal performance roles during vocal interactions in nightingales. Behavioral Ecology and Sociobiology, 11, 253-260.

Hultsch, H. \& Todt, D. 2008. Comparative aspects of song learning. In: Neuroscience of Birdsong (Ed. by H. P. Zeigler \& P. Marler), pp. 204-216: Cambridge University Press.

Hunter, M. L. \& Krebs, J. R. 1979. Geographical variation in the song of the great tit (Parus major) in relation to ecological factors. Journal of Animal Ecology, 48, 759-785. 
Hurnard, S. M. 1978. Climatic factors in the seasonality of New Zealand insects: a meteorological viewpoint. The New Zealand Entomologist, 6, 337-343.

Ince, S. A., Slater, P. J. B. \& Weismann, C. 1980. Changes with time in the songs of a population of chaffinches. Condor, 82, 285-290.

Irwin, D. E. 2000. Song variation in an avian ring species. Evolution, 54, 9981010.

Jenkins, P. F. 1978. Cultural transmission of song patterns and dialect development in a free-living bird population. Animal Behaviour, 26, 50-78. Jouventin, P., Aubin, T. \& Lengagne, T. 1999. Finding a parent in a king penguin colony: the acoustic system of individual recognition. Animal Behaviour, $57,1175-1183$.

Keddy, P. A. 1992. A pragmatic approach to functional ecology. Functional Ecology, 6, 621-626.

King, C. M., McDonald, R. M., Martin, R. D. \& Dennis, T. 2009a. Why is eradication of invasive mustelids so difficult? Biological Conservation, 142, 806816.

King, C. M., Roberts, C. D., Bell, B. D., Fordyce, R. E., Nicoll, R. S., Worthy, T. H., Paulin, C. D., Hitchmough, R. A., Keyes, I. W., Baker, A. N., Stewart, A. L., Hiller, N., McDowall, R. M., Holdaway, R. N., McPhee, R. P., Schwarzhans, W. W., Tennyson, A. J. D., Rust, S. \& Macadie, I. 2009b. Phylum Chordata. In: New Zealand Inventory of Biodiversity. Kingdom Animalia (Ed. by D. P. Gordon), pp. 431-551. Christchurch: Canterbury University Press.

Kirschel, A. N. G., Blumstein, D. T., Cohen, R. E., Buermann, W., Smith, T. B. \& Slabbekoorn, H. 2009. Birdsong tuned to the environment: green hylia song varies with elevation, tree cover, and noise. Behavioral Ecology, 20, 1089-1095. 
Koetz, A. H., Westcott, D. A. \& Congdon, B. C. 2007. Geographical variation in song frequency and structure: the effects of vicariant isolation, habitat type and body size. Animal Behaviour, 74, 1573-1583.

Krause, B. 1987. Bioacoustics, habitat ambience in ecological balance. Whole Earth Review, 57, 14-18.

Krause, B. L. 1993. The niche hypothesis: a hidden symphony of animal sounds, the origins of musical expression and the health of habitats. Explorers Journal, 71, 156-160.

Krebs, J., Ashcroft, R. \& Webber, M. 1978. Song repertoires and territory defence in the great tit. Nature, 271, 539-542.

Krebs, J. R. 1977. The significance of song repertoires: the beau geste hypothesis. Animal Behaviour, 25, 428-478.

Kroodsma, D. E. 2004. The diversity and plasticity of birdsong. In: Nature's Music: The Science of Birdsong (Ed. by P. Marler \& H. Slabbekoorn), pp. 111-130. London: Elsevier Academic press.

Kroodsma, D. E. 1976. Reproductive development in a female songbird: differential stimulation by quality of male song. Science, $192,574-575$. Kroodsma, D. E. 1985. Geographic variation in songs of the Bewick's wren: a search for correlations with avifaunal complexity. Behavioral Ecology and Sociobiology, 16, 143-150.

Kroodsma, D. E. 1999. Making ecological sense of song development by songbirds. In: The Design of Animal Communication (Ed. by M. D. Hauser \& M. Konishi), pp. 319-342. Cambridge, MA: Massachusetts Institute of Technology. Kroodsma, D. E. \& Canady, R. A. 1985. Differences in repertoire size, singing behavior, and associated neuroanatomy among marsh wren populations have a genetic basis. Auk, 102, 439-446. 
Kroodsma, D. E. \& Miller, E.H. 1982. Acoustic Communication in Birds. New York: Academic Press.

Kroodsma, D. E. \& Pickert, R. 1980. Environmentally dependent sensitive periods for avian vocal learning. Nature, 288, 477-479.

Kroodsma, D. E. \& Verner, J. 1978. Complex singing behaviors among Cistothorus wrens. Auk, 95, 703-716.

Kroon, F. J. \& Westcott, D. A. 2006. Song variation and habitat structure in the golden bowerbird. Emu, 106, 263-272.

Laiolo, P. \& Rolando, A. 2003. Comparative analysis of the rattle calls in Corvus and Nucifraga: the effect of body size, bill size, and phylogeny. Condor, 105, 139144.

Langerhans, R. B., Knouft, J. H. \& Losos, J. B. 2006. Shared and unique features of diversification in Greater Antillean Anolis ecomorphs. Evolution, 60, 362-369.

Larom, D., Garstang, M., Payne, K., Raspet, R. \& Lindeque, M. 1997. The influence of surface atmospheric conditions on the range and area reached by animal vocalizations. Journal of Experimental Biology, 200, 421-431.

Leader, N., Wright, J. \& Yom-Tov, Y. 2000. Microgeographic song dialects in the orange-tufted sunbird (Nectarinia osea). Behaviour, 137, 1613-1627.

Lemon, R., Struger, J., Lechowicz, M. \& Norman, R. 1981. Song features and singing heights of American warblers: maximization or optimization of distance. Journal of Acoustical society of America, 69, 1169-1176.

Lemon, R. E. 1975. How birds develop song dialects. Condor, 77, 385-406. Lengagne, T., Aubin, T., Lauga, J. \& Jouventin, P. 1999. How do king penguins Aptenodytes patagonicus apply the mathematical theory of information to communicate in windy conditions? Proceedings of the Royal Society of London, Series B, 266, 1623-1628. 
Lever, C. 1987. Naturalized Birds of the World. New York: Iongman Science tech.

Littel, R. C., Freund, R. J. \& Spector, P. C. 1991. SAS System for Linear Models: SAS Institute Inc.

Locantore, N., Marron, J., Simpson, D., Tripoli, N., Zhang, J., Cohen, K., Boente, G., Fraiman, R., Brumback, B., Croux, C., Fan, J., Kneip, A., Marden, J., Peña, D., Prieto, J., Ramsay, J., Valderrama, M. \& Aguilera, A. 1999. Robust principal component analysis for functional data. TEST, 8, 1-73.

Lohr, B. \& Dooling, R. J. 1998. Detection of changes in timbre and harmonicity in complex sounds by zebra finches (Taeniopygia guttata) and budgerigars (Melopsittacus undulatus). Journal of Comparative Psychology, 112, 36-47.

Lord, K., Feinstein, M. \& Coppinger, R. 2009. Barking and mobbing. Behavioural Processes, 81, 358-368.

Loreau, M. 2010. Linking biodiversity and ecosystems: towards a unifying ecological theory. Philosophical Transactions of the Royal Society, Biological Sciences, 365, 49-60.

Losos, J. B. 1992. The evolution of convergent structure in Caribbean Anolis communities. Systematic Biology, 41, 403-420.

Losos, J. B., Jackman, T. R., Larson, A., De Queiroz, K. \& RodríguezSchettino, L. 1998. Contingency and determinism in replicated adaptive radiations of island lizards. Science, 279, 2115-2118.

Luther, D. 2009. The influence of the acoustic community on songs of birds in a neotropical rain forest. Behavioral Ecology, 20, 864-871.

Luther, D. \& Baptista, L. 2010. Urban noise and the cultural evolution of bird songs. Proceedings of the Royal Society of London, Series B, 277, 469-473. Lynch, A. 1996. The population mimetics of birdsong. In: Ecology and Evolution of Acoustic Communication in Birds (Ed. by D. E. Kroodsma \& E. H. Miller), pp. 181197. Ithaca, NY: Cornell University Press. 
MacDougall-Shackleton, S. A. 1997. Sexual selection and the evolution of song repertoires. In: Current Ornithology (Ed. by V. J. Nolan, E. D. Ketterson \& C. F. Thompson), pp. 81-124. New York, NY: Plenum Press.

MacLeod, C. J., Newson, S. E., Blackwell, G. \& Duncan, R. P. 2009. Enhanced niche opportunities: can they explain the success of New Zealand's introduced bird species? Diversity and Distributions, 15, 41-49.

Marchant, S., Higgins, P. J., Ambrose, S. J., Davies, S. J. J. F. \& Steele, W. K. 2006. Handbook of Australian, New Zealand \& Antarctic Birds, South Melbourne: Oxford University Press.

Marion, W. R. 1977. Growth and development of the plain chachalaca in South Texas. The Wilson Bulletin, 89, 47-56.

Mark, P. 2004. Reverberation and frequency attenuation in forests? implications for acoustic communication in animals. Journal of the Acoustical Society of America, 115, 402-410.

Marler, P. 2004. Bird calls: a cornucopia for communication. In: Nature's Music: The Science of Birdsong (Ed. by P. Marler \& H. Slabbekoorn), pp. 132-177. New York, NY: Elsevier Academic Press. .

Marler, P. \& Peters, S. 1987. A sensitive period for song acquisition in the song sparrow (Melospiza melodia): a case of age-limited learning. Ethology, 76, 89-100. Marler, P. \& Peters, S. 1988. The role of song phonology and syntax in vocal learning preferences in the song sparrow (Melospiza melodia). Ethology, 77, 125149.

Marler, P. \& Sherman, V. 1985. Innate differences in singing behavior of sparrows reared in isolation from adult conspecific song. Animal Behaviour, 33, $57-71$

Marler, P. \& Slabbekoorn, H. W. 2004. Nature's Music: The Science of Birdsong. San Diego, California: Elsevier Academic Press. 
Marler, P. \& Tamura, M. 1964. Culturally transmitted patterns of vocal behavior in sparrows. Science, 146, 1483-1486.

Marten, K. \& Marler, P. 1977. Sound transmission and its significance for animal vocalization. Behavioral Ecology and Sociobiology, 2, 271-290.

Marten, K., Quine, D. \& Marler, P. 1977. Sound transmission and Its significance for animal vocalization: tropical forest habitats. Behavioral Ecology and Sociobiology, 2, 291-302.

Martens, M. J. M. 1980. Foliage as a low-pass filter: experiments with model forests in an anechoic chamber. Journal of the Acoustical Society of America, 67, 66-72.

Martens, M. J. M., Severens, P. P. J., Van Wissen, H. A. W. M. \& Van Der Heijden, L. A. M. 1985. Acoustic reflection characteristics of deciduous plant leaves. Environmental and Experimental Botany, 25, 285-292.

Mason, C. F. 1998. Habitats of the song thrush Turdus philomelos in a largely arable landscape. Journal of Zoology, 244, 89-93.

Mathevon, N., Dabelsteen, T. \& Blumenrath, S. H. 2005. Are high perches in the blackcap (Sylvia atricapilla) song or listening posts? A sound transmission study. Journal of Acoustical society of America, 117, 442-451.

May, B., Moody, D. B. \& Stebbins, W. C. 1989. Categorical perception of conspecific communication sounds by Japanese macaques, Macaca fuscata. Journal of the Acoustical Society of America, 85, 837-847.

McGregor, P. K. 1980. Song dialects in the corn bunting (Emberiza calandra). Zeitschrift für Tierpsychologie, 54, 285-297.

McGregor, P. K. \& Krebs, J. R. 1984. Sound degradation as a distance cue in great tit (Parus major) song. Behavioral Ecology and Sociobiology, 16, 49-56. 
McGregor, P. K., Krebs, J. R. \& Ratcliffe, L. M. 1983. The reaction of great tits (Parus major) to playback of degraded and undegraded songs: the effect of familiarity with the stimulus song type. Auk, 100, 898-906.

McGregor, P. K., Peake, T. M. \& Gilbert, G. 2000. Communication behaviour and conservation. In: Behaviour and Conservation (Ed. by L. M. Gosling \& W. J. Sutherland), pp. 261-280. Cambridge: University Press.

Michelsen, A. 1983. Biophysical basis of sound communication. In: Bioacoustics: A Comparative Approach (Ed. by B. Lewis), pp. 3-38. London: Academic Press. Miller, E. H. 1982. Character and variance shift in acoustic signals of birds. In: Acoustic Communication in Birds (Ed. by D. E. Kroodsma \& E. H. Miller), pp. 253295. New York: Academic Press.

Miskelly, C., Empson, R. \& Wright, K. 2005. Forest birds recolonising Wellington. Notornis, 52, 21-26.

Moles, A. T. \& Drake, D. R. 1999. Potential contributions of the seed rain and seed bank to regeneration of native forest under plantation pine in New Zealand. New Zealand Journal of Botany, 37, 83-93.

Morton, E. S. 1975. Ecological sources of selection on avian sounds. American Naturalist, 109, 17.

Morton, E. S., Gish, S. L. \& van der Voort, M. 1986. On the learning of degraded and undegraded songs in the Carolina wren. Animal Behaviour, 34, 815-820.

Mundinger, P. C. 1982. Microgeographic and macrogeographic variation in acquired vocalizations in birds. In: Acoustic Communication in Birds (Ed. by D. E. Kroodsma \& E. H. Miller), pp. 147-208. New York: Academic Press.

Naguib, M. 1995. Auditory distance assessment of singing conspecifies in Carolina wrens: the role of reverberation and frequency-dependent attenuation. Animal Behaviour, 50, 1297-1307. 
Naguib, M. 1996. Auditory distance estimation in song birds: implications, methodologies and perspectives. Behavioural Processes, 38, 163-168.

Naguib, M. 1997a. Ranging of songs in Carolina wrens: effects of familiarity with the song type on use of different cues. Behavioral Ecology and Sociobiology, 40, 385-393.

Naguib, M. 1997b. Use of song amplitude for ranging in Carolina wrens (Thryothorus Iudovicianus). Ethology, 103, 723-731.

Naguib, M. 1998. Perception of degradation in acoustic signals and its implications for ranging. Behavioral Ecology and Sociobiology, 42, 139-142.

Naguib, M. 2003. Reverberation of rapid and slow trills: Implications for signal adaptations to long-range communication. Journal of the Acoustical Society of America, 113, 1749-1756.

Naguib, M., Klump, G. M., Hillmann, E., Griessmann, B. \& Teige, T. 2000. Assessment of auditory distance in a territorial songbird: accurate feat or rule of thumb? Animal Behaviour, 59, 715-721.

Naguib, M. \& Wiley, R. H. 2001. Estimating the distance to a source of sound: mechanisms and adaptations for long-range communication. Animal Behaviour, $62,825-837$.

Naugler, C. \& Ratcliffe, L. 1994. Character release in bird song: a test of the acoustic competition hypothesis using American tree sparrows (Spizella arborea). Journal of Avian Biology, 25, 142148.

Nelson, B. S. 2000. Avian dependence on sound pressure level as an auditory distance cue. Animal Behaviour, 59, 57-67.

Nelson, D. A. 1997. Social Interaction and Sensitive Phases for Song Learning: A Critical Review. Cambridge: Cambridge University Press.

Nelson, D. A. 1999. Ecological influences on vocal development in the whitecrowned sparrow. Animal Behaviour, 58, 21-36. 
Nelson, D. A. \& Marler, P. 1990. The perception of birdsong and an ecological concept of signal space. In: Comparative Perception Volume II: Complex Signals (Ed. by M. A. Berkley \& W. C. Stebbins), pp. 443-478. New York: John Wiley and Sons.

Nelson, D. A. \& Soha, J. A. 2004. Perception of geographical variation in song by male puget sound white-crowned sparrows, Zonotrichia leucophrys pugetensis. Animal Behaviour, 68, 395-405.

Nemeth, E. \& Brumm, H. 2009. Blackbirds sing higher-pitched songs in cities: adaptation to habitat acoustics or side-effect of urbanization? Animal Behaviour, $78,637-641$.

Nemeth, E., Dabelsteen, T., Pedersen, S. B. \& Winkler, H. 2006. Rainforests as concert halls for birds: are reverberations improving sound transmission of long song elements? Journal of Acoustical society of America, 119, 620-622.

Nemeth, E., Winkler, H. \& Dabelsteen, T. 2001. Differential degradation of antbird songs in a Neotropical rainforest: adaptation to perch height? Journal of the Acoustical Society of America, 110, 3263-3274.

Newman, M. M., Yeh, P. J. \& Price, T. D. 2006. Reduced territorial responses in dark-eyed juncos following population establishment in a climatically mild environment. Animal Behaviour, 71, 893-899.

Nicholls, J. A. \& Goldizen, A. W. 2006. Habitat type and density influence vocal signal design in satin bowerbirds. Journal of Animal Ecology, 75, 549-558.

Nichols, J. D., Hines, J. E., Sauer, J. R., Fallon, F., Fallon, J. \& Heglund, P. J. 2000. A double-observer approach for estimating detection probability and abundance from avian point counts. Auk, 117, 393-408.

NIWA. 2010. National climate centre. http://www.niwa.co.nz/education-andtraining/schools/resources/climate/overview. 
Nottebohm, F., Nottebohm, M. E. \& Crane, L. 1986. Developmental and seasonal changes in canary song and their relation to changes in the anatomy of song control nuclei. Behavioral and Neural Biology, 46, 445-471.

Nowicki, S., Searcy, W. A. \& Hughes, M. 1998. The territory defence function of song in song sparrows: a test with the speaker occupation design. Behaviour, 135, $615-628$.

Osiejuk, T., Ratynska, K., Cygan, J. \& Dale, S. 2003. Song structure and repertoire variation in ortolan bunting (Emberiza hortulana L.) from isolated Norwegian population. Annals Zoologica Fennici, 40, 3-16.

Ovington, J. D. \& Pryor, L. D. 1983. Temperate Broad-leaved Evergreen Forests of Australia. Amsterdam: Elsevier.

Padgham, M. 2004. Reverberation and frequency attenuation in forests, implications for acoustic communication in animals. Journal of the Acoustical Society of America, 115, 402-410.

Patricelli, G. L. \& Blickley, J. L. 2006. Avian communication in urban noise: causes and consequences of vocal adjustment. Auk, 123, 639-649.

Patten, M. A., Rotenberry, J. T. \& Zuk, M. 2004. Habitat selection, acoustic adaptation, and the evolution of reproductive isolation. Evolution, 58, 2144-2155. Paul, R. S. \& McKenzie., H. R. 1975. A bushman's seventeen years of noting birds. Part B - New Zealand Pipit, grey warbler, North Island fantail and silvereye. Notornis, 22, 273-282.

Payne, R. B., Payne, L. L. \& Doehlert, S. M. 1988. Biological and cultural success of song memes in indigo buntings. Ecology, 69, 104-117.

Payne, R. B., Payne, L. L. \& Woods, J. L. 1998. Song learning in brood-parasitic indigobirds Vidua chalybeata: song mimicry of the host species. Animal Behaviour, $55,1537-1553$. 
Payne, R. B., Thompson, W. L., Fiala, K. L. \& Sweaney, L. L. 1981. Local song traditions in indigo buntings: cultural transmission of behavior patterns across generations. Behaviour, 77, 199-221.

Peres-Neto, P. R., Jackson, D. A. \& Somers, K. M. 2003. Giving meaningful interpretation to ordination axes: assessing loading significance in principal component analysis. Ecology, 84, 2347-2363.

Pfennig, K. S. 2000. Female spadefoot toads compromise on mate quality to ensure conspecific mating. Behavioral Ecology, 11, 220-227.

Pijanowski, B., Farina, A., Gage, S., Dumyahn, S. \& Krause, B. 2011a. What is soundscape ecology? An introduction and overview of an emerging new science. Landscape Ecology, 26, 1213-1232.

Pijanowski, B. C., Villanueva-Rivera, L. J., Dumyahn, S. L., Farina, A., Krause, B. L., Napoletano, B. M., Gage, S. H. \& Pieretti, N. 2011b. Soundscape ecology: the science of sound in the landscape. BioScience, 61, 203-216.

Planqué, R. \& Slabbekoorn, H. 2008. Spectral overlap in songs and temporal avoidance in a peruvian bird assemblage. Ethology, 114, 262-271.

Podos, J. 2001. Correlated evolution of morphology and vocal signal structure in Darwin's finches. Nature, 409, 185-193.

Podos, J. \& Nowicki, S. 2004. Beaks, adaptation, and vocal evolution in darwin's finches. BioScience, 54, 501-510.

Podos, J. \& Warren, P. S. 2007. The evolution of geographic variation in birdsong. In: Advances in the Study of Behavior (Ed. by H. J. Brockmann, T. J. Roper, M. Naguib, K. E, C. Wynne-Edwards \& B. John), pp. 403-458: Academic Press.

Price, J. J., Friedman, N. R. \& Omland, K. E. 2007. Song and plumage evolution in the new world orioles (Icterus) show similar liability and convergence in patterns. Evolution, 61, 850-863. 
Price, T. D. 2008. Speciation in Birds. Greenwood: Robert and Company Publishers.

Pytte, C. L., Rusch, K. M. \& Ficken, M. S. 2003. Regulation of vocal amplitude by the blue-throated hummingbird, Lampornis clemenciae. Animal Behaviour, 66, 703-710.

Richards, D. G. 1981. Estimation of distance of singing conspecifics by the Carolina wren. Auk, 98, 127-133.

Robertson, C. J. R., Hyvönen, P., Fraser, M. J. \& Pickard, C. R. 2007. Atlas of Bird Distribution in New Zealand 1999-2004. Wellington: Ornithological Society of New Zealand.

Robinson, R. A., Green, R. E., Baillie, S. R., Peach, W. J. \& Thomson, D. L. 2004. Demographic mechanisms of the population decline of the song thrush (Turdus philomelos) in Britain. Journal of Animal Ecology, 73, 670-682.

Rosenblum, E. B. 2006. Convergent evolution and divergent selection: lizards at the white sands ecotone. American naturalist, 167, 1-15.

Rosenstock, S. S., Anderson, D. R., Giesen, K. M., Leukering, T. \& Carter, M. F. 2002. Land bird counting techniques: current practices and an alternative. Auk, $119,46-53$

Rost, R. 1990. Hormones and behaviour: a joint examination of studies on seasonal variation in song production and plasma levels of testosterone in the great tit (Parus major). Journal of Ornithology, 131, 403-411.

Rothstein, S. I. \& Fleischer, R. C. 1987. Vocal dialects and their possible relation to honest status signalling in the brown-headed cowbird. Condor, 89, 1-23.

Ryan, M. J. \& Brenowitz, E. A. 1985 . The role of body size, phylogeny, and ambient noise in the evolution of bird song. American Naturalist, 126, 87-100. 
Sakai, H., Shibata, S. \& Ando, Y. 2001. Orthogonal acoustical factors of a sound field in a bamboo forest. Journal of the Acoustical Society of America, 109, 28242830.

Schmidt, R., Kunc, H. P., Amrhein, V. \& Naguib, M. 2008. Aggressive responses to broadband trills are related to subsequent pairing success in nightingales. Behavioral Ecology, 19, 635-641.

Schwabl, H. \& Kriner, E. 1991. Territorial aggression and song of male European robins (Erithacus rubecula) in autumn and spring: effects of antiandrogen treatment. Hormones Behavior, 25, 180-194.

Schwartz, J. J. \& Wells, K. D. 1983. The Influence of background noise on the behavior of a neotropical treefrog (Hyla ebraccata). Herpetologica, 39, 121-129.

Searcy, W. A. \& Andersson, M. 1986. Sexual selection and the evolution of song. Annual Review of Ecology and Systematics 17, 507-533.

Searcy, W. A. \& Yasukawa, K. 1996. Song and female choice. In: Ecology and Evolution of Acoustic Communication in Birds (Ed. by D. E. Kroodsma \& E. H. Miller), pp. 454-473. Ithaca, NY: Cornell University Press.

Seddon, N. 2005. Ecological adaptation and species recognition drives vocal evolution in neotropical suboscine birds. Evolution, 59, 200-215.

Simon, J. C., Pratt, T. K., Berlin, K. E., Kowalsky, J. R., Fancy, S. G. \& Hatfield, J. S. 2002. Temporal variation in bird counts within a Hawaiian rainforest. Condor, 104, 469-481.

Slabbekoorn, H. 2004a. Habitat-dependent ambient noise: consistent spectral profiles in two African forest types. Journal of Acoustical society of America, 116, 3727-3733.

Slabbekoorn, H. 2004b. Singing in the wild: the ecology of birdsong. In: Nature's Music: The Science of Birdsong (Ed. by M. Peter \& S. Hans), pp. 181-208. San Diego, CA: Academic Press. 
Slabbekoorn, H. \& den Boer-Visser, A. 2006. Cities change the songs of birds. Current Biology, 16, 2326-2331.

Slabbekoorn, H., Ellers, J. \& Smith, T. B. 2002. Birdsong and sound transmission: the benefits of reverberations. Condor, 104, 564-573.

Slabbekoorn, H. \& Peet, M. 2003. Birds sing at a higher pitch in urban noise. Nature, 424, 267.

Slabbekoorn, H. \& Smith, T. B. 2002a. Bird song, ecology, and speciation. Philosophical Transactions of the Royal Society of London, Biological science, $357,493-503$.

Slabbekoorn, H. \& Smith, T. B. 2002b. Habitat-dependent song divergence in the little greenbul: an analysis of environmental selection pressures on acoustic signals. Evolution, 56, 1849-1858.

Slabbekoorn, H., Yeh, P. \& Hunt, K. 2007. Sound transmission and song divergence: a comparison of urban and forest acoustics. Condor, 109, 67-78. Slabbekoorn, H., Yeh, P. \& Hunt, K. 2009. Sound transmission and song divergence: a comparison of urban and forest acoustics. Condor, 109, 67-78. Slater, P. J. B. 1986. The cultural transmission of bird song. Trends in Ecology and Evolution, 1, 94-97.

Slater, P. J. B. 1989. Bird song learning: causes and consequences. Ethology Ecology and Evolution, 1, 19-46.

Slater, P. J. B. 2003. Fifty years of bird song research: a case study in animal behaviour. Animal Behaviour, 65, 633-639.

Smith, G. T., Brenowitz, E. A., Wingfield, J. C. \& Baptista, L. F. 1995. Seasonal changes in song nuclei and song behavior in Gambel's white-crowned sparrows. Jornal of Neurobiology, 28, 114-125.

Snow, D. W. \& Perrins, C. M. 1998. The Birds of the Western Palearctic: Oxford University Press. 
Sutherland, W. J. 2006. Ecological Census Techniques: A Handbook. New York: Cambridge University Press.

Taylor, D. 1971. Noise reduction by vegetation and ground. Journal of the Acoustical Society of America, 51, 197-205.

Taylor, S. S., Jamieson, I. G. \& Armstrong, D. P. 2005. Successful island reintroductions of New Zealand robins and saddlebacks with small numbers of founders. Animal Conservation, 8, 415-420.

Thompson, W. L. 2002. Towards reliable bird surveys: accounting for individuals present but not detected. Auk, 119, 18-25.

Trainer, J. M. 1989. Cultural evolution in song dialects of yellow-rumped caciques in Panama. Ethology, 80, 190-204.

Tramontin, A. D. \& Brenowitz, E. A. 2000. Seasonal plasticity in the adult brain. Trends in Neurosciences, 23, 251 - 258.

Trust, K. W. S. 1997. Karori Wildlife Sanctuary Draft Management Plan. Karori Wildlife Sanctuary Trust, P .O . Box 28-107, Wellington, New Zealand.

Tubaro, P. L. \& Lijtmaer, D. A. 2006. Environmental correlates of song structure in forest grosbeaks and saltators. Condor, 108, 120-129.

Turelli, M., Barton, N. H. \& Coyne, J. A. 2001. Theory and speciation. Trends in Ecology and Evolution, 16, 330-343.

Vallet, E. \& Kreutzer, M. 1995. Female canaries are sexually responsive to special song phrases. Animal Behaviour, 49, 1603-1610.

Ward, S. \& Slater, P. J. B. 2005. Raised thermoregulatory costs at exposed song posts increase the energetic cost of singing for willow warblers, Phylloscopus trochilus. Journal of Avian Biology, 36.

Wardle, P. 2002. Vegetation of New Zealand. New Jersey, U.S.A.: Blackburn Press. 
Warren, P. S. 2002. Geographic variation and dialects in songs of the bronzed cowbird (Molothrus aeneus). Auk, 119, 349-361.

Waser, P. M. \& Brown, C. H. 1986. Habitat acoustics and primate communication. American Journal of Primatology, 10, 135-154.

Weiher, E., Clarke, G. D. P. \& Keddy, P. A. 1998. Community assembly Rules, morphological dispersion, and the coexistence of plant species. Oikos, 81, 309322.

Weiher, E. \& Keddy, P. A. 1995. Assembly rules, null models, and trait dispersion: new questions from old patterns. Oikos, 74, 159-164.

Weiss, D. J. \& Hauser, M. D. 2002. Perception of harmonics in the combination long call of cottontop tamarins, Saguinus oedipus. Animal Behaviour, 64, 415-426.

Westcott, D. A. \& Kroon, F. J. 2002. Geographic song variation and Its consequences in the golden bowerbird. Condor, 104, 750-760.

Whitney, C. L. 1992. Temporal stability of song in a local population of wood thrushes. The Wilson Bulletin, 104, 516-520.

Wiley, R. H. 1991. Associations of song properties with habitats for territorial oscine birds of eastern North America. American Naturalist, 138, 973-993.

Wiley, R. H. 1994. Errors, exaggeration, and deception in animal communication. In: Behavioral Mechanisms in Evolutionary Ecology (Ed. by L. A. Real), pp. 157189. Chicago: University of Chicago Press.

Wiley, R. H. 2000. A new sense of the complexities of bird song. Auk, 117, 861868.

Wiley, R. H. 2006. Signal detection and animal communication. Advances in the Study of Behavior, 36, 217-247.

Wiley, R. H. \& Godard, R. 1996. Ranging of conspecific songs by Kentucky warblers and its implications for interactions of territorial Males. Behaviour, 133, 81-102. 
Wiley, R. H. \& Richards, D. G. 1978. Physical constraints on acoustic communication in the atmosphere: implications for the evolution of animal vocalizations. Behavioral Ecology and Sociobiology, 3, 69-94.

Wiley, R. H. \& Richards, D. G. 1982. Adaptations for acoustic communication in birds sound transmission and signal detection. In: Acoustic Communication in Birds Production, Perception, and Design Features of Sounds (Ed. by D. E. Kroodsma \& E. H. Miller), pp. 132-181. New York: Academic Press.

Wilson, D. M. \& Bart, J. 1985. Reliability of singing bird surveys: effects of song phenology during the breeding season. Condor, 87, 69-73.

Wodzicki, K. \& Wright, S. 1984. Introduced birds and mammals in New Zealand and their effect on the environment. Tuatara, 27, 77-104.

Wollerman, L. \& Wiley, R. H. 2002. Background noise from a natural chorus alters female discrimination of male calls in a Neotropical frog. Animal Behaviour, $63,15-22$

Wood, W. E., Yezerinac, S. M. \& Dufty, J. A. M. 2006. Song sparrow (Melospiza melodia) song varies with urban noise. Auk, 123, 650-659.

Yasukawa, K. 1981. Song and territory defence in the red-winged blackbird (Agelaius phoeniceus). Auk, 98, 185-187. 